\title{
CAROLINA MARTINS DO PRADO
}

\section{Desenvolvimento de metodologia para a determinação dos genótipos principais dos genes CYP2D6, CYP2C19 e CYP2C9: aplicação na Farmacogenética}

\author{
Dissertação apresentada ao \\ Programa de Pós-Graduação \\ Interunidades em Biotecnologia \\ USP/Instituto Butantan/IPT, para \\ obtenção do Título de Mestre em \\ Biotecnologia.
}




\title{
CAROLINA MARTINS DO PRADO
}

\section{Desenvolvimento de metodologia para a determinação dos genótipos principais dos genes CYP2D6, CYP2C19 e CYP2C9: aplicação na Farmacogenética}

\author{
Dissertação apresentada ao \\ Programa de Pós-Graduação \\ Interunidades em Biotecnologia \\ USP/Instituto Butantan/IPT, para \\ obtenção do Título de Mestre em \\ Biotecnologia. \\ Área de concentração: Biotecnologia \\ Orientador: Profa. Dra. Elida Paula \\ Benquique Ojopi
}




\section{UNIVERSIDADE DE SÃO PAULO \\ INSTITUTO DE CIÊNCIAS BIOMÉDICAS}

Candidato(a): Carolina Martins do Prado

Dissertação: Desenvolvimento de metodologia para a determinação dos genótipos principais dos genes CYP2D6, CYP2C19 e CYP2C9: aplicação na Farmacogenética.

Orientador (a): Profa. Dra Elida Paula Benquique Ojopi

A Comissão Julgadora dos Trabalhos de Defesa da Dissertação de Mestrado, em sessão pública realizada a .............,
( ) Aprovado(a)
( ) Reprovado(a)

Examinador (a) Assinatura

Nome

Instituição

Examinador (a) Assinatura

Nome

Instituição

Presidente Assinatura

Nome

Instituição 
Folha de Reprodução do Certificado/Parecer da Comissão de Ética

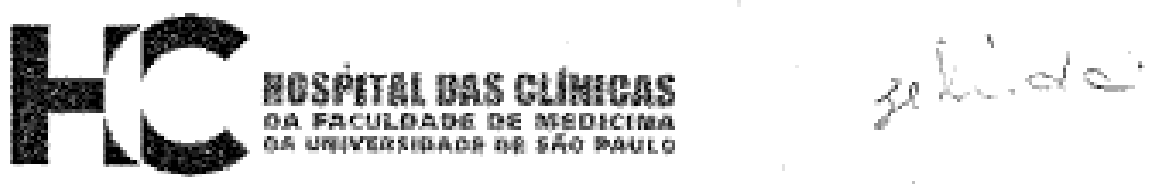

\title{
APROVACÃO
}

O Presidente da Comissão de Ética para Análise de Projetos de Pesquisa - CAPPesq da Diretoria Clínica do Hospital das Clínicas e da Faculdade de Medicina da Universidade de São Paulo em 10.02.06, APROVOU, ad-referendum, o Protocolo de Pesquisa $n^{\circ} 1148 / 05$, intitulado "O uso de polimorfismos de DNA e análise da expressão gênica no estudo da Depressão em humanos e em animais", apresentado pelo Departamento de PSIQUIATRIA, inclusive Termo de Consentimento Livre e Esclarecido.

Cabe ao pesquisador elaborar e apresentar à CAPPesq, os relatórios parciais e final sobre a pesquisa (Resolução do Conselho Nacional de Saúde $n^{\circ} 196$, de 10.10.1996, inciso IX.2, letra "c").

Pesquisador(a) Responsável: Dr. Wagner Farid Gattaz

Pesquisador(a) Executante: Dra. Elida Paula Benquique Ojopi

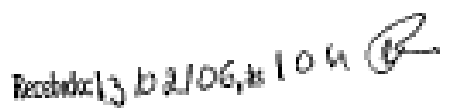

CAPPesq, 10 de Fevereiro de 2006.

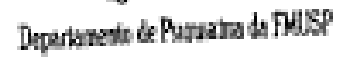

\author{
Whatho \\ PROF. DR. EUCLIDES AYRES DE CASTILHO \\ Presidente da Comissão Ética para Análise \\ de Projetos de Pesquisa
}

\footnotetext{
Cominelo de fition para Andiso de Projeter de Pesquiasdo HCFNUSP e da PMUSP

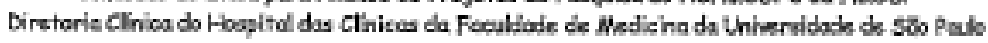

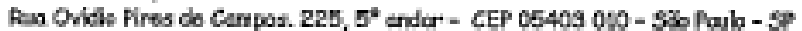

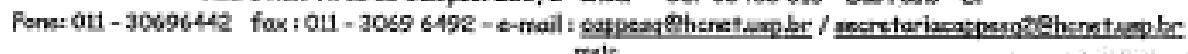


À minha mãe Edna pelo amor, paciência e ajuda em todos os momentos dessa jornada. Ao meu pai Luiz Carlos, irmão Carlos Guilherme e ao vovô Remo, que sempre estiveram ao meu lado me apoiando e incentivando. 


\section{AGRADECIMENTOS}

À minha orientadora Profa. Dra. Elida por acreditar em mim e por conta da sua capacidade profissional me mostar o caminho do aprendizado.

Ao Prof. Dr Wagner F. Gattaz por oferecer um laboratório com todos os recursos para que eu pudesse desenvolver o meu projeto.

Ao Prof. Dr Ricardo Moreno e a toda equipe do GRUDA por terem fornecido além de pacientes, informações necessárias ao trabalho.

Ao Dr. Ulrich M. Zanger que prontamente me enviou da Alemanha amostras que possibilitaram a identificação do $C N V$.

A toda equipe do Laboratório de Neurociências (LIM 27 HC-FMUSP) pelo carinho e convivência. Às minhas amigas Vanessa e Maria Carolina pela inestimável ajuda, pelo incentivo nos momentos difíceis e pelas longas conversas (sem vocês eu estaria perdida!). A Giselle e Julien pela amizade e ajuda quando precisava de socorro. A Leda pela sua sabedoria, a Dona Edivany por sempre ter uma palavra de atenção e cuidado comigo, a Lú, a Sandra, a menina Helena pela atenção e ajuda.

Ao Eduardo pela valiosa ajuda com a estatística.

À minha enorme família e todos os meus amigos que de alguma maneira, contribuiram para que mais uma etapa do meu aprendizado fosse concluída, sempre dando amor, força e alegrias.

À Juliana por sempre estar ao meu lado.

Ao meu querido amigo e tio Dr Laerte, pelos sábios conselhos e por sempre me incentivar a continuar nos momentos em que tudo parecia estar perdido. 


\section{Beware Of Darkness}

Watch out now, take care Beware of falling swingers

Dropping all around you

The pain that often mingles

In your fingertips

Beware of darkness

Watch out now, take care Beware of the thoughts that linger

Winding up inside your head The hopelessness around you

In the dead of night

Beware of sadness

It can hit you

It can hurt you

Make you sore and what is more

That is not what you are here for

Watch out now, take care Beware of soft shoe shufflers Dancing down the sidewalks As each unconscious sufferer Wanders aimlessly

Beware of Maya

Watch out now, take care

Beware of greedy leaders They take you where you should not go While Weeping Atlas Cedars They just want to grow, grow and grow Beware of darkness. 


\section{RESUMO}

Prado CM. Desenvolvimento de metodologia para a determinação dos genótipos principais dos genes CYP2D6, CYP2C19 e CYP2C9: aplicação na farmacogenética [Dissertação]. São Paulo: Instituto de Ciências Biomédicas da Universidade de São Paulo; 2009.

É comum pacientes responderem de maneiras diferentes a um mesmo tratamento e essa variabilidade na resposta pode ser atribuída a múltiplos fatores como idade, gênero, etnia, fatores genéticos, ambientais entre outros. A superfamília do Citocromo P450 (CYP) representa as enzimas responsáveis pelo metabolismo de substâncias endógenas e xenobióticos e, dentre os últimos, inclui-se mais de 60\% de todas as medicações utilizadas. Sozinhas, as enzimas CYP2D6, CYP2C19 e CYP2C9 são responsáveis pelo metabolismo de aproximadamente metade dos 200 medicamentos mais prescritos nos EUA. Os polimorfismos do gene CYP2D6 têm grande importância na farmacogenética da Depressão Unipolar e atualmente alguns grupos de pesquisa recomendam ajustes de doses baseadas no seu genótipo, visto que muitos antidepressivos tricíclicos são metabolizados mais eficientemente pela enzima CYP2D6. Além dessa enzima, há a participação de CYP2C19 e CYP2C9 no metabolismo de outros medicamentos o que também torna interessante a avaliação de polimorfismos nos genes que as codificam. Desse modo, padronizamos ensaios de genotipagem para os genes CYP2D6 (alelos *1, *2, *3, *4, ${ }^{*} 5,{ }^{*} 6,{ }^{*} 9,{ }^{*} 10,{ }^{*} 15$, *17, *29, *35, *39, *40, *41), CYP2C19 (alelos *1, *2, *3 e *17) e CYP2C9 (alelos *1, *2 e *3) baseados na discriminação alélica com o sistema TaqMan ${ }^{\circledR}$. De um total de 198 indivíduos, 148 foram genotipados para o gene CYP2D6. Os alelos *1 e *2 foram os mais freqüentes (39,2 e 17,2\% respectivamente), seguidos pelos alelos *4 $(14,5 \%),{ }^{*} 41(5,4 \%),{ }^{*} 35(4,1 \%),{ }^{*} 17(3,4 \%),{ }^{*} 5(2,7 \%),{ }^{*} 10(2,4 \%),{ }^{*} 6(0,7 \%),{ }^{*} 29$ $(0,7 \%)$ e *9 (0,3\%). Desenvolvemos também uma nova metodologia para a determinação do número de cópias do gene CYP2D6 e as duplicações do gene representaram 9,5\% da amostra. Para o gene CYP2C19, 198 indivíduos foram genotipados e o alelo ${ }^{*} 1$ foi o mais frequente $(63,7 \%)$, seguido pelos alelos ${ }^{*} 17$ $(20,7 \%),{ }^{*} 2(15,3 \%)$ e *3 $(0,3 \%)$. Nosso estudo foi o primeiro a determinar a 
freqüência alélica do gene CYP2C19 no Brasil. Para o gene CYP2C9, 152 indivíduos tiveram seus genótipos determinados e 0 alelo *1 foi o mais frequente $(86,8 \%)$ seguido pelos alelos ${ }^{*} 2(9,2 \%)$ e ${ }^{*} 3(3,9 \%)$. Com este projeto, conseguimos desenvolver uma nova metodologia reprodutível e acessível para a genotipagem dos polimorfismos principais dos genes CYP2D6, CYP2C19 e CYP2C9. A identificação precoce de indivíduos suscetíveis a efeitos adversos, bem como de metabolizadores rápidos pode trazer grandes benefícios aos pacientes possibilitando assim uma medicina personalizada.

Palavras-chave: CYP2D6. CYP2C19. CYP2C9. Número de cópias do gene CYP2D6. Discriminação alélica. PCR em tempo real. Farmacogenética. 


\begin{abstract}
Prado CM. Development of methodology for determining the major genotypes of CYP2D6, CYP2C19 and CYP2C9 genes: application in pharmacogenetics [Master thesis]. São Paulo: Instituto de Ciências Biomédicas da Universidade de São Paulo; 2009.
\end{abstract}

It is a common thing for patients to respond differently to the same treatment. Thus, the variability in drug response can be attributed to multiple factors such as age, gender, ethnicity, genetic and environmental factors among others. The cytochrome P450 (CYP) superfamily contains the enzymes that are responsible for the metabolism of endogenous substances and xenobiotics, including more than $60 \%$ of all medications used. It is known that the enzymes CYP2D6, CYP2C19 and CYP2C9 metabolize approximately half of the 200 most prescribed drugs in the USA. The genetic polymorphisms of CYP2D6 have a major importance in the pharmacogenetics of the Unipolar Depression and recently some research groups already suggest dose adjustments based on the individual's CYP2D6 genotypes, since many triciclic antidepressants are mainly metabolized by the CYP2D6 enzyme. Besides this enzyme, CYP2C19 and CYP2C9 also contribute for the metabolism of others drugs, fact that makes important the analysis of polymorphisms in these genes. Thus, we standardized genotyping tests for the genes CYP2D6 (alleles * 1 , ${ }^{*} 2,{ }^{*} 3,{ }^{*} 4,{ }^{*} 5,{ }^{*} 6,{ }^{*} 9,{ }^{*} 10,{ }^{*} 15,{ }^{*} 17,{ }^{*} 29,{ }^{*} 35,{ }^{*} 39,{ }^{*} 40,{ }^{*} 41$ ), CYP2C19 (alleles *1, *2, *3 and * 17) and CYP2C9 (alleles *1, *2 and *3) based on allelic discrimination, using TaqMan $^{\circledR}$ genotyping system. Among 198 individuals, 148 were genotyped for the CYP2D6 gene. Allele ${ }^{*} 1$ and ${ }^{*} 2$ were the most frequent (39.2 and $17.2 \%$ respectively), followed by alleles *4 (14.5\%), *41 (5.4\%), *35 (4.1\%), *17 (3.4\%), *5 $(2.7 \%),{ }^{*} 10(2.4 \%),{ }^{*} 6(0.7 \%),{ }^{*} 29(0.7 \%)$ and ${ }^{*} 9(0.3 \%)$. We have also developed a new methodology for determining the copy number variations of the CYP2D6 gene that accounted for $9.5 \%$ of the duplications in our sample. For the CYP2C19 gene, 198 subjects were genotyped and the allele *1 was the most common (63.7\%), followed by the alleles ${ }^{*} 17(20.7 \%),{ }^{*} 2(15.3 \%)$ and ${ }^{*} 3(0.3 \%)$. In our concern, our study was the first to determine the allele frequency of the CYP2C19 gene in Brazil. 
For CYP2C9, 152 individuals were genotyped and the allele ${ }^{*} 1$ was the most common $(86.8 \%)$ followed by the alleles $* 2(9.2 \%)$ and $* 3(3.9 \%)$. With this project, we were able to develop a new methodology, which is reproducible and accessible for genotyping the most important polymorphisms of the genes CYP2D6, CYP2C19 and CYP2C9. The previous identification of individuals at risk to develop adverse drug reactions as well as ultrarapid-metabolizers may bring benefits to the patients, thus leading to a personalized therapy.

Keywords: CYP2D6. CYP2C19. CYP2C9. Copy number variations. Allelic discrimination. Real-time PCR. Pharmacogenetics. 


\section{LISTA DE FIGURAS}

Figura 1 - Representação esquemática de fatores que podem contribuir para a variabilidade na

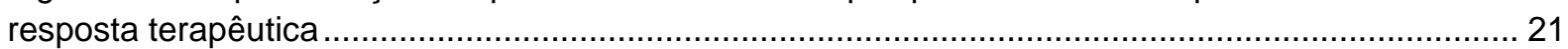

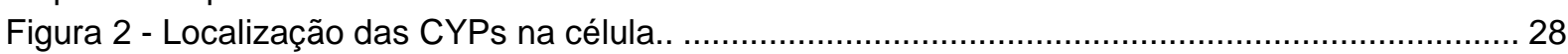

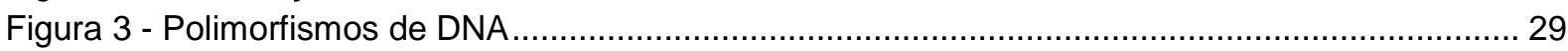

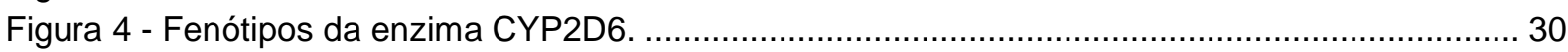

Figura 5 - Representação esquemática da atividade enzimática da CYP2D6 ................................... 31

Figura 6 - Esquema de dose e resposta terapêutica baseada no genótipo de CYP2D6 .................... 32

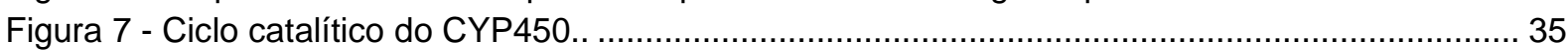

Figura 8 - Percentual de CYPs responsáveis pelo metabolismo de fase 1 ...................................... 37

Figura 9 - Relação entre o número de alelos funcionais de CYP2D6 e o steady-state da paroxetina 45

Figura 10 - Relação entre o genótipo de CYP2D6 e o índice metabólico ............................................ 46

Figura 11 - Distribuição do índice metabólico do omeprazol e S/R-mefenitoína em relação ao genótipo

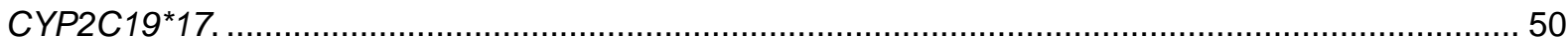

Figura 12 - Concentrações plasmáticas de escitalopram em relação ao genótipo CYP2C19 ............. 51

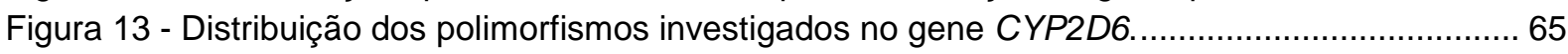

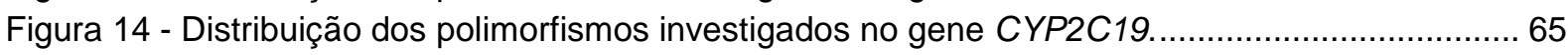

Figura 15 - Esquema da long PCR para a detecção do alelo CYP2D6*5 ........................................ 73

Figura 16 - Esquema da long template PCR para a detecção da amplificação do gene CYP2D6 ..... 74

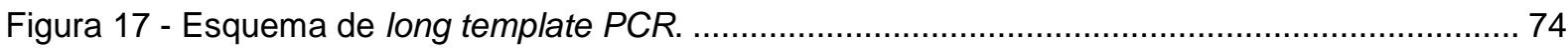

Figura 18 - Curva de amplificação das triplicatas dos genes CYP2D6 e RNase $P$.............................. 80

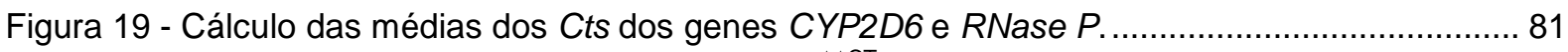

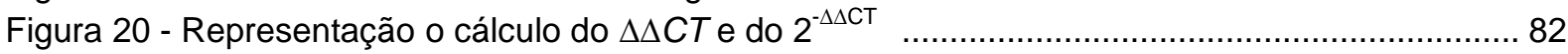

Figura 21 - Gel de agarose mostrando o fragmento amplificado que contém o polimorfismo $100 \mathrm{C}>\mathrm{T} 90$

Figura 22 - Gel de agarose mostrando o fragmento amplificado que contém o polimorfismo -3402

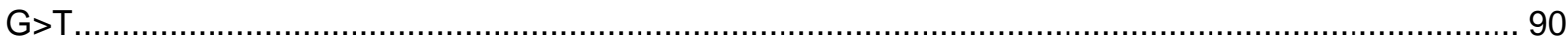

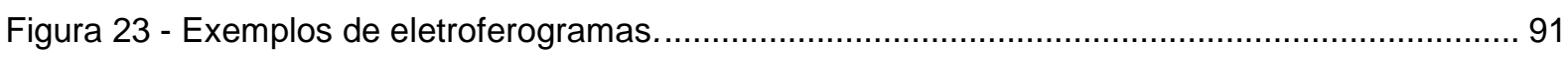

Figura 24 - Gel de agarose mostrando resultado da long template PCR ......................................... 92

Figura 25 - Gel de agarose mostrando resultados da multiplex long PCR ........................................ 93

Figura 26 - Representação gráfica da curva de amplificação do gene CYP2D6 e albumina............... 94

Figura 27 - Representação gráfica da curva de amplificação dos genes CYP2D6 e RNase $P$........... 95

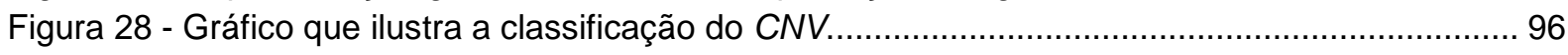

Figura 29 - Representação da curva de amplificação de uma amostra heterozigona para o

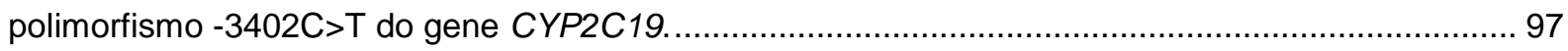

Figura 30 - Representação da curva de amplificação de uma amostra homozigota CC para o

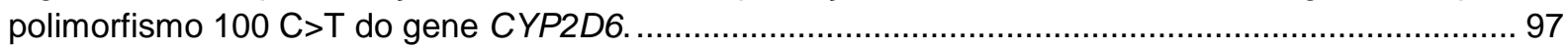

Figura 31 - Representação da curva de amplificação de uma amostra homozigota TT para o

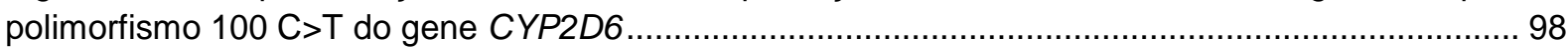

Figura 32 - Representação da curva de amplificação de uma amostra homozigota GG para o

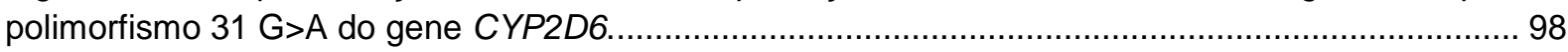

Figura 33 - Representação da curva de amplificação de uma amostra heterozigota $A>C$ para 0

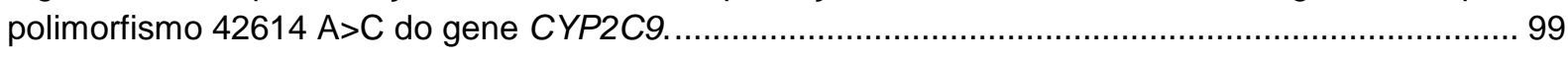

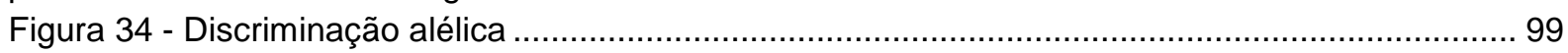




\section{LISTA DE QUADROS}

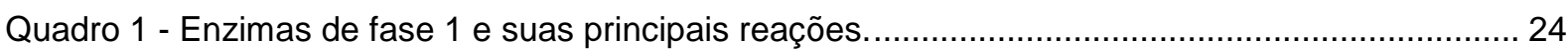

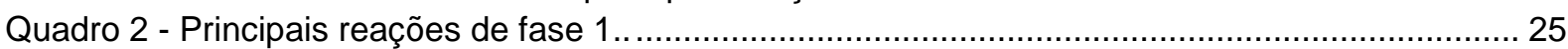

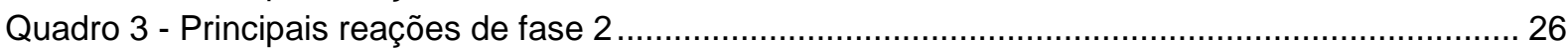

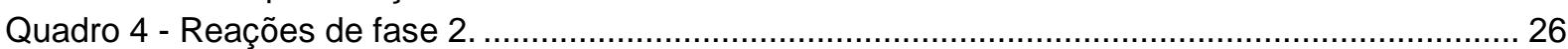

Quadro 5 - Medicamentos metabolizados pelas enzimas CYP2D6, CYP2C19 e CYP2C9 ................ 37

Quadro 6 - Polimorfismos selecionados no gene CYP2D6 e suas seqüências-alvo..........................66

Quadro 7 - Polimorfismos avaliados no gene CYP2C19 e suas seqüências-alvo................................66

Quadro 8 - Polimorfismos avaliados no gene CYP2C9 e suas seqüências-alvo................................. 66

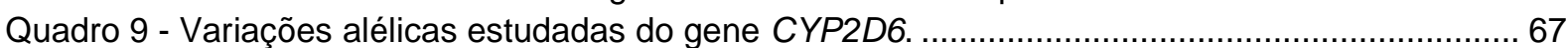

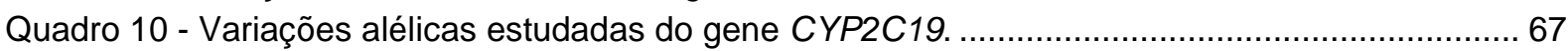

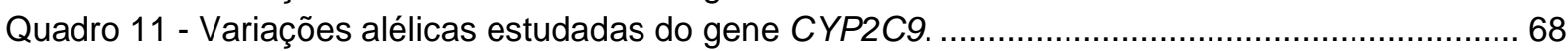

Quadro 12 - Pares de oligonucleotídeos para amplificar seqüências-alvo do gene CYP2C19.......... 68

Quadro 13 - Pares de oligonucleotídeos para amplificar seqüências-alvo do gene CYP2D6............69

Quadro 14 - Pares de oligonucleotídeos para amplificar seqüências-alvo do gene CYP2C9. ............ 69

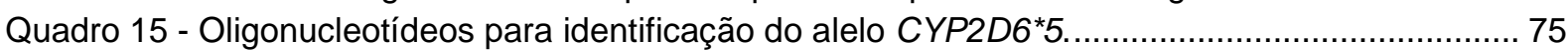

Quadro 16 - Oligonucleotídeos para identificação da amplificação do gene CYP2D6 ....................... 75

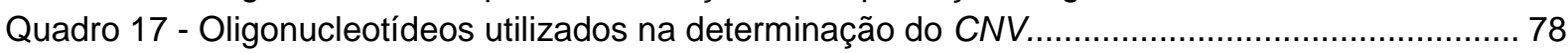

Quadro 18 - Sondas utilizadas na determinação do CNV . .............................................................. 78

Quadro 19 - Ensaios TaqMan ${ }^{\circledR}$ Drug Metabolism SNP Genotyping Assays e Custom TaqMan ${ }^{\circledR}$ SNP

Genotyping Assays utilizados para detecção dos polimorfismos no gene CYP2C19....................... 85

Quadro 20 - Ensaios TaqMan ${ }^{\circledR}$ Drug Metabolism SNP Genotyping Assays e Custom TaqMan ${ }^{\circledR}$ SNP

Genotyping Assays utilizados para detecção dos polimorfismos no gene CYP2D6 ........................... 85

Quadro 21 - Seqüencias de oligonucleotídeos e sondas dos ensaios feitos sob encomenda (Custom

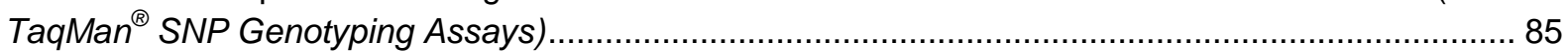

Quadro 22 - Identificação dos ensaios TaqMan $^{\circledR}$ Drug Metabolism SNP Genotyping Assays utilizados

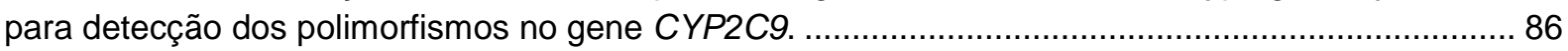

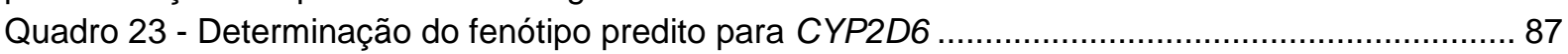

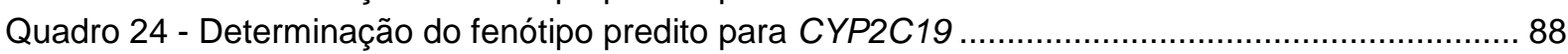

Quadro 25 - Determinação do fenótipo predito para CYP2C9 …..................................................... 88 


\section{LISTA DE TABELAS}

Tabela 1 - Principais alelos CYP2D6, efeito no metabolismo enzimático e freqüências (\%) alélicas em

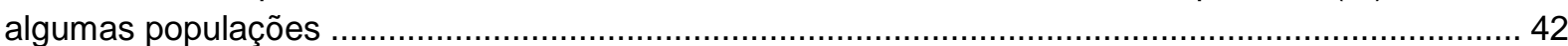

Tabela 2 - Freqüências (\%) fenotípicas de UMs e PMs para CYP2D6 em diferentes populações...... 44 Tabela 3 - Principais alelos CYP2C19, efeito no metabolismo enzimático e freqüências (\%) alélicas

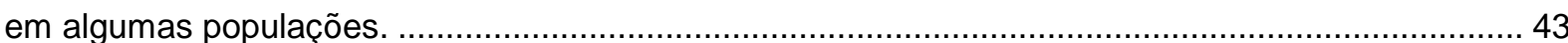

Tabela 4 - Freqüências (\%) alélicas para CYP2C9 em diferentes populações..................................... 54

Tabela 5 - Médias de idade (anos) da amostra de 198 pacientes e controles..................................... 62

Tabela 6 - Regras de classificação (pontos de cortes) utilizadas para a determinação do CNV ......... 68

Tabela 7 - Freqüências alélicas identificadas em nossa amostra para o gene CYP2D6.................. 100

Tabela 8 - Freqüências dos genótipos amplificados encontrados em nossa amostra....................... 101

Tabela 9 - Freqüências alélicas identificadas em nossa amostra para o gene CYP2C19................ 101

Tabela 10 - Freqüências alélicas identificadas em nossa amostra para o gene CYP2C9................ 102

Tabela 11 - Freqüências fenotípicas para CYP2D6 encontradas em nossa amostra........................ 102

Tabela 12 - Freqüências fenotípicas para CYP2C19 encontradas em nossa amostra...................... 103

Tabela 13 - Freqüências fenotípicas para CYP2C9 encontradas em nossa amostra........................ 103 


\title{
LISTA DE ABREVIATURAS E SIGLAS
}

\author{
ADR - Ração adversa a medicamento (adverse drug reaction) \\ CNVs - Variações no número de cópias (copy number variations) \\ $\mathrm{COOH}$ - Ácido carboxílico \\ CYP - Citocromo P450 \\ CYP2C19 - Citocromo P450, família 2, subfamília C, polipeptídeo 19 \\ CYP2C9 - Citocromo P450, família 2, subfamília C, polipeptídeo 9 \\ CYP2D6 - citocromo P450, família 2, subfamília D, polipeptídeo 6 \\ EHs - Epóxe-hidrolases \\ EM - Metabolizador extensivo ou normal (extensive metabolizer) \\ FMOs - Flavina mooxigenases \\ GST - Glutationa-S-transferase \\ IM - Metabolizador intermediário (intermediate metabolizer) \\ $\mathrm{kb}$ - Quilobase \\ MR - Índice metabólico (metabolic ratio) \\ MT - Metiltransferases \\ NADPH - Nicotinamida adenina dinucleotídeo fosfato \\ NAT - N-acetiltransferase \\ $\mathrm{NH}_{2}-$ Amina \\ $\mathrm{OH}$ - Hidroxila \\ $\mathrm{Pb}$ - Pares de bases \\ PM - Metabolizador lento (poor metabolizer) \\ PPIs - Inibidores de bomba de próton (proton pump inhibitors) \\ RE - Retículo endoplasmático \\ $\mathrm{RH}$ - Substrato orgânico \\ $\mathrm{SH}-\mathrm{Tiol}$ \\ $S N P$ - Polimorfismos de base única (single nucleotíde polymorphisms) \\ $S S R I s$ - Inibidores seletivos de recaptação de serotonina (SSRI - selective serotonin \\ re-uptake inhibitors) \\ STAR*D - Sequenced Treatment Alternatives to Relieve Depression \\ SULT - Sulfotransferase \\ TCA - Antidepressivos tricíclicos (triciclics antidepressants) \\ UGT - UDP-glucuronil transferase \\ UM - Metabolizador ultra-rápido (ultrarapid metabolizer) \\ xN - Amplificação do gene CYP2D6
}




\section{SUMÁRIO}

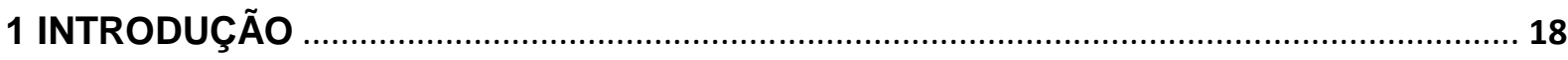

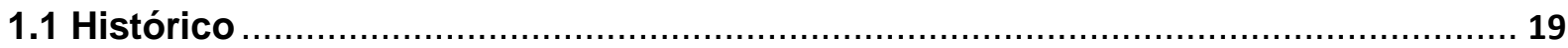

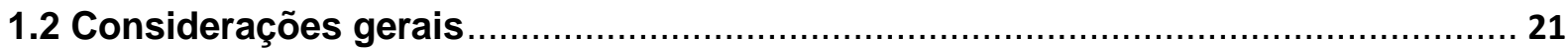

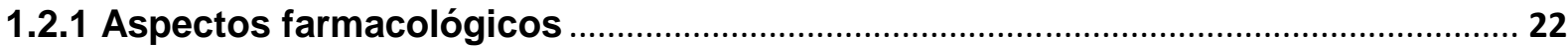

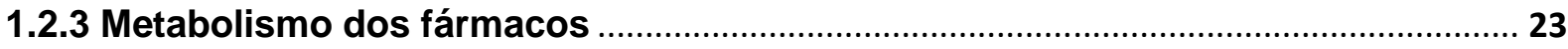

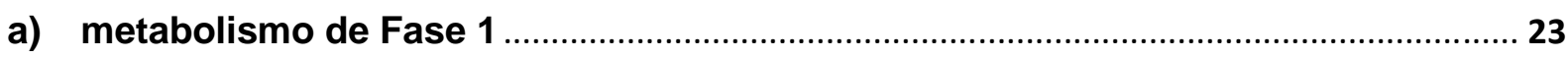

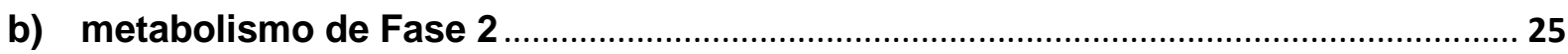

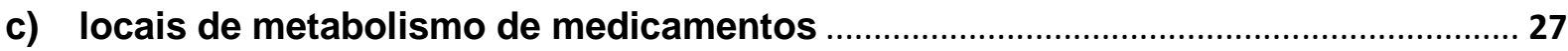

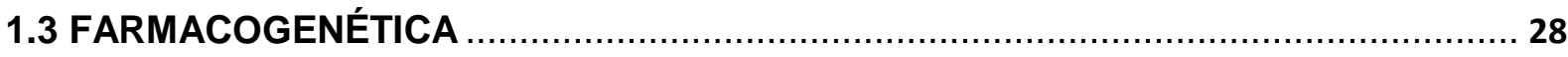

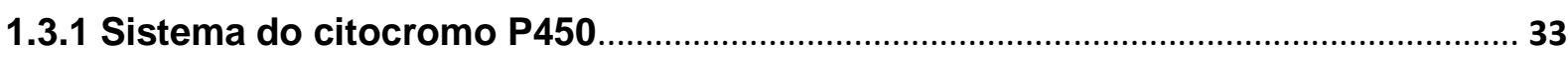

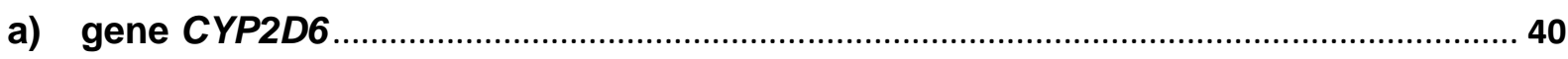

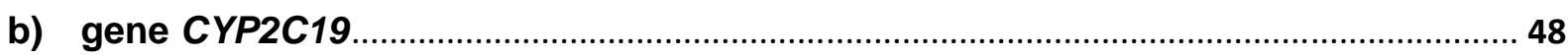

c) gene CYP2C9

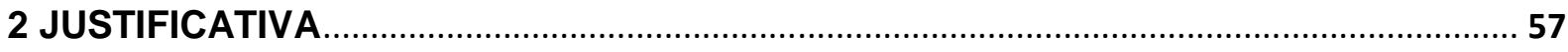

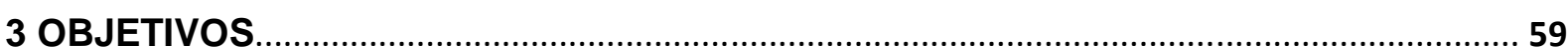

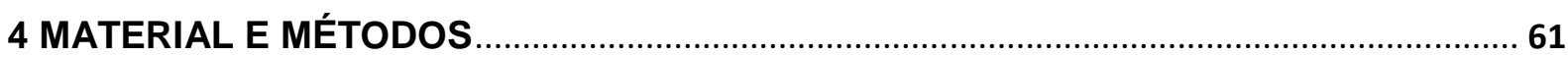

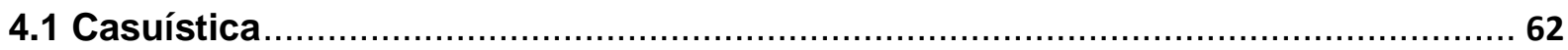

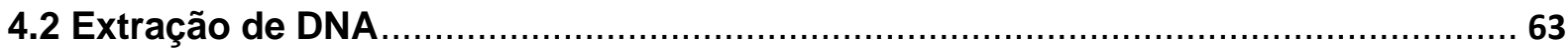

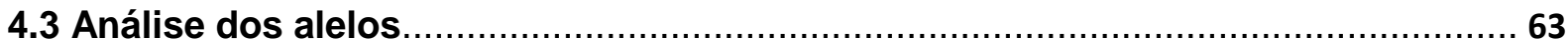

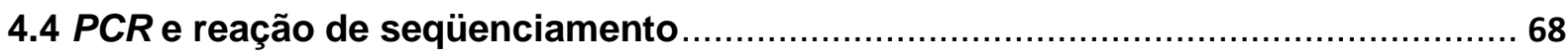

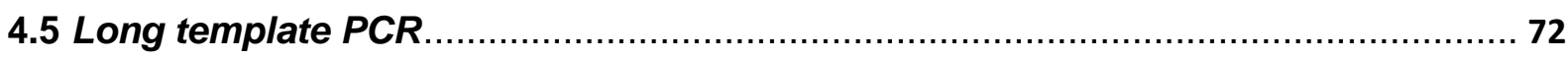

4.6 PCR em tempo real - determinação do número de cópias do gene CYP2D6......... 77

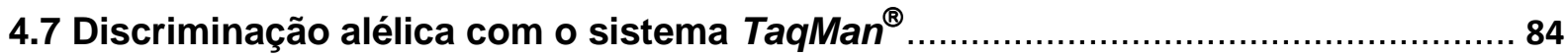

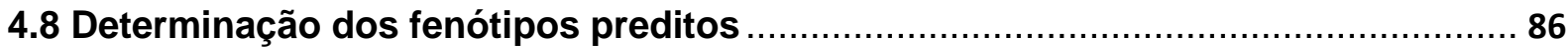

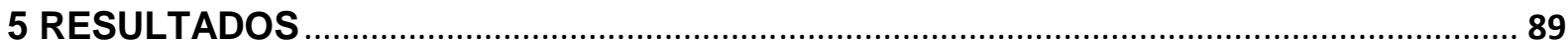

5.1 Padronização das $P C R s$ e reações de seqüenciamento ..................................... 90

5.2 Long template PCR para detecção da duplicação do gene CYP2D6 e do alelo CYP2D6*5

5.3 Padronização da $P C R$ em tempo real para a quantificação do número de cópias do

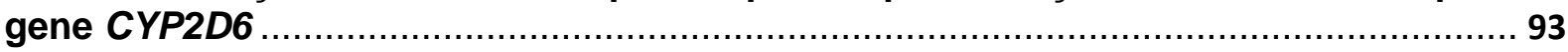

5.4 Análises dos resultados - cálculo do número teórico de cópias do gene CYP2D6 95

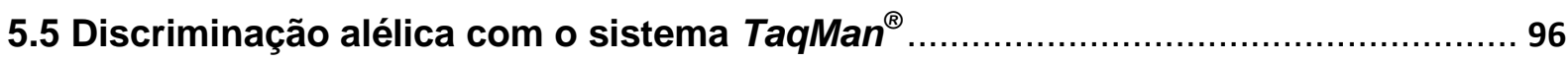

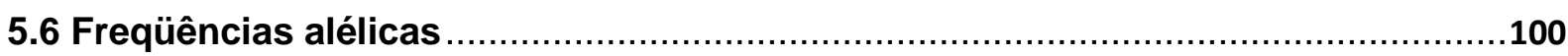

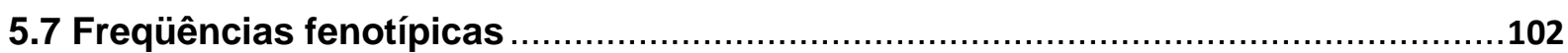


6 DISCUSSÃO.

104

7 CONCLUSÃO

REFERÊNCIAS BIBLIOGRÁFICAS

120

ANEXO A - Haplótipos do gene CYP2D6 encontrados em nossa amostra. 132

ANEXO B - Haplótipos do gene CYP2C19 encontrados em nossa amostra. 136 
1 INTRODUÇÃO 


\subsection{Histórico}

A década de 1950 foi a época na qual a farmacogenética emergiu como uma nova ciência, quando iniciou-se a idéia de que fatores genéticos poderiam alterar a farmacocinética e a farmacodinâmica do medicamento (Meyer, 2004; Eichelbaum et al., 2006). Nesse período, novas técnicas permitiram medidas mais acuradas das atividades enzimáticas, dos metabólitos e conseqüentemente, da resposta a fármacos.

Em 1959, o pesquisador alemão Friedrich Vogel utilizou pela primeira vez o termo 'farmacogenética' (Nebert et al., 2008) mas somente em 1962, no livro escrito por Kalow, que a farmacogenética foi definida como estudo da hereditariedade e resposta às drogas (Meyer, 2004).

Durante a Segunda Guerra Mundial, pesquisadores observaram que soldados afro-americanos apresentaram grave hemólise quando expostos a doses habituais de primaquina (medicamento antimalárico). Mais tarde constatou-se que esta hemólise era causada por uma deficiência hereditária da enzima glicose-6-fosfato desidrogenase (G6PD) a qual, alterava o metabolismo eritrocitário (Meyer, 2004). Esta descoberta explicou porque a hemólise foi observada principalmente em afroamericanos nos quais a deficiência é comum e raramente em caucasianos descendentes do Norte, Oeste e Leste Europeu (Eichelbaum et al., 2006). O fármaco succinilcolina, um relaxante muscular administrado como adjuvante da anestesia, é outro exemplo de que uma variação genética pode causar uma resposta anormal ao medicamento - neste caso, uma prolongada apnéia em alguns pacientes (Motulsky et al., 2006). Investigações subseqüentes atribuíram esse efeito adverso a uma alteração da enzima butiril-colinesterase que mais tarde mostrou ser uma alteração genética autossômica recessiva (Enson et al., 2001; Meyer, 2004).

Em 1968, foram realizados estudos com grupos de gêmeos idênticos e fraternos com o intuito de se determinar a contribuição genética na taxa da concentração plasmática de vários medicamentos. Estes estudos promoveram uma evidência convincente de que, para muitos medicamentos, os fatores genéticos são responsáveis pela maioria da variabilidade na meia-vida plasmática entre diferentes indivíduos (Meyer, 1994; Meyer, 2004). 
Apesar dos primeiros eventos na pesquisa farmacogenética envolverem algumas deficiências comuns em enzimas metabolizadoras de medicamentos, esta área de estudo foi impulsionada pela descoberta, nos anos 1970, do polimorfismo na enzima reponsável pela oxidação dos medicamentos debrisoquina (antihipertensivo) e esparteína (antiarrítmico). Dois grupos independentes observaram reações adversas inesperadas para estes medicamentos em participantes de estudos farmacocinéticos; análises do plasma destes indivíduos identificaram uma diferença na concentração sérica do medicamento maior do que os participantes que não apresentaram as reações adversas e desse modo dois fenótipos de resposta foram identificados: os metabolizadores extensivos ou normais (EMs - extensive metabolizers) e os metabolizadores lentos (PMs - poor metabolizers) (Eichelbaum et al., 1979; Smith et al., 1986). Na mesma época, Bertilsson et al. (1985), mostrou que o metabolismo da nortriptilina e desmipramina apresentava esta variação. Estudos subseqüentes mostraram que estes medicamentos eram metabolizados pela mesma enzima, P450 citocromo monooxidase que mais tarde foi denominada de CYP2D6. As bases genéticas do polimorfismo debrisoquina/esparteína foram elucidadas apenas 15 anos mais tarde, quando os alelos CYP2D6*3 e CYP2D6*4 foram identificados. Em seguida um terceiro grupo (Johansson et al., 1993), identificou indivíduos com metabolismo muito rápido para a debrisoquina o que, mais tarde, originaria a primeira descrição de um gene multiplicado, estável e ativo, e assim foi definido o termo metabolizador ultra-rápido (UM - ultrarapid-metabolizers) (Meyer, 1994; Meyer, 2004).

Devido a limitações técnicas, os primeiros trabalhos de farmacogenética eram focados em cuidadosas observações de idiossincrasias no fenótipo. No entanto, com - avanço das técnicas moleculares, tornou-se possível a identificação e caracterização de variações específicas no DNA. Os mais importantes alvos da farmacogenética são os genes que codificam enzimas responsáveis pela farmacocinética e farmacodinâmica dos medicamentos (Hines et al., 2008). Portanto, a estratégia primária da farmacogenética é estudar variações nas seqüências em genes com potencial de afetar a resposta aos medicamentos (Enson et al., 2001). 


\subsection{Considerações gerais}

É comum pacientes responderem de maneiras diferentes ao mesmo tratamento. Isto explica o fato de que nenhum fármaco é $100 \%$ eficaz para quaisquer indivíduos. A variabilidade na resposta ao medicamento pode ser atribuída a uma conseqüência de múltiplos fatores tais como: idade, gênero, massa corpórea, funcionamento renal e hepático, terapia concomitante, natureza da doença, etnia, fatores genéticos e ambientais (Clayton et al., 2006) (Figura 1).

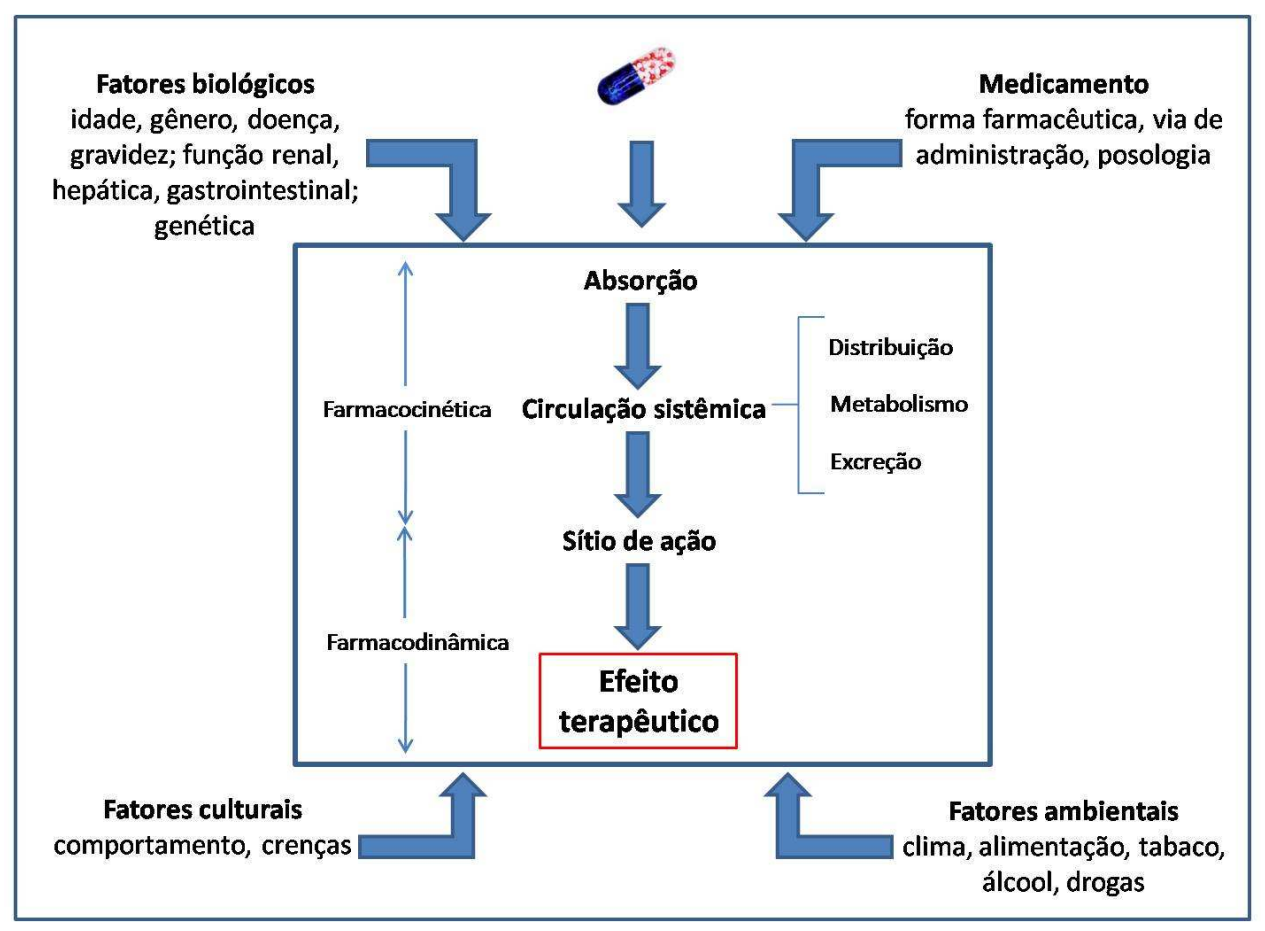

Figura 1 - Representação esquemática de fatores que podem contribuir para a variabilidade na resposta terapêutica (adaptado de Poolsup et al., 2000). Quando o medicamento é absorvido, ele passa por processos farmacocinéticos e farmacodinâmicos para que seu efeito terapêutico seja obtido. Múltiplos fatores podem interferir nestes processos desde como o medicamento é administrado (via de administração, forma farmacêutica), até fatores culturais, ambientais e biológicos.

Estima-se que a genética pode ser a razão de $20 \%$ a $95 \%$ da variabilidade na biodisponibilidade do medicamento e em seus efeitos (Kerb et al., 2006). O fármaco, uma vez administrado, é absorvido e distribuído até seu sítio de ação, onde interage 
com enzimas ou receptores, sendo metabolizado e depois excretado. Cada um desses processos pode envolver variações genéticas clinicamente significativas tendo a capacidade de influenciar a resposta terapêutica (Ingelman-Sundberg, 2004).

De acordo com Zhou et al. (2008), diferenças funcionais em genes que codificam enzimas metabolizadoras, transportadores e receptores celulares de medicamentos estão associadas à variação na depuração (clearance) do medicamento e na reposta terapêutica. Essas diferenças são freqüentemente relevantes entre membros de uma mesma população (Kerb et al., 2006). Assim sendo, medicamentos que são eficazes ou bem tolerados por algumas pessoas podem ser ineficazes ou tóxicos a outras (Wolf et al., 2000), ocasionando reações adversas que variam de moderadas e toleráveis a incômodas e graves.

Reação adversa a medicamento (RAM ou ADR - adverse drug reaction), segundo a Organização Mundial de Saúde, é "uma reação nociva e não-intencional a um medicamento, que ocorre em doses normalmente utilizadas no Homem para a profilaxia, o diagnóstico ou o tratamento de uma doença, ou para a modificação de uma função fisiológica." (http://www.who-umc.org/DynPage.aspx?id=22676). As ADRs causam morbidade e mortalidade significativas, sendo onerosas para os sistemas de saúde e indústria farmacêutica (Shah et al., 2005; Eichelbaum et al., 2006; Jorgensen et al., 2008).

\subsubsection{Aspectos farmacológicos}

Os efeitos que os fármacos causam resultam de um conjunto complexo de processos em que intervêm fatores diversos. Na ação dos fármacos, geralmente, observam-se três fases: farmacêutica, farmacocinética e farmacodinâmica.

$\mathrm{Na}$ fase farmacêutica, ocorre a desintegração da forma em que o fármaco é administrado. Durante a fase farmacocinética, processa-se a absorção, distribuição, metabolismo e excreção do fármaco. A fase farmacodinâmica compreende o processo de interação do fármaco com o seu receptor; desta interação resulta um 
estímulo que, após uma série de fenômenos químicos e bioquímicos, se traduz no efeito biológico esperado (Testa e Kramer, 2006).

Os fármacos e xenobióticos são armazenados no organismo ou removidos deste após um período de tempo. Desse modo, podem sofrer transformações químicas que originam os seguintes tipos de compostos: (a) menos ativos; (b) mais ativos; (c) com atividade semelhante ou diferente. Este processo de alteração química de fármacos no interior do organismo recebe o nome de metabolismo.

\subsubsection{Metabolismo dos fármacos}

O metabolismo de fármacos em metabólitos mais hidrofílicos é essencial para sua eliminação do organismo, bem como para sua ação biológica e farmacológica. Muitos dos fármacos são compostos lipofílicos os quais, na falta da metabolização, não seriam eliminados de maneira eficiente e se acumulariam no organismo, possivelmente causando toxicidades. Os fármacos são geralmente biotransformados em metabólitos de polaridade crescente até que possam ser excretados. A excreção consiste na eliminação da substância quimicamente inalterada ou de seus metabólitos. As principais vias de excreção são: rins, sistema hepatobiliar, pulmões.

O metabolismo dos medicamentos (ou reações de biotransformação) é classificado como: reações de fase 1 ou reações de fase 2. Os sistemas enzimáticos envolvidos na biotransformação estão localizados principalmente no fígado, embora algumas aconteçam no plasma, pulmões, cérebro ou no intestino.

\section{a) metabolismo de Fase 1}

As reações de fase 1 são catabólicas (oxidação, redução ou hidrólise) e com freqüência, os produtos são quimicamente mais reativos, portanto, algumas vezes mais tóxicos do que a substância original. Estas são catalisadas pelas superfamílias 
das enzimas do citocromo P450 (CYPs), flavinas monooxigenases (FMOs), e epóxe hidrolases (EHs) (Brunton e Parker, 2008).

A introdução de grupos funcionais $\left(-\mathrm{OH},-\mathrm{COOH},-\mathrm{SH},-\mathrm{O}-\right.$, ou $\left.-\mathrm{NH}_{2}\right)$ pelas enzimas de Fase 1 (Quadro 1) tem a finalidade de aumentar a hidrossolubilidade dos compostos, para que se tornem moléculas inativas ou para que moléculas originalmente inativas tornem-se ativas. Medicamentos inativos que necessitam ser metabolizados para tornarem-se ativos são chamados de pró-fármacos (Hang et al., 2003; Brunton e Parker, 2008).

Quadro 1 - Enzimas de fase 1 e suas principais reações.

\begin{tabular}{|c|c|}
\hline Enzimas de fase $\mathbf{1}$ (monooxigenases) & Reações \\
\hline Citocromo P450 (P450 ou CYP) & C e O - oxidação, desalquilação, outras \\
\hline Flavinas monooxigenase (FMO) & $\mathrm{N}, \mathrm{S}$ e P oxidação \\
\hline Epóxi hidrolase (EH) & Hidrólise de epóxidos \\
\hline
\end{tabular}

FONTE: Brunton e Parker, 2008

Nas reações de fase 1 (Quadro 2), os fármacos polares são em geral inativados ou, em alguns casos, ativados pela introdução de grupos polares por meio de reações de: Oxidação (desalquilação, desaminação, dessulforilação, formação de óxido, hidroxilação, oxidação alcoólica, oxidação aldeídica); redução (azorredução, nitrorredução, redução aldeídica ou cetônica); hidrólise (desaminação, desesterificação) (Korolkovas e Burckhalter, 1988). 
Quadro 2 - Principais reações de fase 1. A Figura mostra os principais tipos de reações de fase 1 e alguns exemplos de medicamentos que sofrem estas reações.

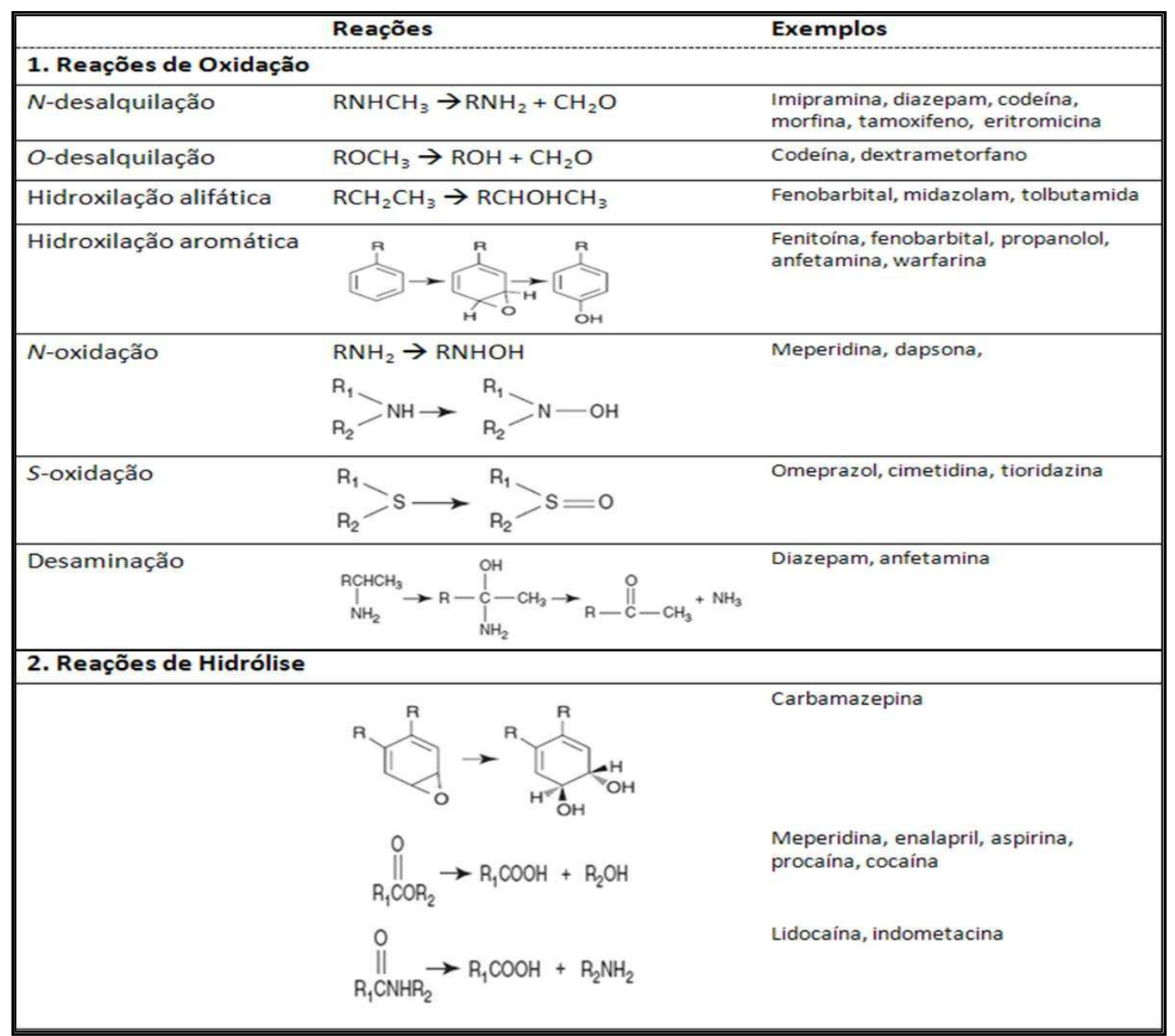

FONTE: adaptado de Brunton e Parker, 2008.

\section{b) metabolismo de Fase 2}

As reações de fase 2 são sintéticas (anabólicas) e envolvem a conjugação, que habitualmente resulta em produtos inativos. As enzimas de Fase 2 (Quadro 3) incluem algumas superfamílias de enzimas que catalisam reações de conjugação como a glutationa-S-transferase (GSTs), UDP-glucuronil transferase (UGT), sulfotransferases (SULTs), N-acetiltransferase (NATs) e metiltransferases (MTs) (Brunton e Parker, 2008). 
Quadro 3 - Principais reações de fase 2 e as respectivas enzimas responsáveis.

\begin{tabular}{|l|l|}
\hline \multicolumn{1}{|c|}{ Enzimas de fase 2 } & \multicolumn{1}{c|}{ Reações } \\
\hline Sulfotransferases (SULT) & Adição de sulfato \\
\hline UDP-gulcuronil transferase (UGT) & Adição de ácido glucurônico \\
\hline Glutationa-S-transferase (GST) & Adição de glutationa \\
\hline$N$-acetil transferase (NAT) & Adição de grupamento acetil \\
\hline Metiltrasnferase (MT) & Adição de grupamento metil \\
\hline
\end{tabular}

FONTE: Brunton e Parker, 2008; Korolkovas e Burckhalter, 1988.

Estas reações de conjugação (Quadro 4) geralmente necessitam que o substrato tenha átomos de oxigênio (grupos hidroxila ou epóxido), nitrogênio ou enxofre para servirem como aceptores elétrons de um grupo funcional hidrofílico (glutationa, ácido glucurônico, sulfato ou um grupamento acetil) que é unido por ligações covalentes ao aceptor da molécula. Geralmente, a oxidação pela fase 1 tanto adiciona quanto expõe um grupo funcional permitindo assim que os produtos sirvam como substratos para a conjugação na Fase 2 (Brunton e Parker, 2008).

Quadro 4 - Reações de fase 2. Nas reações de fase 2 os compostos polares são inativados por processos de síntese ou conjugação, tais como: metilação, acilação, formação de tiocianato, formação de ácido mercaptopúrico, conjugação com ácido glucurônico, conjugação com aminoácidos e conjugação com sulfatos.

\begin{tabular}{|c|c|c|}
\hline & Reações & Exemplos \\
\hline \multicolumn{3}{|c|}{ 3. Reações de Conjugação } \\
\hline Glucuronidação & $\underbrace{\mathrm{COOH}}_{\text {UDP-ácido glucurónico }} \rightarrow \underbrace{\mathrm{OH}}_{\mathrm{OH}}+\mathrm{OHP}$ & $\begin{array}{l}\text { Morfina, oxazepam, } \\
\text { loazepam }\end{array}$ \\
\hline Adição de sulfato & 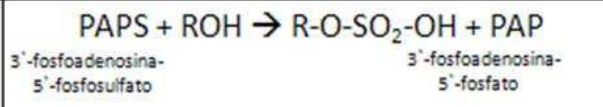 & $\begin{array}{l}\text { Acetaminofeno, esteróides, } \\
\text { metildopa }\end{array}$ \\
\hline Acetilação & $\mathrm{COAS}-\mathrm{CO}-\mathrm{CH}_{3}+\mathrm{RNH}_{2} \rightarrow \mathrm{RNH}-\mathrm{CO}-\mathrm{CH}_{3}+\mathrm{COA}-\mathrm{SH}$ & $\begin{array}{l}\text { Izoniazida, dapsona, } \\
\text { clonazepam }\end{array}$ \\
\hline
\end{tabular}

FONTE: adaptado Brunton e Parker, 2008. 


\section{c) locais de metabolismo de medicamentos}

As enzimas metabolizadoras de medicamentos são expressas na maioria dos tecidos. Contudo, os maiores níveis de expressão são encontrados no trato gastrointestinal (fígado, intestino delgado e cólon). Desse modo, medicamentos administrados por via oral, sofrem o metabolismo de primeira passagem (também conhecido como metabolismo pré-sistêmico ou efeito de primeira passagem) que é um fenômeno no qual a concentração do medicamento é significativamente reduzida pelas enzimas hepáticas, antes de atingir a circulação sistêmica. Enquanto alguns medicamentos não sofrem esse efeito, as passagens subseqüentes no fígado resultam em posterior metabolismo do medicamento até sua eliminação.

As enzimas de Fase 1 (CYPs, FMOs e EHs), e algumas de Fase 2, principalmente UGTs, estão localizadas no retículo endoplasmático das células. O lúmen do retículo endoplasmático é fisicamente diferente dos outros componentes do citosol que é perfeitamente ajustado para a função metabólica dessas enzimas: moléculas hidrofóbicas entram na célula e encaixam na bicamada lipídica, onde elas encontram as enzimas de Fase 1 (Neve e Ingelman-Sundberg, 2008) (Figura 2).

Uma vez oxidados, os fármacos são conjugados na membrana pelas UGTs ou pelas transferases e os metabólitos são então transportados para a corrente sanguínea. Hepatócitos, que constituem mais de $90 \%$ das células do fígado, são responsáveis pela maioria do metabolismo, produzindo os substratos conjugados que podem também ser transportados pela membrana do canal biliar para a bile e para a eliminação no intestino (Brunton e Parker, 2008). 


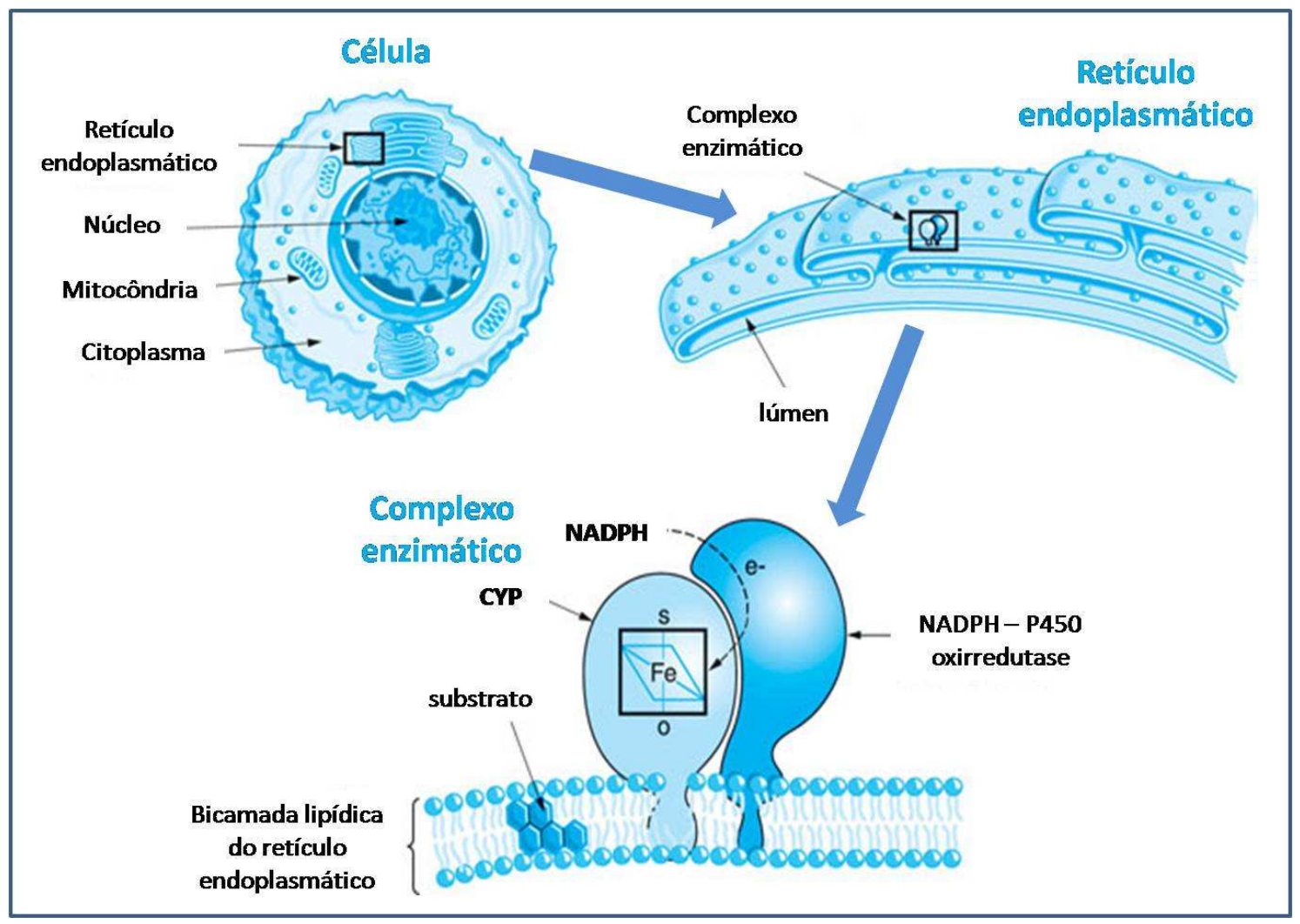

Figura 2 - Localização das CYPs na célula. As CYPs estão encaixadas na bicamada lipídica do reticulo endoplasmático (RE). A maioria das enzimas está localizada na superfície citoplasmática do RE. Uma segunda enzima, a NADPH-citocromo P450 oxirredutase, transfere elétrons para a CYP que oxida substratos xenobióticos, na presença do $\mathrm{O}_{2}$, muitos dos quais são hidrofóbicos e solubilizados no RE. Uma única espécie de NADPHCYP oxirredutase transfere elétrons para todas as isoformas CYPs no RE (adaptado de Brunton e Parker, 2008).

\subsection{Farmacogenética}

Farmacogenética é a ciência que estuda como diferentes fatores genéticos influenciam a variação da resposta ao uso de fármacos (Meyer, 2004; Koo et al., 2006); ela associa características fenotípicas de resposta a medicamentos, a marcadores genéticos tais como os polimorfismos de uma única base (single nucleotide polymorphisms - SNPS), inserções, deleções e repetições de microssatélites, e o splicing de RNA (Krejsa et al., 2006; Zhou et al., 2008).

Polimorfismos de DNA (Figura 3) são variações que ocorrem no genoma e podem afetar o fenótipo do indivíduo, determinando desde a cor da pele até a diferença na resposta a medicamentos. 
- Microssatélites $\rightarrow$ exemplo de uma repetição trinucleotídica que varia em número entre os indivíduos.

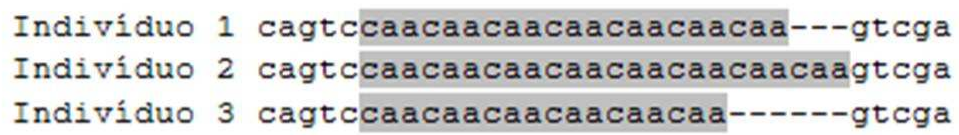

- Inserçốes e deleçốes $\rightarrow$ exemplo de uma deleção de três nucleotideos.

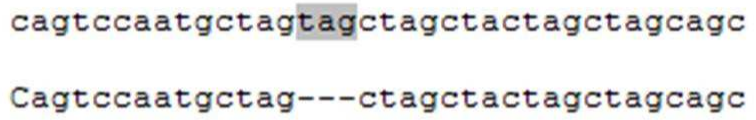

- $\mathrm{SNPs}_{\mathrm{S}} \rightarrow$ exemplo de uma alteração de G para A na região codificadora de um gene (SNP não-sinônimo), que resulta na substituição de um aminoácido valina por uma metionina na proteína codificada por esse gene.

.. GAC ACt TtC GAA CAC GTg ATA GAA GAg CTG...

$\begin{array}{cccccccccc}\text { D } & \text { T } & \text { F } & \text { E } & \text { H } & \bar{V} & \text { I } & \text { E } & \text { E } & \text { I } \\ \ldots \text { GAC } & \text { ACT } & \text { TTC } & \text { GAA } & \text { CAC } & \text { ATG } & \text { ATA } & \text { GAA } & \text { GAG } & \text { CTG... }\end{array}$

$\begin{array}{llllllllll}D & T & F & E & H & M & I & E & E & I\end{array}$

Figura 3 - Polimorfismos de DNA. Microssatélites são seqüências de bases que se repetem. Existe uma grande diversidade de microssatélites em nosso genoma, dentre eles microssatélites de 2, 3 ou 4 bases, ou de maior número de bases. Inserções ou deleções de seqüências de bases podem ou não ocorrer entre indivíduos. SNPS são os mais comumente encontrados no genoma humano. Muitos ocorrem em regiões intrônicas ou intergênicas, não tendo grandes repercussões funcionais. Quando ocorrem em regiões codificadoras de genes, podem resultar na alteração de um aminoácido da proteína (SNPs não sinônimos); podem também ocorrer em regiões promotoras, resultando na alteração da expressão de genes, bem como em sítios de splicing do RNA.

Os alvos mais importantes da farmacogenética são os genes que codificam enzimas responsáveis pela farmacocinética (absorção, metabolismo e excreção) e também, genes responsáveis pela farmacodinâmica (interação com receptores) dos medicamentos (Enson et al., 2001; McCarthy et al., 2005; Hines et al., 2008). A atividade das enzimas metabolizadoras de medicamentos pode ser estudada in vivo. Um dos métodos para a predição do fenótipo de resposta a medicamentos é a fenotipagem que consiste na determinação do índice metabólico do indivíduo, ou seja, da quantidade do medicamento excretado não metabolizado em relação à quantidade de metabólito. Uma substância teste (probe drug) é administrada ao indivíduo e depois de um período determinado, colhe-se urina para a verificação do índice metabólico. Uma variação deste método é a verificação da taxa metabólica no 
plasma. A razão entre a quantidade de medicamento não metabolizado e do seu metabólito é então determinada por meio de métodos cromatográficos. Em um experimento típico de fenotipagem, uma dose da substância-teste é administrada oralmente e a urina é coletada de 8 a 24 horas. As concentrações da substância não metabolizada e de seus metabólitos são determinadas e o índice metabólico é calculado. $O$ índice metabólico é a porcentagem da substância não metabolizada excretada dividida pela porcentagem do seu metabólito excretado. Ao se estudar populações, é possível visualizar a freqüência da distribuição dos fenótipos em um histograma (Figura 4) (Black et al., 2007).

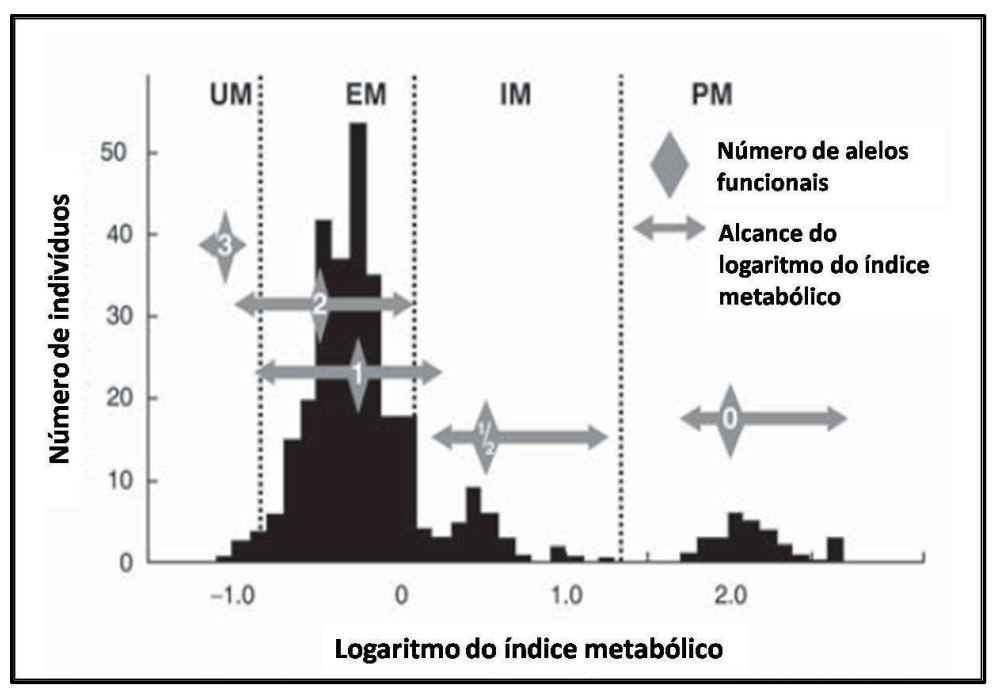

Figura 4 - Fenótipos da enzima CYP2D6. Quatro fenótipos foram observados em um estudo realizado com a substância-teste esparteína. A média e o alcance do índice metabólico (MR - metabolic ratio) da esparteína correspondem aos genótipos com um, dois, três ou nenhum alelo funcionail. $O$ "1/2" indica a presença de um alelo funcional e um de atividade reduzida (adaptado de Bernard et al., 2006).

Os genes que codificam enzimas metabolizadoras de medicamentos exibem um papel importante devido a sua grande influência na eliminação de xenobióticos. De modo geral, conforme a característica observada na atividade enzimática do indivíduo, o fenótipo pode ser dividido em quatro categorias: metabolizadores lentos (PMs - poor metabolizers), metabolizadores intermediários (IMs - intermediate metabolizers), metabolizadores extensivos (EMs - extensive metabolizers) e 
metabolizadores ultra-rápidos (UMs - ultrarapid metabolizers) (Rogers et al., 2002)

(Figura 5). Esta classificação pode mudar de acordo com o gene estudado.

(a)

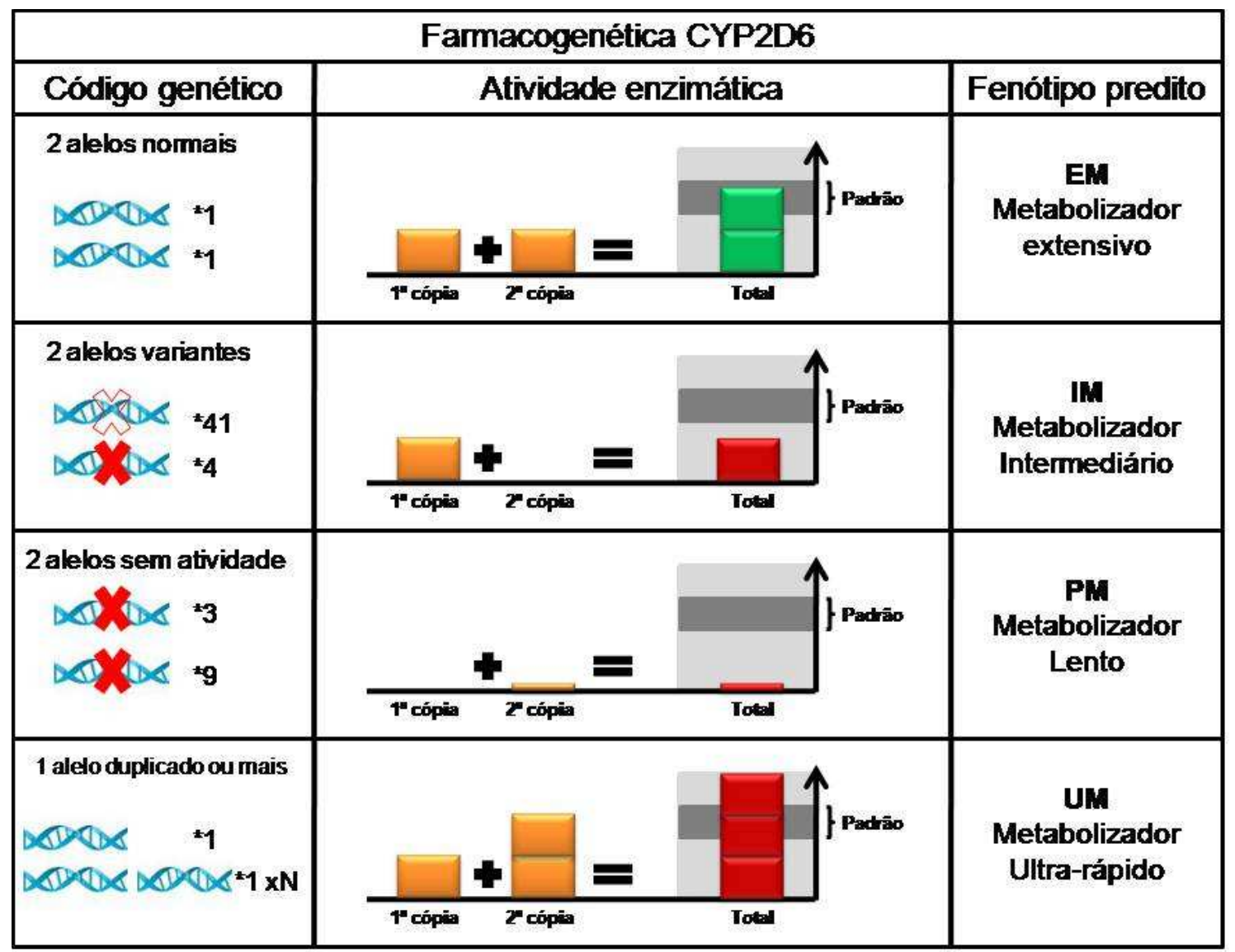

Figura 5 - Representação esquemática da atividade enzimática da CYP2D6 (adaptado de: <http://www.signaturegenetics.com/public/2/226.html>). (a) A atividade enzimática de indivíduos com duas cópias normais do gene é a padrão, apresentando um fenótipo normal. (b) Em indivíduos com alelos variantes que codificam uma proteína de atividade reduzida, a atividade enzimática não consegue ser suficiente para atingir o padrão caracterizando um fenótipo intermediário. (c) Indivíduos com alelos não funcionais, não codificam uma proteína com atividade apresentando um fenótipo lento. (d) Três ou mais cópias funcionais do gene provocam um aumento além do padrão normal, da atividade enzimática.

Indivíduos que possuem enzimas não funcionais ou inativas, são considerados PMs. Pró-fármacos, que requerem biotransformação para serem ativados, com freqüência não cumprem seu papel terapêutico nestes pacientes. A toxicidade do fármaco também pode ser observada em pacientes PMs devido à depuração insatisfatória dos medicamentos. IMs são os pacientes que apresentam 
atividade enzimática deficiente e desse modo, diminuído metabolismo. EMs são os pacientes com atividade enzimática normal (extensiva), no qual é esperado que a resposta ao medicamento seja observada em doses usuais (padrão). UMs são pacientes que tem atividade enzimática aumentada, devido a uma maior expressão enzimática (Figura 6). Doses normais de medicamentos para pacientes UMs podem ocasionar uma resposta reduzida ao medicamento, levando a falha terapêutica ou reações tóxicas ao se utilizar pró-fármacos (Rogers et al., 2002).

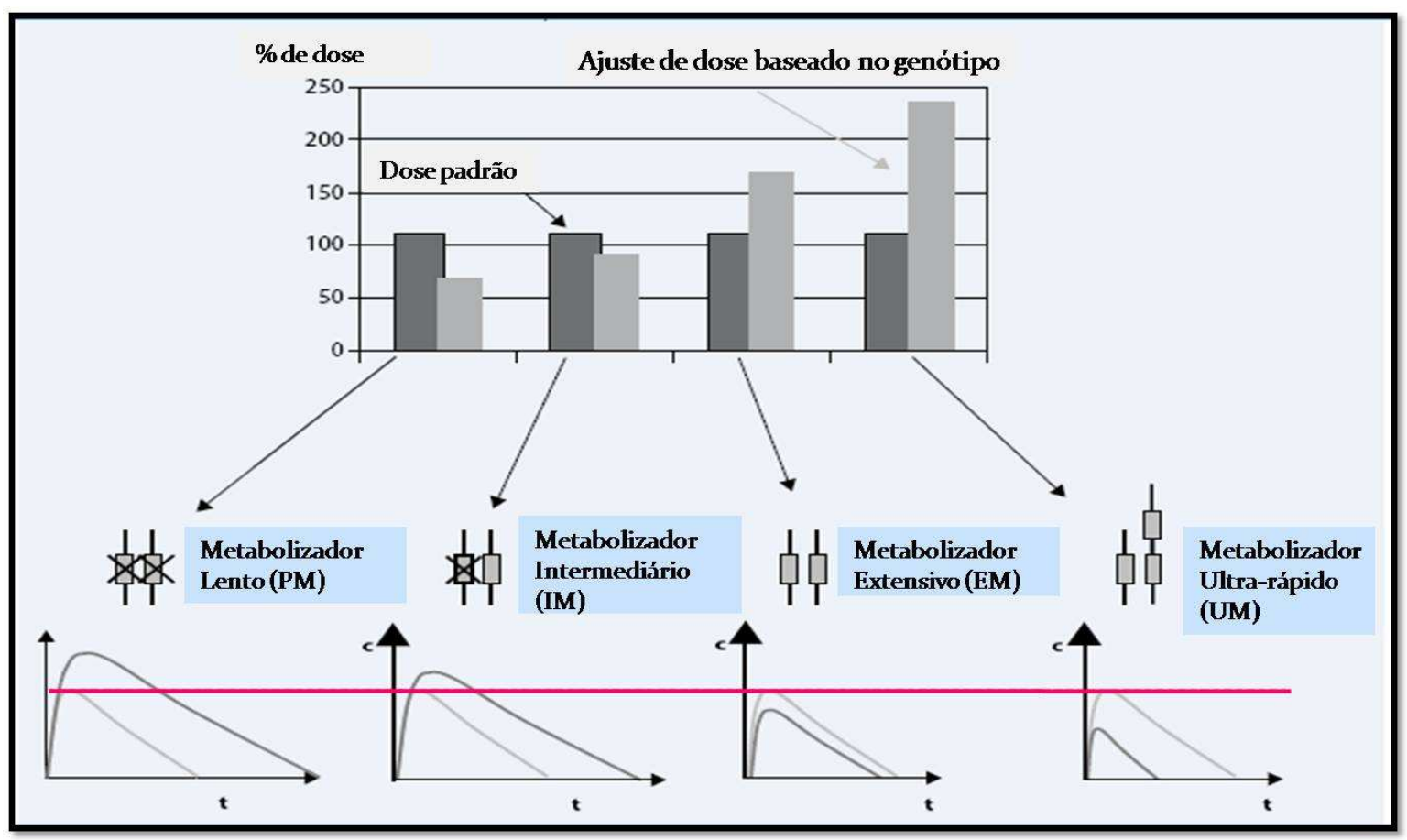

Figura 6 - Esquema de dose e resposta terapêutica baseada no genótipo de CYP2D6. PMs apresentam uma elevada concentração plasmática em relação ao normal e UMs apresentam uma diminuída concentração não atingindo o nível terapêutico (indicado pela linha rosa). A dose baseada nos genótipos (barra clara no gráfico) também varia em relação à dose padrão (barra escura no gráfico) (Adaptado de Kirchheiner et al., 2006).

Polimorfismos que conduzem à perda de função de enzimas metabolizadoras de medicamentos resultam em uma maior concentração plasmática dos mesmos. Se tais concentrações são associadas à grande probabilidade de efeitos tóxicos, é altamente provável que o paciente que possui este genótipo, desenvolva os efeitos tóxicos com a mesma dose administrada a pacientes que possuem o tipo selvagem 
(wild-type) de alelos desse gene. Contudo, se um paciente que não possui o polimorfismo é concomitantemente tratado com um medicamento que inibe a enzima, mostrará um fenótipo (alta concentração da droga) igual ao de pacientes que possuem dois alelos não funcionais para o gene, um fenômeno chamado fenocópia (phenocopying) (Eichelbaum et al., 2006).

Liao et al. (2008) recentemente, mostrou uma simulação quantitativa indicando que a utilização da informação farmacogenômica melhoraria significantemente $\mathrm{o}$ tratamento e reduziria acentuadamente a suspensão dos estudos de novos medicamentos na fase clínica. Durante esta simulação de ensaio clínico, a duração do tratamento, bem como a determinação do número de indivíduos que atingiram o nível terapêutico, foram melhoradas quando testes farmacogenéticos foram utilizados para individualização da dose. Desse modo, a pesquisa em farmacogenética visa ajudar na prescrição do medicamento correto em doses apropriadas, a fim de atingir a máxima eficácia com a mínima toxicidade, baseada em um teste genético, geralmente realizado antes do início da terapia.

Sendo assim, ao se investigar os polimorfismos associados com o efeito do medicamento no paciente, podem-se adaptar as decisões clínicas e terapêuticas para o fenótipo. Esta estratégia de determinar a terapia medicamentosa de acordo com a constituição genética do paciente é chamada de "medicina personalizada" (McMacarthy et al., 2005; Koo et al., 2006). Portanto, a farmacogenética e a farmacogenômica têm o potencial de melhorar significantemente a qualidade e a segurança dos medicamentos, a eficiência do desenvolvimento de medicamentos e o tratamento de pacientes.

\subsubsection{Sistema do citocromo P450}

Citocromo P450 pertence a um grupo de enzimas conhecidas como monooxigenases, às quais incorporam um átomo de oxigênio em substratos orgânicos (Martinus et al., 2000). As enzimas do citocromo P450 (CYPs), integram uma superfamília de enzimas do tipo heme. Elas são encontradas nos cinco reinos 
biológicos, possivelmente, indicando que as P450s podem ter evoluído a partir de um ancestral comum (Ito et al., 2008).

A superfamília das CYPs tem sido o foco da maioria das pesquisas farmacogenéticas. Isso é devido ao fato delas representarem as mais importantes enzimas de fase 1 e por serem responsáveis pelo metabolismo de substâncias endógenas e xenobióticos, incluindo mais de $60 \%$ de todas as medicações geralmente utilizadas (Zhou et al., 2008).

Essas enzimas diferem umas das outras na sua seqüência de aminoácidos, na regulação por inibidores e agentes indutores e na especificidade das reações que catalisam. As enzimas P450 possuem propriedades espectrais singulares; quando reduzidas e ligadas ao monóxido de carbono apresentam um composto rosado (daí o "P"de pink, rosa), com absorção de luz máxima no comprimento de onda 450 nm (Hang et al., 2003).

A nomenclatura para as isoenzimas do CYP450 é baseada no agrupamento das enzimas e genes em famílias e subfamílias com o prefixo CYP designando citocromo P450 (mammalian cytochrome P450). As famílias são identificadas por um número arábico (exemplo: CYP2) e as subfamílias são indicadas por uma letra (CYP2D). A enzima individual é caracterizada por um algarismo arábico, como em CYP2D6 (Poolsup et al., 2000). Membros únicos das subfamílias representam um gene em particular (CYP2D6 por exemplo). Um asterisco seguido de um número designa 0 alelo ( ${ }^{*} 1 \mathrm{e}^{*} 2$, dois alelos). $\mathrm{O}$ alelo ${ }^{*} 1$ é conhecido como o tipo-selvagem (wild-type) e denota atividade enzimática normal (Rogers et al., 2002). Os alelos das isoenzimas P450 são descritos em um site internacional e de livre acesso: <http://www.cypalleles.ki.se/>.

Existem pelo menos 57 genes CYP em humanos e aproximadamente 0 mesmo número de pseudogenes, os quais estão agrupados em 18 famílias e 44 subfamílias de acordo a similaridade das suas seqüências (Zanger et al., 2008).

O fígado contém a maior quantidade das CYPs; elas também são expressas no trato gastrointestinal e em pequenas proporções nos pulmões rins e sistema nervoso central (Neve e Ingelman-Sundberg, 2008).

O mecanismo da oxidação das substâncias pelo sistema do citocromo P450 envolve um complexo ciclo (Figura 7), porém o efeito final global da reação é 
simples. Em geral, reação catalisada pelas enzimas do citocromo P450 apresentam a seguinte estequiometria (Poolsup et al., 2000):

$$
\mathrm{RH}+\mathrm{NADPH}+\mathrm{O}_{2}+\mathrm{H}^{+} \rightarrow \mathrm{ROH}+\mathrm{NADP}^{+}+\mathrm{H}_{2} \mathrm{O}
$$

Esta reação exige a presença do substrato (" $\mathrm{RH}$ "), da enzima $\mathrm{P} 450$, de oxigênio molecular $\left(\mathrm{O}_{2}\right)$, NADPH e uma flavoproteína (NADPH-P450 redutase). O ferro heme se liga ao oxigênio no sítio ativo da CYP, onde a oxidação dos substratos ocorre. Elétrons são cedidos pela enzima NADPH-P450 redutase e seu co-fator, NADPH. O metabolismo de um substrato pela CYP consome uma molécula de $\mathrm{O}_{2} \mathrm{e}$ produz um substrato oxidado e uma molécula de água (Martinus et al., 2000; Hang et al., 2003).

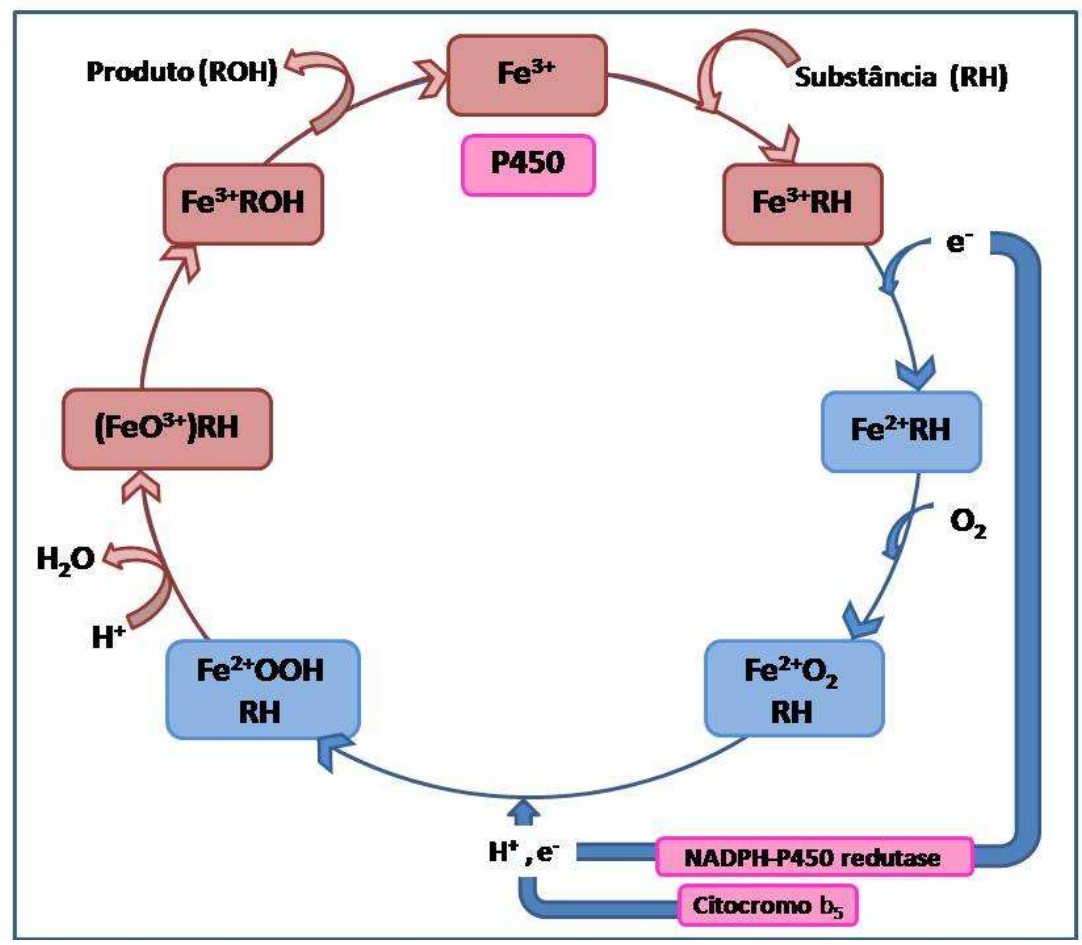

Figura 7 - Ciclo catalítico do CYP450. O P450, que contém ferro na forma férrica $\left(\mathrm{Fe}^{3+}\right)$, combina-se com uma molécula de medicamento $(\mathrm{RH})$, recebe um elétron da NADPH-P450 redutase, que reduz o ferro a $\mathrm{Fe}^{2+}$, combina-se com o oxigênio molecular, um próton e um segundo elétron (da NADPH-P450 redutase ou do citocromo $b 5$ ) para formar um complexo $\mathrm{Fe}^{2+} \mathrm{OOH} \cdot \mathrm{RH}$. Esse complexo combina-se com outro próton, produzindo água e um complexo oxeno férrico $(\mathrm{FeO})^{3+} \cdot \mathrm{RH}$. O $(\mathrm{FeO})^{3+}$ extrai um átomo de hidrogênio do $\mathrm{RH}$, com formação de um par de radicais livres de vida curta, liberação do medicamento oxidado (ROH) do complexo e regeneração da enzima P-450 (adaptado de Hang et al., 2003). 
Entre as diversas reações feitas pelas CYPs em mamíferos, estão a $\mathrm{N}$ desalquilação, O-desalquilação, hidroxilação aromática, N-oxidação, S-oxidação, desaminação e desalogenação (Brunton e Parker, 2008).

As CYPs estão envolvidas no metabolismo de xenobióticos, componentes alimentares, além da síntese de substâncias endógenas derivadas do colesterol (hormônios esteroidais e ácidos biliares). As CYPs que metabolizam xenobióticos possuem a capacidade de metabolizar um grande número de moléculas estruturalmente diferentes. Isto é devido às múltiplas formas de CPYs e à capacidade de uma única CYP metabolizar substratos estruturalmente diferentes. Um único composto pode ser metabolizado por várias CYPs e CYPs podem metabolizar um único composto em várias posições (Hang et al., 2003). Esta promiscuidade das CYPs é devida ao seu grande e fluído sítio de ligação ao substrato, ocorrendo a um custo de relativa diminuição nas taxas de catalisação. A grande especificidade de substratos das CYPs é uma das razões para a alta freqüência de interações medicamentosas. Quando dois medicamentos que são metabolizados pela mesma CYP são administrados em conjunto, eles competem pelo sítio ativo da enzima. Isto pode resultar na inibição do metabolismo de um ou ambos os medicamentos, levando ao aumento dos níveis plasmáticos. Para medicamentos com um pequeno índice terapêutico, uma elevada concentração plasmática pode causar toxicidade. Interações medicamentosas são as principais causas de ADRs (Brunton e Parker, 2008).

De acordo com Lynch et al. (2007), o conhecimento do fenótipo de resposta ao medicamento deve ser aplicado para evitar as interações medicamentosas que podem resultar em alterações no metabolismo das enzimas CYP450. Em indivíduos PMs, os $A D R s$ podem ser agravados com a adição de um inibidor das enzimas do citocromo na sua terapia. Medicamentos que causam interações metabólicas com o P450 são referidos como inibidores ou indutores.

Os polimorfismos das enzimas do citocromo P450 têm um grande efeito nas variações das respostas a medicamentos utilizados no tratamento de muitas doenças tais como: depressão, psicoses, câncer, doenças cardiovasculares e gastrintestinais, dor, epilepsia, entre outras. Estas enzimas são responsáveis por cerca de $80 \%$ de todo o metabolismo de fase 1 (Ingelman-Sundberg et al., 2007). 
As enzimas CYP2C9, CYP2C19 e CYP2D6 são responsáveis pelo metabolismo de mais de $40 \%$ dos 200 medicamentos mais prescritos nos EUA (Figura 8) (Quadro 5) (Zanger et al., 2008).

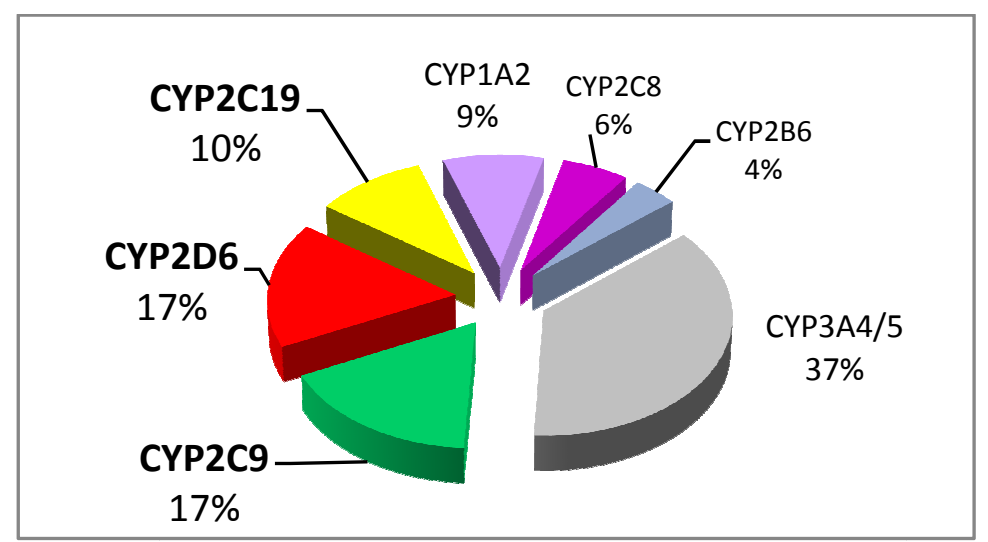

Figura 8 - Percentual de CYPs responsáveis pelo metabolismo de fase 1 dos 200 medicamentos mais prescritos nos EUA.

Quadro 5 - Medicamentos metabolizados pelas enzimas CYP2D6, CYP2C19 e CYP2C9 (continua).

\begin{tabular}{|c|c|c|c|}
\hline \multirow{2}{*}{ Medicamentos } & \multicolumn{3}{|c|}{ Metabolismo } \\
\cline { 2 - 4 } & CYP2D6 & CYP2C19 & CYP2C9 \\
\hline ANTIDEPRESSIVOS & & & \\
\hline Amitriptilina & $\mathrm{X}$ & $\mathrm{X}$ & \\
\hline Clomipramina & $\mathrm{X}$ & $\mathrm{X}$ & \\
\hline Desimipramina & $\mathrm{X}$ & & \\
\hline Imipramina & $\mathrm{X}$ & $\mathrm{X}$ & \\
\hline Nortriptilina & $\mathrm{X}$ & $\mathrm{X}$ & \\
\hline Citalopram & & $\mathrm{X}$ & \\
\hline Escitalopram & & $\mathrm{X}$ & \\
\hline Fluoxetina & $\mathrm{X}$ & $\mathrm{X}$ & $\mathrm{X}$ \\
\hline Fluvoxamina & $\mathrm{X}$ & & \\
\hline Paroxetina & $\mathrm{X}$ & & \\
\hline Sertralina & & $\mathrm{X}$ & \\
\hline Venlafaxina & $\mathrm{X}$ & & \\
\hline ANSIOLÍTICOS & & & \\
\hline Diazepam & & $\mathrm{X}$ & \\
\hline Flunitrazepam & & $\mathrm{X}$ & \\
\hline ANTICONVULSIVANTES & & & \\
\hline Fenitoína & & $\mathrm{X}$ & $\mathrm{X}$ \\
\hline Valproato & & & $\mathrm{X}$ \\
\hline
\end{tabular}


Quadro 5 - Medicamentos metabolizados pelas enzimas CYP2D6, CYP2C19 e CYP2C9 (continuação).

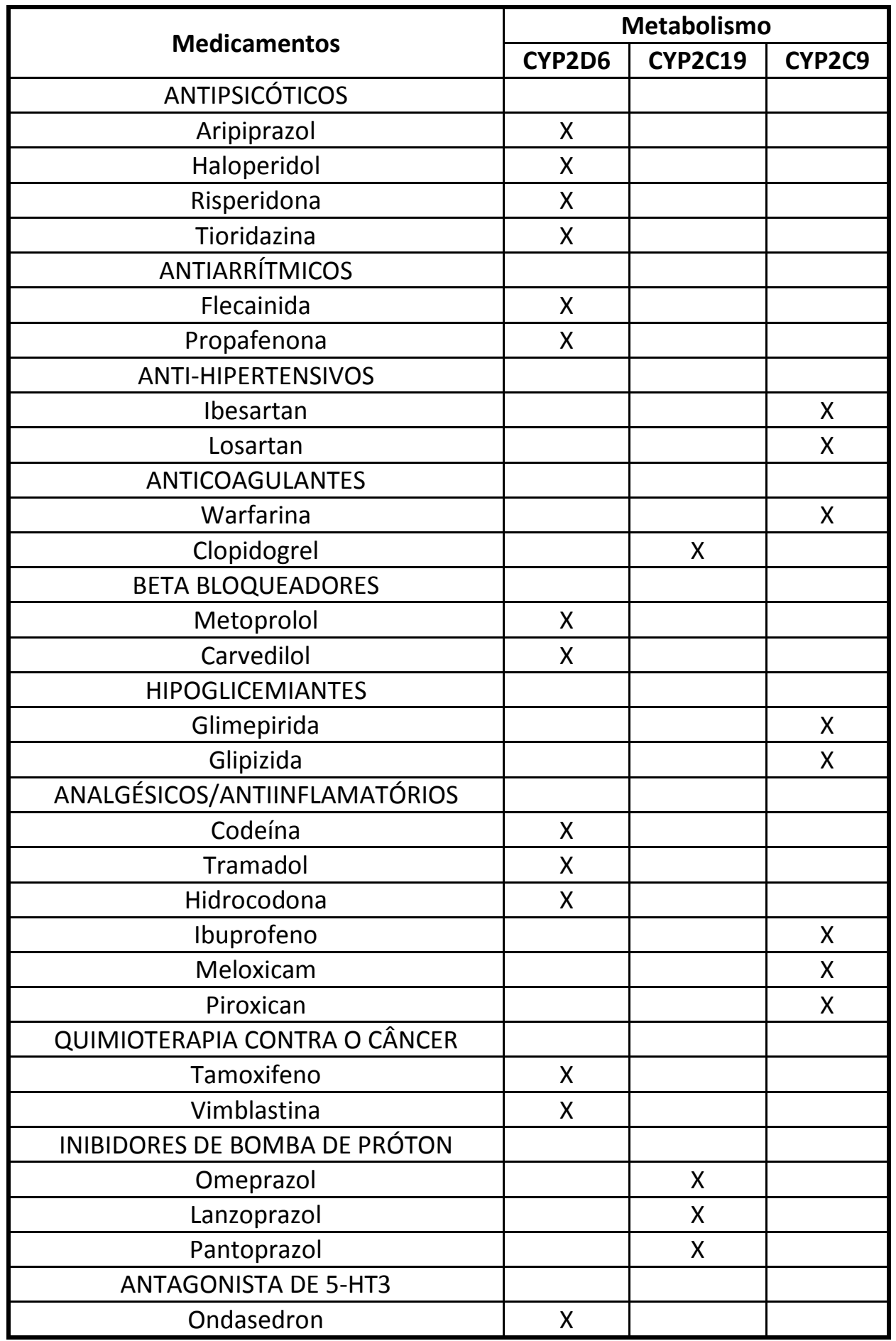

FONTE: Zanger et al., 2008; Preskorn et al., 2008; http://www.signaturegenetics.com/public/ 4/411.htm|\#21112. 
No que diz respeito à psiquiatria, o tratamento é caracterizado por uma grande diferença na resposta ao medicamento e na dose requerida entre os pacientes. Todos os antipsicóticos e antidepressivos são moléculas altamente lipofílicas, que estão sujeitas a metabolização extensiva principalmente pelas enzimas do citocromo P450, antes de serem excretadas. Estima-se que 50 a 60\% da dose do medicamento é dependente das enzimas CYP2D6 e CYP2C19 (van der Weide et al., 2006) e cerca de $80 \%$ dos antidepressivos e antipsicóticos são metabolizados pela CYP2D6 e CYP2C19, CYP2C9 (Maier et al., 2008).

A dose do medicamento é freqüentemente ajustada na base da tentativa e erro e o ajuste da dose de acordo com o genótipo melhoraria este processo consideravelmente (van der Weide et al., 2006).

Os polimorfismos do gene CYP2D6 têm grande importância na farmacogenética da Depressão Unipolar (Binder et al., 2006) e recomendações de doses baseadas no genótipo CYP2D6 já foram sugeridas (Kirchheiner et al., 2004). Para o tratamento com antidepressivos, existe uma grande evidência de que principalmente para CYP2D6 e em menor escala para CYP2C19, os polimorfismos afetam a farmacocinética de muitos antidepressivos e possivelmente afetam a resposta terapêutica e os $A D R s$ (Steimer et al., 2001; Stadoon et al., 2002; Steimer et al., 2005; Tomalik-Scharte et al., 2008).

Muitos dos antidepressivos tricíclicos (TCAs - triciclic antidepressants) são melhores metabolizados pela CYP2D6 do que qualquer outra CYP (Steimer et al., 2005; Zanger et al., 2008) entretanto, alguns TCAs como a amitriptilina, imipramina, e clomipramina são também metabolizados pela CYP2C19 (Brøsen, 2004; Steimer et al., 2005; Bertilsson, 2007). Segundo Kirchheiner et al. (2004), pacientes que utilizam TCAs podem se beneficiar da genotipagem se forem indivíduos PMs ou UMs para CYP2D6. PMs têm neste caso, $50 \%$ ou mais dos valores diminuídos na depuração para amitriptilina, clomipramina, desipramina, imipramina e nortriptilina.

Alguns inibidores seletivos de recaptação de serotonina (SSRI - selective serotonin re-uptake inhibitors) como a fluoxetina, fluvoxamina, e paroxetina são potentes inibidores da enzima CYP2D6. Portanto, múltiplas doses causam uma auto-inibição da CYP2D6 e uma conversão do EM ao fenótipo IM ou do fenótipo UM para o fenótipo EM. Os mesmos autores observaram que nenhuma influência foi 
descrita para os polimorfismos de CYP2D6 sob parâmetros farmacocinéticos dos SSRIs sertralina e citalopram. No grupo dos SSRIs, a inibição da CYP é um problema para as interações medicamentosas, mas para os polimorfismos do gene CYP2D6 têm menos efeito e o ajuste de dose baseado no genótipo não parece ser útil para este grupo de antidepressivos (com exceção da paroxetina) (TomalikScharte et al., 2008).

Muitos antipsicóticos como a risperidona, clorpromazina, tioridazina (Murray, 2006), também são metabolizados pela CYP2D6 (Bertilsson, 2007). Os níveis plasmáticos da flufenazina e do haloperidol são influenciados por esta enzima. Estes medicamentos têm um pequeno índice terapêutico e os $A D R s$ são influenciados pelos polimorfismos do gene CYP2D6 (Dorado et al., 2007).

No caso dos benzodiazepínicos, seu metabolismo é influenciado pela enzima CYP2C19. Esta é uma classe de medicamentos com propriedades sedativas, ansiolíticas e anticonvulsivantes (Inomata et al., 2005).

\section{a) gene CYP2D6}

Entre os genes que codificam enzimas metabolizadoras de medicamentos, CYP2D6 (citocromo P450, família 2, subfamília D, polipeptídeo 6) é um dos melhores caracterizados (Sabbagh et al., 2006; Naveen et al., 2006a). Este gene codifica a enzima CYP2D6 que é responsável pelo metabolismo de aproximadamente $25 \%$ dos medicamentos mais utilizados que incluem os betabloqueadores, antiarrítmicos, opióides e um grande número de antidepressivos (TCAs, SSRIs), antipsicóticos e fármacos utilizados na quimioterapia do câncer (Ingelman-Sundberg, 2005; Sabbagh et al., 2006; Goetz et al., 2008).

A enzima CYP2D6, polipeptídeo composto por 497 aminoácidos, representa uma pequena porcentagem de todas as CYPs hepáticas. Os substratos da CYP2D6 são bases lipofílicas com um átomo de nitrogênio protonável. A reação de hidroxilação acontece a uma distância de 5 ou $7 \AA$ do átomo de nitrogênio (Ingelman-Sundberg, 2004). Esta enzima tem uma grande afinidade por alcalóides e 
é a única entre as CYPs que não sofre indução e, portanto, sua variação genética contribui para a variação da atividade enzimática (Ingelman-Sundberg, 2005).

O gene CYP2D6 está localizado no cromossomo 22q13.1 e é constituído por nove éxons e $4.378 \mathrm{pb}$ (pares de bases) (Kimura et al., 1989). CYP2D6 pertence a um cluster gênico de dois pseudogenes altamente similares: CYP2D7 e CYP2D8 (Zou et al., 2008).

CYP2D6 é um gene altamente polimórfico com mais de 90 variações e subvariações alélicas identificadas até o momento. As freqüências alélicas do gene CYP2D6 mostram-se bastante diferentes dentro de uma mesma população e entre diferentes grupos étnicos (Sistonen et al., 2007) (Tabela 1). Essas variações alélicas são resultantes de alterações pontuais (SNPs), deleções ou inserções, deleção ou multiplicação do gene inteiro (Sabbagh et al., 2006). O efeito causado por tais polimorfismos depende do medicamento e da variante alélica envolvida. 
Tabela 1- Principais alelos CYP2D6, efeito no metabolismo enzimático e freqüências (\%) alélicas em algumas populações.

\begin{tabular}{|c|c|c|c|c|c|c|c|c|c|c|c|c|c|}
\hline \multirow[b]{3}{*}{ Populações } & \multicolumn{12}{|c|}{ Alelos CYP2D6 } & \multirow[b]{3}{*}{ Referência } \\
\hline & \multicolumn{2}{|c|}{ Funcionais } & \multicolumn{4}{|c|}{ Não-funcionais } & \multicolumn{5}{|c|}{ Função reduzida } & \multirow[b]{2}{*}{ XN } & \\
\hline & $*_{1}$ & $* 2$ & $* 3$ & $* 4$ & $* 5$ & $* 6$ & $* g$ & $* 10$ & $* 17$ & $* 29$ & $* 41$ & & \\
\hline $\begin{array}{c}\text { África } \\
\text { Subsaariana }\end{array}$ & 24,4 & 32,7 & - & 2,8 & 5,9 & - & 0 & 4,3 & 12,2 & 6,7 & 2,8 & 6,7 & $\begin{array}{l}\text { Sistonen et al. } \\
\text { (2007) }\end{array}$ \\
\hline $\begin{array}{c}\text { África } \\
\text { Oriental (A) }\end{array}$ & - & 27,2 & 0,1 & 3,0 & 3,9 & 0 & 0 & 5,2 & 18,4 & 18,2 & 0 & 13 & $\begin{array}{l}\text { Sistonen et al. } \\
\text { (2009) }\end{array}$ \\
\hline $\begin{array}{l}\text { Oriente } \\
\text { Médio }\end{array}$ & 35,1 & 25,0 & - & 6,8 & 3,7 & 1,4 & 0 & 0,7 & 2,0 & - & 16,9 & 7,1 & $\begin{array}{l}\text { Sistonen et al. } \\
\text { (2007) }\end{array}$ \\
\hline Sul da Índia & - & 34,8 & 0 & 7,3 & 1,9 & - & - & 10,2 & 0 & - & - & - & $\begin{array}{l}\text { Naveen et al. } \\
(2006)\end{array}$ \\
\hline $\begin{array}{c}\text { Ásia } \\
\text { central/sul }\end{array}$ & 43,3 & 29,0 & - & 8,1 & 3,8 & - & 0 & 3,8 & - & 0,2 & 10,5 & 1,0 & $\begin{array}{l}\text { Sistonen et al. } \\
\text { (2007) }\end{array}$ \\
\hline $\begin{array}{c}\text { Ásia } \\
\text { ocidental (C) }\end{array}$ & - & 30,1 & 0 & 7,0 & 2,6 & 1,1 & 0,1 & 4,1 & 1,5 & 0 & 16,9 & 7,8 & $\begin{array}{l}\text { Sistonen et al. } \\
\text { (2009) }\end{array}$ \\
\hline $\begin{array}{l}\text { China e } \\
\text { Japão }\end{array}$ & - & 15,8 & 0 & 3,5 & 6,4 & 0 & 0 & 38,3 & 0 & 0 & 3,8 & 1,6 & $\begin{array}{l}\text { Sistonen et al. } \\
\text { (2009) }\end{array}$ \\
\hline Japão & - & 12,9 & 0 & 0 & 6,2 & - & - & 38,6 & 0 & - & - & - & $\begin{array}{l}\text { Kubota et al. } \\
(2000)\end{array}$ \\
\hline Europa & 34,4 & 28,7 & 0,3 & 17,2 & 3,2 & 0,6 & 2,5 & 2,9 & - & - & 7,0 & 2,8 & $\begin{array}{l}\text { Sistonen et al. } \\
\text { (2007) }\end{array}$ \\
\hline $\begin{array}{c}\text { Sul da } \\
\text { Europa (B) }\end{array}$ & - & 30,2 & 1,5 & 16,8 & 2,1 & 1,1 & 1,5 & 2,4 & 0,1 & 0 & 4,5 & 2,7 & $\begin{array}{l}\text { Sistonen et al. } \\
\text { (2009) }\end{array}$ \\
\hline $\begin{array}{l}\text { França e } \\
\text { Alemanha }\end{array}$ & - & 29,3 & 1,1 & 18,9 & 5,1 & 0,5 & 3,5 & 2,9 & 0 & 0 & 7,1 & 2,3 & $\begin{array}{l}\text { Sistonen et al. } \\
\text { (2009) }\end{array}$ \\
\hline América & 60,2 & 30,1 & - & 3,2 & 0,9 & - & 0 & - & 0,5 & - & - & 5,1 & $\begin{array}{l}\text { Sistonen et al. } \\
\text { (2007) }\end{array}$ \\
\hline $\begin{array}{l}\text { América } \\
\text { central }\end{array}$ & - & 22,2 & 0,4 & 9,6 & 1,0 & 0,1 & 0 & 5,6 & 1,1 & 0 & 0 & 6,1 & $\begin{array}{l}\text { Sistonen et al. } \\
\text { (2009) }\end{array}$ \\
\hline $\begin{array}{c}\text { Argentina e } \\
\text { Paraguai }\end{array}$ & 39,9 & 23,8 & 0 & 17,8 & - & - & - & $\begin{array}{l}2,5 a \\
14,3\end{array}$ & - & - & - & - & $\begin{array}{l}\text { Baillet et al. } \\
\text { (2007) }\end{array}$ \\
\hline Brasil (D) & 38,4 & 18,3 & 1,1 & 13,2 & 2,2 & 0,5 & 1,6 & 2,1 & 1,3 & - & 8,2 & 4,6 & $\begin{array}{l}\text { Kohlausch et } \\
\text { al. (2008) }\end{array}$ \\
\hline
\end{tabular}

(A) Zimbábue, Tanzania, Etiópia, (B) Grécia, Croácia, Itália, Espanha; (C) Turquia, Israel, Arábia Saudita, Yemen; (D) Rio Grande do Sul, Brasil. "XN" significa alelo multiplicado.

A atividade enzimática da CYP2D6 abrange desde a completa deficiência enzimática até o metabolismo ultra-rápido de substâncias (Bernard et al., 2006; Sabbagh et al., 2006).

O fenótipo da metabolização do medicamento pela CYP2D6 pode ser determinado segundo 0 índice metabólico (medicamento não- 
metabolizado/metabólito) na urina ou plasma de uma substância-teste (debrisoquina, dextrametorfano ou esparteína) (Zanger et al., 2008).

De acordo com a atividade enzimática de CYP2D6, pode-se identificar quatro fenótipos: PMs, IMs, EMs e UMs. Desse modo, as variações alélicas podem ser associadas com ausência, redução, extensiva (normal) ou aumento de atividade enzimática. Alelos não-funcionais são aqueles que não codificam um produto gênico funcional e, portanto, não geram uma enzima com atividade funcional (Bernard et al., 2006; Beverage et al., 2007; Brockmöller et al., 2008).

O alelo IM CYP2D6*10 apresenta um SNP não-sinônimo que leva a uma substituição de aminoácido (Pro34Ser) gerando uma proteína instável e assim, uma enzima com atividade reduzida (Zhou et al., 2008). Os alelos não funcionais mais importantes são o CYP2D6*4 (defeito de splicing levando a não formação da proteína) e o CYP2D6*5 (deleção total do gene), enquanto que, os alelos IMs mais comuns são representados por ${ }^{*} 10,{ }^{*} 17$ e *41 (defeito de splicing) (Zhou et al., 2008). Este gene está sujeito a muitas variações no número de cópias (CNVs - copy number variations); já foram identificados alelos com $0,1,2,3,4,5$ e 13 cópias. A amplificação do gene pode acontecer com alelos PMs, IMs e EMs (IngelmanSundberg et al., 2005; Bertilsson, 2007).

O fenótipo EM é encontrado na maioria da população mundial e é por isso considerado normal. Indivíduos definidos como PMs metabolizam os medicamentos mais lentamente. O fenótipo IM possui uma taxa de metabolismo entre EM e PM. Já o fenótipo UM apresenta um excesso de atividade enzimática e pode levar a perda do efeito terapêutico do medicamento em doses usuais (Sabbagh et al., 2006; Bernard et al., 2006) ou reações tóxicas ao se utilizar pró-fármacos (Rogers et al., 2002). Estes quatro fenótipos principais ocorrem em diferentes freqüências entre distintos grupos étnicos (Sistonen et al., 2007).

A Europa é caracterizada pela mais alta frequeência de fenótipos PM (8\%) (Sistonem et al., 2007). Geralmente, caucasianos têm a freqüência mais alta do fenótipo PM, com britânicos e suíços representando incidências de 8,9\% e 10\% respectivamente (Lopez et al., 2005; Bernard et al., 2006). Na população asiática, a frequência de PMs é relativamente baixa entre chineses e japoneses $(0-1 \%, 2 \%)$ (Kubota et al., 2000; Bernard et al., 2006). A prevalência de PMs na população 
africana difere muito, com uma estimativa de variação entre 0-19\%. Em afroamericanos a incidência de PMs está entre 1,9-7,3\%. Em hispânicos, a prevalência de PMs está entre 2,2\%-6,6\% (Lopez et al., 2005; Bernard et al., 2006). O segundo grupo metabólico mais comum no norte da África, parte da Europa e América é o fenótipo UM (40\%, 12\% e $8 \%$ respectivamente). As variações de função diminuída, *10, *17 e *41, levam a um elevado número de IMs no leste da Ásia, África e parte da Europa, maiores que em outras regiões (Sistonem et al., 2007). Enquanto os alelos PMs são encontrados principalmente na Europa, os UMs (multiplicação de alelo ativo) são comuns no norte da África (Tabela 2).

Tabela 2 - Freqüências (\%) fenotípicas de UMs e PMs para CYP2D6 em diferentes populações.

\begin{tabular}{l|c|c|l}
\hline & \multicolumn{2}{|c|}{ Fenótipos CYP2D6 } & \\
\hline Populações & PM & UM & Referência \\
\hline Europa & 8 & 12 & Sistonem et al. (2007) \\
\hline Britânicos & 8,9 & & Lopez et al. (2005); Bernard et al. (2006) \\
\hline Suíços & 10 & & Lopez et al. (2005); Bernard et al. (2006) \\
\hline África & $0-19$ & & Lopez et al. (2005); Bernard et al. (2006) \\
\hline Norte da África & & 40 & Sistonem et al. (2007) \\
\hline América & & 8 & Sistonem et al. (2007) \\
\hline Afro-americanos & $1,9-7,3$ & & Lopez et al. (2005); Bernard et al. (2006) \\
\hline Hispânicos & $2,2-6,6$ & & Lopez et al. (2005); Bernard et al. (2006) \\
\hline Chineses & 1 & & Kubota et al. (2000); Bernard et al. (2006) \\
\hline Japoneses & 2 & & Kubota et al. (2000); Bernard et al. (2006) \\
\hline
\end{tabular}

Estudos farmacoepidemiológicos com antidepressivos metabolizados pela CYP2D6 confirmam que as variações do nível plasmático dos medicamentos e metabólitos, são muitas vezes determinados pelo gene CYP2D6. A maioria dos $A D R s$ graves ocorre na prática clínica quando são prescritos tratamentos com SSRIs dependentes do metabolismo da CYP2D6 e podem ser correlacionados com alelos CYP2D6 UMs ou PMs (Maier et al., 2008).

No Japão, Ueda et al. (2006), estudou a influência dos genótipos de CYP2D6 na concentração plasmática do antidepressivo paroxetina em 55 pacientes. Foram administradas doses de 10 a $40 \mathrm{mg}$ de paroxetina por dia e estas foram mantidas por duas semanas para que a concentração plasmática constante (steady-state) 
fosse atingida. Os indivíduos foram genotipados para os alelos *1, *2, ${ }^{*} 10,{ }^{*} 5$ e *41 e a determinação da concentração plasmática da paroxetina foi realizada por HPLC (high performance liquid chromatography - cromatografia líquida de alta eficiência). Este estudo constatou que, existe uma diferença significativa dos níveis plasmáticos de paroxetina entre os três grupos de genótipos (dois alelos funcionais, um alelo funcional e nenhum alelo funcional) observados. Contudo, esta diferença somente foi detectada nos pacientes tratados com $30 \mathrm{mg} / \mathrm{dia}$ do medicamento (Figura 9). Os autores concluíram que possuir um alelo não funcional pode ser um indicador de uma elevada concentração plasmática de paroxetina quando doses relativamente altas (30 mg/dia) são administradas.

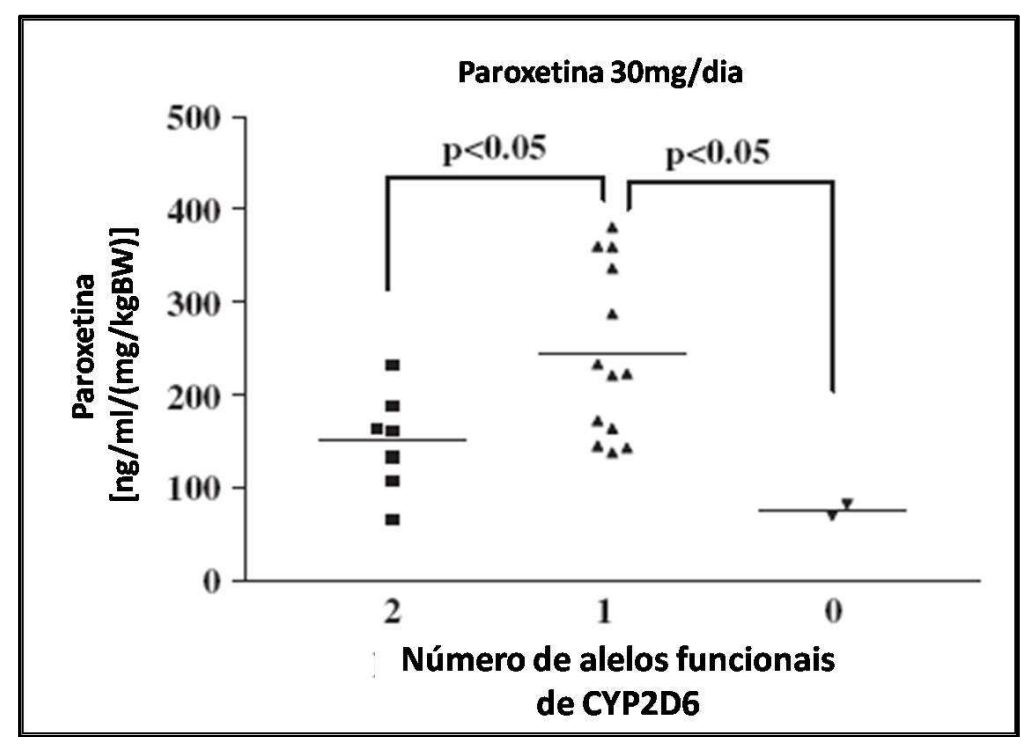

Figura 9 - Relação entre o número de alelos funcionais para do gene CYP2D6 e o steady-state da paroxetina corrigidas para a dose diária e massa corpórea (BW). Diferenças significativas na concentração plasmática de paroxetina foram encontradas em pacientes tratados com $30 \mathrm{mg} / \mathrm{dia}$ do medicamento. As concentrações plasmáticas em pacientes com apenas um alelo funcional foram superiores às de pacientes com um ou nenhum alelo funcional (adaptado de Ueda et al., 2006). Os números 2, 1 e 0 correspondem a 2 alelos funcionais, 1 alelo funcional e nenhum alelo funcional.

A venlafaxina $(\mathrm{V})$, um antidepressivo que inibe a recaptação de serotonina, noradrenalina e dopamina, é metabolizada pela enzima CYP2D6 em Odesmetilvenlafaxina (ODV) (um metabólito também ativo) que sofre ação de outras enzimas CYPs, entre elas a CYP2C19, para a formação de metabólitos inativos. A 
concentração plasmática de venlafaxina e ODV depende principalmente da atividade enzimática da CYP2D6, sugerindo que a resposta ao tratamento e os ADRs também estão relacionados ao genótipo CYP2D6 (Thuerauf, 2006). Shams et al. (2006) realizou um estudo com 100 pacientes tratados com venlafaxina; os que apresentaram índices metabólicos anormais foram genotipados para o gene CYP2D6. Este estudo revelou uma correlação significativa entre o genótipo-fenótipo de CYP2D6 (Figura 10) com UMs apresentando uma elevada concentração plasmática do metabólito ODV quando comparado a EMs; PMs e IMs, apresentaram uma pequena concentração do metabólito. $O$ ajuste da dose ou a seleção de um antidepressivo alternativo (que não seja substrato da enzima CYP2D6), foi considerado para pacientes com o genótipo PM e que por isso, apresentavam ADRs induzidos pela elevada concentração plasmática de venlafaxina.

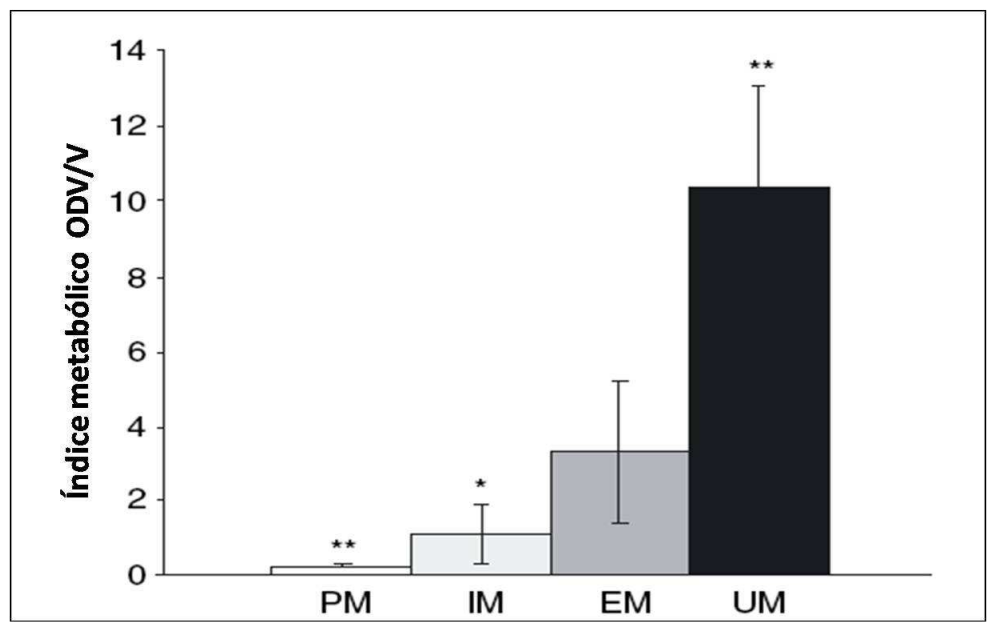

Figura 10 - Relação entre o genótipo de CYP2D6 e o índice metabólico ODV/V em pacientes que atingiram o steady-state para o medicamento venlafaxina (adaptado de Shams et al., 2006). PM, IM, EM e UM correspondem aos genótipos de metabolizadores lentos, intermediários, extensivos e ultra-rápidos.

Laika et al. (2009), realizou um estudo com o objetivo de verificar o impacto do gene CYP2D6 na resposta terapêutica e nos efeitos colaterais, apresentados por pacientes psiquiátricos que eram tratados com neurolépticos ou antidepressivos (30\% estavam tomando pelo menos um substrato da CYP2D6). Foram coletadas informações quanto à dose, resposta terapêutica e efeitos colaterais em 4 semanas 
de tratamento para 353 pacientes. A genotipagem do CYP2D6 encontrou 8,5\% PMs, $37,8 \%$ IMs, 50,6\% EMs e 3,0\% UMs. O grupo constatou que pacientes tratados com medicamentos substratos da CYP2D6 tiveram um maior tempo de internação e atraso na resposta terapêutica quando comparados a pacientes tratados com outros medicamentos. A comparação entre IMs e EMs mostrou que IMs tratados com doses máximas de substratos da CYP2D6 apresentaram mais efeitos colaterais que IMs tratados com doses mínimas; EMs tratados com doses máximas de substratos da CYP2D6 e IMs tratados com outras medicações. Os resultados encontrados pelo grupo indicam que a genotipagem pode ser útil, não somente para pacientes PMs (devido aos efeitos colaterais) ou para os UMs (falha terapêutica) mas também para IMs e EMs. Enquanto EMs podem tolerar doses máximas de medicamentos, IMs apresentam uma maior tendência a sofrer de efeitos colaterais quando tratados com doses máximas. Assim, concluiu-se que não apenas PMs e UMs são beneficiados com a genotipagem, mas todos os pacientes tratados com medicamentos metabolizados pela CYP2D6. A genotipagem prévia melhora a relação custobenefício do tratamento, pois, além de prevenir o aparecimento de efeitos colaterais, pode ajudar a reduzir o tempo e o custo do tratamento.

Já está bem estabelecido que polimorfismos no gene CYP2D6 afetam a farmacocinética do metoprolol e do carvedilol. Assim, a genotipagem para CYP2D6 em pacientes que necessitam utilizar esses fármacos pode ser útil na predição da resposta terapêutica (Tomalik-Scharte et al., 2008). A CYP2D6 também metaboliza os antiarrítmicos encainida, flecainida, propafenona.

Tamoxifeno é um medicamento comumente utilizado para o tratamento do câncer de mama (Borges et al., 2006). Ele é um pró-fármaco clássico, que necessita da ativação metabólica para obter a atividade farmacológica. A enzima CYP2D6 converte os metabólitos farmacologicamente inativos (tamoxifeno e $\mathrm{N}$ desmetiltamoxifeno) para endoxifeno (metabólito ativo com maior atividade terapêutica) (Borges et al., 2006; Beverage et al., 2007).

A conversão de tamoxifeno em endoxifeno parece estar correlacionada com a freqüência e a severidade de alguns efeitos adversos. A co-administração de inibidores de CYP2D6 e tamoxifeno também possui resultados clínicos importantes. De acordo com Beverage et al. (2007), a administração de SSRIs em pacientes que 
recebiam tamoxifeno, demonstraram uma redução significativa do nível plasmático do endoxifeno. Estes estudos sugerem que a administração de SSRIs e tamoxifeno tem um impacto importante na função de metabolizar tamoxifeno em endoxifeno (Beverage et al., 2007). A co-administração de fluoxetina ou paroxetina pode converter um metabolizador extensivo para um fenótipo PM, demonstrado pela redução da concentração plasmática de endoxifeno para níveis similares aos do genótipo PM (Jin et al., 2005).

Segundo Goetz et al. (2008), mulheres tratadas com tamoxifeno que apresentam alelos CYP2D6 associados com a ausência ou redução da atividade enzimática (CYP2D6*4, CYP2D6*5, CYP2D6*10, CYP2D6*41), apresentam menor tempo de reincidência e piora na progressão da doença quando comparadas com mulheres que possuem alelos funcionais. As pacientes PMs também podem sofrer ADRs devido à grande exposição ao tamoxifeno que inclui trombose venosa e câncer endometrial (Beverage et al., 2007).

Cerca de $40 \%$ das lactantes nos EUA fazem uso da codeína para o alívio de dores associadas ao parto. A codeína é um pró-fármaco e seu efeito analgésico depende da biotransformação em morfina pela CYP2D6. Após o relato da morte de um neonato devido a intoxicação por opióide, amamentado por uma mãe UM que fazia uso de coideína. Manadi et al. (2009) estudou mães e bebês com ou sem sinais de intoxicação após a exposição à codeína enquanto amamentados. Os pesquisadores constataram uma concordância de $71 \%$ entre intoxicação materna e dos neonatos. Duas mães com bebês que apresentaram severa intoxicação eram UMs para CYP2D6. Desse modo, mães UMs que fazem uso de codeína, quando amamentam, podem oferecer risco aos seus filhos recém nascidos.

\section{b) gene CYP2C19}

O gene CYP2C19 (Citocromo P450, família 2, subfamília C, polipeptídeo 19), codifica a enzima CYP2C19 responsável pelo metabolismo de aproximadamente $10 \%$ dos medicamentos mais comumente utilizados, incluindo os inibidores de 
bomba de próton (PPIs - proton pump inhibitors) como omeprazol, lanzoprazol e pantoprazol; benzodiazepínicos (diazepam, flunitrazepam) e os anticonvulsivantes fenitoína, fenobarbital (Brockmöller et al., 2008; Zhou et al., 2008). O fenótipo de CYP2C19 também afeta a farmacocinética dos antidepressivos tricíclicos amitriptilina, nortriptilina e clomipramina e dos SSRIs sertralina e citalopram (Ingelman-Sundberg et al., 2007; Zanger et al., 2008).

A enzima CYP2C19 é uma proteína de 490 aminoácidos, codificada pelo gene CYP2C19 que possui 9 éxons, 90.209 pares de bases e está localizado no cromossomo 10 (10q24. 1-q24.3). Até o momento, cerca de 21 variações alélicas foram identificadas para CYP2C19 (Zhou et al., 2008). Os substratos da CYP2C19 são bases fracas ou amidas (Zanger et al., 2008).

As relações entre genótipo e fenótipo para CYP2C19 conhecidas são baseadas na identificação do fenótipo EM e PM para o substrato 4-hidroximetilfenitoína que são determinados por polimorfismos genéticos (Justenhoven et al., 2008). O fenótipo PM é o resultado de dois alelos não funcionais, o que leva a codificação de uma proteína inativa, enquanto que EMs possuem pelo menos um alelo funcional (Sugimoto et al., 2008; Zanger et al., 2008).

O alelo CYP2C19*2 foi a primeira variação alélica a ser identificada e apresenta um SNP no éxon 5 que leva a um defeito de splicing e conseqüentemente uma proteína sem atividade funcional. O alelo CYP2C19*3 apresenta um SNP que resulta em um stop códon prematuro no éxon 4 . Ambos $C Y P 2 C 19^{*} 2$ e *3 são alelos não funcionais, que resultam em ausência de atividade enzimática. A maioria dos PMs de CYP2C19 deve-se a estas duas variações alélicas (Justenhoven et al., 2008; Zhou et al., 2008).

O fenótipo UM foi identificado por Sim et al. (2006), com base em observações de variações na resposta a medicamento em indivíduos EMs, sendo provocado pelo alelo CYP2C19*17 que apresenta SNPs na região promotora do gene, levando a um aumento da sua transcrição. Para este estudo, os indivíduos tiveram sua taxa metabólica determinada com as substâncias-teste para o gene CYP2C19 no caso, omeprazol e mefenitoína. O índice metabólico (MR- metabolic ratio) do omeprazol para homozigotos CYP2C19*1 foi duas vezes maior do que em homozigotos para o alelo ${ }^{*} 17$ e 1,2 vezes maior do que em heterozigotos ${ }^{*} 1{ }^{*} 17$ 
[Figura $11(\mathrm{~A})$ ]. Para o fármaco mefenitoína (mistura racêmica S/R-mefenitoína), o índice metabólico em homozigotos para o alelo ${ }^{*} 1$ foi 4,3 vezes maior quando comparados a homozigotos CYP2C19*17 enquanto que, a média do índice metabólico em indivíduos com o genótipo ${ }^{*} 1{ }^{*} 17$ foi 3,7 vezes maior do que em homozigotos para o alelo *17 [Figura $11(\mathrm{~B})]$.

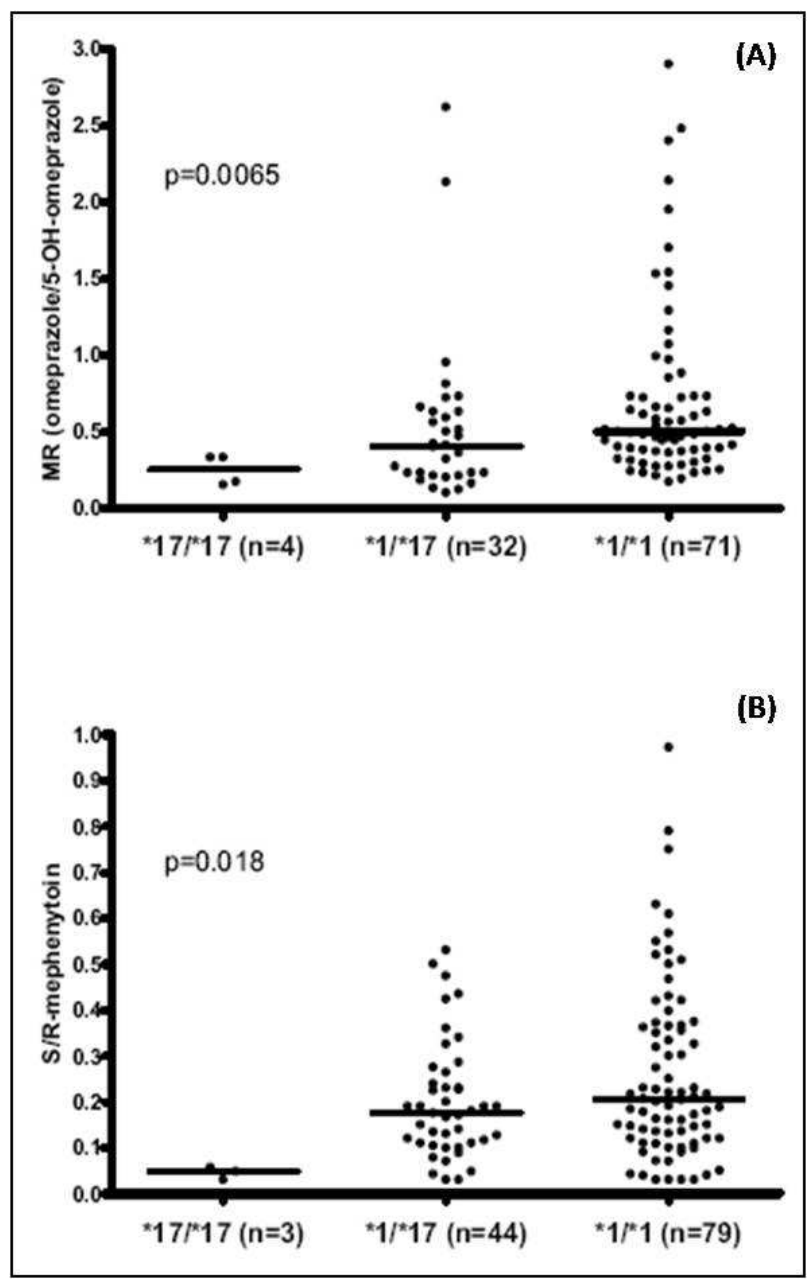

Figura 11 - Distribuição do índice metabólico (MR - metabolic ratio) do omeprazol e S/R-mefenitoína em relação ao genótipo CYP2C19*17. As barras representam as médias. O fenótipo PM (metabolizador lento) e indivíduos com alelos *2 e *3 foram excluídos do estudo (Sim et al., 2006).

A existência do alelo *17 pode explicar porque indivíduos apresentam diferenças nas respostas a alguns antidepressivos e PPIs devido a uma incomum depuração acelerada nesses medicamentos (Ingelman-Sundberg et al., 2007; 
Rudberg et al., 2007; Justenhoven et al., 2008). Os polimorfismos do alelo *17, nas posições -3402 (C>T) e -806 (C>T) estão em completo desequilíbrio de ligação (Sim et al., 2006). Homozigotos para o alelo CYP2C19*17 metabolizam fenitoína e omeprazol, duas droga-teste da enzima CYP2C19, mais rapidamente que homozigotos para o alelo CYP2C19 *1 (Ohlsson Rosenborg et al., 2008).

De acordo com Rudberg et al. (2007), indivíduos homozigotos para o alelo CYP2C19*17 têm uma diminuição na concentração plasmática do escitalopram quando comparados a homozigotos para 0 alelo selvagem ( $\left.{ }^{*} 1\right)$, sugerindo que pacientes com 0 genótipo ${ }^{*} 17^{\star} 17$ atinjam menos de $2 / 3$ do steady-state que pacientes ${ }^{*} 1{ }^{*}$. Assim, um indivíduo homozigoto para o alelo ${ }^{*} 17$ necessitará de uma dose $50 \%$ maior de escitalopram para atingir uma concentração plasmática semelhante ao indivíduo *1*1. Este estudo constatou que o grupo de indivíduos PMs apresenta uma concentração plasmática de escitalopram 5 a 7 vezes maior que os EMs. Isto tem um efeito substancialmente maior do que a redução de $42 \%$ da concentração plasmática em homozigotos para o alelo *17. Além disso, alelos CYP2C19 não funcionais parecem ter um maior efeito no metabolismo enzimático do que o alelo *17. Pacientes heterozigotos para o alelo *17 e um alelo PM possuem uma concentração plasmática similar a indivíduos com genótipo *1*1 (Figura 12).

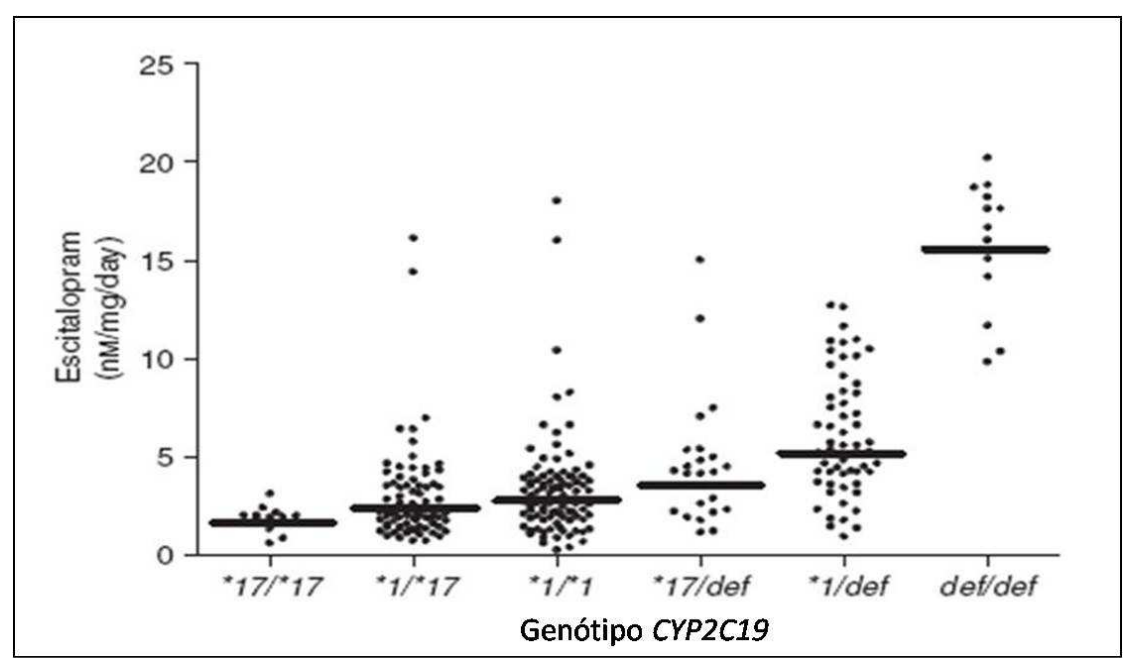

Figura 12 - Concentrações plasmáticas de escitalopram em relação ao genótipo CYP2C19. ("def" neste exemplo, representa um alelo sem atividade como o *2 ou *3 do gene CYP2C19). 
Inibidores de bomba de próton são metabolizados extensivamente pela enzima CYP2C19. A farmacocinética e o efeito da inibição ácida já estão bem correlacionados com o genótipo CYP2C19 in vivo (Schwab et al., 2004). Assim, o genótipo CYP2C19 é um forte determinante no sucesso do tratamento de refluxo grastroesofágico, e úlceras gástricas $H$. pilory positivas. De acordo com Kurzawski et al. (2006), o efeito de alelos EMs é a baixa concentração plasmática dos PPIs e a diminuição da taxa de cura em pacientes quando comparados com pacientes PMs. No Japão onde aproximadamente $20 \%$ das pessoas são PMs, Furuta et al. (2007), constatou que a terapia baseada no genótipo de CYP2C19 levava a 96\% de sucesso no tratamento da $H$. pilory enquanto apenas $70 \%$ dos pacientes se beneficiaram do tratamento padrão. O custo dos dois tratamentos foi similar, indicando assim que, a eficiência do tratamento pode ser atingida sem custos adicionais.

Até o momento, nenhum efeito significativo do genótipo de CYP2C19 na resposta ao tratamento com antidepressivos foi mostrado, contudo, o risco de ADRs foi associado com o genótipo de CYP2C19 durante o tratamento com amitriptilina (Steimer et al., 2005).

De acordo com Kim et al. (2008), o genótipo de CYP2C19 afeta a concentração plasmática do pró-fármaco clopidogrel, um antiagregante plaquetário, sendo responsável pela variação na resposta a este medicamento. Alelos PMs para CYP2C19 levam a uma reduzida bioativação deste fármaco (Hulot et al., 2006).

Cerca de $3-5 \%$ de caucasianos e africanos e até $20 \%$ dos asiáticos possuem dois alelos não funcionais, sendo que os mais comuns são CYP2C19*2, o qual ocorre em caucasianos e negróides; e CYP2C19*3 que ocorre principalmente em asiáticos (Ingelman-Sundberg et al., 2007; Brockmöller et al., 2008).

A freqüência do alelo*2 é de aproximadamente 17\% em afro-americanos, $30 \%$ em chineses e cerca de $15 \%$ em caucasianos. O alelo *3 é mais freqüente em chineses $(5 \%)$ e menos freqüente em afro-americanos $(0,4 \%)$ e caucasianos (0,04\%). O alelo CYP2C19*17 está presente em chineses, suecos e etíopes em freqüências de 4 a 19\% (Zhou et al., 2008) (Tabela 3). 
Tabela 3 - Principais alelos CYP2C19, efeito no metabolismo enzimático e freqüências (\%) alélicas em algumas populações.

\begin{tabular}{l|c|c|c|c|l}
\hline & \multicolumn{3}{|l|}{ Alelos CYP2C19 } & \multirow{2}{*}{} \\
\cline { 2 - 5 } & Funcional & \multicolumn{2}{|l|}{ Não-funcionais } & $\begin{array}{l}\text { Atividade } \\
\text { aumentada }\end{array}$ & \\
\hline Populações & $\boldsymbol{*}_{1}$ & $\boldsymbol{*}_{\mathbf{2}}$ & $\boldsymbol{* 3}^{\mathbf{3}}$ & $\boldsymbol{*}_{\mathbf{1 7}}$ & Referência \\
\hline Suécia & - & - & - & 18,0 & Sim et al. (2006) \\
\hline Etiópia & - & - & - & 18,0 & Sim et al. (2006) \\
\hline Noruega & 59,3 & 18,1 & 0,6 & 22,0 & Rudberg et al. (2007) \\
\hline China & 69,7 & 24,7 & 3,3 & 1,2 & Chen et al. (2008) \\
\hline Japão & 57,9 & 27,9 & 12,8 & 1,3 & Sugimoto et al. (2008) \\
\hline Sul da África & - & 21,7 & 0 & - & Sistonen et al. (2009) \\
\hline África Oriental & - & 14,9 & 0,7 & - & Sistonen et al. (2009) \\
\hline Sul da Europa & - & 13,3 & 0 & - & Sistonen et al. (2009) \\
\hline Europa Oriental & - & 14,0 & 0,2 & - & Sistonen et al. (2009) \\
\hline América central & - & 9,7 & 0,1 & - & Sistonen et al. (2009) \\
\hline
\end{tabular}

\section{c) gene CYP2C9}

O gene CYP2C9 (Citocromo P450, família 2, subfamília C, polipeptídeo 9), é expresso principalmente no fígado, em níveis que são os mais elevados entre as enzimas CYP2C e representa cerca de $20 \%$ de todas as CYPs hepáticas (IngelmanSundberg et al., 2007).

A enzima CYP2C9 é uma proteína de 490 aminoácidos, codificada pelo gene CYP2C9 que possui 8 éxons e está localizado no cromossomo 10 (10q24. 1-q24.3). Este gene possui 50.346 pares de bases. Até o momento, cerca de 29 variações alélicas foram identificadas para CYP2C9 (Zhou et al., 2008). Os substratos da CYP2C9 são ácidos fracos com um hidrogênio aceptor (Zanger et al., 2008).

Esta enzima está envolvida no metabolismo de aproximadamente $10 \%$ dos medicamentos incluindo alguns com pequeno índice terapêutico. Seus substratos incluem os hipoglicemiantes orais, antiinflamatórios não esteroidais, diuréticos, anticonvulsivantes, inibidores de angiotensina II, antidepressivos, anticoagulantes orais (como a warfarina) entre outros. Além disso, esta enzima está envolvida no metabolismo de substratos endógenos como o ácido araquidônico e o linolênico (Ingelman-Sundberg et al., 2007; Zhou et al., 2008). 
A respeito das variações genéticas, é bem conhecido o fato dos polimorfismos de CYP2C9 apresentarem conseqüências funcionais na farmacocinética in vitro e in vivo, na resposta terapêutica e $A D R s$. Dentre as variantes descritas para este gene, parece que apenas os alelos *2 e *3 determinam seu comportamento polimórfico (Ingelman-Sundberg et al., 2007). As variações alélicas * 4 e *5 são pouco freqüentes e a relevância clínica das mesmas ainda é pouco conhecida (Kim et al., 2009).

A primeira variação alélica identificada foi o CYP2C9*2, que apresenta um SNP na posição 430T>C que causa uma troca de aminoácido (Arg144Cys) provocando uma diminuição de aproximadamente 20 a 30\% da atividade enzimática. O alelo CYP2C9*3 apresenta um SNP no éxon 7, o que também leva a uma troca de aminoácido (Ile359Leu), podendo causar uma redução de $70 \%$ da atividade enzimática (Zhou et al., 2008).

As freqüências dos alelos CYP2C9*2 e CYP2C9*3 variam entre diferentes populações (Tabela 4). Kirchheiner e Brockmoller (2005) relatam que os alelos *2 e *3 estão presentes principalmente em caucasianos (11\% e 7\% respectivamente) enquanto que em africanos, a freqüência é menor ( $4 \%$ e $2 \%$ respectivamente). Em asiáticos, a freqüência do alelo *3 é de $3 \%$ e o alelo *2 não foi encontrado.

Tabela 4- Freqüências (\%) alélicas para CYP2C9 em diferentes populações.

\begin{tabular}{c|c|c|c}
\hline & \multicolumn{2}{|c|}{ Alelos } & \\
\hline Populações & $\boldsymbol{*}$ & $\boldsymbol{*} \mathbf{3}$ & Referência \\
\hline África Oriental & 4,3 & 1,2 & Sistonen et al. (2009) \\
\hline Norte da África & 13,4 & 10,2 & Sistonen et al. (2009) \\
\hline Europa & 13,1 & 6,7 & Sistonen et al. (2009) \\
\hline Oeste da Ásia & 8,6 & 9,0 & Sistonen et al. (2009) \\
\hline Sul da Ásia & 0,6 & 3,0 & Sistonen et al. (2009) \\
\hline Norte da América & 1,5 & 3,0 & Sistonen et al. (2009) \\
\hline América Central & 7,0 & 4,0 & Sistonen et al. (2009) \\
\hline América do Sul & 5,7 & 4,4 & Sistonen et al. (2009) \\
\hline Brasil & 8,6 & 6,5 & Vianna et al. (2004) \\
\hline
\end{tabular}

Os alelos *2 e *3 afetam a depuração de diferentes medicamentos tais como: $S$-acenocoumarol, S-warfarina, glimepirida, tolbutamina, losartam, celecoxibe, 
diclofenaco, ibuprofeno, tenoxicam, fluvastatina, fenitoina (Kirchheiner e Brockmoller, 2005).

O alelo ${ }^{*} 3$ parece ter um maior efeito na farmacocinética do que o alelo *2. Para a maioria dos substratos, indivíduos heterozigotos com um alelo *3 têm aproximadamente $50 \%$ da depuração do alelo normal e homozigotos *3 tem uma redução de 5 a 10 vezes da depuração. Para o alelo *2, foi detectado um efeito significativo na depuração dos medicamentos $S$-warfarina, acenocoumarol, tolbitamida e celecoxibe. Isto sugere que existe uma diferença na especificidade de substrato para as enzimas codificadas pelos alelos *1, *2 e *3. Desse modo, os polimorfismos de CYP2C9 são clinicamente significantes e também substratodependentes (Ingelman-Sundberg et al., 2007).

De acordo com Zanger et al. (2008), estudos têm demonstrado a significância clínica dos alelos *2 e *3 para a maioria dos substratos já mencionados. Os autores exemplificam que indivíduos que possuem alelos *2 e *3 tiveram maiores incidências de ADRs como hipoglicemia devido ao uso de hipoglicemiantes, sangramentos gastrointestinais decorrentes da utilização de antiinflamatórios não esteroidais e severa hemorragia relacionada ao tratamento com warfarina, onde a resposta anticoagulante também depende de variantes no gene da vitamina K epóxi redutase.

$\mathrm{O}$ antagonista de vitamina $\mathrm{K}$, warfarina, é o anticoagulante oral mais prescrito para o tratamento de tromboembolismo venoso e das tromboses arteriais. Este anticoagulante é caracterizado por um pequeno índice terapêutico que varia muito entre os pacientes. A warfarina inibe a enzima vitamina $\mathrm{K}$ epóxi-redutase codificada pelo gene VKORC1 (Singh et al., 2007). No metabolismo da warfarina os alelos *2 e *3 codificam enzimas que apresentam aproximadamente $12 \%$ e $5 \%$, respectivamente, da capacidade enzimática normal. Desse modo, ambos os alelos têm um efeito substancial na depuração deste medicamento. Indivíduos homozigotos para o alelo *3 mostraram uma redução de $90 \%$ na eliminação da $S$ warfarina em comparação com homozigotos para o alelo selvagem (Zhou et al., 2008). Deste modo, a presença dos alelos de atividade diminuída CYP2C9*2 e *3 está associada a um aumento da concentração plasmática da warfarina, aumentando o risco de sangramentos. Polimorfismos no gene VKORC1 também estão associados com a dose requerida de warfarina. Indivíduos com risco elevado 
de hemorragia e trombose poderiam ser previamente identificados com um teste genético para os genes CYP2C9 e VKORC1 antes do início da terapia (Singh et al., 2007). Desse modo, polimorfismos genéticos do CYP2C9 são uns dos fatores que mais podem afetar a segurança e a eficácia do tratamento (Tomalik-Scharte et al., 2008).

Segundo Kirchheiner e Brockmoller (2005), o valor da genotipagem antes do início do tratamento para CYP2C9 ainda necessita ser confirmada por estudos clínicos nos quais, um grupo de pacientes é tratado levando-se em conta a informação genotípica e outro grupo recebe o tratamento convencional. Além disso, a freqüência do genótipo $C Y P 2 C{ }^{*} 3^{*} 3$, que é realmente um importante indicativo de atividade enzimática reduzida, possui uma prevalência de apenas $0,5 \%$ ou até mesmo menor, na maioria das populações. Desse modo, na opinião dos autores, a genotipagem de um grande número de pacientes para identificar apenas uma pequena porção de indivíduos com um real risco de apresentar ADRs não seria econômica a menos que o ADR seja severo e não detectado por meio de nenhum outro monitoramento clinico usual. Para Kirchheiner e Brockmoller (2005) a relação custo-benefício da genotipagem prévia para CYP2C9 ainda não é evidente. 
A existência de vários estudos comprova a importância dos polimorfismos genéticos de CYP2D6, CYP2C19 e CYP2C9 no metabolismo de diversos medicamentos. Tratamentos com doses-padrão provocam diferentes efeitos adversos e com freqüência causam uma remissão parcial de sintomas ou até mesmo nenhum efeito.

Sabendo que a resposta ao tratamento com antidepressivos também varia entre pacientes e que tais respostas podem diferir em função de polimorfismos nas enzimas CYP2D6, CYP2C19 e CYP2C9 aliados à inexistência de um teste acessível no Brasil, justifica-se esse estudo. 
Desenvolvimento de metodologia para a determinação dos genótipos principais dos genes CYP2D6, CYP2C19 e CYP2C9.

\section{Objetivos específicos}

1. Estabelecer uma metodologia para a análise de polimorfismos de nucleotídeo único, inserções, deleções e variações no número de cópias em CYP2D6, CYP2C19 e CYP2C9.

2. Determinar os alelos mais freqüentes e com repercussão funcional mais importante dos genes CYP2D6, CYP2C19 e CYP2C9 em nossa amostra.

3. Disponibilizar a metodologia desenvolvida no item 2 para a prática clínica na Psiquiatria. 


\subsection{Casuística}

Coletamos um total de 198 amostras de DNA sendo 147 mulheres e 51 homens, com idade média de 43,0 anos (DP 1,6; mínimo 19; máximo 74) para mulheres e 42,7 anos (DP 11,6; mínimo 21; máximo 63) para homens. Desses, 117 indivíduos [85 mulheres, idade média 42,1 anos (DP 12,0; mínimo 19; máximo 72) e 32 homens, idade média 40,5 anos (DP 11,9; mínimo 21; máximo 60)] são provenientes de pacientes do Grupo de Estudos de Doenças Afetivas (GRUDA) do Departamento e Instituto de Psiquiatria do Hospital das Clínicas da Faculdade de Medicina da Universidade de São Paulo, coordenado pelo Dr. Ricardo A. Moreno. Estes pacientes inicialmente foram diagnosticados com Depressão Maior. Os demais 81 [62 mulheres, idade média 45,2 anos (DP 11,2; mínimo 27; máximo 74) e 19 homens, idade média 45,2 anos (DP 11; mínimo 26, máximo 63)] são indivíduos sem histórico pessoal/familial de doença psiquiátrica obtidos do banco de DNA do Laboratório de Neurociências - LIM 27 (IPq-HCFMUSP) (Tabela 5). Todos os participantes foram informados sobre o protocolo do estudo e somente participaram aqueles que concordaram e assinaram o Termo de Consentimento Livre e Esclarecido.

Tabela 5 - Médias de idade (anos) da amostra de 198 pacientes e controles.

\begin{tabular}{l|c|c|c|c|c}
\hline & $\mathbf{n}$ & Média & DP & Mínimo & Máximo \\
\hline Controles & 62 & 45.18 & 11.23 & 27 & 74 \\
\hline Feminino & 19 & 45.21 & 11.01 & 26 & 63 \\
\hline Masculino & 19 & \multicolumn{5}{|l}{} \\
\hline Pacientes & 85 & 42.19 & 11.98 & 19 & 72 \\
\hline Feminino & 32 & 40.52 & 11.93 & 21 & 60 \\
\hline Masculino & $\mathbf{1 9 8}$ & $\mathbf{4 3 . 1 9}$ & $\mathbf{1 1 . 6 9}$ & $\mathbf{1 9}$ & $\mathbf{7 4}$ \\
\hline Total & $\mathbf{1 9}$
\end{tabular}

NOTA: DP - desvio padrão. 


\subsection{Extração de DNA}

O DNA genômico foi extraído a partir dos leucócitos do sangue periférico, utilizando-se protocolo baseado em salting-out (Laitinen, 1994). O DNA foi ressuspendido em tampão TE [Tris- $\mathrm{HCl}$ a $10 \mathrm{mM}$ e EDTA a $1 \mathrm{mM}(\mathrm{pH}$ 8,0)] em quantidade que variou de acordo com o pellet obtido (300 a $1000 \mu \mathrm{L}$ ) e o mesmo foi armazenado $\mathrm{a}-20^{\circ} \mathrm{C}$. A determinação da concentração de DNA extraído foi feita por espectrofotometria a $260 \mathrm{~nm}$, utilizando o NanoDrop ${ }^{\circledR}$ ND-1000 UV-Vis

Spectrophotometer (NanoDrop Technologies, Wilmington, Delaware, EUA), com coeficiente de extinção $50 \mathrm{ng}-\mathrm{cm} / \mu \mathrm{L}$ e comprimento da trajetória da luz $\mathrm{OD}_{260} 0,1$ cm, seguindo a equação de Beer-Lambert:

Concentração de DNA $[\mathrm{ng} / \mu \mathrm{L}]=\left(\mathrm{OD}_{260} \times 50 \mathrm{ng}-\mathrm{cm} / \mu \mathrm{L}\right) / 0,1 \mathrm{~cm}$.

A pureza do DNA foi determinada pela relação $A_{260 \mathrm{~nm}} / \mathrm{A}_{280 \mathrm{~nm}}$ e a integridade das amostras foi avaliada por eletroforese em gel de agarose $1 \%$ utilizando tampão TBE 1X [Tris-HCl a $45 \mathrm{mM}$, ácido bórico a $45 \mathrm{mM}$ e EDTA a $1 \mathrm{mM}(\mathrm{pH} 8,0)$ ] (Sambrook, 2001) e corado com brometo de etídio $(0,4 \mathrm{mg} / \mathrm{mL})$. A separação eletroforética foi realizada a $120 \mathrm{~V}$ e $60 \mathrm{~mA}$ por 30 minutos, em cuba de eletroforese horizontal e o DNA foi visualizado sob luz UV e fotodocumentado em sistema de captura de imagem Multillmage Light Cabinet, Chemilmager v 5.5, (Alpha Innotech Corporation, San Leandro, CA, EUA).

\subsection{Análise dos alelos}

\section{Alelos avaliados para os genes CYP2D6, CYP2C19 e CYP2C9}


A escolha dos alelos avaliados foi baseada na seleção dos alelos com repercussões funcionais importantes e também naqueles mais freqüentes em diferentes populações, segundo revisão de literatura.

Para a identificação das variações alélicas CYP2D6*1, CYP2D6*2, CYP2D6*3, CYP2D6*4, CYP2D6*5, CYP2D6*6, CYP2D6*9, CYP2D6*10, CYP2D6*15, CYP2D6*17, CYP2D6*29, CYP2D6*35, CYP2D6*39, CYP2D6*40, CYP2D6* $^{*} 41$ e duplicações do gene CYP2D6 [AY545216 <http://www.cypalleles.ki.se/cyp2d6.htm>] (Figura 13); CYP2C19*1, CYP2C19*2, CYP2C19*3 e CYP2C19*17 do gene CYP2C19 [NT_030059
[N_0 <http://www.cypalleles.ki.se/cyp2c19.htm>] (Figura 14) e CYP2C9*1, CYP2C9*2, CYP2C9*3 do gene CYP2C9 [NM_000771 <http://www.cypalleles.ki.se/cyp2c9.htm>] os polimorfismos (Quadros 6, 7 e 8), foram identificados inicialmente pelo método de seqüenciamento direto e posteriormente por discriminação alélica no aparelho de $P C R$ em tempo real com o sistema TaqMan ${ }^{\circledR}$. Para a identificação da duplicação e deleção do gene CYP2D6, foi realizada inicialmente a Long-template PCR. A determinação do número de cópias do gene CYP2D6 foi realizada utilizando-se $P C R$ em tempo real.

Sugeriu-se, com base na reduzida diversidade haplotípica e altos níveis de desequilíbrio de ligação ( $L D$ - Linkage disequilibrium) que CYP2D6 poderia ser tratado como um único bloco não recombinante no genoma. De fato, cada combinação de polimorfismos localizada na seqüência do gene CYP2D6 em um único cromossomo constitui um haplótipo distinto que é tratado como um alelo do sistema de haplótipos (Saggagh et al., 2006), de acordo com o CYP Allele nomenclature Comitee <www.imm.ki.se/CYPalleles/cyped6.htm>. Além disso, o grande $L D$ no gene CYP2D6 pode ocasionar muitos polimorfismos redundantes fazendo com que não haja a necessidade da identificação de todas as variações. Somente um pequeno número de polimorfismos seria suficiente para determinar toda a informação neste lócus. 


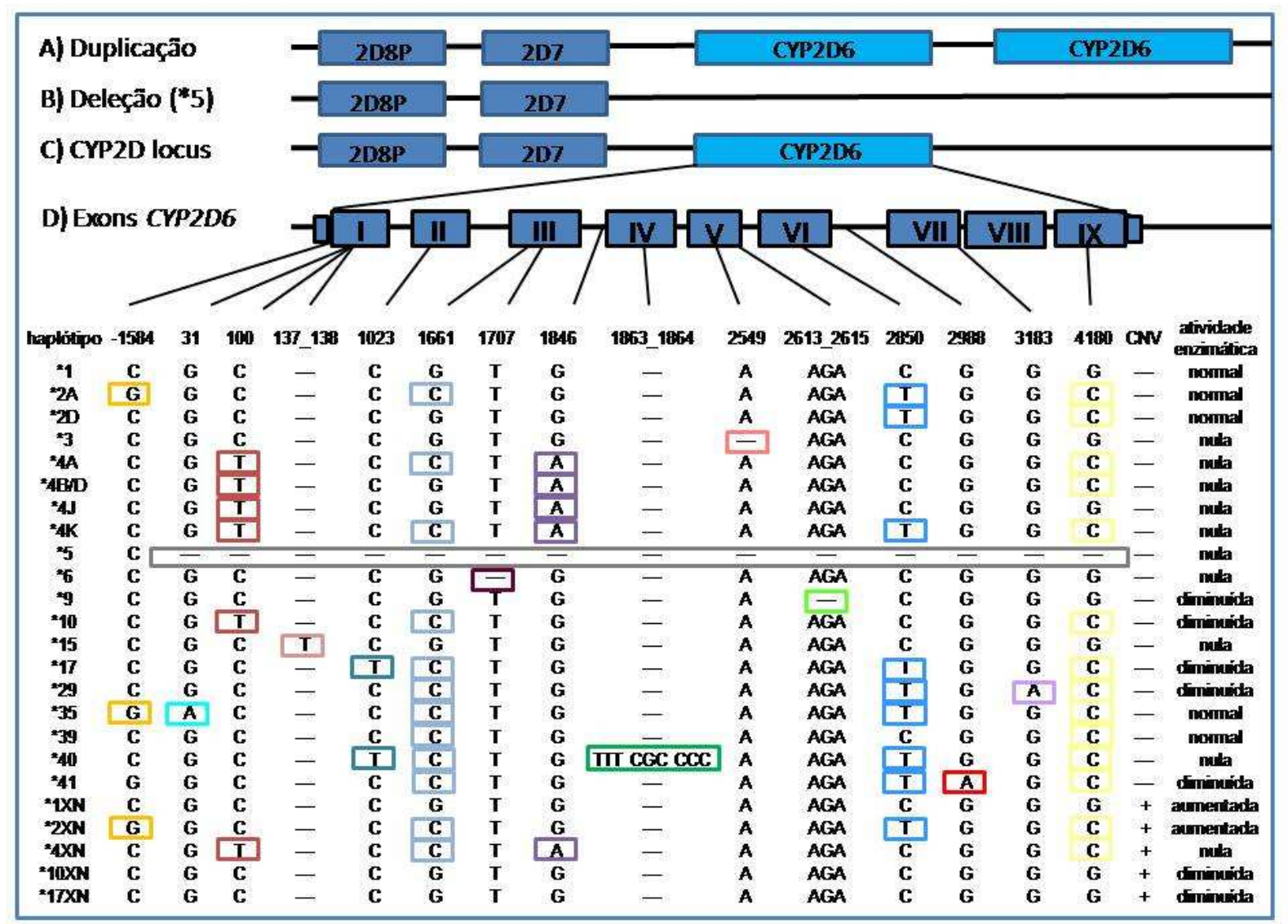

Figura 13 - Distribuição dos polimorfismos investigados no gene CYP2D6. Alelos nomeados segundo regras do Human Cytocrome P450 (CYP) Allele Nomenclature Commitee. A Figura indica a variação no número de cópias do gene CYP2D6, com duplicação $(A)$, deleção (B) ou cópia única no genoma haplóide (C). O item D indica as bases polimórficas distribuídas ao longo dos 9 éxons. (adaptado de Sistonen et al., 2007).

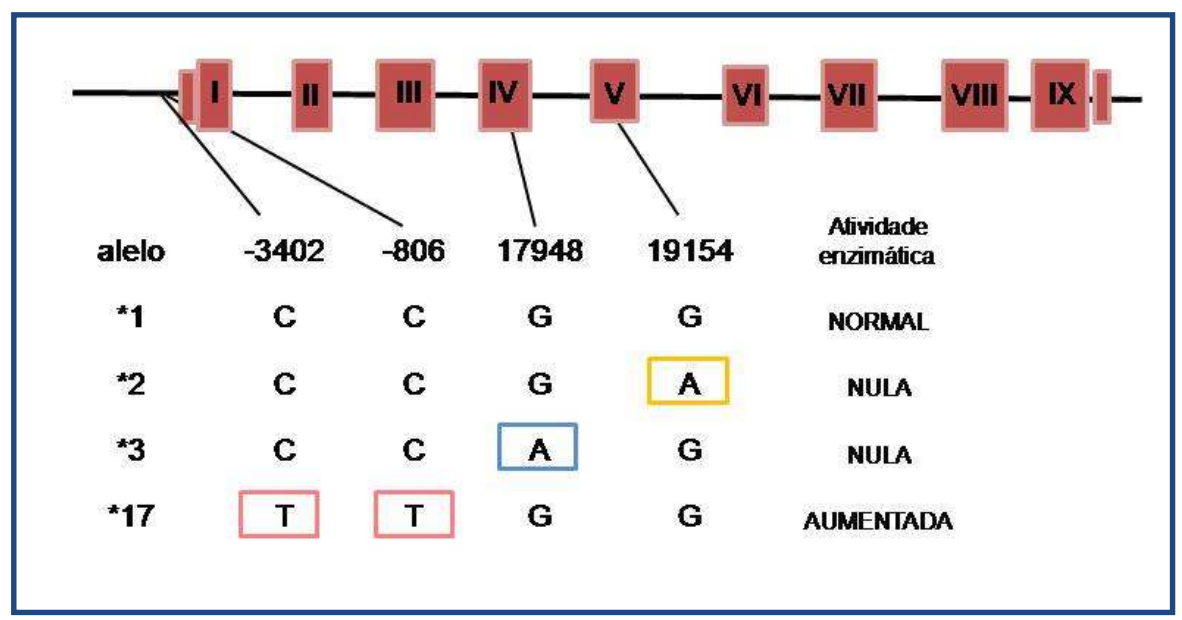

Figura 14 - Distribuição dos polimorfismos investigados no gene CYP2C19. Alelos nomeados segundo regras do Human Cytocrome P450 (CYP) Allele Nomenclature Commitee. A Figura indica a distribuição dos principais polimorfismos ao longo dos 9 éxons. 
Quadro 6 - Polimorfismos selecionados no gene CYP2D6, os alelos a que fazem parte e suas seqüências-alvo. (Ref SNP - SNP referência).

\begin{tabular}{|c|c|c|c|}
\hline CYP2D6 & & & \\
\hline Polimorfismo & Alelos & Ref SNP ID & Seqüência \\
\hline$-1584 C>G$ & $* 2, * 35, * 41$ & rs1080985 & CCAGCCTGGACAACTTGGAAGAACC [C/G] GGTCTCTACAAAAAATACAAAATTA \\
\hline $31 \mathrm{G}>\mathrm{A}$ & *35 & rs769258 & GCTAGAAGCACTGGTGCCCCTGGCC [G/A] TGATAGTGGCCATCTTCCTGCTCCT \\
\hline $100 \mathrm{C}>\mathrm{T}$ & $* 4, * 10$ & rs1065852 & GCGCCAACGCTGGGCTGCACGCTAC [C/T ] CACCAGGCCCCCTGCCACTGCCCGG \\
\hline 137_138insT & *15 & 107707653 & TGTGTTCTGGAAGTCCACATGCAGC [-/A] AGGTTGCCCAGCCCGGGCAGTGGCA \\
\hline $1023 \mathrm{C}>\mathrm{T}$ & $* 17, * 40$ & rs28371706 & GCCGACCGCCCGCCTGTGCCCATCA [C/T] CCAGATCCTGGGTTTCGGGCCGCGT \\
\hline $1661 \mathrm{G}>\mathrm{C}$ & $\begin{array}{l}* 2, * 4, * 10, \\
* 17, \\
* 35, * 40, * 41\end{array}$ & & GGCGCGAGCAGAGGCGCTTCTCCGT [G/C] TCCACCTTGCGCAACTTGGGCCTGG \\
\hline 1707 del T & *6 & rs5030655 & AGGCAGGCGGCCTCCTCGGTCACCC [A/-] CTGCTCCAGCGACTTCTTGCCCAGG \\
\hline $1846 \mathrm{G}>\mathrm{A}$ & *4 & rs3892097 & CCCTTACCCGCATCTCCCACCCCCA [G/A] GACGCCCCTTTCGCCCCAACGGTCT \\
\hline $\begin{array}{l}\text { 1863_1864 } \\
\text { ins(TTTCGCCCC)2 }\end{array}$ & $* 40$ & & TGTCCAAGAGACCGTT [ GGGGCGAAAGGGGCGAAA/-] GGGGCGAAAGGGGCGTC \\
\hline 2549 delA & *3 & rs35742686 & GCTGGATGAGCTGCTAACTGAGCAC [A/- ] GGATGACCTGGGACCCAGCCCAGCC \\
\hline 2613_2615delAGA & *g & & CCACCGTGGCAGCCACTCTCACCT [ TCT/-] CCATCTCTGCCAGGAAGGCCTCAG \\
\hline $2850 \mathrm{C}>\mathrm{T}$ & $\begin{array}{l}* 2, * 4, * 17, * 34, \\
* 35, * 40, * 41\end{array}$ & rs 16947 & GAGAACAGGTCAGCCACCACTATGC [C/T] CAGGTTCTCATCATTGAAGCTGCTC \\
\hline $2988 \mathrm{G}>\mathrm{A}$ & *41 & rs28371725 & GGAAACAGTGCAGGGGCCGAGGGAG [G/A] AAGGGTACAGGCGGGGGCCCATGAA \\
\hline $3183 \mathrm{G}>\mathrm{A}$ & *29 & rs59421388 & TCTGGTCGCCGCACCTGCCCTATCA [C/T] GTCGTCGATCTCCTGTTGGACACGG \\
\hline $4180 \mathrm{G}>\mathrm{C}$ & $\begin{array}{l}* 2, * 4, * 6, \\
* 10, * 17, * 35, \\
* 40, * 41\end{array}$ & rs 1135840 & CATGGTGTCTTTGCTTTCCTGGTGA [G/C] CCCATCCCCCTATGAGCTTTGTGCT \\
\hline
\end{tabular}

Quadro 7 - Polimorfismos avaliados no gene CYP2C19 e suas seqüências-alvo. (Ref SNP - SNP referência).

\begin{tabular}{|c|l|l|l|}
\hline CYP2C19 & & & \\
\hline Polimorfismo & Alelos & Ref SNP ID & Seqüência \\
\hline-806 C $>$ T & $* 17$ & rs12248560 & AAATTTGTGTCTTCTGTTCTCAAAG [C/T ] ATCTCTGATGTAAGAGATAATGCGC \\
\hline-3405 C >T & $* 17$ & rs11188072 & AATGGGCAACGGGTCTGAACAGACA [C/T ] CTCACCAAGAAGACATACAGATACC \\
\hline 17948 G>A & $* 3$ & rs4986893 & ACATCAGGATTGTAAGCACCCCCTG [ G/A] ATCCAGGTAAGGCCAAGTTTTTTGC \\
\hline 19154 G>A & $* 2$ & rs4244285 & TTCCCACTATCATTGATTATTTCCC [ G/A ] GGAACCCATAACAAATTACTTAAAA \\
\hline
\end{tabular}

Quadro 8 - Polimorfismos avaliados no gene CYP2C9 e suas seqüências-alvo. (Ref SNP - SNP referência).

\begin{tabular}{|l|l|l|c|}
\hline CYP2C9 & & & \\
\hline Polimorfismo & Alelos & Ref SNP ID & Seqüência \\
\hline $3608 C>T$ & $* 2$ & rs1799853 & GATGGGGAAGAGGAGCATTGAGGAC[C/T]GTGTTCAAGAGGAAGCCCGCTGCCT \\
\hline $42614 A>C$ & $* 3$ & rs1057910 & TGTGGTGCACGAGGTCCAGAGATAC[A/C]TTGACCTTCTCCCCACCAGCCTGCC \\
\hline
\end{tabular}


Cada alelo das enzimas CYP2D6, CYP2C19 e CYP2C9 tem sua atividade enzimática determinada ou predita por experimentos in vivo e/ou in vitro e as mesmas estão disponíveis na página Human Cytochrome P450 (CYP) Allele Nomenclature Committee <http://www.cypalleles.ki.se> (Quadros 9, 10 e 11).

Quadro 9 - Variações alélicas estudadas do gene CYP2D6 de acordo com a página CYP2D6 Allele Nomenclature Committee <http://www.cypalleles.ki.se/cyp2d6.htm>. Os polimorfismos em negrito são os principais SNPS ou alterações responsáveis pelo fenótipo correspondente a cada alelo.

\begin{tabular}{|c|c|c|}
\hline CYP2D6 & & Atividade \\
\hline Alelos & Polimorfismos & enzimática \\
\hline $2 \mathrm{D} 6 * 1$ & ausente (alelo referência - wild-type) & Normal \\
\hline $2 \mathrm{D} 6 * 2$ & $-1584 \mathrm{G}>\mathrm{C} ; 1661 \mathrm{G}>\mathrm{C} ; 2850 \mathrm{C}>\mathrm{T} ; 4180 \mathrm{G}>\mathrm{C}$ & Normal \\
\hline $2 \mathrm{D} 6 * 3$ & 2549 delA & Nula \\
\hline $2 \mathrm{D} 6 * 4$ & $100 \mathrm{C}>\mathrm{T} ; 1661 \mathrm{G}>\mathrm{C} ; 1846 \mathrm{G}>\mathrm{A} ; 4180 \mathrm{G}>\mathrm{C}$ & Nula \\
\hline $2 \mathrm{D} 6 * 5$ & deleção do gene CYP2D6 & Nula \\
\hline $2 \mathrm{D} 6 * 6$ & 1707 delT; $19776 \mathrm{G}>\mathrm{A} ; 4180 \mathrm{G}>\mathrm{C}$ & Nula \\
\hline $2 D 6 * 9$ & 2615_2617 delAGA & Diminuída \\
\hline $2 \mathrm{D} 6 * 10$ & $100 \mathrm{C}>\mathrm{T} ; 1661 \mathrm{G}>\mathrm{C} ; 4180 \mathrm{G}>\mathrm{C}$ & Diminuída \\
\hline $2 \mathrm{D} 6 * 15$ & 137_138 insT & Nula \\
\hline $2 \mathrm{D} 6 * 17$ & $1023 \mathrm{C}>\mathrm{T} ; 1661 \mathrm{G}>\mathrm{C} ; 2850 \mathrm{C}>\mathrm{T} ; 4180 \mathrm{G}>\mathrm{C}$ & Diminuída \\
\hline $2 D 6 * 29$ & $1661 \mathrm{G}>\mathrm{C} ; 2850 \mathrm{C}>\mathrm{T} ; 3183 \mathrm{G}>\mathrm{A} ; 4180 \mathrm{G}>\mathrm{C}$ & Diminuída \\
\hline $2 D 6 * 35$ & $-1584 \mathrm{C}>\mathrm{G} ; 31 \mathrm{G}>\mathrm{A} ; 1661 \mathrm{G}>\mathrm{C} ; 2850 \mathrm{C}>\mathrm{T} ; 4180 \mathrm{G}>\mathrm{C}$ & Normal \\
\hline $2 \mathrm{D} 6 * 40$ & 1023C>T; 1661G>C; 1863_1864ins(TTT CGC CCC)2; 2850C>T; 4180G>C & Nula \\
\hline $2 \mathrm{D} 6 * 41$ & 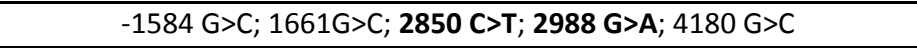 & Diminuída \\
\hline $2 \mathrm{D6*} \times \mathrm{XN}$ & amplificação do gene & Alelo-dependente \\
\hline
\end{tabular}

Quadro 10 - Variações alélicas estudadas do gene CYP2C19 de acordo com a página CYP2C19 Allele Nomenclature Committee <http://www.cypalleles.ki.se/cyp2c19.htm>. Os polimorfismos em negrito são os principais SNPS ou alterações responsáveis pelo fenótipo correspondente a cada alelo.

\begin{tabular}{|c|c|c|}
\hline CYP2C19 & Atividade \\
Alelos & Polimorfismos & Normal \\
\hline 2 C19*1 & ausente (alelo referência - wild-type) & Aumentada \\
\hline 2 C19*17 & -3405 C $>$ T; -806 C $>$ T & Nula \\
\hline 2 C19*3 & $\mathbf{1 7 9 4 8}$ G>A & Nula \\
\hline 2 C19*2 & $\mathbf{1 9 1 5 4}$ G>A & \\
\hline
\end{tabular}


Quadro 11 - Variações alélicas estudadas do gene CYP2C9 de acordo com a página CYP2C9 Allele Nomenclature Committee <http://www.cypalleles.ki.se/cyp2c9.htm>. Os polimorfismos em negrito são os principais SNPS ou alterações responsáveis pelo fenótipo correspondente a cada alelo.

\begin{tabular}{|c|c|c|}
\hline CYP2C9 & Atividade \\
Alelos & Polimorfismos & Normal \\
\hline 2 C9*1 & ausente (alelo referência - wild-type) & Diminuída \\
\hline 2 C9*2 & 3608 C $>$ T & Diminuída \\
\hline 2 C9*3 & $\mathbf{4 2 6 1 4}$ A $>C$ & C \\
\hline
\end{tabular}

\subsection{PCR e reação de seqüenciamento}

\section{Escolha das regiões dos oligonucleotídeos}

Para PCRs e reações de seqüenciamento, foram escolhidas regiões delimitadas pelos oligonucleotídeos para amplificar as seqüências-alvo que identificam polimorfismos que compõem cada alelo determinado segundo o site Human Cytochrome P450 (CYP) Allele Nomenclature Committee <http://www.cypalleles.ki.se> (Quadros 12, 13 e 14). Oligonucleotídeos que não foram obtidos na literatura foram determinados com a ferramenta Primer3 <http://biotools.umassmed.edu/bioapps/primer3_www.cgi>.

Quadro 12 - Pares de oligonucleotídeos escolhidos para amplificar as seqüências-alvo do gene CYP2C19 Todos os pares foram selecionados com a ferramenta Primer 3.

\begin{tabular}{|c|c|c|c|}
\hline CYP2C19 & & & \\
\hline Nome & Seqüência (5'-3') & Fragmento & Polimorfismo \\
\hline 2C19_2_F & CAACCAGAGCTTGGCATATT & \multirow{2}{*}{$298 \mathrm{pb}$} & \multirow[t]{2}{*}{$19154 G>A$} \\
\hline 2C19_2_R & CAAATACGCAAGCAGTCACA & & \\
\hline 2C19_3_F & СCCTGTGATCCCACTTTCAT & \multirow{2}{*}{$248 p b$} & \multirow[t]{2}{*}{$17948 G>A$} \\
\hline 2C19_3_R & TGTACTTCAGGGCTTGGTCA & & \\
\hline 2C19_17_1 & TGACAAGACACAGACTGGGATAA & \multirow{2}{*}{$230 \mathrm{pb}$} & \multirow{2}{*}{$-3042 C>T$} \\
\hline 2C19_17_2 & GTCATCGGGGTTTTAGCTTG & & \\
\hline 2C19_17_3 & ATGTCTGGAGGAGACCAGGA & \multirow{2}{*}{$497 p b$} & \multirow{2}{*}{$-806 \mathrm{C}>\mathrm{T}$} \\
\hline 2C19_17_4 & ACGTGAAGGCAGGAATTGTT & & \\
\hline
\end{tabular}


Quadro 13 - Pares de oligonucleotídeos escolhidos para amplificar as seqüências-alvo do gene CYP2D6.

\begin{tabular}{|c|c|c|c|c|}
\hline CYP2D6 & & & & \\
\hline Nome & Seqüência $\left(5^{\prime}-3^{\prime}\right)$ & Fragmento & Polimorfismo & Referência \\
\hline 1new & TCCCAGCTGGAATCCGGTGTCG & \multirow{2}{*}{$750 \mathrm{pb}$} & \multirow{2}{*}{$\begin{array}{c}1661 \text { G >C; } 1707 \text { del T; } 1846 \text { G>A; } \\
\text { 1863_1864 ins(TTT CGC CCC)2 }\end{array}$} & Hersberger et al. (2000) \\
\hline 2new & GGAGCTCGCCCTGCAGAGACTCCT & & & Hersberger et al. (2000) \\
\hline 2D6*3_F & GCGGAGCGAGAGACCGAGGA & \multirow{2}{*}{$789 \mathrm{pb}$} & \multirow{2}{*}{2549 delA; 2613_2615 del AGA } & Hersberger et al. (2000) \\
\hline $2 \mathrm{D} 6 * 3 \mathrm{R}^{*}$ & GTCCCGAGTATGCTCTCG G & & & Renata Canalle \\
\hline 2D6*10_F & GTGCTGAGAGTGTCCTGC & \multirow{2}{*}{$343 \mathrm{pb}$} & \multirow{2}{*}{$31 \mathrm{G}>\mathrm{A} ; 100 \mathrm{C}>\mathrm{T} ;$; 137_138 insT } & Naveen et al. (2006) \\
\hline 2D6*10_R & CACCCACCATCCATGTTTGC & & & Naveen et al. (2006) \\
\hline $2 \mathrm{D} 6 * 41 \_\mathrm{F}$ & CCGTTCTGTCCCGAGTATGC & \multirow{2}{*}{$340 \mathrm{pb}$} & \multirow{2}{*}{$2850 \mathrm{C}>\mathrm{T} ; 2988 \mathrm{G}>\mathrm{A}$} & Hinrichs et al.(2007) \\
\hline 2D6*41_R & CGGCCCTGACACTCCTTCTT & & & Hinrichs et al. (2007) \\
\hline 2D6*17_F & GATCCTGGCTTGACAAGAGG & \multirow{2}{*}{$280 \mathrm{pb}$} & \multirow{2}{*}{$1023 \mathrm{C}>\mathrm{T}$} & \\
\hline 2D6*17B_R & AGCTCGGACTACGGTCATCA & & & \\
\hline 2D6_2_F & TCTTCTTCACCTCCCTGCTG & \multirow{2}{*}{$250 \mathrm{pb}$} & \multirow{2}{*}{$4180 \mathrm{G}>\mathrm{C}$} & \\
\hline 2D6_2_R & CTGAGGAGGATGATCCCAAC & & & \\
\hline 2D6_2P_F & CCTCCCACAAAAGACAGGAT & \multirow{2}{*}{$292 \mathrm{pb}$} & \multirow{2}{*}{$-1584 C>G$} & \\
\hline 2D6_2P_R & CATGTTGGCCAGGCTAGT & & & \\
\hline
\end{tabular}

* oligonucleotídeo gentilmente cedido pela Dra Renata Canalle.

Quadro 14 - Pares de oligonucleotídeos escolhidos para amplificar as seqüências-alvo do gene CYP2C9. Todos os pares foram desenhados com o auxílio da ferramenta Primer 3.

\begin{tabular}{|l|l|c|c|}
\hline \multicolumn{1}{|c|}{ CYP2C9 } & & \\
\cline { 1 - 2 } Nome & Seqüência (5'-3') & Fragmento & Polimorfismo \\
\hline 2C9_2_F & AATTGTTTTCAGCAATGGAAAGAA & \multirow{2}{*}{$195 \mathrm{pb}$} & $3608 \mathrm{C}>\mathrm{T}$ \\
\cline { 1 - 2 } 2C9_2_R & AGATAGTAGTCCAGTAAGGTCAGT & \multirow{2}{*}{$250 \mathrm{pb}$} & $42614 \mathrm{~A}>\mathrm{C}$ \\
\hline 2C9_3_F & GCTAAAGTCCAGGAAGAGATTGA & \\
\hline 2C9_3_R & GATACTATGAATTTGGGGACTTC & \\
\hline
\end{tabular}

Mais de um polimorfismo pode ser identificado nas seqüências delimitadas pelos oligonucleotídeos 1new e 2new [1661G>C, 1707 delT, 1864G>A, 1863_1864 ins(TTT CGC CCC)2], pelos oligonucleotídeos 2D6*41_F e 2D6*41R (2850C>T, 2988G>A), 2D6*10_F e 2D6*10_R (31 G>A, 100 C>T, 137_138 insT), 2D6*3_F e 2D6*3_R (2549 delA, 2613_2615 del AGA) (Quadro 13).

\section{Padronização das $P C R s$ e reações de seqüenciamento}

O método desenvolvido por Sanger e colaboradores (1977), envolve a utilização de 2', 3' - dideoxinucleosídeos trifosfatos (ddNTP), que não apresentam o 
grupo 3' hidroxila em suas estruturas. Cada ddNTP é marcado com uma molécula fluorescente diferente. Durante a elongação da fita de DNA, quanto um ddNTP é incorporado ele impede a continuidade de extensão da fita. Fragmentos de diferentes tamanhos são gerados dependendo da posição onde um ddNTP foi incorporado. Estes fragmentos são submetidos à eletroforese capilar no seqüenciador ABI3100 (Applied Biosystems, Foster City, CA, USA), que detecta a fluorescência emitida pelos ddNTPs e transforma os resultados da eletroforese em um eletroferograma.

Para a identificação do polimorfismo $-1584 \mathrm{G}>\mathrm{C}$, na região promotora do gene CYP2D6, a $P C R$ foi padronizada segundo as seguintes condições: $B$ uffer $\mathrm{MgCl}_{2}$ free 1x (Invitrogen, CA, USA); 0,125 mM de dNTPs; 2,25 mM de cloreto de magnésio (Invitrogen, CA, USA); 0,2 $\mu \mathrm{M}$ de cada oligonucleotídeo 2D6_2P_F e 2D6_2P_R (Dialab, Belo Horizonte, MG, Brasil); 0,45 M de betaína (Sigma, Saint Louis, Missouri, USA); 0,05 U/ $\mu \mathrm{L}$ de Platinum ${ }^{\circledR}$ Taq DNA Polymerase (Invitrogen, CA, USA); $0,5 \mathrm{ng} / \mu \mathrm{L}$ de DNA; e água Milli $Q$ q.s.p. $10,00 \mu \mathrm{L}$. A termociclagem utilizada foi a seguinte: 3 minutos a $94{ }^{\circ} \mathrm{C}$ seguido de 40 ciclos de 30 segundos a $94{ }^{\circ} \mathrm{C}, 20$ segundos a $60,0 \stackrel{\circ}{\circ}$, 30 segundos a $72{ }^{\circ} \mathrm{C}$ e, por fim, 5 minutos a $72 \stackrel{\circ}{\circ}$.

$\mathrm{O}$ produto amplificado foi aplicado em gel de agarose $1 \%$ corado com de brometo de etídio $[0,4 \mu \mathrm{L} / \mathrm{mL}]$ e visualizado sob luz UV.

Depois de realizada a $P C R$, seus produtos foram seqüenciados segundo a reação: 1,0 $\mu \mathrm{L}$ de Big Dye Terminator v.3 (Applied Biosystems, Foster City, CA, USA); 2,0 $\mu \mathrm{L}$ de Buffer (200 mM Tris $\mathrm{HCl} \mathrm{pH}$ 9.0; $5 \mathrm{mM} \mathrm{MgCl}$ ); 0,32 $\mu \mathrm{M}$ de oligonucleotídeo sense; $0,45 \mathrm{M}$ de betaína; $1,0 \mu \mathrm{L}$ do produto de $P C R$ previamente amplificado e água Milli Q q.s.p. 10,00 $\mu$ L. A termociclagem utilizada foi a seguinte: 3 minutos a $95 \stackrel{\circ}{\circ}$ seguido de 37 ciclos de 20 segundos a $95 \stackrel{\circ}{\circ}$, 20 segundos a $55^{\circ} \mathrm{C}$ e, por fim, 4 minutos a $60^{\circ} \mathrm{C}$.

A reação de seqüenciamento foi então precipitada com Isopropanol $70 \%$ (Merck KGaA, Darmstadt, Germany) e Etanol 75\% (Merck KGaA, Darmstadt, Germany). As amostras são analisadas no aparelho seqüenciador de DNA $A B I$ PRISM® 3100 Genetic Analyzer (Applied Biosystems, Foster City, CA). 
A identidade dos produtos da amplificação foi confirmada utilizando-se a ferramenta BLAST (Altschul et al., 1990) para busca por seqüências similares em bancos de dados.

Para os demais polimorfismos investigados nos genes CYP2D6, CYP2C19 e CYP2C9, as PCRs foram padronizadas nas mesmas condições: $B$ uffer $\mathrm{MgCl}_{2}$ free $1 \mathrm{x}$ (Invitrogen, CA, USA); 0,125 mM de dNTPs; 2,25 mM de cloreto de magnésio (Invitrogen, CA, USA); 0,2 $\mu \mathrm{M}$ de cada oligonucleotídeo sense e antisense (Dialab, Belo Horizonte, MG, Brasil); 5\% de Dimetilsulfóxido -DMSO- (Merck KGaA, Darmstadt, Germany); 0,05 U/ $\mu \mathrm{L}$ de Platinum ${ }^{\circledR}$ Taq DNA Polymerase (Invitrogen, $C A$, USA); $0,5 \mathrm{ng} / \mu \mathrm{L}$ de DNA; e água Milli Q q.s.p. 10,0 $\mu \mathrm{L}$. A termociclagem utilizada foi a seguinte: 3 minutos a $94 \stackrel{\circ}{\circ}$ seguido de 40 ciclos de 30 segundos a $94 \stackrel{\circ}{\circ}, 20$ segundos a $63,0 \stackrel{\circ}{ } \mathrm{C}, 30$ segundos a $72 \stackrel{\circ}{ } \mathrm{C}$ e, por fim, 5 minutos a $72 \stackrel{\circ}{\circ}$.

Os produtos amplificados foram então verificados em gel de Agarose 1\% corado com brometo de etídio $[0,4 \mu \mathrm{L} / \mathrm{mL}]$ e visualizado sob luz UV.

A seguir, foram realizadas as reações de seqüenciamento também padronizadas nas mesmas condições para todos os polimorfismos: 1,0 $\mu \mathrm{L}$ de Big Dye Terminator v.3 (Applied Biosystems, Foster City, CA, USA); 2,0 $\mu \mathrm{L}$ de Save Money Buffer (200 mM Tris $\mathrm{HCl} \mathrm{pH}$ 9.0; $5 \mathrm{mM} \mathrm{MgCl}_{2}$ ); 0,32 $\mu \mathrm{M}$ de oligonucleotídeo; $5 \%$ de Dimetilsulfóxido -DMSO- (Merck KGaA, Darmstadt, Germany); 1,0 $\mu \mathrm{L}$ do produto de $P C R$ e água Milli $Q$ q.s.p. 10,0 $\mu \mathrm{L}$. A termociclagem utilizada foi a seguinte: 3 minutos a $95{ }^{\circ} \mathrm{C}$ seguido de 37 ciclos de 20 segundos a $95 \stackrel{\circ}{\mathrm{C}}, 20$ segundos a $55^{\circ} \mathrm{C}$ e, por fim, 4 minutos a $60 \stackrel{\circ}{\circ}$.

As reações de seqüenciamento foram precipitadas conforme descrito anteriormente. Ao término da precipitação, as amostras foram analisadas no seqüenciador de DNA ABI PRISM ${ }^{\otimes} 3100$ Genetic Analyzer (Applied Biosystems, Foster City, CA).

A identidade dos produtos da amplificação foi também confirmada utilizandose a ferramenta (Altschul et al., 1990).

Os eletroferogramas gerados pelo seqüenciador foram então analisados nos programas Chromas $^{\circledR}$ (2001 Technelysium Pty Ltd) e FinchTV ${ }^{\circledR}(2004$ - 2006 Geospiza, Inc.). 


\subsection{Long template PCR}

\section{Long template PCR para deteccão da duplicacão do gene CYP2D6 e do alelo CYP2D6*5}

Steen et al. (1995) foi o primeiro a utilizar a long template PCR com sucesso para a identificação do alelo CYP2D6*5. Devido à grande homologia com os pseudogenes CYP2D8 e CYP2D7, torna-se difícil a escolha de oligonucleotídeos para a long template PCR. Baseado nesta informação, Steen et al. (1995) selecionou dois pares de oligonucleotídeos que se anelam a regiões não homólogas do DNA. O oligonucleotídeo sense, anela na inserção de 1,6 kb downstream do gene CYP2D7 e o oligonucleotídeo antisense, possui uma seqüência que anela em uma região aproximadamente $3,5 \mathrm{~kb}$ downstream do gene CYP2D6 (Figura 15). Com estes oligonucleotídeos foi possível amplificar um produto de $P C R$ de $3,5 \mathrm{~kb}$ na presença do alelo deletado de $13 \mathrm{~kb}$. Um produto de $15 \mathrm{~kb}$ indicaria a presença do alelo selvagem entretanto, devido a limitações da reação, a formação deste produto é ignorada. Johansson et al. (1996) descreveu um diferente método de long PCR no qual um fragmento de $6 \mathrm{~kb}$ é gerado na presença do alelo ${ }^{*} 5$. $O$ oligonucleotídeo sense utilizado neste ensaio é específico para o éxon 9 do CYP2D7, enquanto que o antisense está localizado na mesma região que flanqueia CYP2D6 como o oligonucleotídeo utilizado por Steen et al. (1995) (Figura 15). O método desenvolvido por Johansson et al. (1996) não amplifica nenhum fragmento que indica a presença do alelo selvagem. Na reação de multiplex long PCR descrita por Hersberger et al. (2000), dois produtos de amplificação são gerados simultaneamente: um indica a deleção do gene CYP2D6 (fragmento de 3,2 kb) e o outro, indica o alelo selvagem (fragmento de 5,1 kb) (Figura 15). Ambos os oligonucleotídeos sense e antisense utilizados para a identificação do alelo *5 estão localizados na mesma região nãohomóloga usada por Steen et al. (1995) (Meijerman et al., 2007). 


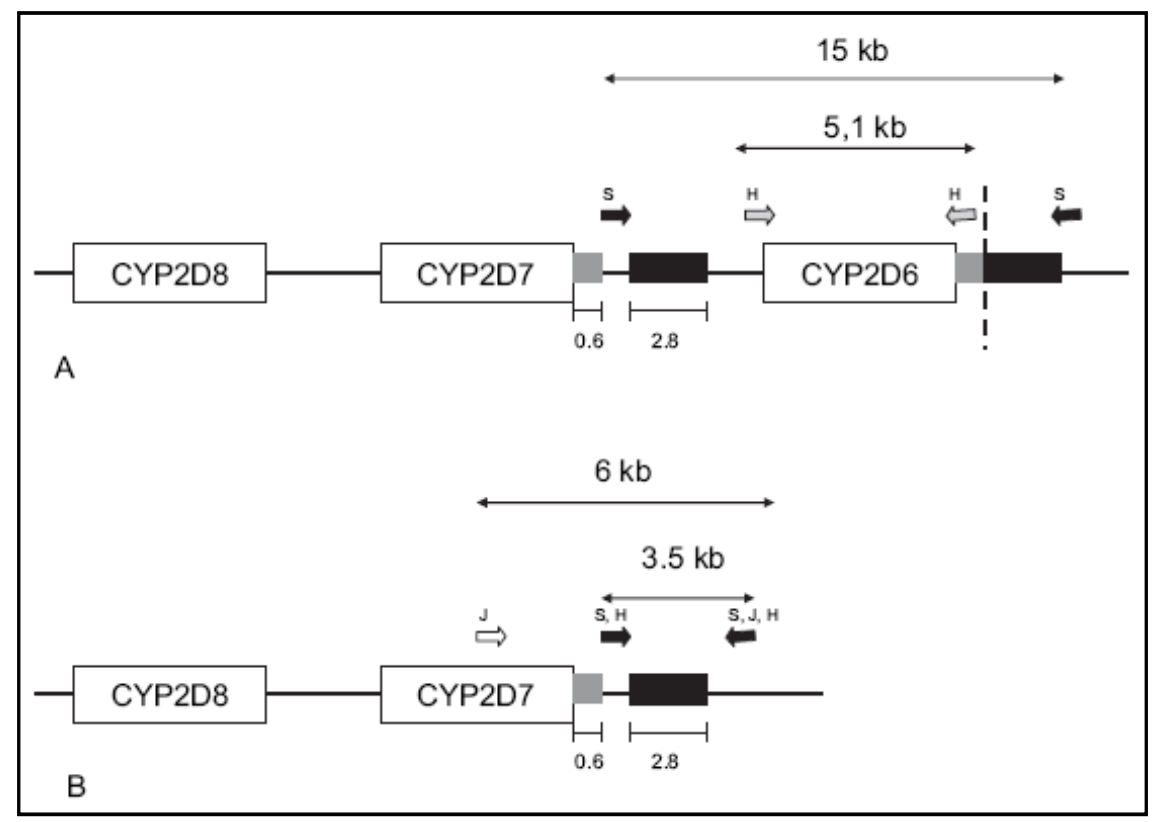

Figura 15 - Esquema da long PCR para a detecção do alelo CYP2D6*5. Dois pseudogenes, CYP2D7 e CYP2D8 upstream do gene CYP2D6. As seqüências do gene e dos pseudogenes possuem grande homologia e a escolha de oligonucleotídeos para a PCR torna-se difícil. As áreas pretas e cinzas são regiões quase idênticas de nucleotídeos na região intergênica. A linha tracejada mostra o ponto da deleção. A Figura (A) representa o tipo selvagem de gene (normal). A Figura (B) indica a deleção do gene CYP2D6. As setas escuras indicadas com a letra $S$ são os oligonucleotídeos escolhidos por Steen et al. (1995). As setas indicadas com a letra J, são os oligonucleotídeos desenhados por Johansson et al. (1996) e as setas indicadas com a letra $\mathrm{H}$ representam os oligonucleotídeos segundo Hersberger: 5,1 kb para o alelo selvagem e 3,5 kb o alelo deletado (Meijerman et al., 2007).

Para a identificação da amplificação do gene CYP2D6, Johansson et al. (1996) utilizou um par de oligonucleotídeos: o sense que se anela a uma região do éxon 9 e o antisense anela a uma região do intron 2 do gene CYP2D6 (Figura 16) juntos, estes oligonucleotídeos geram um produto de amplificação de $10 \mathrm{~kb}$ que indica a duplicação do gene. Lundqvist et al. (1999) desenvolveu um método que amplifica um fragmento específico de $3,5 \mathrm{~kb}$ que também indica a duplicação do gene. Este fragmento de 3,5 kb foi obtido por meio da combinação de um específico oligonucleotídeo sense para a região que flanqueia o gene CYP2D6 e um oligonucleotídeo antisense para uma região do pseudogene CYP2D7. 


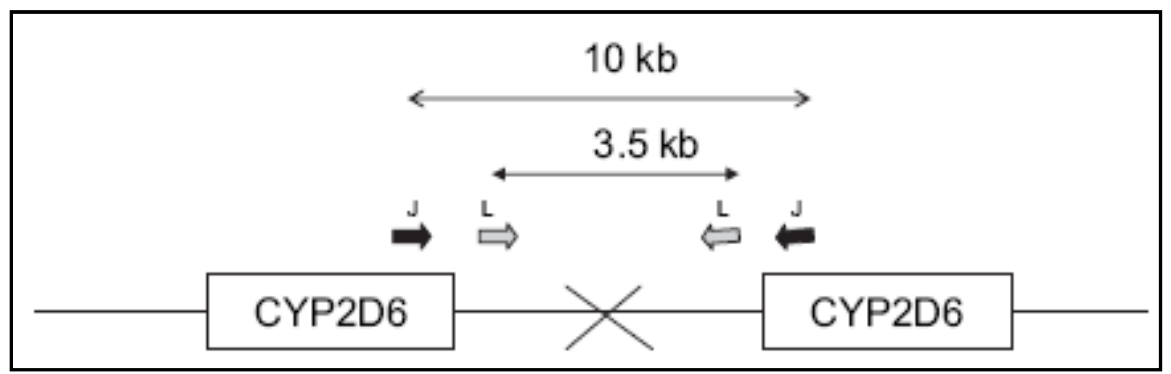

Figura 16 - Esquema da long template PCR para a detecção da amplificação do gene CYP2D6. As setas indicadas com a letra $\mathrm{J}$ representam os oligonucleotídeos utilizados por Johansson et al. (1996) e as setas indicadas com a letra L os oligonucleotídeos utilizados por Lundqvist et al. (1999) (fonte: Meijerman et al., 2007).

Lovlie et al. (1996) desenvolveu um método baseado na identificação de uma seqüência homóloga de 3,4 kb presente na região downstream do gene CYP2D6 e do pseudogene CYP2D7. Um par de oligonucleotídeos foi utilizado como um controle interno da $P C R$ gerando um fragmento de $5,2 \mathrm{~kb}$ da região entre os genes CYP2D7 e CYP2D6. Este mesmo par de oligonucleotídeo amplifica um fragmento de 3,6 kb na presença da duplicação do gene CYP2D6 (Figura 17) (Meijerman et al., 2007).

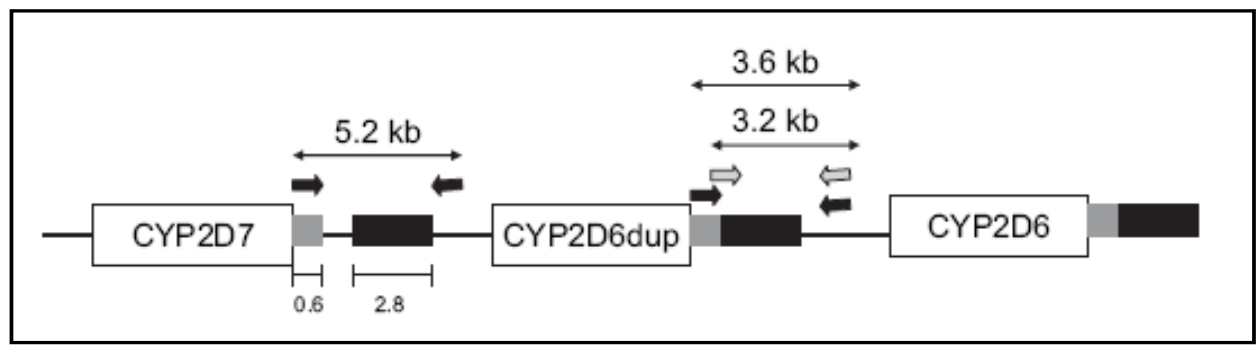

Figura 17 - Esquema de long template PCR para a detecção da amplificação do gene CYP2D6 segundo o método descrito por Lovlie et al. (1996). As áreas de cor cinza e preta são praticamente idênticas as seqüências de nucleotídeos localizados na região intergênica. As setas cinza indicam a posição dos oligonucleotídeos que detectam a amplificação $(3,6 \mathrm{~kb})$. As setas pretas representam os oligonucleotídeos que amplificam o controle interno da reação (5,2 kb) (fonte: Meijerman et al., 2007).

Em nosso estudo, o primeiro método escolhido para a identificação do alelo CYP2D6*5 e da duplicação do gene CYP2D6 foi a long template PCR. Para esta técnica, oligonucleotídeos foram selecionados a partir de uma revisão da literatura (Quadros 15 e 16) (Figuras 15, 16 e 17). Devido ao grande número de oligonucleotídeos, cada par (sense + antisense) foi designado como um conjunto representado por um número. 
Quadro 15 - Oligonucleotídeos para identificação do alelo CYP2D6*5.

\begin{tabular}{|c|c|c|c|c|c|}
\hline & & Oligonucleotídeo & \multicolumn{2}{|c|}{ Fragmento (Kb) } & \\
\hline Conjunto & Nome & Seqüência (5'- 3') & Deleção & Wild-type & Referência \\
\hline \multirow{2}{*}{1} & 2D6_del_Sf & ACCGGGCACCTGTACTCCTCA & \multirow{2}{*}{$3,5 \mathrm{~kb}$} & \multirow{2}{*}{$15,0 \mathrm{~kb}$} & Steen et al. (1995) \\
\hline & 2D6_del_Sr & GCATGAGCTAAGGCACCCAGA & & & Steen et al. (1995) \\
\hline \multirow{2}{*}{2} & 2D6_del_Jf & GCCACTCTCGTGTCGTCAGCTTT & \multirow{2}{*}{$6,0 \mathrm{~kb}$} & \multirow{2}{*}{ - } & Johansson et al. (1996) \\
\hline & 2D6_del_Jr & GGCATGAGCTAAGGCACC & & & Johansson et al. (1996) \\
\hline \multirow{2}{*}{3} & 2D6_del_H2r* & GCCGACTGAGCCTGGGAGGTAGGTA & \multirow{2}{*}{ - } & \multirow{2}{*}{$5,1 \mathrm{~kb}$} & Hersberger et al. (2000) \\
\hline & DPK up & GTTATCCCAGAAGGCTTTGCAGGCTTCA & & & Hersberger et al. (2000) \\
\hline \multirow{2}{*}{3} & D low & CAGGCATGAGCTAAGGCACCCAGAC & \multirow{2}{*}{$3,2 \mathrm{~kb}$} & & Hersberger et al. (2000) \\
\hline & D up & CACACCGGGCACCTGTACTCCTCA & & & Hersberger et al. (2000) \\
\hline
\end{tabular}

* DPKlow modificado

Quadro 16 - Oligonucleotídeos para identificação da amplificação do gene CYP2D6.

\begin{tabular}{|c|c|c|c|c|c|}
\hline \multirow[b]{2}{*}{ Conjunto } & \multirow[b]{2}{*}{ Nome } & \multirow{2}{*}{$\begin{array}{l}\text { Oligonucleotídeo } \\
\text { Seqüência (5'- 3') }\end{array}$} & \multicolumn{2}{|c|}{ Fragmento (Kb) } & \multirow[b]{2}{*}{ Referência } \\
\hline & & & Duplicação & Wild-type & \\
\hline \multirow{2}{*}{4} & 2D6_dup_Jf & GCCACCATGGTGTCTTTGCTTTC & \multirow{2}{*}{$10,0 \mathrm{~kb}$} & \multirow{2}{*}{-} & Johansson et al. (1996) \\
\hline & 2D6_dup_Jr & ACCGGATTCCAGCTGGGAAATG & & & Johansson et al. (1996) \\
\hline \multirow{2}{*}{5} & 2D6_dup_Lf & CCTGGGAAGGCCCCATGGAAG & \multirow{2}{*}{$3,5 \mathrm{~kb}$} & \multirow{2}{*}{ - } & Lundqvist et al. (1999) \\
\hline & 2D6_dup_Lr & CAGTTACGGCAGTGGTCAGCT & & & Lundqvist et al. (1999) \\
\hline \multirow{2}{*}{6} & 2D6_dup_CNf & TCCCCCACTGACCCAACTCT & \multirow{2}{*}{$3,6 \mathrm{~kb}$} & \multirow{2}{*}{$5,2 \mathrm{~kb}$} & Lovlie et al. (1996) \\
\hline & 2D6_dup_CNr & CACGTGCAGGGCACCTAGAT & & & Lovlie et al. (1996) \\
\hline
\end{tabular}

O kit GeneAmp ${ }^{\circledR} \mathrm{XL}$ (Applied Biosystems, Foster City, CA, USA) foi utilizado nas reações de identificação da duplicação do gene CYP2D6 e do alelo CYP2D6*5. As amostras empregadas nestas reações são amostras apresentando possível deleção e possível duplicação de acordo com a PCR em tempo real que determina o CNV do gene CYP2D6.

Seis long template PCRs foram realizadas, cada qual com um conjunto diferente de oligonucleotídeo. Nas reações dos conjuntos 1, 2 e 3, utilizou-se uma amostra de DNA com uma possível deleção do gene CYP2D6. Nos conjuntos 4, 5 e 6, o DNA empregado foi uma amostra com uma possível duplicação do gene CYP2D6. Para que a reação ocorresse, fez-se necessária preparação dos chamados "lower mix" e do "upper mix". Depois do lower mix ser submetido à etapa de hot start o upper mix é adicionado à reação. O lower e o upper mix de cada reação foram compostos de: 
- lower mix: 0,5x de 3.3XL buffer; $2 \mathrm{mM}$ de dNTP Blend; $0,2 \mu \mathrm{M}$ de cada oligonucleotídeo "F" e "R"; $3,75 \mathrm{mM}$ de $\mathrm{Mg}(\mathrm{OAc})_{2}$ e água DEPC (Invitrogen, CA, USA) q.s.p. $20 \mu \mathrm{L}$.

- upper mix: 0,5x de 3.3XL buffer; $2 \mathrm{U} / \mu \mathrm{L}$ de rTh DNA Polymerase, XL (Applied Biosystems, Foster City, CA, USA); $2,5 \mathrm{ng} / \mu \mathrm{L}$ de DNA e água DPEC (Invitrogen, $C A, U S A$ ) q.s.p. $30 \mu \mathrm{L}$.

O termociclador usado foi o Gene Amp ${ }^{\circledR}$ PCR System 9700 (Applied Biosystems). Após o hot start de $80{ }^{\circ} \mathrm{C}$ por 10 minutos e $4{ }^{\circ} \mathrm{C}$ por 5 minutos, a seguinte termociclagem ocorreu: $94{ }^{\circ} \mathrm{C}$ por 1 minuto seguido de 35 ciclos de $94{ }^{\circ} \mathrm{C}$ por 1 minuto, $68{ }^{\circ} \mathrm{C}$ por 10 minutos e, por fim, $10 \mathrm{~m}$ inutos a $72 \stackrel{\circ}{\circ} \mathrm{C}$. O produto de $P C R$ foi aplicado em gel de agarose a $0,5 \%$ corado com brometo de etídio $[0,4 \mu \mathrm{L} / \mathrm{mL}]$ e visualizado sob luz UV.

A seguir, um novo teste foi realizado com o conjunto de oligonucleotídeos 3 , com a finalidade de verificar se a multiplex long PCR (que utiliza dois pares de oligonucleotídeos) descrita por Hersberger et al. (2000) funcionaria apropriadamente com o Kit GeneAmp ${ }^{\circledR} \mathrm{XL}$ (Applied Biosystems, Foster City, CA, USA). A reação é descrita a seguir:

- lower mix: 0,5x de 3.3XL buffer; 0,18 mM de dNTP Blend; 0,34 mM dos oligonucleotídeos Dup e Dlow e, 0,68 mM dos oligonucleotídeos 2D6_del_H2R e DPKup; $3,4 \mathrm{mM}$ de $\mathrm{Mg}(\mathrm{OAc})_{2}$, volume final de $22 \mu \mathrm{L}$.

- upper mix: 0,5x de 3.3XL buffer; $2 \mathrm{U} / \mu \mathrm{L}$ de rTh DNA Polymerase, XL (Applied Biosystems); $5,36 \mathrm{ng} / \mathrm{\mu L}$ de DNA e água DEPC (Invitrogen, CA, USA) q.s.p. $28 \mu \mathrm{L}$.

Empregamos as mesmas amostras da reação anterior. $O$ termociclador utilizado foi o Gene Amp ${ }^{\circledR}$ PCR System 9700 (Applied Biosystems). Após o hot start de $80{ }^{C} \mathrm{C}$ por 10 minutos e $4{ }^{\circ} \mathrm{C}$ por 5 minutos, a cic lagem foi a seguinte: $94{ }^{\circ} \mathrm{C}$ por 2 minutos seguido de 40 ciclos de $94{ }^{\circ} \mathrm{C}$ por 1 minuto, $60{ }^{\circ} \mathrm{C}$ por 45 segundos e $68 \mathrm{C}$ por 5 minutos. O produto de $P C R$ foi aplicado em gel de agarose a $0,8 \%$ corado com brometo de etídio $[0,4 \mu \mathrm{L} / \mathrm{mL}]$ e visualizado sob luz UV.

O termociclador utilizado foi o Gene $A{ }^{\circledR}$ PCR System 9700 (Applied Biosystems). A ciclagem foi a seguinte: $94^{\circ} \mathrm{C}$ por 2 minutos s eguido de 40 ciclos de $94{ }^{\circ} \mathrm{C}$ por 1 minuto, $60^{\circ} \mathrm{C}$ por 45 segundos e $68^{\circ} \mathrm{C} p$ or 5 minutos. $\mathrm{O}$ produto de 
$P C R$ foi aplicado em gel de agarose a $0,8 \%$ corado com brometo de etídio [0,4 $\mu \mathrm{L} / \mathrm{mL}$ ] e visualizado sob luz UV.

\subsection{PCR em tempo real - determinação do número de cópias do gene CYP2D6}

\section{Padronização da $P C R$ em tempo real para a quantificação do número de cópias do gene CYP2D6}

As técnicas de $P C R$ em tempo real para a quantificação de DNA permitiram o desenvolvimento de métodos sensíveis que são capazes de discriminar deleções de genes, duplicações e multiplicações (Meijerman et al., 2007).

No geral, toda $P C R$ é caracterizada por três fases: (1) fase geométrica ou exponencial - caracterizada por apresentar precisão na duplicação do número de moléculas da reação. Todos os reagentes estão presentes em quantidades suficientes para o início da replicação. (2) fase linear - a taxa de produção de novas cadeias de DNA via $P C R$ passa gradualmente para uma progressão linear. (3) platô - a eficiência de amplificação cai a níveis insignificantes.

Com a técnica de $P C R$ em tempo real, compostos fluorescentes são utilizados para a monitorização do processo de $P C R$ no momento que a reação ocorre. As curvas de amplificação da $P C R$ mostram a quantidade de fluorescência na fase exponencial da reação que pode então ser utilizada para calcular a relativa quantidade do material inicial (Meijerman et al., 2007).

Um dos sistemas mais comumente utilizados são as sondas TaqMan para amplificar seqüências-alvo e simultaneamente gerar um sinal do produto de $P C R$. Em uma reação com o sistema $\operatorname{TaqMan}^{\circledR}$ três específicos oligonucleotídeos: um sense e outro antisense além de uma sonda $\operatorname{TaqMan}^{\oplus}$. A sonda está ligada a um fluoróforo e um quencher. Enquanto a sonda não estiver ligada ao DNA, o sinal da fluorescência é baixo devido a presença do quencher. Quando a sonda está anelada ao DNA, o quencher é liberado do fluoróforo e o sinal fluorescente pode ser medido (Meijerman et al., 2007). 
O objetivo da padronização do teste que utiliza a técnica de $P C R$ em tempo real é determinar o número teórico de cópias do gene CYP2D6 (presença de um alelo ou deleção de ambos, dois alelos, três ou mais alelos). Essa técnica necessita de um controle endógeno que deve ser um gene de cópia única no genoma haplóide que é usado como normalizador. Para o gene CYP2D6 o primeiro controle endógeno adotado foi o gene da albumina, mas posteriormente, outro controle endógeno foi selecionado, o gene RNase P (TaqMan endogenous control kit - Applied Biosystems, Foster City, CA, USA) (Quadros 17 e 18).

Quadro 17 - Oligonucleotídeos utilizados na determinação do CNV.

\begin{tabular}{|l|l|l|l|}
\hline \multirow{2}{*}{ Gene } & Oligonucleotídeo & Seqüência (5'-3') & Referência \\
\hline \multirow{2}{*}{ Albumina } & 2D6/ex9/f3 (2D6_F) & CTTCACCTCCCTGCTGCAG & Schaeffeler et al.(2003) \\
\cline { 2 - 4 } & 2D6/ex9/r3 (2D6_R) & TCACCAGGAAAGCAAAGACA & Schaeffeler et al.(2003) \\
\cline { 2 - 4 } & alb/ex12/f (ALB_F) & TGTTGCATGAGAAAACGCCA & Schaeffeler et al.(2003) \\
\cline { 2 - 4 } & alb/ex12/r_b (ALB_R_B)* & GTCGCCTGTTCACCAAGGAT & Schaeffeler et al.(2003) \\
\hline
\end{tabular}

${ }^{*}$ ALB_R modificado.

Quadro 18 - Sondas utilizadas na determinação do CNV.

\begin{tabular}{|l|l|l|l|}
\hline Gene & Sonda & Seqüência $\left(5^{\prime}\right.$ - $\mathbf{3}^{\prime}$ ) & Fluoróforo \\
\hline CYP2D6 & 2D6/ex9/p (probe 2D6) & CCGGCCCAGCCACCATGG & FAM \\
\hline Albumina & ALB/ex12/p (probe ALB) & AAGTGACAGAGTCACCAAATGCTGCAG & VIC \\
\hline RNase $P^{*}$ & & & VIC \\
\hline
\end{tabular}

${ }^{\star}$ TaqMan ${ }^{\circledR}$ RNase P Control Reagents P/N: 4316844 (Applied Biosystems, Foster City, CA, USA).

A primeira tentativa de padronização dessa reação foi realizada com o gene da albumina como controle endógeno. As condições de reação tanto para o genealvo como para o controle endógeno foram as seguintes: 1,25x de $\operatorname{TaqMan}^{\circledR}$ Universal Master Mix (P/N 4304437; Applied Biosystems, Foster City, CA, USA); 1 $\mu \mathrm{M}$ de cada oligonucleotídeo (F) e (R); 0,367 $\mu \mathrm{M}$ de TaqMan ${ }^{\circledR}$ probe; 1,25 ng/ $\mu \mathrm{L}$ de DNA e água Milli $Q$ q.s.p. $15 \mu \mathrm{L}$. A termociclagem utilizada é descrita a seguir: 2 minutos a $50 \stackrel{\circ}{ } \mathrm{C}, 10$ minutos a $95{ }^{\circ} \mathrm{C}$ seguido de 40 ciclos de 15 segundos a $96{ }^{\circ} \mathrm{C}$ e 1 minuto a $60 \stackrel{\circ}{\circ}$. 
Realizou-se a PCR no aparelho 7500 Real-Time PCR System (Applied Biosystems, Foster City, CA, USA) e 7500 System SDS Software (Applied Biosystems, Foster City, CA, USA). As reações foram avaliadas em triplicata.

Devido a uma grande diferença de eficiência de amplificação entre a seqüência escolhida do gene da albumina e o fragmento do CYP2D6, o controle endógeno passou a ser o gene RNase $P$. As condições de reação foram as seguintes: 1,25x de TaqMan $^{\circledR}$ Gene Expression Master Mix (P/N: 4374657; Applied Biosystems, Foster City, CA, USA); $1 \mu \mathrm{M}$ de cada oligonucleotídeo sense e antisense; $0,367 \mu \mathrm{M}$ de TaqMan $^{\circledR}$ probe $[11,76 \mu \mathrm{M}] ; 1,25 \mathrm{ng} / \mu \mathrm{L}$ de DNA; $0,08 \mathrm{M}$ de betaína (Sigma, Saint Louis, Missouri, USA) e água DEPC (Invitrogen, CA, USA) q.s.p. $15 \mu \mathrm{L}$. A reação do controle endógeno RNase $P$ foi a seguinte: $1,25 \mathrm{x}$ de TaqMan $^{\circledR}$ Gene Expression Master Mix (P/N: 4374657; Applied Biosystems, Foster City, CA, USA); $1 \mathrm{x}$ de RNase $P ; 1,25 \mathrm{ng} / \mu \mathrm{L}$ de DNA e água DEPC (Invitrogen, $C A$, USA) q.s.p. $15 \mu \mathrm{L}$. A termociclagem utilizada é descrita a seguir: 2 minutos a $50{ }^{\circ} \mathrm{C}$, 10 minutos a $95^{\circ} \mathrm{C}$ seguido de 40 ciclos de 15 segundos a $96 \stackrel{\circ}{\mathrm{C}}$ e 1 minuto a $60 \stackrel{\circ}{ } \mathrm{C}$.

\section{Cálculo do número teórico de cópias do gene CYP2D6}

O objetivo da $P C R$ em tempo real foi separar as amostras em diferentes grupos, de acordo com o número de cópias do gene CYP2D6 que elas possuem. Estes grupos são: presença de um alelo ou deleção de ambos, presença dos dois alelos (genótipo "normal") e a presença de três ou mais alelos (duplicação, amplificação ou multiplicação). A separação das amostras nestes três grupos foi possível após a elaboração de um modelo de regressão logística multinomial

Os resultados obtidos na $P C R$ em tempo real foram determinados segundo 0 método $\Delta \triangle C T$ de Livak e Schmittgem (2001). Que será explicado a seguir.

Para o cálculo, foi utilizada uma média do valor do Ct (thereshold cycle) das triplicatas. Ct é definido como ciclo no qual a amplificação do gene de uma dada amostra ultrapassa o limite de amplificação estabelecido. Realizadas as médias, calcula-se o $\triangle$ Ct pela diferença do valor da média do Ct do gene alvo (CYP2D6) e da média do $C t$ do controle endógeno (albumina ou RNase P). Depois, o $\Delta \Delta C t$ foi 
calculado pela diferença do valor de $\Delta C t$ de cada amostra e o valor do $\Delta C t$ do calibrador (uma amostra normal - dois alelos do gene CYP2D6) e, por fim, aplica-se a fórmula $2^{-\Delta \Delta C t}$.

As etapas para a obtenção do resultado do $\Delta C t$ são expostas a seguir:

a) a quantificação relativa das amostras é feita em triplicata na mesma placa, tanto para o gene-alvo como para o controle endógeno RNase $P$;

b) após a reação de cada amostra, obtemos as curvas de amplificação (Figura 18) dos genes CYP2D6 e RNase $P$;

c) terminada a reação que determina a quantificação relativa fazemos 0 estudo da quantificação relativa (Figura 18) onde verificamos se alguma amostra da triplicata será excluída da análise. O Critério de exclusão é um desvio padrão maior que 1,0. Esta etapa também nos informa o Ct de cada amostra [ $C t=$ Threshold cicle ou ciclo no qual a amplificação do gene alvo e do controle endógeno de uma dada amostra ultrapassa o limite de amplificação estabelecido (threshold)];

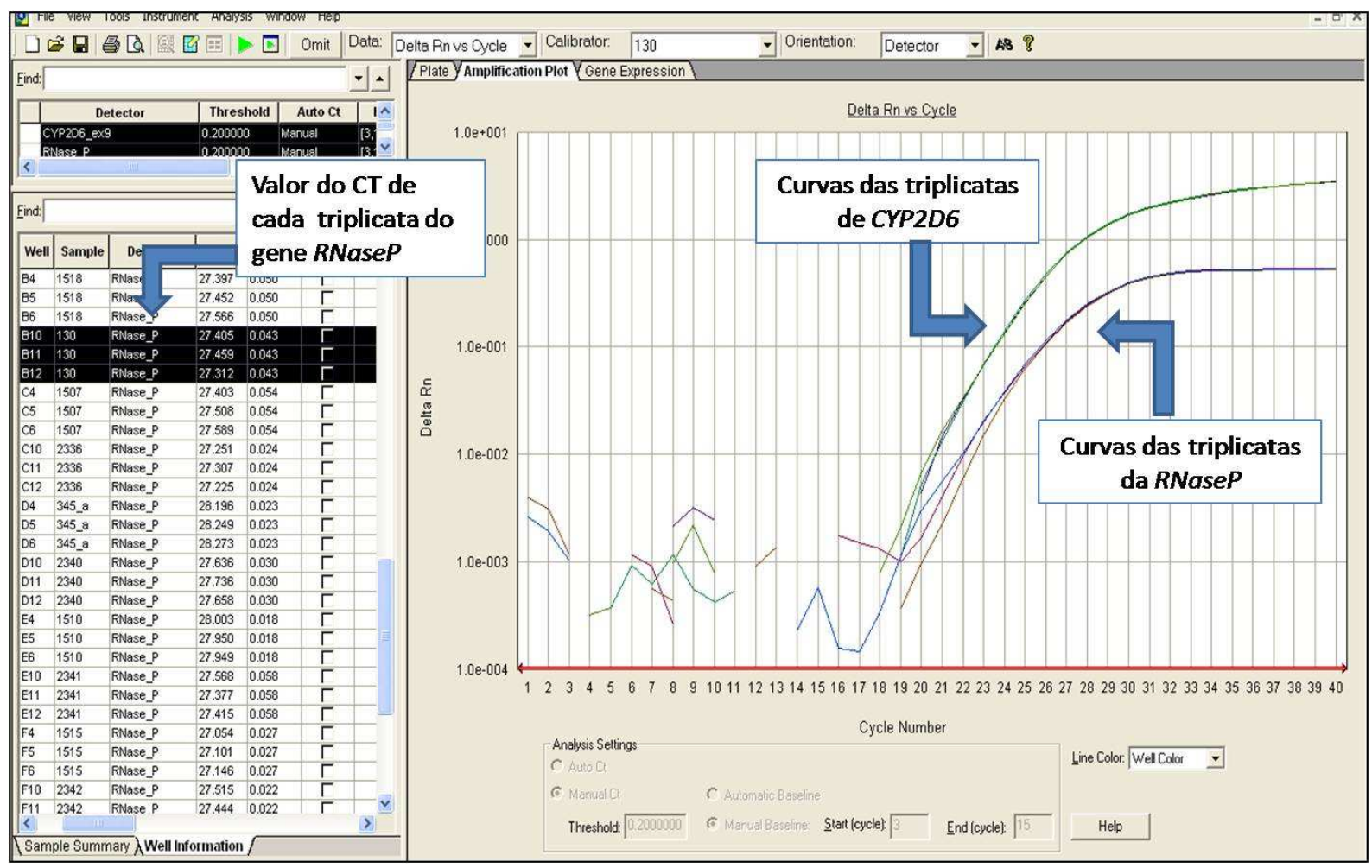

Figura 18 - Curva de amplificação das triplicatas dos genes CYP2D6 e RNase P. Estudo da quantificação relativa. $O$ valor o desvio padrão das triplicatas da $R$ Nase $P$ é 0,043 . 
d) os resultados obtidos no estudo da quantificação relativa são então transferidos para uma planilha do programa Excel (versão 2007, Microsoft Corporation, USA). Onde as médias dos Cts das triplicatas do gene CYP2D6 e da RNase P são calculadas (Figura 19);

e) cálculo do $\triangle C T \rightarrow \triangle C T=$ média do $C T$ do gene $C Y P 2 D 6$ - média do $C T$ da RNase P (Figura 19);

\begin{tabular}{|c|c|c|c|c|c|c|c|c|c|}
\hline \multicolumn{6}{|c|}{ CYP2D6 } & \multicolumn{4}{|c|}{ RNaseP } \\
\hline Sample & $\mathrm{Ct}$ & Ct std err & média Ct & desvp & $\Delta \mathrm{Ct}$ & $\mathrm{Ct}$ & Ct std err & média Ct & desvp \\
\hline 345 & 24,226 & 0,009 & \multirow[b]{3}{*}{24,210} & \multirow[b]{3}{*}{0,016} & \multirow[b]{3}{*}{$-2,921$} & 27,312 & 0,1 & \multirow[b]{3}{*}{27,131} & \multirow[b]{3}{*}{0,172} \\
\hline 345 & 24,209 & 0,009 & & & & 26,969 & 0,1 & & \\
\hline 345 & 24,195 & 0,009 & & & & 27,113 & 0,1 & & \\
\hline 130 & 24,536 & 0,031 & \multirow[b]{3}{*}{24,521} & \multirow[b]{3}{*}{0,054} & \multirow[b]{3}{*}{$-2,871$} & 27,405 & 0,043 & \multirow[b]{3}{*}{27,392} & \multirow[b]{3}{*}{0,074} \\
\hline 130 & 24,462 & 0,031 & & & & 27,459 & 0,043 & & \\
\hline 130 & 24,566 & 0,031 & & & & 27,312 & 0,043 & & \\
\hline 1507 & 24,619 & 0,045 & \multirow[b]{3}{*}{24,636} & \multirow[b]{3}{*}{0,078} & \multirow[b]{3}{*}{$-2,864$} & 27,403 & 0,054 & \multirow[b]{3}{*}{27,500} & \multirow[b]{3}{*}{0,093} \\
\hline 1507 & 24,568 & 0,045 & & & & 27,508 & 0,054 & & \\
\hline 1507 & 24,722 & 0,045 & & & & 27,589 & 0,054 & & \\
\hline 2336 & 25,122 & 0,009 & \multirow[b]{3}{*}{25,137} & \multirow[b]{3}{*}{0,015} & \multirow[b]{3}{*}{$-2,124$} & 27,251 & 0,024 & \multirow[b]{3}{*}{27,261} & \multirow[b]{3}{*}{0,042} \\
\hline 2336 & 25,152 & 0,009 & & & & 27,307 & 0,024 & & \\
\hline 2336 & 25,138 & 0,009 & & & & 27,225 & 0,024 & & \\
\hline 2341 & 25,079 & 0,01 & \multirow[b]{3}{*}{25,086} & \multirow[b]{3}{*}{0,017} & \multirow[b]{3}{*}{$-2,367$} & 27,568 & 0,058 & \multirow[b]{3}{*}{27,453} & \multirow[b]{3}{*}{0,101} \\
\hline 2341 & 25,074 & 0,01 & & & & 27,377 & 0,058 & & \\
\hline 2341 & 25,106 & 0,01 & & & & 27,415 & 0,058 & & \\
\hline 1515 & 24,286 & 0,018 & \multirow[b]{3}{*}{24,293} & \multirow[b]{3}{*}{0,031} & \multirow[b]{3}{*}{$-2,808$} & 27,054 & 0,027 & \multirow[b]{3}{*}{27,100} & \multirow[b]{3}{*}{0,046} \\
\hline 1515 & 24,326 & 0,018 & & & & 27,101 & 0,027 & & \\
\hline 1515 & 24,266 & 0,018 & & & & 27,146 & 0,027 & & \\
\hline
\end{tabular}

Figura 19 - Cálculo das médias dos Cts dos genes CYP2D6 e RNase $P$. Valores de $\triangle C T$.

f) para o cálculo do $\triangle \Delta C T$, precisamos de calibradores, no nosso caso, os calibradores são amostras sabidamente normais, ou seja, amostras com apenas duas cópias do gene CYP2D6. O valor do $\triangle \triangle C T$ é calculado segundo a seguinte fórmula: $\triangle \Delta C T=\triangle C T$ da amostra - $\triangle C T$ do calibrador (amostra normal, com duas cópias do gene), fazemos este cálculo três vezes pois temos três calibradores (Figura 20);

g) cálculo do $2^{-\triangle \Delta C T}$ de cada calibrador (Figura 20);

h) média do $2^{-\Delta \Delta C T}$ dos três calibradores (Figura 20); 
i) a média do valor do $2^{-\Delta \Delta C T}$ da amostra em relação aos três calibradores é utilizada na equação do modelo de regressão logística multinomial (Figura 20).

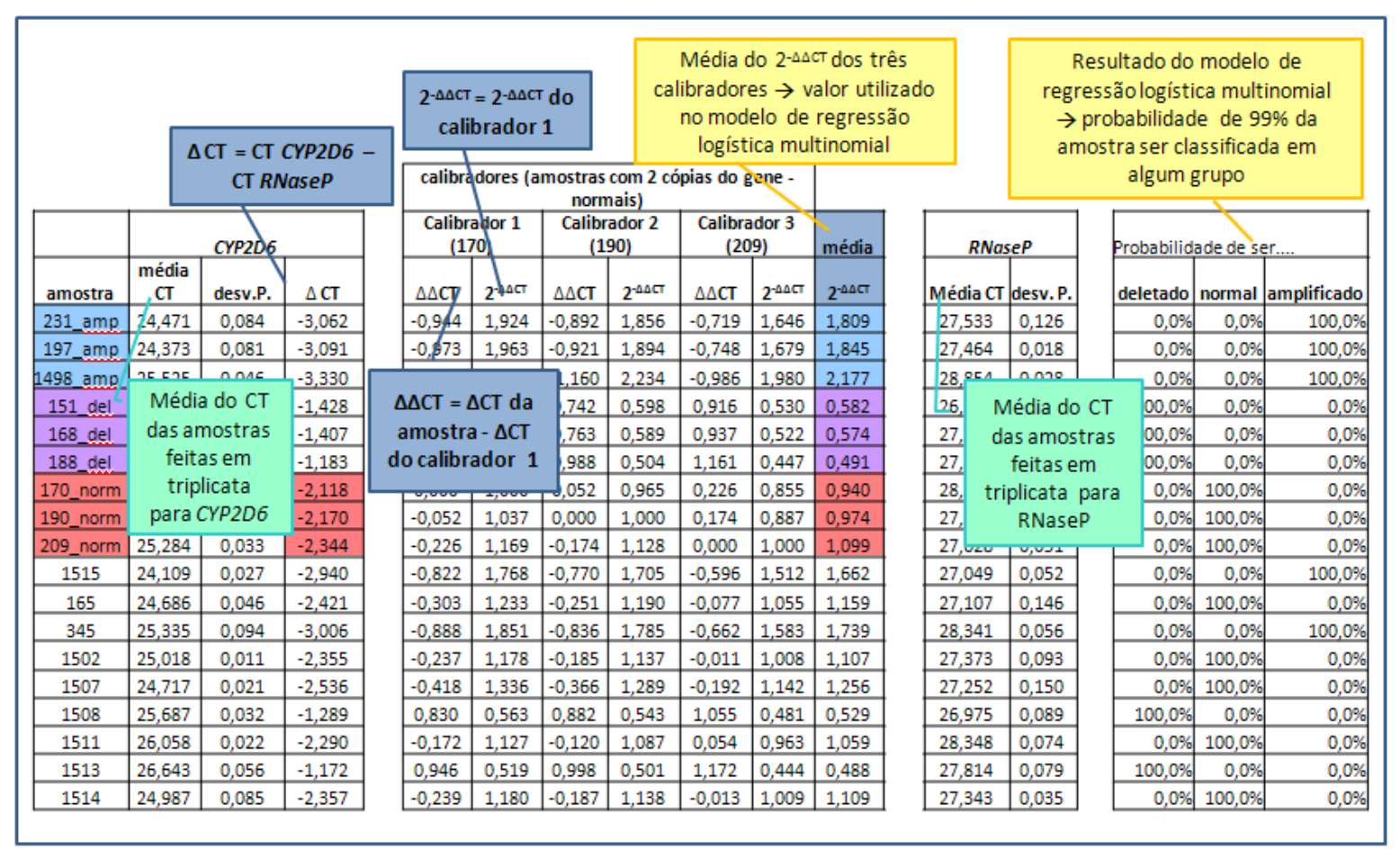

Figura 20 - Representação do cálculo do $\Delta \Delta C T$ e do $2^{-\Delta \Delta C T}$ que é utilizado no modelo de regressão logística multinomial.

Primeiramente, a escolha do melhor calibrador, isto é, a amostra que aparentava apresentar apenas duas cópias do gene CYP2D6 foi baseada na estatística de Kappa. Para isso 101 amostras tiveram seus resultados de $\Delta \Delta C t$ analisados. Escolheu-se três calibradores que possuíam valores de $\Delta \Delta C t$ em perfeita concordância com os três grupos de genótipo: presença de um alelo ou deleção de ambos, dois alelos (indivíduo considerado "normal"), três ou mais alelos. Para a separação de tais grupos, utilizou-se os resultados de corte sugeridos por Schaeffeler et al. (2003).

Entretanto, só pudemos validar o método de determinação do $C N V$ depois que amostras controle [duas amostras de genótipo sabidamente duplicados (CYP2D6 $\left.{ }^{*}{ }^{*} 2 \times N ;{ }^{*}{ }^{*} 2 x N\right)$, três normais $\left(C Y P 2 D 6^{*} 1^{*} 1\right)$, três heterozigotos deletados 
(CYP2D5*1*5) e uma homozigota deletada (CYP2D6*5*5)], foram gentilmente cedidas pelo Dr. Ulrich M. Zanger (Dr. Margarete Fischer-Bosch Institute of Clinical Pharmacology, Stuttgard, Germany). Também utilizamos uma amostra amplificada do nosso banco de amostras. Esta amostra deve sua amplificação confirmada pela técnica de long template PCR.

Para determinar os valores de $2^{-\Delta \Delta C t}$ que separam os três grupos de classificação das amostras, (presença de um alelo ou deleção de ambos, presença dos dois alelos e a presença de três ou mais alelos), as seguintes etapas foram realizadas:

- as amostras controles foram submetidas à reação para que seu delta-delta $C T$ fosse determinado;

- para os cálculos do $2^{-\Delta \Delta C t}$ as três amostras controles com dois alelos foram determinadas como calibradores, desse modo, foram utilizados três calibradores por amostra;

- a média dos valores dos três calibradores foi utilizada para o cálculo do CNV de cada amostra;

- os pontos de cortes para a classificação do número teórico de cópias do gene CYP2D6 foram obtidos baseando-se numa amostra de três indivíduos com duas cópias, três heterozigotos para a deleção e três indivíduos com duplicação (as nossas amostras controle);

- com base no resultado das médias dos $2^{-\Delta \Delta C t}$ dos três calibradores para estes nove indivíduos, os pontos de cortes foram obtidos por meio de um modelo de Regressão Logística Multinomial, considerando uma probabilidade de $99 \%$ para a classificação isto é, a amostra só é classificada se a mesma apresentar uma probabilidade mínima de $99 \%$ de pertencer a algum dos três grupos (Tabela 6). Com este modelo espera-se que $1 \%$ das amostras não sejam classificadas. 
Tabela 6 - Regras de classificação (pontos de cortes) utilizadas para a determinação do CNV.

\begin{tabular}{c|c}
\hline Classificação (CNV) & Valores de corte \\
\hline Deletado & $2^{-\Delta \Delta \mathrm{Ct}} \leq 0,711$ \\
\hline Sem classificação & $0,711<2^{-\Delta \Delta \mathrm{Ct}} \leq 0,801$ \\
\hline Normal (dois alelos) & $0,801<2^{-\Delta \Delta \mathrm{Ct}} \leq 1,367$ \\
\hline Sem classificação & $1,367<2^{-\Delta \Delta \mathrm{Ct}} \leq 1,541$ \\
\hline Duplicado & $2^{-\Delta \Delta \mathrm{Ct}}>1,541$ \\
\hline
\end{tabular}

As fórmulas utilizadas para a probabilidade de classificação (Modelo de Regressão Logística Multinomial) são apresentadas a seguir:

$$
\begin{gathered}
P[\text { Deletado }]=\frac{\exp \left(73,948-95,331 \times 2^{-\Delta \Delta C t}\right)}{1+\exp \left(73,948-95,331 \times 2^{-\Delta \Delta C t}\right)+\exp \left(-113,228+92,557 \times 2^{-\Delta \Delta C t}\right)} \\
P[\text { Normal }]=\frac{1}{1+\exp \left(73,948-95,331 \times 2^{-\Delta \Delta C t}\right)+\exp \left(-113,228+92,557 \times 2^{-\Delta \Delta C t}\right)} \\
P[\text { Duplicado }]=\frac{\exp \left(-113,228+92,557 \times 2^{-\Delta \Delta C t}\right)}{1+\exp \left(73,948-95,331 \times 2^{-\Delta \Delta C t}\right)+\exp \left(-113,228+92,557 \times 2^{-\Delta \Delta C t}\right)}
\end{gathered}
$$

\subsection{Discriminação alélica com o sistema $\operatorname{TaqMan}^{\circledR}$}

Cada polimorfismo nos genes CYP2D6 [-1584 C>G, $31 \mathrm{G}>\mathrm{A}, 100 \mathrm{C}>\mathrm{T}$, 137_138 ins T, 1023 C>T, 1707 del T, 1846 G>A, 1863_1864 ins(TTTCGCCCC)2, 2549 del A, 2613_2615 del AGA, 2850 C>T, 2988 G>A, 3183 G>A, 4180 G>C], CYP2C19 [-806 C>T, $17948 \mathrm{G}>\mathrm{A}, 19154 \mathrm{G}>\mathrm{A}$ ] e CYP2C9 [3608 C>T, $42614 \mathrm{~A}>\mathrm{C}$ ] passou a ser determinado utilizando ensaios TaqMan $^{\circledR}$ tipo Drug Metabolism SNP Genotyping Assays (P/N: 4362691, Applied Biosystems, Foster City, CA, USA). Para os polimorfismos $1661 \mathrm{G}>\mathrm{C}$ do gene CYP2D6 e -3402 C>T do gene CYP2C19, são empregados ensaios Custom TaqMan $^{\circledR}$ SNP Genotyping Assays (P/N: 4331349, Applied Biosystems, Foster City, CA, USA) (Quadros 19, 20, 21 e 22). 
Quadro 19 - Identificação dos ensaios TaqMan ${ }^{\circledR}$ Drug Metabolism SNP Genotyping Assays e Custom TaqMan $^{\Theta}$ SNP Genotyping Assays utilizados para detecção dos polimorfismos no gene CYP2C19.

\begin{tabular}{|l|l|l|l|}
\hline CYP2C19 & & & \\
\hline Identificação do ensaio & Polimorfismo & Alelos CYP2C19 & Disponibilidade \\
\hline C_25986767_70 & 19154 G>A & $* 2$ & Inventoriado \\
\hline C_27861809_10 & 17948 G>A & $* 3$ & Inventoriado \\
\hline C__469857_10 & -806 C >T & $* 17$ & Inventoriado \\
\hline & -3402 C>T & $* 17$ & Sob encomenda \\
\hline
\end{tabular}

Quadro 20 - Identificação dos ensaios TaqMan ${ }^{\circledR}$ Drug Metabolism SNP Genotyping Assays e Custom $\operatorname{TaqMan}^{\Theta}$ SNP Genotyping Assays utilizados para detecção dos polimorfismos no gene CYP2D6.

\begin{tabular}{|c|c|c|c|}
\hline \multicolumn{4}{|l|}{ CYP2D6 } \\
\hline Identificação do ensaio & Polimorfismo & Alelos CYP2D6 & Disponibilidade \\
\hline C_32407252_30 & $-1584 C>G$ & $* 2, * 35, * 41$ & Inventoriado \\
\hline C_27102444_80 & $31 \mathrm{G}>\mathrm{A}$ & *35 & Inventoriado \\
\hline C_11484460_40 & $100 \mathrm{C}>\mathrm{T}$ & $* 4, * 10$ & Inventoriado \\
\hline C__32407245_40 & 137_138 ins T & $* 15$ & Inventoriado \\
\hline \multirow[t]{2}{*}{ C_ 2222771_40 } & $1023 \mathrm{C}>\mathrm{T}$ & $* 17, * 40$ & Inventoriado \\
\hline & $1661 \mathrm{G}>C$ & $* 2, * 4, * 10, * 17, * 35, * 40, * 41$ & Sob encomenda \\
\hline C_32407243_20 & 1707 del T & $* 6$ & Inventoriado \\
\hline C__27102431_D0 & $1846 \mathrm{G}>\mathrm{A}$ & $* 4$ & Inventoriado \\
\hline C_32407240_20 & 1863_1864ins(TTTCGCCCC)2 & $* 40$ & Inventoriado \\
\hline C_32407232_50 & 2549 del A & $* 3$ & Inventoriado \\
\hline C_32407229_60 & 2613_2615 del AGA & $* 9$ & Inventoriado \\
\hline C_27102425_10 & $2850 \mathrm{C}>\mathrm{T}$ & $* 2, * 4, * 17, * 34, * 35, * 40, * 41$ & Inventoriado \\
\hline C_34816116_20 & $2988 \mathrm{G}>\mathrm{A}$ & $* 41$ & Inventoriado \\
\hline C_34816113_20 & $3183 \mathrm{G}>\mathrm{A}$ & $* 29$ & Inventoriado \\
\hline C_27102414_10 & $4180 \mathrm{G}>\mathrm{C}$ & $* 2, * 4, * 6, * 10, * 17, * 35, * 40, * 41$ & Inventoriado \\
\hline
\end{tabular}

Quadro 21 - Seqüencias de oligonucleotídeos e sondas dos ensaios feitos sob encomenda (Custom TaqMan $^{\circledR}$ SNP Genotyping Assays).

\begin{tabular}{|l|l|l|}
\hline Polimorfismo & CYP2C19_-3402 & CYP2D6_1661 \\
\hline Oligonucleotídeo 3'- 5' & AAATGGGCAACGGGTCTGA & TCCTGGCGCGCTATGG \\
\hline Oligonucleotídeo 5' - 3' & AGTTCCCTAATGACATTTAATGATTAGTACTTTTCATATATT & TGCCCAGGCCCAAGTTG \\
\hline Sonda 1 (VIC) & CTTGGTGAGGTGTCTGT & CTTCTCCGTGTCCACC \\
\hline Sonda 2 (FAM) & TTCTTGGTGAGATGTCTGT & CTTCTCCGTCTCCACC \\
\hline
\end{tabular}


Quadro 22 - Identificação dos ensaios TaqMan ${ }^{\circledR}$ Drug Metabolism SNP Genotyping Assays utilizados para detecção dos polimorfismos no gene CYP2C9.

\begin{tabular}{|l|l|l|l|}
\hline CYP2C9 & & & \\
\hline Identificação do ensaio & Polimorfismo & Alelos CYP2C9 & Disponibilidade \\
\hline C_25625805_10 & 3608 C>T & $* 2$ & Inventoriado \\
\hline C_27104892_10 & 42614 A $>$ G & $* 3$ & Inventoriado \\
\hline
\end{tabular}

As reações para a identificação dos polimorfismos $100 \mathrm{C}>\mathrm{T}, 137$ 138 ins $\mathrm{T}$, 1846 G>A, 1863_1864 ins(TTTCGCCCC)2, 2613_2615 del AGA , 3183 G>A , 4180 $\mathrm{G}>\mathrm{C}, 31 \mathrm{G}>\mathrm{A}, 1661 \mathrm{G}>\mathrm{C}, 1707$ del $\mathrm{T}$ do gene CYP2D6; -3402 $\mathrm{C}>\mathrm{T},-806 \mathrm{C}>\mathrm{T}$, $17948 \mathrm{G}>\mathrm{A}, 19154 \mathrm{G}>\mathrm{A}$ do gene CYP2C19 e $3608 \mathrm{C}>\mathrm{T}, 42614 \mathrm{~A}>\mathrm{C}$ do gene CYP2C9 foram padronizadas segundo a reação: 1x de TaqMan® Universal Master Mix (P/N 4304437; Applied Biosystems, Foster City, CA, USA), 1x de assay, $5 \mathrm{ng}$ de DNA e água DEPC (Invitrogen, CA, USA) q.s.p. $5 \mu \mathrm{L}$. A termociclagem utilizada foi a seguinte: primeira desnaturação de 10 minutos a $95{ }^{\circ} \mathrm{C}$ seguida de 40 ciclos de desnaturação a $95 \stackrel{\circ}{\circ}$ por 15 segundos e anelamento a $60 \stackrel{\circ}{\circ}$ por um minuto. $\mathrm{O}$ processo de discriminação alélica foi realizada por 1 minuto a $60 \stackrel{\circ}{\mathrm{C}}$ no aparelho de 7500 Real-Time System (Applied Biosystems, Foster City, CA).

Para os polimorfismos 1023 C>T, 2549 del A, 2850 C>T, 2988 G>A do gene CYP2D6 as reações padronizadas foram: $1 \mathrm{x}$ de $\operatorname{TaqMan}^{\circledR}$ Universal Master Mix (P/N 4304437; Applied Biosystems, Foster City, CA, USA), 1x de assay, 5 ng de DNA e água DEPC (Invitrogen, CA, USA) q.s.p. $5 \mu \mathrm{L}$. A termociclagem utilizada foi a seguinte: primeira desnaturação de 10 minutos a $95{ }^{\circ} \mathrm{C}$ seguida de 45 ciclos de desnaturação a $95 \stackrel{\circ}{\circ}$ por 20 segundos e anelamento a $58{ }^{\circ} \mathrm{C}$ por 1 minuto e 30 segundos. $O$ processo de discriminação alélica foi realizada por 1 minuto a $60 \stackrel{\circ}{ } \mathrm{C}$ no aparelho de 7500 Real-Time System (Applied Biosystems, Foster City, CA).

\subsection{Determinação dos fenótipos preditos}

\section{- $\underline{\text { CYP2D6 }}$}


$\mathrm{Na}$ classificação dos fenótipos preditos para CYP2D6 a presença de um alelo funcional (CYP2D6*1 ou CYP2D6*2) determinou o fenótipo EM (Bernard et al., 2006; Sabbagh et al., 2006). Homozigotos para dois alelos funcionais ou heterozigotos para um alelo funcional duplicado $\left(C Y P 2 D 6^{*} 1 x N\right.$ ou $\left.C Y P 2 D 6^{*} 2 x M\right)$ e um alelo nãofuncional (CYP2D6*3, *4, $\left.{ }^{*} 5,{ }^{*} 6,{ }^{*} 15,{ }^{*} 40\right)$ também foram classificados como EMs segundo Kirchheiner et al. (2004). Dois alelos de atividade intermediária (CYP2D6*9, *10, *17, *41) combinados ou, a combinação de um alelo de atividade intermediária com uma variante não funcional foi classificado como IM. Indivíduos UMs foram definidos como portadores de uma duplicação ou multiplicação de um alelo ativo em conjunto com um alelo funcional (Sistonem et al., 2007). Os PMs foram definidos como homozigotos para alelos não funcionais (CYP2D6*3, ${ }^{*} 4,{ }^{*} 5,{ }^{*} 6,{ }^{*} 15,{ }^{*} 40$ ) (Bernard et al., 2006; Sabbagh et al., 2006) (Quadro 23).

Quadro 23 - Determinação do fenótipo predito para CYP2D6 de acordo com a combinação alélica.

\begin{tabular}{|c|c|}
\hline Fenótipo predito & Combinação de alelos \\
\hline $\mathrm{EM}$ & $\mathrm{EM}+\mathrm{EM} ; \mathrm{EM}+\mathrm{PM} ; \mathrm{EM}+\mathrm{IM} ; \mathrm{EM} \times \mathrm{N}+\mathrm{PM}$ \\
\hline $\mathrm{IM}$ & $\mathrm{IM}+\mathrm{IM} ; \mathrm{IM}+\mathrm{PM}$ \\
\hline $\mathrm{UM}$ & $\mathrm{EM} \times \mathrm{N}$ \\
\hline $\mathrm{PM}$ & $\mathrm{PM}+\mathrm{PM}$ \\
\hline
\end{tabular}

\section{- $\underline{\text { CYP2C19 }}$}

A determinação do fenótipo predito para CYP2C19 foi realizada segundo Ragia et al. (2009) que classifica como UMs homozigotos para o alelo de atividade aumentada *17; "UMs heterozigotos" a presença do alelo *17 em combinação com um alelo de atividade normal $\left({ }^{*} 1\right)$ porque sua capacidade metabólica está entre UMs e EMs. Indivíduos que possuem um alelo de atividade aumentada ( $\left.{ }^{*} 17\right)$ e um alelo de atividade nula ( ${ }^{*} 2$ ou ${ }^{*} 3$ ) foram classificados como EMs. Heterozigotos para um alelo de atividade nula e um alelo funcional foram classificados como IMs e homozigotos de alelos não funcionais classificados como PMs (Quadro 24). 
Quadro 24 - Determinação do fenótipo predito para CYP2C19 de acordo com a combinação alélica.

\begin{tabular}{|c|c|}
\hline Fenótipo predito & Combinação de alelos \\
\hline $\mathrm{EM}$ & $\mathrm{EM}+\mathrm{EM} ; \mathrm{UM}+\mathrm{PM}$ \\
\hline $\mathrm{IM}$ & $\mathrm{EM}+\mathrm{PM}$ \\
\hline $\mathrm{UM}$ & $\mathrm{UM}+\mathrm{UM}$ \\
\hline UM heterozigoto & $\mathrm{UM}+\mathrm{EM}$ \\
\hline $\mathrm{PM}$ & $\mathrm{PM}+\mathrm{PM}$ \\
\hline
\end{tabular}

\section{- CYP2C9}

A determinação do fenótipo predito para CYP2C9 foi realizada segundo Scott et al. (2007) que classifica como EMs homozigotos para o alelo normal *1; IMs indivíduos que possuem um alelo normal e um alelo de atividade reduzida ( ${ }^{*} 2$ ou *3) e PMs como homozigotos para alelos de atividade reduzida (Quadro 25).

Quadro 25 - Determinação do fenótipo predito para CYP2C9 de acordo com a combinação alélica.

\begin{tabular}{|c|c|}
\hline Fenótipo predito & Combinação de alelos \\
\hline EM & $E M+E M$ \\
\hline IM & $E M+I M$ \\
\hline PM & $I M+I M$ \\
\hline
\end{tabular}


5 RESULTADOS 


\subsection{Padronização das PCRs e reações de seqüenciamento}

Todas as $P C R s$ e reações de seqüenciamento descritas anteriormente foram padronizadas com sucesso e os produtos de cada reação foram visualizados em gel de agarose a $1 \%$ corado com brometo de etídio $[0,4 \mu \mathrm{g} / \mathrm{mL}]$ (Figuras 21 e 22).

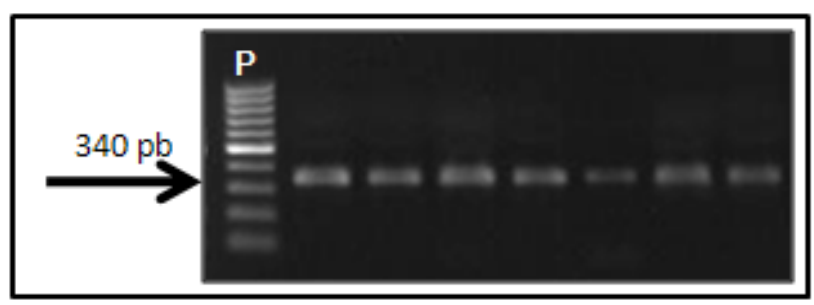

Figura 21 - Gel de agarose 1,0\%, corado com brometo de etídio [0,4 $\mu \mathrm{g} / \mathrm{mL}$ ] mostrando o fragmento amplificado que contém o polimorfismo 100C>T no gene CYP2D6. A letra P simboliza o padrão molecular utilizado, 100 pb (GIBCO - Invitrogen, CA, USA).

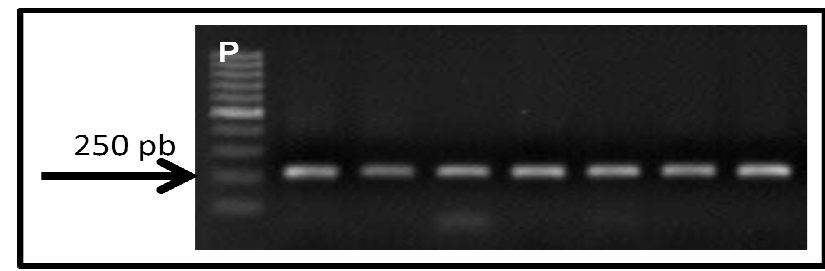

Figura 22 - Gel de agarose 1,0\%, corado com brometo de etídio [0,4 $\mu \mathrm{g} / \mathrm{mL}$ ] mostrando o fragmento amplificado que contém o polimorfismo $-3402 \mathrm{G}>\mathrm{T}$ no gene CYP2C19. A letra $\mathrm{P}$ simboliza o padrão molecular utilizado, 100 pb (GIBCO - Invitrogen, CA, USA).

Os eletroferogramas gerados pelo programa 3100 Detection Software (Applied Biosystems, Foster City, CA, USA) foram visualizados no programa FinchTV $^{\circledR}$ (2006 Geospiza, Inc.) (Figura 23). 
(A) Eletroferograma obtido no seqūenciamento da amostra 1496 do alelo CYP2D6*10 $(100 \bigcirc \mathrm{T})$ utilizando oligonucleotideo foward (F). Individuo homozigoto $T$.

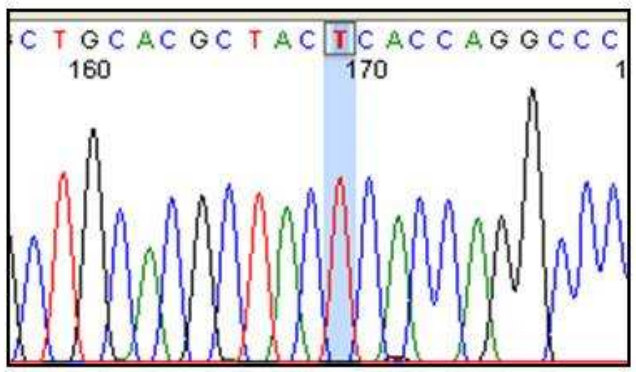

\section{(B): Eletroferograma obtido no} seqūenciamento da amostra 1495 do alelo CYP2D6*41 (2850 $>$ T) utilizando oligonucleotídeo reverse (R). Individuo heterozigoto $\mathrm{CT}$.

(C): Eletroferograma obtido no seqūenciamento da amostra 1741 (paciente) do alelo CYP2D6*17(1023 $\bigcirc$ T) utilizando oligonucleotídeo foward (F). Individuo homozigoto $\mathrm{CC}$.
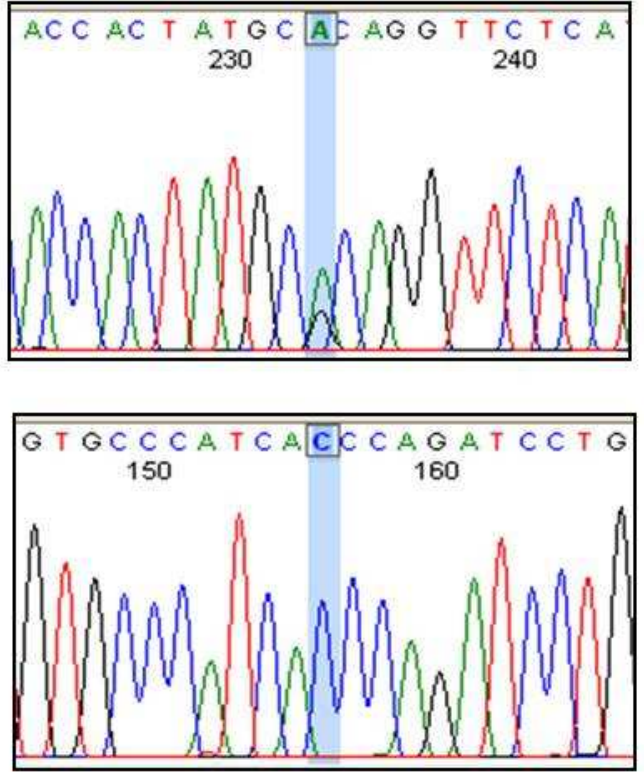

\section{(D): Eletroferograma obtido no} seqūenciamento da amostra 1723 do alelo $\mathrm{CYP2C19}$ 2 2 (19154 G>A) utilizando oligonucleotídeo reverse (R). Indivíduo heterozigoto $\mathbf{G}>\mathbf{A}$.

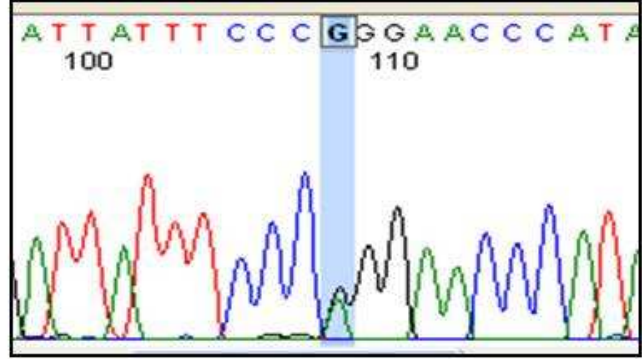

(E): Eletroferograma obtido no seqūenciamento da amostra 642 do alelo $\mathrm{CYP}_{2} \mathrm{C9}^{*} 3$ (42614A $>\mathrm{C}$ ) utilizando oligonucleotideo foward (F). Individuo heterozigoto $\mathrm{A} \subset \mathrm{C}$

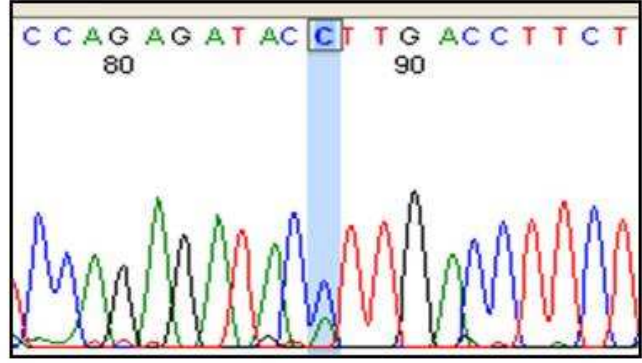

Figura 23 - Exemplos de eletroferogramas referentes aos seqüenciamentos para identificação dos polimorfismos $100 \mathrm{C}>\mathrm{T}$ no alelo CYP2D6*10, 2850C>T no alelo CYP2D6*41, 1023C>T no alelo CYP2D6*17, $19154 \mathrm{G}>\mathrm{A}$ no alelo CYP2C19² e $42614 \mathrm{~A}>\mathrm{C}$ no alelo CYP2C9*3. 


\subsection{Long template PCR para detecção da duplicação do gene CYP2D6 e do alelo CYP2D6*5}

Long template PCRs (Figura 24) foram realizadas com a finalidade de identificar o alelo CYP2D6 5 e a duplicação do gene CYP2D6.

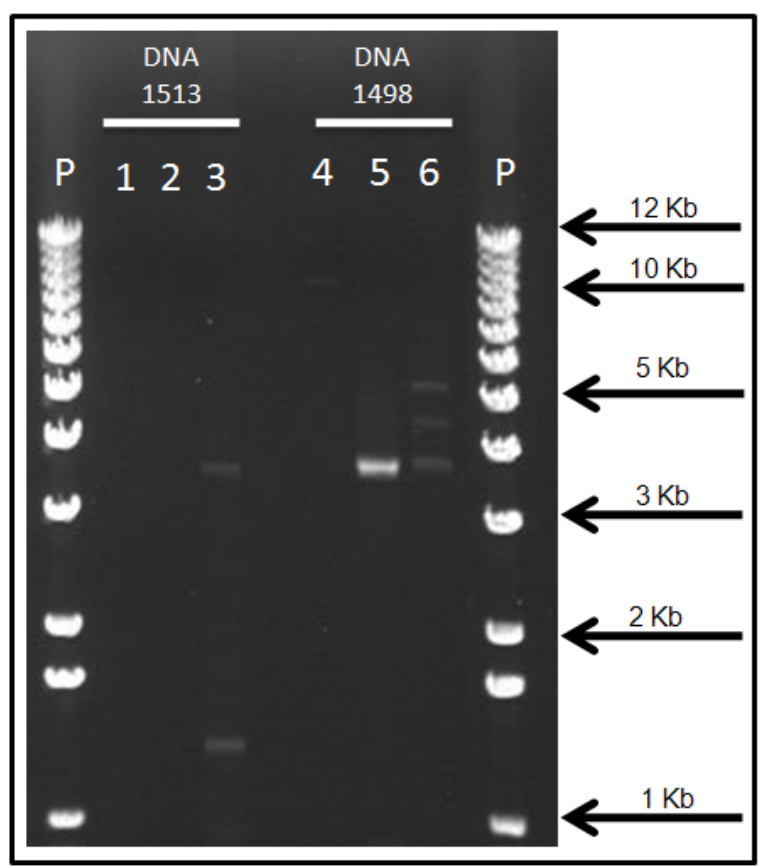

Figura 24 - Gel de agarose $0,5 \%$, corado com brometo de etídio $[0,4 \mu \mathrm{g} / \mathrm{mL}]$ mostrando resultados das PCRs. Os números 1,2 e 3 correspondem aos oligonucleotídeos que detectam 0 alelo CYP2D6 5 e, os números 4,5 e 6 aos que detectam a duplicação do gene CYP2D6. A letra $\mathrm{P}$ simboliza o padrão molecular utilizado: 1000 pb (1Kb Plus DNA Ladder, Invitrogen, CA, USA).

As reações 1 e 2 (Figura 24) não funcionaram porque os fragmentos esperados de 3,5 Kb e 6,0 Kb não apareceram. Na reação 3, eram esperadas uma banda de $3,2 \mathrm{~Kb}$ (indicando o alelo CYP2D6*5) e outra de 5,1 Kb (indicando o alelo selvagem). Somente a banda de 3,2 $\mathrm{Kb}$ apareceu. A banda de 5,1 Kb também deveria ter aparecido porque esta amostra não é homozigota para o alelo CYP2D6*5 como já foi confirmado em $P C R s$ e reações de seqüenciamento para a identificação de polimorfismos; o fato de somente uma banda ter aparecido mostra que a reação 
funcionou apenas parcialmente. As reações 4,5 e 6 funcionaram. Os fragmentos de $10 \mathrm{~Kb}$ e 3,5 Kb esperados para as reações 4 e 5 respectivamente, amplificaram. $\mathrm{Na}$ reação 6 os produtos da amplificação de 3,6 Kb e 5,2 KB, também foram detectados.

Tivemos muita dificuldade na padronização da multiplex long PCR. Não houve amplificação do fragmento esperado de $3,1 \mathrm{~Kb}$ que identifica o alelo CYP2D6*5 na amostra homozigota "deletada". Entretanto, para a amostra multiplicada, a banda esperada de 5,1 Kb pode ser identificada (Figura 25). A replicabilidade foi comprometida e decidimos, então, determinar o número de cópias utilizando $P C R$ em tempo real.

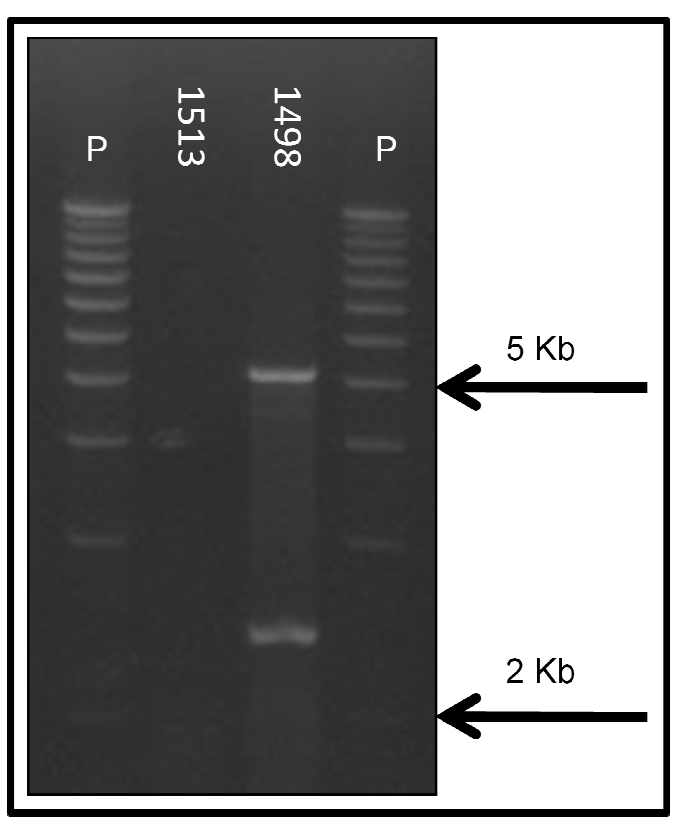

Figura 25 - Gel de agarose $0,8 \%$, corado com brometo de etídio $[0,4 \mu \mathrm{L} / \mathrm{mL}]$ mostrando resultados da multiplex long PCR. A letra P simboliza o padrão molecular utilizado: 1000 pb (1 Kb Plus DNA Ladder, Invitrogen, CA, USA).

\subsection{Padronização da $P C R$ em tempo real para a quantificação do número de cópias do gene CYP2D6}

O primeiro teste para a padronização da reação de determinação do $C N V$ foi realizado com o gene da albumina como controle endógeno. Ao se calcular o $2^{-\Delta \Delta C t}$ das amostras, fizemos algumas repetições do experimento e os resultados de CNV 
das mesmas amostras variavam cada vez que a reação era feita fazendo com que uma mesma amostra ora fosse classificada como normal (dois alelos), ora como possuindo deleção de um alelo ou como amplificada. Após compararmos as curvas de amplificação do gene CYP2D6 e da albumina (Figura 26), verificou-se que a amplificação da albumina foi bastante instável e pouco reprodutível e que isto poderia interferir nos cálculos do $C N V$.

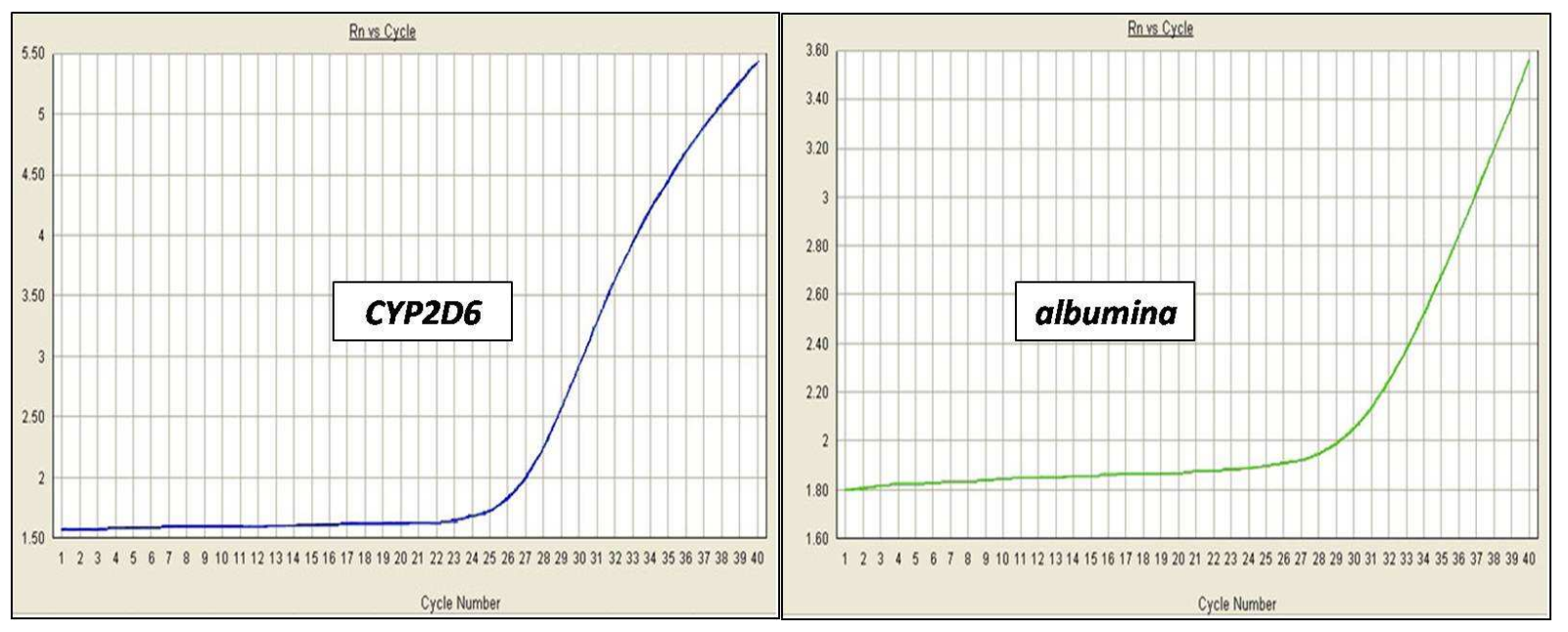

Figura 26 - Representação gráfica da curva de amplificação dos genes CYP2D6 e albumina. A curva de amplificação do gene endógeno albumina apresenta uma amplificação tardia em relação ao gene CYP2D6.

Desse modo, o controle endógeno albumina foi substituído pelo kit $\operatorname{TaqMan}^{\oplus}$ RNase P Control Reagents (VIC dye), (Applied Biosystems, Foster City, CA, USA). Ao se comparar as curvas de amplificação, observou-se que a curva da RNase $P$ e do gene CYP2D6 apresentavam um padrão de amplificação similar (Figura 27). 


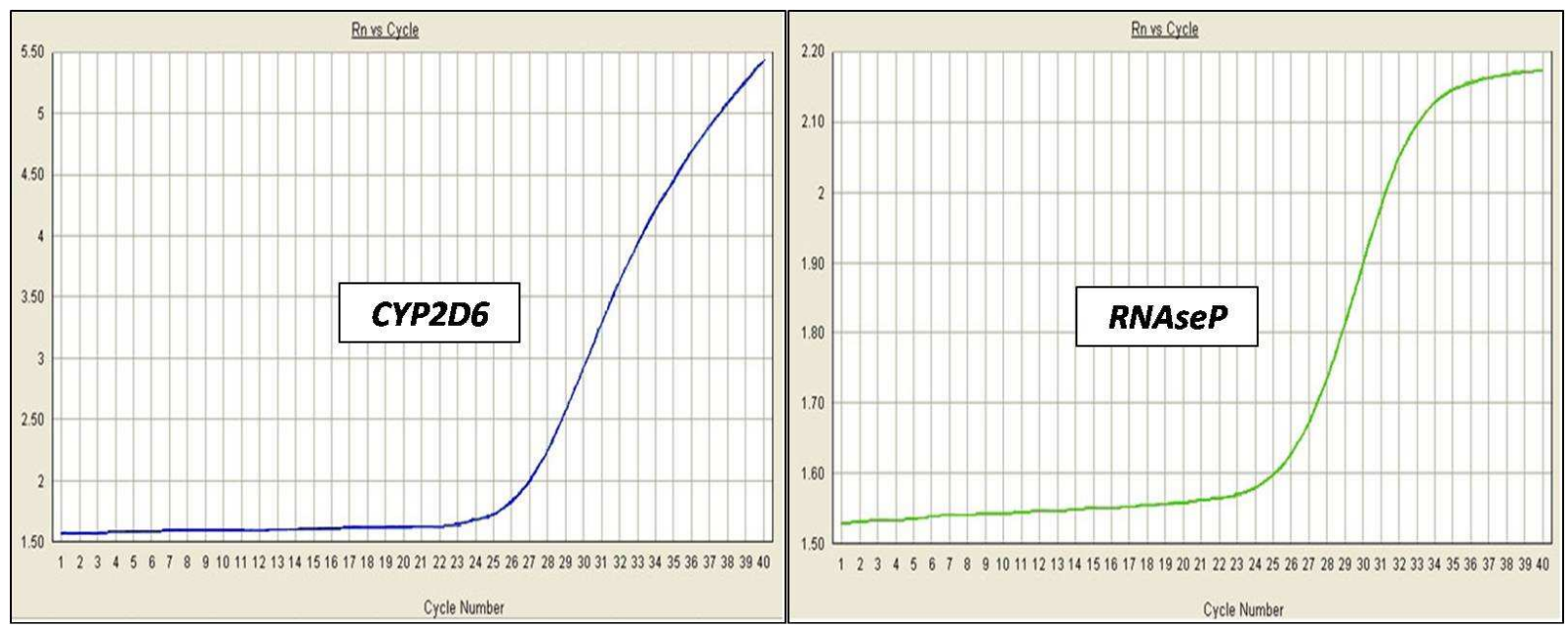

Figura 27 - Representação gráfica da curva de amplificação dos genes CYP2D6 e RNase $P$.

Ao se substituir o controle endógeno, o problema da variação dos resultados de CNV de uma mesma amostra foi resolvido. Assim, todas as amostras que já haviam sido feitas com a albumina como controle endógeno foram refeitas.

\subsection{Análises dos resultados - cálculo do número teórico de cópias do gene CYP2D6}

As amostras foram submetidas à $P C R$ em tempo real utilizando a $R N A$ se $P$ como controle endógeno. Após o cálculo do $2^{-\Delta \Delta C T}$, obtemos os valores que são utilizados para o cálculo do modelo de Regressão Logística Multinomial. Nele as amostras são classificadas em grupos de uma cópia, duas cópias, três ou mais cópias do gene e amostras sem classificação (Figura 28). 


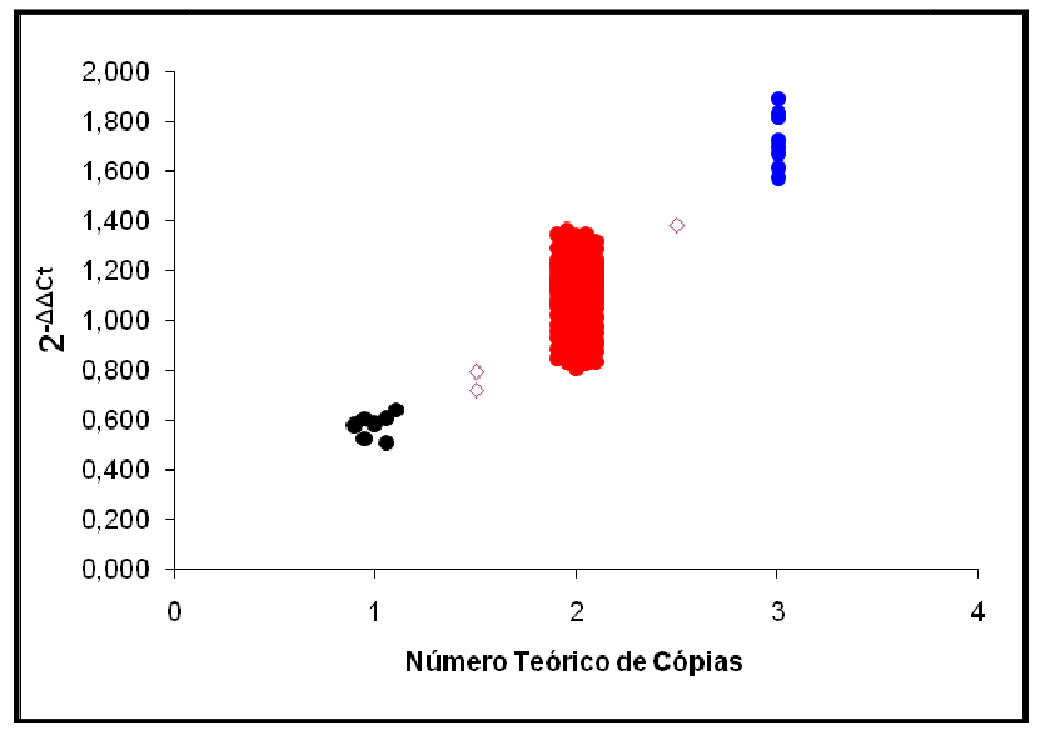

Figura 28 - Gráfico que ilustra a classificação do número teórico de cópias (CNV) para 149 amostras como o previsto pelo modelo de regressão. Algumas amostras não foram classificadas (losangos).

\subsection{Discriminação alélica com o sistema $\operatorname{TaqMan}^{\circledR}$}

Dos 15 os ensaios selecionados para a determinação dos polimorfismos nos genes CYP2D6, todos foram padronizados com sucesso. Os quatro ensaios para os polimorfismos do gene CYP2C19 e dois ensaios para o gene CYP2C9 também foram padronizados com sucesso. A seguir, são demonstrados exemplos gráficos de curvas de amplificação de uma amostra heterozigota para o polimorfismo -3402 C>T do gene CYP2C19 (Figura 29), uma amostra homozigota CC e outra homozigota TT para o polimorfismo $100 \mathrm{C}>\mathrm{T}$ do gene CYP2D6 (Figura 30 e 31); uma amostra homozigota GG para o polimorfismo $31 \mathrm{G}>\mathrm{A}$ (Figura 32) e uma amostra heterozigota para o polimorfismo $42614 \mathrm{~A}>\mathrm{C}$ do gene CYP2C9 (Figura 33). 


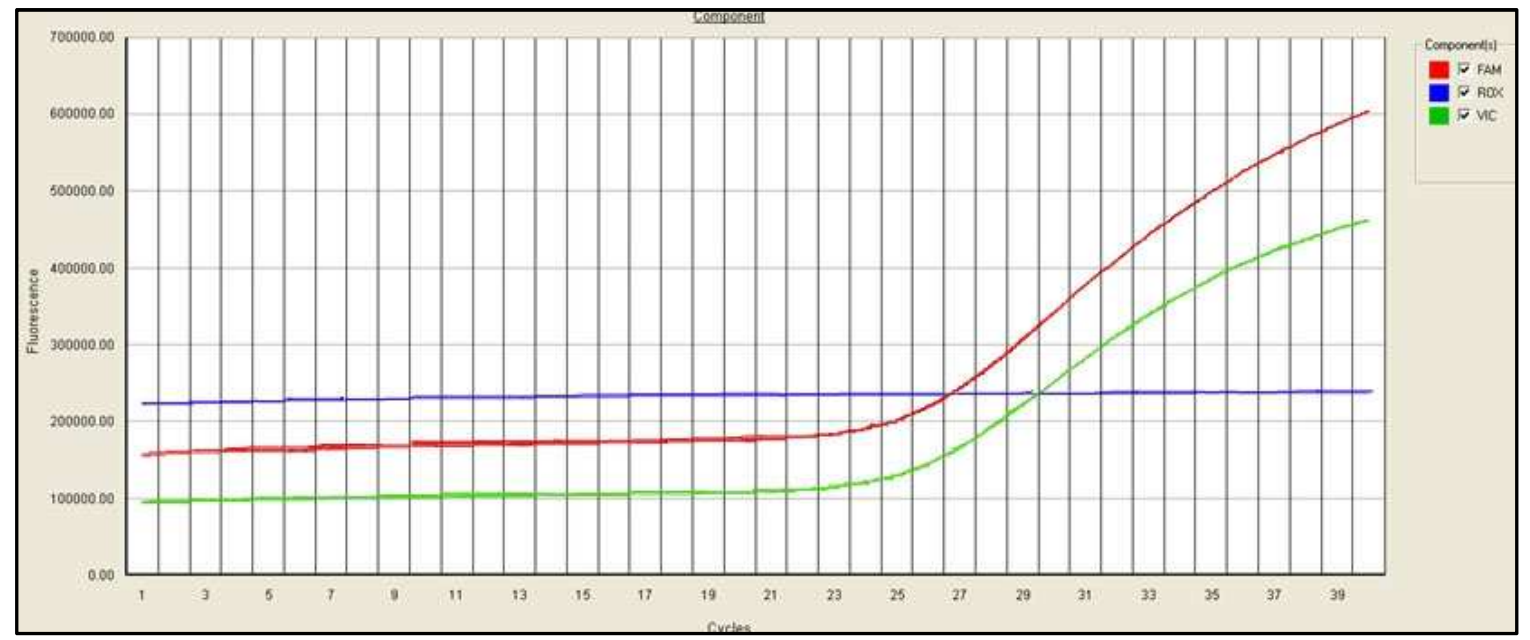

Figura 29 - Representação da curva de amplificação de uma amostra heterozigota CT para o polimorfismo -3402 C>T do gene CYP2C19, indicada segundo as fluorescências VIC e FAM crescentes.

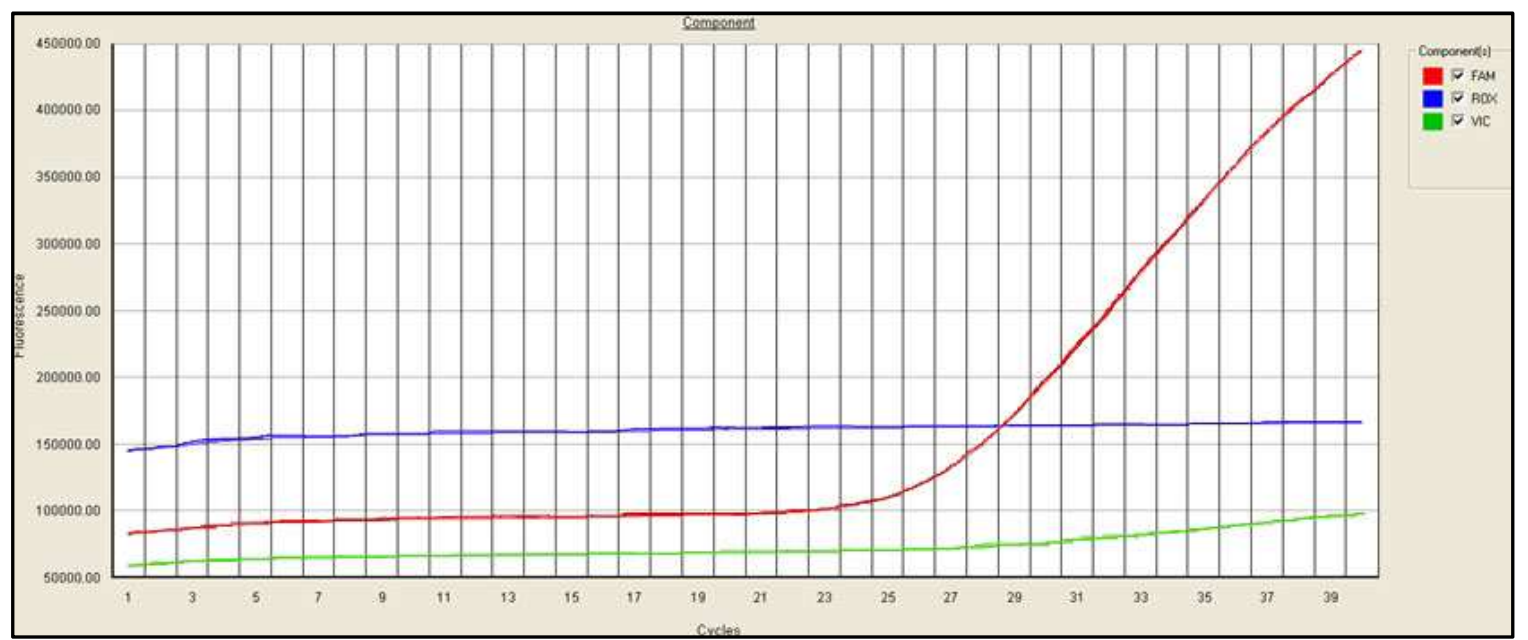

Figura 30 - Representação da curva de amplificação de uma amostra homozigota CC para o polimorfismo $100 \mathrm{C}>\mathrm{T}$ do gene CYP2D6, indicada segundo a fluorescência FAM crescente. 


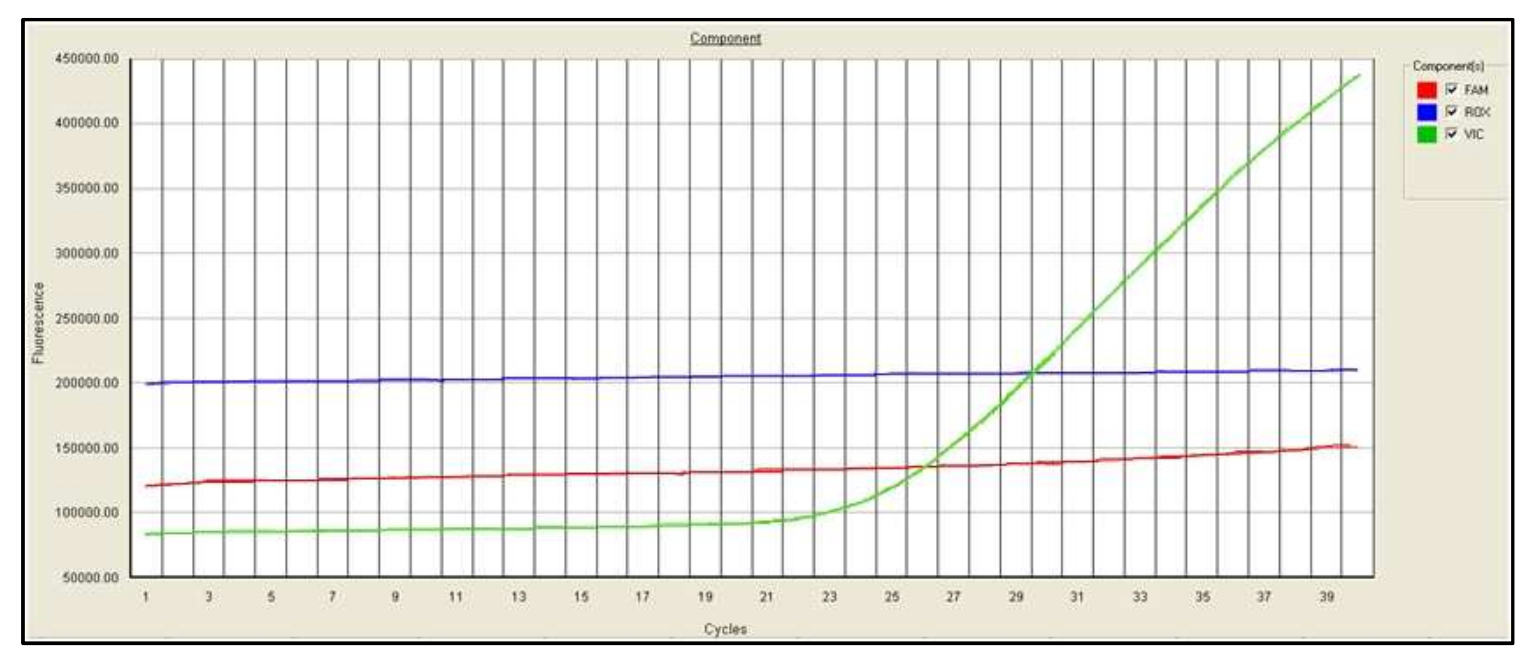

Figura 31 - Representação da curva de amplificação de uma amostra homozigota TT para o polimorfismo $100 \mathrm{C}>\mathrm{T}$ do gene CYP2D6, indicada segundo a fluorescência VIC crescente.

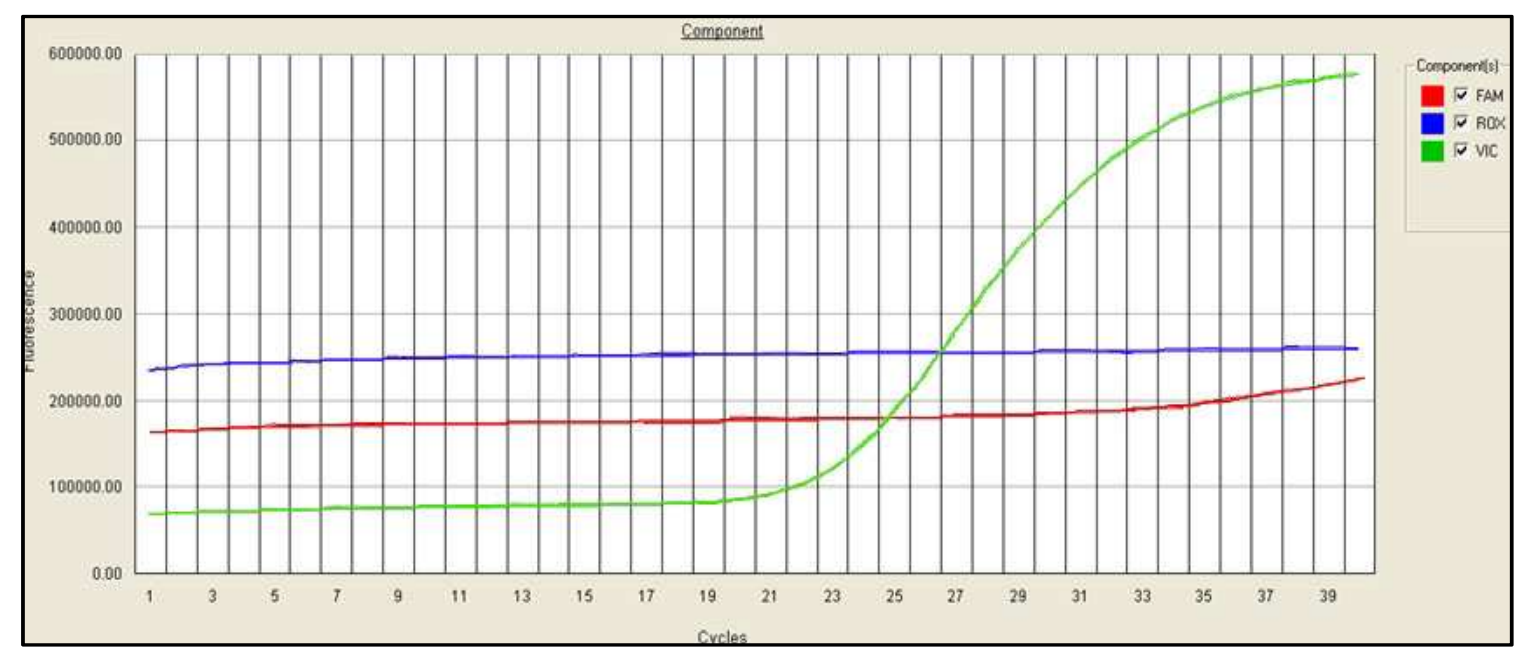

Figura 32 - Representação da curva de amplificação de uma amostra homozigota GG para o polimorfismo $31 \mathrm{G}>\mathrm{A}$ do gene CYP2D6, indicada segundo a fluorescência VIC crescente. 


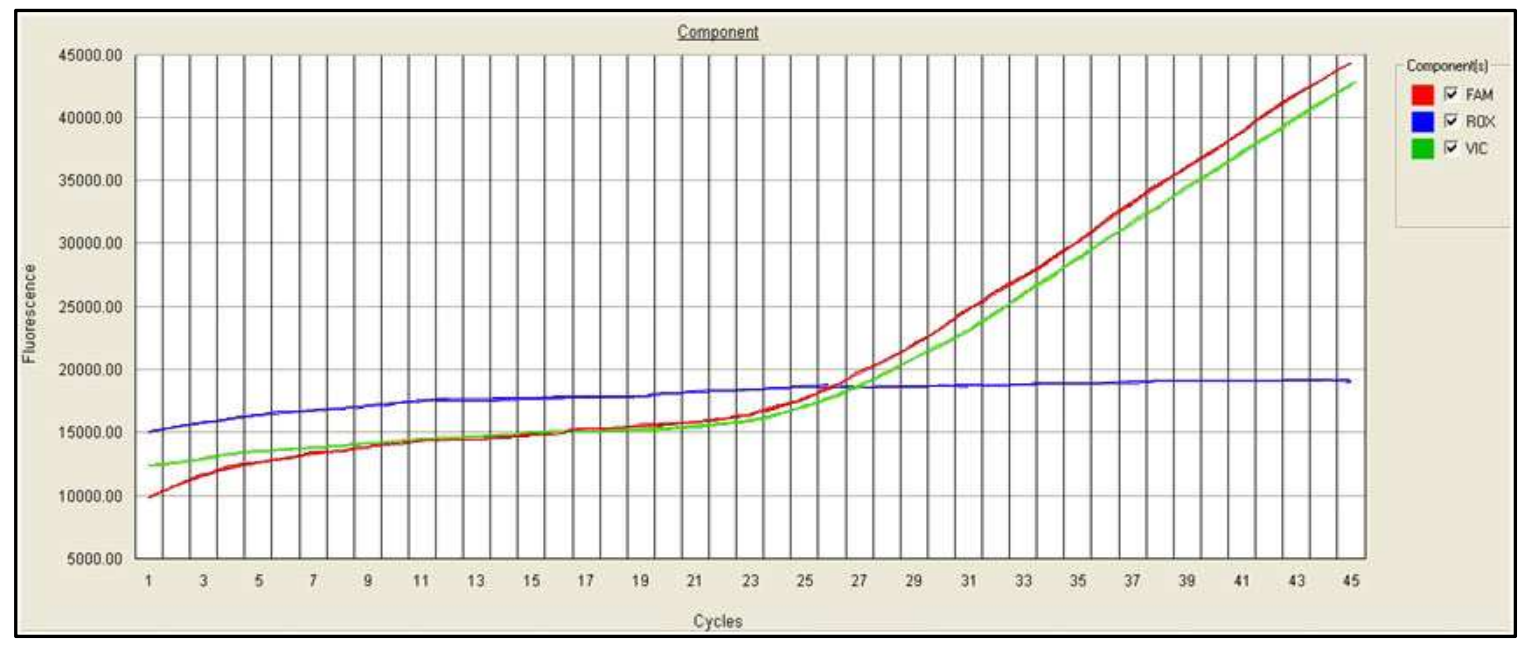

Figura 33 - Representação da curva de amplificação de uma amostra heterozigota $A>C$ para 0 polimorfismo $42614 \mathrm{~A}>\mathrm{C}$ do gene CYP2C9, indicada segundo as fluorescências VIC e FAM crescentes.

Também mostramos resultados (Figura 34) ilustrativos obtidos para o polimorfismo $4180 \mathrm{G}>\mathrm{C}$ do gene CYP2D6 analisados por meio da técnica de $P C R$ em tempo real para discriminação alélica.

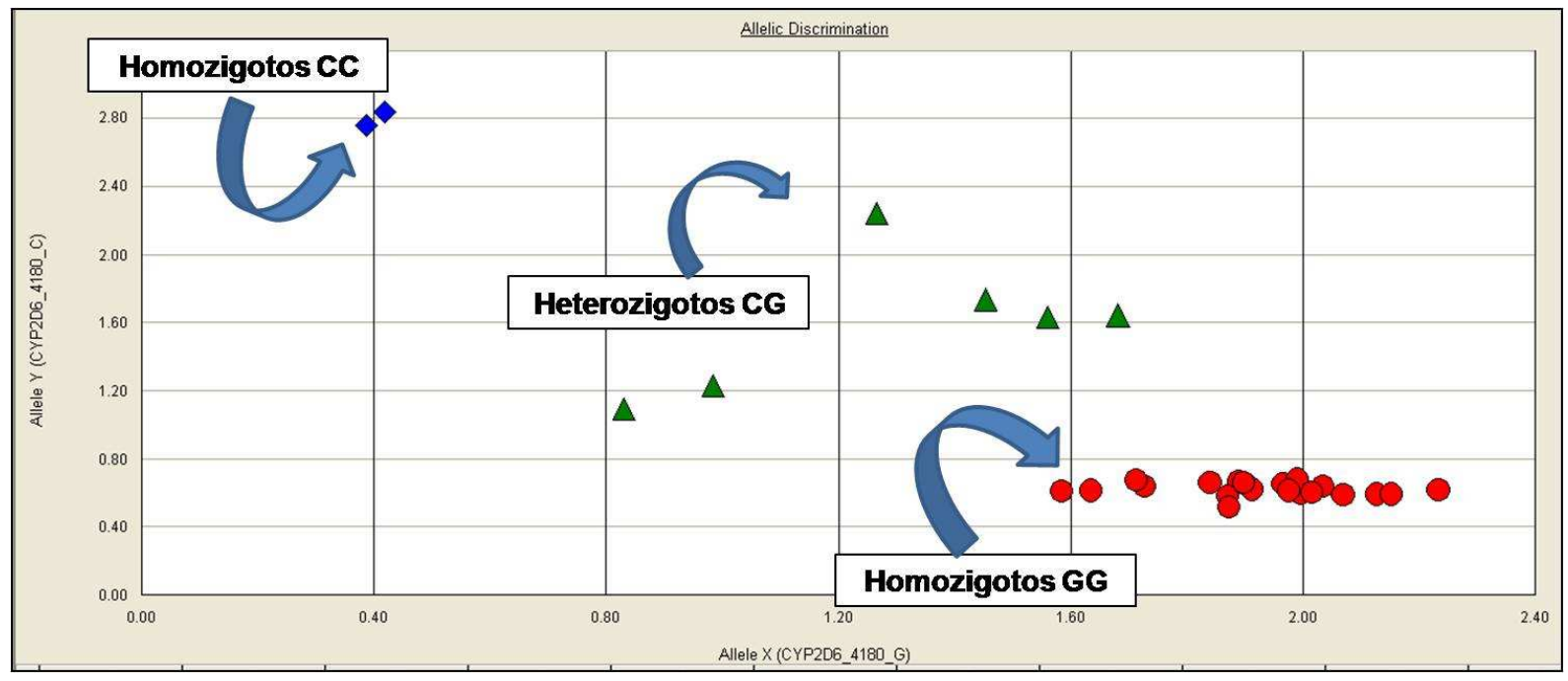

Figura 34 - Discriminação alélica. Gráfico de amostras analisadas para o polimorfismo 4180 G>C do gene CYP2D6. Os losangos indicam amostras homozigotas CC, triângulos amostras heterozigotas $\mathrm{G}>\mathrm{C}$ e círculos amostras homozigotas $\mathrm{G} G$. 


\subsection{Freqüências alélicas}

De um total de 198 indivíduos, 148 foram genotipados para o gene CYP2D6 (anexo A). Os alelos CYP2D6*1 e CYP2D6*2 foram os mais freqüentes em nossa amostra (39,2 e 17,2\% respectivamente), seguidos pelos alelos CYP2D6*4 (14,5\%), duplicações do gene (9,5\%), CYP2D6*41 (5,4\%), CYP2D6*35 (4,1\%), CYP2D6*17 (3,4\%), CYP2D6*5 (2,7\%), CYP2D6*10 (2,4\%), CYP2D6*6 (0,7\%), CYP2D6*29 $(0,7 \%)$ e CYP2D6*9 (0,3\%). Os alelos CYP2D6*3, CYP2D6*15, CYP2D6*39, CYP2D6*40 não foram encontrados nesse estudo (Tabela 7).

Tabela 7 - Freqüências alélicas identificadas em nossa amostra para o gene CYP2D6. Intervalo de confiança (IC) de 95\%.

\begin{tabular}{|c|c|c|c|}
\hline Alelo CYP2D6 & $\%$ & IC $95 \%$ & Número de alelos \\
\hline$* 1$ & 39,2 & $(33,6 ; 44,8)$ & 116 \\
\hline *2 & 17,2 & $(12,9 ; 21,5)$ & 51 \\
\hline *3 & 0,0 & --- & 0 \\
\hline$* 4$ & 14,5 & $(10,5 ; 18,5)$ & 43 \\
\hline$* 5$ & 2,7 & $(0,9 ; 4,6)$ & 8 \\
\hline$* 6$ & 0,7 & $(0,0 ; 1,6)$ & 2 \\
\hline$* 9$ & 0,3 & $(0,0 ; 1,0)$ & 1 \\
\hline$* 10$ & 2,4 & $(0,6 ; 4,1)$ & 7 \\
\hline$* 15$ & 0,0 & --- & 0 \\
\hline$* 17$ & 3,4 & $(1,3 ; 5,4)$ & 10 \\
\hline$* 29$ & 0,7 & $(0,0 ; 1,6)$ & 2 \\
\hline *35 & 4,1 & $(1,8 ; 6,3)$ & 12 \\
\hline *39 & 0,0 & --- & 0 \\
\hline$* 40$ & 0,0 & --- & 0 \\
\hline$* 41$ & 5,4 & $(2,8 ; 8,0)$ & 16 \\
\hline *duplicação & 9,5 & $(6,1 ; 12,8)$ & 28 \\
\hline Total & 100 & & 296 \\
\hline
\end{tabular}

NOTA: IC $95 \%=p \pm 1,96(p(1-p) / n)^{1 / 2}$, onde $p$ é a proporção do alelo observado.

De todas as amostras genotipadas, 14 delas foram classificadas como amplificadas para o gene CYP2D6. O genótipo amplificado com maior freqüência foi o CYP2D6*1 *2 ${ }^{*} N(42,9 \%)$, seguido dos genótipos CYP2D6*2 *2 $\times N(21,4 \%)$, 
CYP2D6*2 *10 x N (14,3\%), CYP2D6*1*10 xN (7,1\%), CYP2D6*2 *4 $4 N(7,1 \%) \mathrm{e}$ CYP2D6*2 *41 x $N(7,1 \%)$ (Tabela 8).

Tabela 8- Freqüências dos genótipos amplificados encontrados em nossa amostra. Intervalo de confiança (IC) de $95 \%$.

\begin{tabular}{c|c|c|c}
\hline $\begin{array}{c}\text { Alelos } \\
\text { amplificados }\end{array}$ & $\%$ & IC 95\% & $\begin{array}{c}\text { Número de } \\
\text { indivíduos }\end{array}$ \\
\hline$* 1 * 2 \times N$ & 42,9 & $(16,9 ; 68,8 \%)$ & 6 \\
\hline$* 2 * 2 \times N$ & 21,4 & $(0,0 ; 42,9)$ & 3 \\
\hline$* 2 * 10 \times N$ & 14,3 & $(0,0 ; 32,6)$ & 2 \\
\hline$* 1 * 10 \times N$ & 7,1 & $(0,0 ; 20,6)$ & 1 \\
\hline$* 2 * 4 \times N$ & 7,1 & $(0,0 ; 20,6)$ & 1 \\
\hline$* 2 * 41 \times N$ & 7,1 & $(0,0 ; 20,6)$ & 1 \\
\hline Total & 100 & & 14 \\
\hline
\end{tabular}

NOTA: IC $95 \%=p \pm 1,96(p(1-p) / n)^{1 / 2}$, onde $p$ é a proporção do alelo observado.

Para o gene CYP2C19 os 198 indivíduos (anexo B) foram genotipados, sendo o alelo CYP2C19*1 foi o mais frequente $(65,2 \%)$, seguido pelo alelo CYP2C19*17 (19,9\%), CYP2C19*2 (14,6\%) e CYP2C19*3 (0,3\%) (Tabela 9).

Tabela 9 - Freqüências alélicas identificadas em nossa amostra para o gene CYP2C19. Intervalo de confiança (IC) de 95\%.

\begin{tabular}{c|c|c|c}
\hline Alelo CYP2C19 & \% & IC 95\% & Número de alelos \\
\hline $\boldsymbol{*}^{1}$ & 65,2 & $(60,5 ; 69,8)$ & 258 \\
\hline${ }^{* 17}$ & 19,9 & $(16,0 ; 23,9)$ & 79 \\
\hline $\boldsymbol{*}^{2}$ & 14,6 & $(11,2 ; 18,1)$ & 58 \\
\hline $\boldsymbol{*}^{\mathbf{3}}$ & 0,3 & $(0,0 ; 0,7)$ & 1 \\
\hline Total & 100 & & 396 \\
\hline
\end{tabular}

NOTA: IC $95 \%=p \pm 1,96(p(1-p) / n)^{1 / 2}$, onde $p$ é a proporção do alelo observado.

Para o gene CYP2C9, 152 indivíduos foram genotipados, sendo o alelo CYP2C9*1 foi o mais frequente (86,8\%), seguido pelo alelo CYP2C9*2 $(9,2 \%)$ e CYP2C19*3 (3,9\%) (Tabela 10). 
Tabela 10 - Freqüências alélicas identificadas em nossa amostra para o gene CYP2C9. Intervalo de confiança (IC) de 95\%.

\begin{tabular}{c|c|c|c}
\hline Alelo CYP2C9 & \% & IC 95\% & Número de alelos \\
\hline $\mathbf{1}$ & 86,8 & $(83,0 ; 90,6)$ & 264 \\
\hline $\mathbf{2}$ & 9,2 & $(6,0 ; 12,5)$ & 28 \\
\hline $\mathbf{3}$ & 3,9 & $(1,8 ; 6,1)$ & 12 \\
\hline Total & 100 & & 304 \\
\hline
\end{tabular}

NOTA: IC $95 \%=p \pm 1,96(p(1-p) / n)^{1 / 2}$, onde $p$ é a proporção do alelo observado.

\subsection{Freqüências fenotípicas}

O fenótipo predito mais freqüente em nossa amostra para o gene CYP2D6 é o metabolizador extensivo (83,1\%) seguido dos fenótipos IM (6,1\%), UM (6,1\%), e PM $(4,7 \%)$ (Tabela 11).

Tabela 11 - Freqüências fenotípicas para CYP2D6 encontradas em nossa amostra. Intervalo de confiança (IC) de $95 \%$.

\begin{tabular}{c|c|c}
\hline Fenótipo predito & $\%$ (N) & IC 95\% \\
\hline EM & $83,1(123)$ & $(26,5 ; 35,6)$ \\
\hline IM & $6,1(9)$ & $(0,8 ; 3,7)$ \\
\hline PM & $4,7(7)$ & $(0,0 ; 3,1)$ \\
\hline UM & $6,1(9)$ & $(0,8 ; 3,7)$ \\
\hline Total & $100(148)$ & \\
\hline
\end{tabular}

NOTA: IC $95 \%=p \pm 1,96(p(1-p) / n)^{1 / 2}$, onde $p$ é a proporção do alelo observado.

Para o gene CYP2C19 (Tabela 12), o fenótipo mais freqüente encontrado em nossa amostra foi o EM (51,5\%), seguidos do heterozigoto UM (26,3\%), IM (16,2\%), PM $(3,0 \%)$ e UM $(3,0 \%)$. 
Tabela 12 - Freqüências fenotípicas para CYP2C19 encontradas em nossa amostra. Intervalo de confiança (IC) de 95\%.

\begin{tabular}{c|c|c}
\hline Fenótipo predito & \% (N) & IC 95\% \\
\hline EM & $51,5(102)$ & $(44,6 ; 58,5)$ \\
\hline UM het & $26,3(52)$ & $(20,1 ; 32,4)$ \\
\hline IM & $16,2(32)$ & $(11,0 ; 21,3)$ \\
\hline PM & $3,0(6)$ & $(0,6 ; 5,4)$ \\
\hline UM & $3,0(6)$ & $(0,6 ; 5,4)$ \\
\hline Total & $100(198)$ & \\
\hline
\end{tabular}

NOTA: IC $95 \%=p \pm 1,96(p(1-p) / n)^{1 / 2}$, onde $p$ é a proporção do alelo observado.

Para o gene CYP2C9 (Tabela 13), o fenótipo mais freqüente encontrado em nossa amostra foi o EM (77,0\%), seguidos do IM (19,7\%) e do PM (3,3\%).

Tabela 13 - Freqüências fenotípicas para CYP2C9 encontradas em nossa amostra. Intervalo de confiança (IC) de $95 \%$.

\begin{tabular}{c|c|c}
\hline Fenótipo predito & \% (N) & IC 95\% \\
\hline EM & $77,0(110)$ & $(33,0 ; 44,0)$ \\
\hline IM & $19,7(30)$ & $(6,5 ; 13,2)$ \\
\hline PM & $3,3(5)$ & $(0,2 ; 3,1)$ \\
\hline Total & $100(152)$ & \\
\hline
\end{tabular}

NOTA: IC $95 \%=p \pm 1,96(p(1-p) / n)^{1 / 2}$, onde $p$ é a proporção do alelo observado. 
A primeira geração de testes farmacogenômicos está disponível para a prática clínica e compreende atualmente (março/2009) e, de acordo com uma revisão extensiva da literatura feita por de Leon et al. (2008), cinco testes principais já comercializados ou prestes a serem comercializados.

Apenas o AmpliChip CYP 450 Test (Roche Molecular Systems Inc.), o qual utiliza tecnologia da Affymetrix, foi aprovado pelo FDA. Esse microarray contém cerca de 15.000 sondas e permite a análise de 20 alelos de CYP2D6, 7 duplicações de CYP2D6, além de 3 alelos para o CYP2C19. O teste não inclui o alelo CYP2C19*17, o qual é responsável pelo metabolismo ultra-rápido dos medicamentos metabolizados pela enzima CYP2C19.

O Luminex Tag-It ${ }^{T M}$ Mutation Detection Kit para CYP450 utiliza a plataforma de genotipagem universal baseada em microesferas do Luminex e detecta atualmente 7 alelos nulos para o CYP2C19 e identifica o genótipo de 12 alelos do CYP2D6, bem como rearranjos associados com deleções e duplicações do gene, e ainda, 5 variantes do CYP2C9.

Arranz et al. (2000) despertou um grande interesse quando desenvolveu um sistema que combinava a determinação de variantes dos genes dos receptores 5 HT2A (HTR2A), 5-HT2C (HTR2C) e H2 e também do transportador de serotonina 5HTT (SLC6A4) para a predição de resposta a clozapina. Essa foi a primeira tentativa de desenvolvimento de um teste de farmacogenética específico para a Psiquiatria. $O$ estudo STAR ${ }^{\star}$ (McMahon et al., 2006; Paddock et al., 2007; Perlis et al., 2008; Peters et al., 2008) e outros similares (Binder et al., 2006; Uhr et al., 2008) levaram a uma explosão de estudos de farmacogenética de antidepressivos. A genotipagem de receptores de serotonina e as variantes do transportador são oferecidos por 2 laboratórios nos Estados Unidos (Mayo Clinic Laboratory; Pathway Diagnostics), mas ainda não há literatura científica que suporte as associações encontradas com receptores de serotonina.

Posteriormente, foram desenvolvidos um teste para a predição de agranulocitose induzida pela clozapina, o PGxPredict ${ }^{T M}$ (PGxHealth, 2008) e um teste para predizer a síndrome metabólica, o PhyzioType (Genomas, 2008). O PGXPredict ${ }^{T M}$ identifica um polimorfismo (do tipo SNP) no íntron 4 do gene HLADQB1 $(6672 \mathrm{G}>\mathrm{C})$ associado com a agranulocitose induzida pela clozapina, onde 
portadores do genótipo GG teriam menor risco e os genótipos GC e CC teriam um risco maior (Athanasiou, in preparation).

Quando inicamos esse estudo, o kit P450 AmpliChip não estava disponível comercialmente e aqueles indivíduos que quisessem conhecer seus genótipos de CYP2D6 e CYP2C19 teriam que enviar suas amostras aos Estados Unidos.

O seqüenciamento direto é o padrão ao qual outras técnicas são comparadas porque ele pode detectar a maioria dos polimorfismos. Atualmente, a genotipagem das CYPs pode ser realizada por meio de inúmeros métodos sendo os mais usuais 0 microarray (como o P450 AmpliChip), PCR alelo específica, seqüenciamento direto e discriminação alélica com sistema $\operatorname{TaqMan}^{\circledR}$.

Como no caso do chip de Microarray que é um sistema de análise "fechado", este não permite a inclusão de novos alelos logo que eles são identificados. Um exemplo dessa limitação é o caso do alelo CYP2C19*17, responsável pelo metabolismo ultra-rápido de medicamentos e apresenta uma freqüência importante na população, e que ainda não foi incluído no chip de microarray.

O sistema desenvolvido em nosso estudo possibilita a inclusão de qualquer alelo assim que o mesmo é identificado. Este fato é considerado uma vantagem em relação à técnica de microarray. Outra vantagem é o preço inferior, o que proporciona acesso a um número maior de indivíduos.

Em função das desvantagens da determinação do índice metabólico e da indisponibilidade do P450 AmpliChip (Roche) no Brasil, necessitávamos de um método de genotipagem sensível, específico, rápido e com preços acessíveis, dada a importância dos genes CYP2D6, CYP2C19 e CYP2C9 no metabolismo dos medicamentos psicotrópicos e outros utilizados com freqüência no Brasil. Desse modo, padronizamos ensaios de genotipagem para o gene CYP2D6 (alelos *1, *2, ${ }^{*} 3,{ }^{*} 4,{ }^{*} 5,{ }^{*} 6,{ }^{*} 9,{ }^{*} 10,{ }^{*} 15,{ }^{*} 17,{ }^{*} 29,{ }^{*} 35,{ }^{*} 39,{ }^{*} 40,{ }^{*} 41$, além do número de cópias), CYP2C19 (alelos *1, *2, *3 e *17) e CYP2C9 (alelos *1, *2 e *3) em nosso laboratório, utilizando inicialmente a técnica de seqüenciamento direto, e posteriormente, $P C R$ em tempo real e discriminação alélica com o sistema TaqMan ${ }^{\circledR}$.

Iniciamos o estudo buscando (1) aqueles alelos com repercussões funcionais importantes e (2) também aqueles mais prevalentes no Brasil. Verificamos na literatura a variabilidade de freqüências alélicas nas populações estudadas. 
Encontramos apenas um estudo que utilizou uma amostra brasileira do Rio Grande do Sul (Kohalusch et al., 2008) e, portanto, havia uma carência de informações de freqüências alélicas para CYP2D6 e CYP2C19 em amostra brasileira. A freqüência alélica do gene CYP2C9 já havia sido determinada em uma amostra do Rio de Janeiro por Vianna et al. (2004).

Em princípio, as genotipagens foram determinadas por seqüenciamento direto dos produtos de PCR das seqüências-alvo para os genes CYP2D6, CYP2C19 e CYP2C9. A determinação do número de cópias seria investigada pela long-template $P C R$, com amplificação de todo o gene, cerca de $5 \mathrm{~Kb}$. O seqüenciamento nos auxiliou enormemente na identificação de homozigotos e heterozigotos para vários dos alelos encontrados em nossa população. A long-template PCR se mostrou pouco reprodutível na determinação dos indivíduos amplificados para o gene CYP2D6. Partimos, então, para a determinação dos genótipos e número de cópias utilizando o sistema TaqMan ${ }^{\circledR}$ (Applied Biosystems, Foster City, CA) no equipamento de PCR em tempo real. Essa metodologia se mostrou mais rápida, sensível e reprodutível. Durante a padronização do teste contamos com a preciosa colaboração do Dr. Ulrich M. Zanger, do Instituto de Farmacologia Clínica Dr. Margarete FischerBosch, Stuttgard, Alemanha, que respondeu prontamente à nossa solicitação e nos enviou amostras-controle para os alelos CYP2D6 ${ }^{*}{ }^{*} 2 x N,{ }^{*}{ }^{*} 2 x N$ e ${ }^{*} 2{ }^{*} 4 x N$, CYP2D6*1*1, CYP2D5*1*5 e CYP2D6*5*5.

Como já constatado por outros pesquisadores, a long template PCR apresenta desvantagens como a impossibilidade da determinação do exato número de cópias do gene CYP2D6. Além disso, esta técnica é muito trabalhosa, demorada o que a torna pouco eficiente quando se quer estudar um grande número de amostras (Meijerman et al., 2007).

Sendo assim, buscamos na literatura outros métodos para a determinação do $C N V$, já que a long template $P C R$ também se mostrou trabalhosa e pouco reprodutível. Fundamentados em dois estudos de padronização de metodologia para a determinação do $C N V$, por meio da técnica de $P C R$ em tempo real com o sistema $\operatorname{TaqMan}^{\circledR}$ (Schaeffeler et al., 2003; Bodin et al., 2005), decidimos utilizar a mesma metodologia em nosso estudo. Schaeffeler et al. (2003) validou sua metodologia com 64 amostras previamente genotipadas para o CNV de CYP2D6 e demonstrou 
que a técnica de $P C R$ em tempo real com o sistema $\operatorname{TaqMan}^{\circledR}$ é sensível e confiável. Bodin et al. (2005) comparou seus resultados obtidos com a sua metodologia com 43 amostras genotipadas previamente pelo método de Southern Blotting-RFLP e mostrou que o método é válido e reprodutível. Os métodos de Schaeffeler et al. (2003) e Bodin et al. (2005) diferem quanto à região de anelamento dos oligonucleotídeos e quanto ao uso de controle endógeno. Schaeffeler et al. (2003) utilizou a albumina como controle endógeno enquanto Bodin et al. (2005) utilizou o a RNAse $P$.

Em nosso estudo, desenvolvemos um método para o cálculo do número de cópias do gene CYP2D6 baseado nos ensaios desenvolvidos por Schaeffeler et al. (2003) e Bodin et al. (2005) que consiste em determinar o número de cópias do gene CYP2D 6 segundo um modelo de regressão logística multinomial.

O nosso modelo de regressão logística multinomial é baseado no cálculo do $2^{\triangle \Delta C T}$ (média do $2^{\Delta \Delta C T}$ dos três calibradores) de 9 amostras; 3 deletadas (1 cópia de gene CYP2D6), 3 amplificadas (3 ou mais cópias do gene CYP2D6) e 3 normais (2 cópias do gene CYP2D6) sendo que, as 3 amostras normais foram utilizadas como calibradores no cálculo do $2^{\Delta \Delta C T}$. Com base nestas 9 amostras, podemos considerar nosso modelo robusto por apresentar excelentes níveis de sensibilidade (e especificidade), classificando corretamente todas as amostras (100\% de acerto).

O modelo é baseado na probabilidade (99\%) da amostra ser classificada em algum grupo (deletado, normal ou amplificado). Diferentemente de outros métodos descritos (Schaeffeler et al., 2003; Bodin et al., 2005) que são baseados em valores de corte de médias do $2^{\Delta \Lambda C T}$ de amostras deletadas, amplificadas e normais, nosso método para o cálculo do $C N V$ é baseado na probabilidade.

Uma limitação existente é a impossibilidade de confirmar a especificidade do método para todas as outras amostras que não foram submetidas à long template $P C R$ (nas amostras que não são controles). Devido ao desconhecimento do genótipo, não é possível determinar a taxa de acerto para a classificação desses novos valores. Uma proposta futura para melhorar a precisão de nosso cálculo, é inserir no modelo mais amostras controles.

Ao se executar a reação de $C N V$, sempre analisávamos nas placas uma amostra sabidamente deletada e outra amplificada, para funcionar como uma 
espécie de controle da reação e até mesmo do modelo de regressão. Estas amostras sempre foram classificadas corretamente. Os DNAs utilizados para esse fim foram as amostras que tiveram seu resultado confirmado na long template PCR. (método de controle interno padronizado para esta reação). Quando estas amostras não eram classificadas corretamente, repetíamos a reação.

O uso da $P C R$ em tempo real, especialmente com o sistema TaqMan $^{\circledR}$ apresenta vantagens em comparação aos métodos mais tradicionais como Southerm Blotting e long template $P C R$, sendo mais rápido, menos trabalhoso, reprodutível e mais específico (Meijerman et al., 2007, Lee e Jeon, 2009). Entretanto, a determinação do CNV por meio do sistema TaqMan ${ }^{\circledR}$ ainda apresenta alguma limitação como a necessidade de bons controles e de um DNA de boa qualidade.

No decorrer do nosso estudo, pudemos observar que a qualidade da amostra de DNA interfere tanto no resultado do cálculo do CNV como no resultado da discriminação alélica pelo sistema $\operatorname{TaqMan}^{\circledR}$. Cukier et al. (2009), constatou que o DNA pode sofrer degradação em condições normais de armazenamento, causando um aumento do número de resultados errados de CNV. Desse modo, a necessidade de uma amostra íntegra e de boa qualidade para a determinação do CNV é imprescindível.

Ao se determinar as freqüências alélicas dos genes estudados, os resultados obtidos em nossa amostra para o gene CYP2D6 foram semelhantes às freqüências alélicas encontradas em outros estudos com diferentes populações: de 198 amostras; 148 indivíduos foram genotipados para o gene CYP2D6, os alelos CYP2D6 ${ }^{*} 1$ e CYP2D6*2 foram os mais freqüentes em nossa amostra amostra $(39,2$ e $17,2 \%$ respectivamente), seguidos pelos alelos CYP2D6*4 (14,5\%), duplicações do gene (9,5\%), CYP2D6*41 (5,4\%), CYP2D6*35 (4,1\%), CYP2D6*17 (3,4\%), CYP2D6*5 (2,7\%), CYP2D6*10 (2,4\%), CYP2D6*6 (0,7\%), CYP2D6*29 (0,7\%) e CYP2D6*9 (0,3\%). Os alelos CYP2D6*3, CYP2D6*15, CYP2D6*39, CYP2D6*40 não foram encontrados na amosra estudada.

Das duplicações do gene CYP2D6 encontradas em nossa amostra, os genótipos mais freqüentes foram $0{ }^{*} 1{ }^{*} 2 \times N(42,9 \%),{ }^{*} 2{ }^{*} 2 \times N(21,4 \%)$ e ${ }^{*}{ }^{*} 10 \times N$ 
(14,3\%). Encontramos uma freqüência de 7,1 \% para cada um dos genótipos *1 ${ }^{*} 10$ $\times N,{ }^{*} 2 * 4 \times N e{ }^{*} 2 * 41 \times N$.

Como o esperado, a freqüência dos alelos CYP2D6*1 e *2 em nossa amostra é superior a 50\%, dado este, de acordo com Sistonem, et al. (2007) que identificou estes alelos como os mais freqüentes e amplamente distribuídos em diferentes regiões do planeta. Bailliet et al. (2007) também identificou tais alelos como os mais freqüentes em nativos da Argentina e Paraguai estando presentes em ambas as populações, com freqüências de 39,9\% e 23,8\% respectivamente. Em um estudo realizado nos Estados Unidos, com uma amostra de 4532 pacientes psiquiátricos, composta por caucasianos e afro-americanos, de Leon et al. (2009) encontrou uma freqüência de $36,8 \%$ para o a alelo ${ }^{*} 1$ e $14,8 \%$ para o alelo *2. No Brasil, uma amostra de 186 indivíduos naturais do Rio Grande do Sul, também apresentou resultados parecidos: $38,4 \%$ para o alelo ${ }^{*} 1$ e $18,2 \%$ para o alelo *2 (Kohlausch et al., 2008). A freqüência encontrada para o alelo CYP2D6*4 em nossa amostra $(14,5 \%)$ também é semelhante à descrita por Kohlausch et al. (2008) sendo esta $13,2 \%$. Este alelo também apresenta uma freqüência de 17,8\% na Argentina e Paraguai (Bailliet et al., 2007). Na França e na Alemanha este alelo está presente em $18,9 \%$ da população (Sistonen et al., 2009). A freqüência do alelo *4 encontrada por de Leon et al. (2009) foi de 19,3\%. As duplicações do gene CYP2D6 tiveram uma freqüência de 9,5\% em nossa amostra, dado este, similar ao encontrado em populações do Oriente médio $(7,8 \%)$ e da África subsaariana (6,7\%) (Sistonen et al., 2007; Sistonen et al., 2009). Na região sul do Brasil, a freqüência das duplicações foi de 4,6\% (Kohlausch et al., 2008). O alelo IM CYP2D6*41 tem uma freqüência de $5,4 \%$ em nossa amostra, freqüência esta muito próxima da encontrada na região sul da Europa (4,5\%) (Sistonen et al., 2009). No Brasil a freqüência encontrada por Kohlausch et al. (2008) foi de 8,3\% enquanto que de em Kentuky, USA, a freqüência do alelo 41 foi de 10,3\% (de Leon et al., 2009). Para o alelo CYP2D6*17 encontramos uma freqüência de $3,4 \%$ na população estudada enquanto que Kohlausch et al. (2008) identificou uma freqüência de 1,3\% entretanto, a freqüência de nossa amostra para este alelo é similar à encontrada por de Leon et al. (2009) $(3,9 \%)$. Este alelo é muito comum em populações africanas onde sua freqüência pode chegar até 18,4\% (Sistonen et al., 2009). A deleção total do gene (CYP2D6*5) 
está presente em 2,7\% de nossa amostra, sendo semelhante à freqüência de 2,2\% encontrada na população estudada por Kohlausch et al. (2008) e a freqüência de 2,4\% encontrada por de Leon et al. (2009). O alelo CYP2D6*5 está presente em uma freqüência de 3,2\% na Europa e de 3,8\% na Ásia central (Sistonen et al., 2009). Em nossa amostra, a freqüência do alelo CYP2D6*10 $(2,4 \%)$ foi similar à encontrada por Kohlausch et al. (2008) (2,1\%). Este alelo é mais comum em populações asiáticas. Sua freqüência é de 38,6\% na China e no Japão (Sistonen et al., 2009; Kubota et al., 2000). Para ambos os alelos *6 e *29, a freqüência em nossa amostra foi de $0,7 \%$. Estes dois alelos estão presentes em 1,0 \% da amostra estudada por de Leon et al. (2009). Na população estudada por Kohlausch et al. (2008), o alelo *6 representa apenas $0,5 \%$ da amostra enquanto que o alelo *29 não foi identificado. 0 alelo *9 está presente em uma freqüência de 0,3\% em nossa amostra. de Leon et al. (2009) encontrou uma freqüência de 2,6\% para o alelo *9 e Kohlausch et al. (2008) encontrou $1,6 \%$ do alelo ${ }^{*} 9$. Para o alelo ${ }^{\star} 35$, Kohlausch et al. (2008) indentificou uma freqüência e 6,2\% em sua amostra, similar a freqüência encontrada em nosso estudo (6,3\%); para este mesmo alelo, de Leon encontrou uma freqüência de 4,4\% em sua população. Neste estudo não identificamos nenhum alelo CYP2D6*3 o que somente confirma o fato deste alelo ser raramente encontrado em populações não Européias e mesmo lá não atingem uma freqüência maior que 1\% (Sistonen et al., 2007). Os alelos CYP2D6*15, e CYP2D6*40 também foram investigados, mas não foram identificados em nossa amostra. O mesmo fato ocorreu com de Leon et al. (2009) que também não encontrou nenhum desses alelos em seu estudo. Contudo, na população estudada por Kohlausch et al. (2008), foram encontrados 1,6\% do alelo CYP2D6*15 e 0,5\% do alelo CYP2D6*40. Após a realização do teste Quiquadrado de Pearson, para a comparação das freqüências encontradas em nosso estudo e as encontradas por Kohlausch et al. (2008), verificamos que existe uma diferença significativa somente para a multiplicação do gene $(p<0,05)$ e para o alelo *15 $(p<0,05)$.

Das freqüências fenotípicas para o gene CYP2D6 encontradas na nossa amostra, a mais freqüente é o $\mathrm{EM}(83,1 \%)$ que é justificado pela elevada freqüência dos alelos *1 e *2. Este fenótipo é encontrado na maioria da população mundial 
(Sabbagh et al., 2006). Os fenótipos IM, UM e PM foram encontrados nas respectivas freqüências: $6,1 \% ; 6,1 \%$ e $4,7 \%$.

Após entrarmos em contato com pesquisadores com experiência em Farmacogenética, verificamos que nosso trabalho foi o primeiro a identificar as freqüências alélicas do gene CYP2C19 no Brasil. Em nossa amostra de 198 indivíduos genotipados, o alelo $C Y P 2 C 19 * 1$ é o mais freqüente $(62,5 \%)$, seguido pelo alelo CYP2C19*17 (19,9\%) e pelo alelo CYP2C19*2 (14,6\%). O alelo CYP2C19*3 foi encontrado em apenas uma amostra (0,3\%). As freqüências encontradas em nossa amostra são similares às encontradas na Noruega: 59,3\%; $18,1 \%, 0,6 \%$ e $22,0 \%$ para os alelos * 1 , *2, *3 e*17 respectivamente (Rudberg et al., 2008). O teste Qui-quadrado de Pearson foi realizado para a comparação das freqüências encontradas em nosso estudo e as encontradas por Ragia et. al.(2009), na Grécia, em 238 indivíduos (67,3\%; 13,0\%, 0 e 19,6\% para os alelos *1, *2, *3 $e^{* 17}$ respectivamente). Não houve diferença significativa $(p=0,567)$ entre as freqüências alélicas das duas amostras. O alelo *3 é comum em japoneses com uma freqüência de 12,8\%, e o alelo *17 é raramente encontrado (1,3\%) (Suginoto et al., 2008). A freqüência do alelo de atividade aumentada *17 em suecos e etíopes é de 18\% (Sim et al., 2006). O alelo *2 é freqüente no sul da Europa (13,3\%), sul da África $(21,7 \%)$ e América Central (9,7\%); nessas populações, o alelo *3 está presente em freqüências menores que 1\% (Sistonen et al., 2009).

Devido a recente descoberta do alelo UM CYP2C19*17 (Sim et al., 2006), a determinação da atividade enzimática predita para as combinações alélicas de CYP2C19 ainda é controversa. No geral, o fenótipo de resposta ao medicamento é realizado segundo a medida do índice metabólico de uma droga teste (Justenhoven et al., 2008). A literatura ainda não disponibilizou modelos confiáveis de resposta ao medicamento (como os que já existem para CYP2D6). Desse modo, para a determinação da freqüência fenotípica nos baseamos na classificação proposta por Ragia et al. (2009). Ele genotipou 238 gregos e encontrou as seguintes freqüências fenotípicas: EM (48,41\%), IM (17,67\%), PM (2,12\%), heterozigoto UM (28,62\%) e UM $(3,18 \%)$. As freqüências encontradas em nossa amostra são bastante similares sendo EM o fenótipo mais freqüente encontrado $(51,5 \%)$, seguidos do heterozigoto UM (26,3\%), IM (16,2\%), PM (3,0\%) e UM (3,0\%). 
Para o gene CYP2C9, as freqüências alélicas encontradas em nosso estudo foram semelhantes às descritas em estudos prévios no Brasil. Em 152 amostras genotipadas, o alelo * 1 foi o mais freqüente $(86,8 \%)$, seguido dos alelos ${ }^{*} 2(9,2 \%)$ e *3 (3,9\%). No Brasil, Vianna et al. (2004), genotipou 662 indivíduos e encontrou as seguintes freqüências: $84,9 \%$ para o alelo *1, 8,6\% para o alelo *2 e 6,5\% para o *3. Outro estudo realizado no Brasil, Perini et al. (2008), encontrou os alelos *2 e *3 em $11,8 \%$ e 5,4\% respectivamente, na amostra estudada. Após a realização do teste Qui-quadrado de Pearson, constatamos que não existe diferença entre os freqüências encontradas em nosso estudo e as encontradas por Vianna et al. (2004) $(p=0,279)$.

Para o gene CYP2C9, o fenótipo mais freqüente encontrado em nossa amostra foi o EM (77,0\%), seguidos do IM (19,7\%) e do PM (3,3\%). Scott et al. (2007), genotipou 250 indivíduos de encontrou as seguintes freqüências fenotípicas: $60,8 \%$ EMs, $32,8 \%$ IMs e $6,4 \%$ PMs.

Outro método freqüentemente utilizado para a determinação do fenótipo é o índice metabólico (MR) entre o medicamento não metabolizado e seu metabólito que é calculado depois da quantificação de ambos os compostos por uma técnica analítica como HPLC (high-performance liquid chormatography).

A fenotipagem é utilizada para determinar o efeito de um determinado polimorfismo in vitro ou in vivo. Para o gene CYP2C9, algumas substâncias-teste foram descritas como diclofenaco, tolbutamida; e para o gene CYP2C19, mefenitoína e omeprazol. Para a fenotipagem de CYP2D6, debrisoquina, esparteína e dextrametorfano são utilizados como substâncias-teste. (Frank et al., 2007; Sin et al., 2007; Black et al., 2007).

Contudo, uma determinação confiável do fenótipo pode ser comprometida pela habilidade de certos medicamentos e outras substâncias inibirem ou induzirem a enzima. (Bernard et al., 2006) ou por fatores como presença de alguma doença hepática ou renal (Gaedigk et al., 2008). Segundo Borges et al. (2005), a associação do índice metabólico do dextrametorfano com seu metabólito, medidos na urina ou no plasma ainda é contraditória.

Um exemplo de interferência na fenotipagem é o caso da enzima CYP2D6 que é inibida por algumas substâncias e que apresenta uma alta afinidade pelo 
substrato sendo facilmente saturada por ele. Nestes casos, a metabolização da substância teste pode ser reduzida, chegando até mesmo a mudar o fenótipo do indivíduo de EM para PM (Bernard et al., 2006).

Para Black et al. (2007), a fenotipagem e genotipagem das CYPs são procedimentos complementares na análise da função dos alelos. A fenotipagem é um processo relativamente simples, entretanto, os resultados podem ser influenciados tanto pelo genótipo quanto por fatores ambientais ou a utilização de substâncias indutoras ou inibidoras da atividade enzimática. Contudo, podem existir diferenças na fenotipagem relativas à substância teste utilizada. Além do mais, quando muitas isoformas das CYPs estão envolvidas na depuração da substância, a determinação acurada da depuração por uma isoforma específica é comprometida. A genotipagem mostra uma análise definitiva do status de metabolização do indivíduo, e pode ser realizada utilizando uma variedade de técnicas. Historicamente, a genotipagem pode ser realizada por meio de técnicas como RFLP (restriction fragment length polymorphisms) seguida de Southerm blotting ou eletroforese de fragmentos de DNA obtidos com a PCR.

A predição do genótipo de CYP2D6 é sobretudo proposta para individualizar a terapia medicamentosa. Esquemas de doses baseadas no genótipo já foram desenvolvidos e propostas para os tratamentos com antidepressivos e antipsicóticos. Estes esquemas são baseados na distinção dos genótipos PMs UMs, IM, e EMs. Dependendo do impacto da atividade enzimática da CYP2D6 no metabolismo de uma droga especifica, a dose recomendada para PMs pode ser 30 a $70 \%$ menor que a dose usual ou no caso de UMs, a dose pode ser 130 a $180 \%$ mais elevada (Maier et al., 2008). Outra conseqüência prática na identificação de genótipos PMs, tanto para CYP2D6 quanto para CYP2C19, é a escolha de medicamentos que não são metabolizados por estas enzimas.

De acordo com Maier et al. (2008), a identificação das variações alélicas que influenciam a atividade enzimática são relevantes para tratamentos em que mais de um medicamento é necessário e quando estes interagem com as enzimas CYP2D6 e CYP2C19. Como o caso dos SSRIs fluoxetina e a paroxetina que inibem a atividade enzimática da CYP2D6. 
Os ADRs associados ao tratamento com nortriptilina, um TCA metabolizado via CYP2D6, incluem boca seca, taquicardia, constipação, sedação, hipotensão ortostática. Estes ADRs geralmente estão relacionados a concentrações tóxicas dos TCAs (Lee et al., 2004). Pacientes que apresentam os genótipos PM podem apresentar severos ADRs devido a alta concentração plasmática de nortriptilina e UMs podem não apresentar resposta devido ao rápido metabolismo da droga. Lee et al. (2004) relatou o caso de um paciente que apresentava o genótipo CYP2D6*5/CYP2D6*10 que provoca um fenótipo IM. Para este paciente, o tratamento com doses preconizadas de nortriptilina (100 mg/dia) por um mês, levou a um nível plasmático tóxico provocando ADRs como tontura, constipação, dentre outros. Após a genotipagem, a dose de nortriptilina foi reduzida a $50 \mathrm{mg} / \mathrm{dia}$. $\mathrm{O}$ paciente relatou melhora de seu estado depressivo e diminuição dos ADRs.

A Amitriptilina é metabolizada em seu metabólito ativo nortriptilina via CYP2C19. E, a nortriptilina metabolizada pela CYP2D6. Para a nortriptilina, a não adesão à terapia e o surgimento de ADRs está associado ao genótipo PM de CYP2D6 e a falha terapêutica é mais freqüente em UMs devido à concentração plasmática abaixo no nível terapêutico (Thuerauf, 2006).

Steimer et al. (2005), estudou 50 pacientes diagnosticados com Depressão Maior tratados com amitriptilina e constatou que a genotipagem para CYP2D6 e CYP2C19 pode correlacionar o genótipo-fenótipo com o surgimento de ADRs em pacientes que possuem 2 ou apenas 1 alelo funcional para esses genes, apresentando um grande impacto na relação custo-benefício do tratamento.

A fluoxetina é uma mistura racêmica de S- e R-fluoxetina que, é metabolizada pela CYP2D6 em R/S-norfluoxetina. A dose inicial de fluoxetina para pacientes PMs deve ser $70 \%$ menor que a dose usual (Thuerauf, 2006).

O TCA imipramina é metabolizado principalmente pelas enzimas CYP2D6 e CYP2C19. Schenk et al. (2007), estudou os principais alelos PMs de CYP2D6 e CYP2C19 além dos alelos IM para CYP2D6 em 181 pacientes com Depressão Maior tratados com imipramina. Este estudo constatou que os níveis plasmáticos do metabólito desimipramina e da imipramina eram diferentes nos quatro fenótipos de CYP2D6 e para PMs de CYP2C19. O autor sugere que o conhecimento do genótipo do indivíduo pode predizer o resultado do tratamento, permitindo que os ajustes de 
dose sejam realizados, evitando assim $A D R s$ ou atraso na recuperação que levaria a uma hospitalização prolongada.

$\mathrm{Na}$ Alemanha, Rau et al. (2004), investigaram 200 pacientes com a finalidade de estabelecer a relação de ADRs após administração de antidepressivos metabolizados pela CYP2D6 em pacientes que possuíam um genótipo PM ou IM. Estes eram tratados com a dose máxima diária do medicamento recomendada pelo fabricante. Nos pacientes que apresentaram $A D R s$, a freqüência do genótipo PM era quatro vezes maior do que a apresentada na população alemã, sugerindo assim, uma associação do fenótipo PM com o aumento da ocorrência de $A D R s$. Os $A D R s$ foram responsáveis pela interrupção do tratamento de aproximadamente $80 \%$ dos pacientes. Também foi encontrada uma associação do fenótipo UM com propensão à falha terapêutica.

$\mathrm{Na}$ Holanda existe um grupo (KNMP - Royal Dutch Society for the Advancement of Pharmacy) cuja finalidade é oferecer recomendações de doses baseadas na farmacogenética, segundo uma revisão sistemática da literatura, integrando estas recomendações em um sistema computadorizado de prescrição de medicamento e farmacovigilância. As recomendações de dose estão disponíveis aos clínicos para o tratamento de pacientes genotipados. Este sistema inclui os genes CYP2D6, CYP2C19 e CYP2C9 (Swen et al., 2008).

Quando o medicamento é adequadamente estudado e a contribuição de cada isoforma das enzimas do citocromo para seu metabolismo é conhecida, torna-se possível, com a genotipagem, predizer o fenótipo do indivíduo e dividi-lo em categorias. Entretanto, o genótipo sozinho não explica toda a variação no metabolismo do medicamento porque, muitas substâncias podem induzir ou inibir a atividade enzimática das CYPs.

Segundo Black et al. (2007), a divisão em categorias fenotípicas não reflete cuidadosamente $\mathrm{o}$ fato de alguns alelos apresentam uma variada atividade dependendo do medicamento envolvido no metabolismo ou seja, alelos podem ter influências diferentes sob determinados substratos. A contribuição relativa de cada enzima no metabolismo de um determinado fármaco in vivo ainda deve ser determinada. Estudos clínicos de indivíduos com genótipos específicos ou estudos utilizando inibidores de CYPs específicas serão necessários a menos que modelos 
in silico possam ser desenvolvidos e validados. A aceitação da genotipagem pelos clínicos ainda é pouca devido a alguns fatores como: insuficiente evidência baseada em pesquisas, incerteza de que o teste trará algum benefício econômico, insegurança na interpretação de resultados da genotipagem principalmente com mais de dois genes (Black et al., 2007).

Acreditamos que a utilização dos genótipos de CYP2D6, CYP2C19 e CYP2C9 para predizer a dose ideal de um medicamento em psiquiatria ainda é precoce. Mas acreditamos também que a determinação dos genótipos pode trazer benefícios clínicos ao identificar os metabolizadores lentos, que muitas vezes abandonam o tratamento por não suportar os $A D R s$ causados pelo medicamento $\mathrm{e}$ também na identificação dos metabolizadores rápidos que não precisariam mais esperar 4 semanas para terem sua resposta a um antidepressivo identificada. Aproximamos, assim, a 'bancada' do 'leito' e caminhamos em direção à medicina personalizada. 
7 CONCLUSÃO 
Com este projeto, conseguimos desenvolver uma nova metodologia reprodutível e acessível para a genotipagem dos polimorfismos principais dos genes CYP2D6, CYP2C19 e CYP2C9 em nosso laboratório, além da determinação do número de cópias do gene CYP2D6.

Foram avaliados no total 23 alelos para os 3 genes e identificamos as freqüências de cada um deles em nossa população (HC-FMUSP). 


\section{REFERÊNCIAS BIBLIOGRÁFICAS ${ }^{\star 1}$}

Altschul SF, Gish W, Miller W, Myers EW, Lipman DJ. Basic local alignment search tool. J Mol Biol. 1990 Oct 5;215(3):403-10.

Arranz MJ, Bolonna AA, Munro J, Curtis CJ, Collier DA, Kerwin RW. The serotonin transporter and clozapine response. Mol Psychiatry. 2000 Mar;5(2):124-5

Bailliet G, Santos MR, Alfaro EL, Dipierri JE, Demarchi DA, Carnese FR, Bianchi NO. Allele and genotype frequencies of metabolic genes in Native Americans from Argentina and Paraguay. Mutat Res. 2007 Mar;5;627(2):171-7.

Bernard S, Neville KA, Nguyen AT, Flockhart DA. Interethnic differences in genetic polymorphisms of CYP2D6 in the U.S. population: clinical implications. Oncologist. 2006 Feb;11(2):126-35.

Bertilsson L, Aberg-Wistedt A, Gustafsson LL, Nordin C. Extremely rapid hydroxylation of debrisoquine: a case report with implication for treatment with nortriptyline and other tricyclic antidepressants. Ther Drug Monit. 1985;7(4):478-80.

Bertilsson L. Metabolism of antidepressant and neuroleptic drugs by cytochrome p450s: clinical and interethnic aspects. Clin Pharmacol Ther. 2007 Nov;82(5):606-9.

Beverage JN, Sissung TM, Sion AM, Danesi R, Figg WD. CYP2D6 polymorphisms and the impact on tamoxifen therapy. J Pharm Sci. 2007 Sep;96 (9):2224-31.

Binder EB, Holsboer F. Pharmacogenomics and antidepressant drugs. Ann Med. 2006;38(2):82-94.

Black JL 3rd, O'Kane DJ, Mrazek DA. The impact of CYP allelic variation on antidepressant metabolism: a review. Expert Opin Drug Metab Toxicol. 2007 Feb;3(1):21-31.

Bodin L, Beaune PH, Loriot MA. Determination of cytochrome P450 2D6 (CYP2D6) gene copy number by real-time quantitative PCR. J Biomed Biotechnol. 2005 Mar;(3):248-53.

\footnotetext{
"De acordo com:
}

International Committee of Medical Journal Editors. Uniform requirements for manuscripts submitted to Biomedical Journal: sample references. Available from: http://www.icmje.org [2007 May 22]. 
Borges S, Desta Z, Li L, Skaar TC, Ward BA, Nguyen A, Jin Y, Storniolo AM, Nikoloff DM, Wu L, Hillman G, Hayes DF, Stearns V, Flockhart DA. Quantitative effect of CYP2D6 genotype and inhibitors on tamoxifen metabolism: implication for optimization of breast cancer treatment. Clin Pharmacol Ther. 2006 Jul; 80(1):61-74.

Borges S, Li L, Ha mman MA, Jones DR, Hall SD, Gorski JC. Dextromethorphan to dextrorphan urinary metabolic ratio does not reflect dextromethorphan oral clearance. Drug Metab Dispos. 2005 Jul;33(7):1052-5.

Brockmöller J, Tzvetkov MV. Pharmacogenetics: data, concepts and tools to improve drug discovery and drug treatment. Eur J Clin Pharmacol. 2008 Feb;64(2):133-57.

Brøsen K. Some aspects of genetic polymorphism in the biotransformation of antidepressants. Therapie. 2004 Jan-Feb;59(1):5-12.

Brunton LL, Parker KL, editors. Goodman \& Gilman's: Manual of Pharmacology and Therapeutics. McGraw Hill, 2008.

Chen L, Qin S, Xie J, Tang J, Yang L, Shen W, Zhao X, Du J, He G, Feng G, He L, Xing Q. Genetic polymorphism analysis of CYP2C19 in Chinese Han populations from different geographic areas of mainland China. Pharmacogenomics. 2008 Jun;9(6):691-702.

Clayton TA, Lindon JC, Cloarec O, Antti H, Charuel C, Hanton G, Provost JP, Le Net JL, Baker D, Walley RJ, Everett JR, Nicholson JK. Pharmaco-metabonomic phenotyping and personalized drug treatment. Nature. 2006 Apr; 20;440(7087):10737.

Cukier HN, Pericak-Vance MA, Gilbert JR, Hedges DJ. Sample degradation leads to false-positive copy number variation calls in multiplex real-time polymerase chain reaction assays. Anal Biochem. 2009 Mar 15;386(2):288-90. Epub 2008 Dec 7

de Leon J, Susce MT, Johnson M, Hardin M, Maw L, Shao A, Allen AC, Chiafari FA, Hillman G, Nikoloff DM. DNA microarray technology in the clinical environment: the AmpliChip CYP450 test for CYP2D6 and CYP2C19 genotyping. CNS Spectr. 2009 Jan;14(1):19-34.

Dorado P, Berecz R, Peñas-Lledó EM, Llerena A. Antipsychotic drugs and QTc prolongation: the potential role of CYP2D6 genetic polymorphism. Expert Opin Drug Metab Toxicol. 2007 Feb;3(1):9-19.

Eichelbaum M, Ingelman-Sundberg M, Evans WE. Pharmacogenomics and individualized drug therapy. Annu Rev Med. 2006 Feb; 57:119-37. 
Eichelbaum M, Spannbrucker N, Steincke B, Dengler HJ. Defective N-oxidation of sparteine in man: a new pharmacogenetic defect. Eur J Clin Pharmacol. 1979 Sep;16(3):183-7

Enson HM, Chang TK, Patel P. Pharmacogenetics: the therapeutic drug monitoring of the future? Clin Pharmacokinet. 2001;40(11):783-802.

Frank D, Jaehde U, Fuhr U. Evaluation of probe drugs and pharmacokinetic metrics for CYP2D6 phenotyping. Eur J Clin Pharmacol. 2007 Apr;63(4):321-33.

Furuta $T$, Shirai $N$, Kodaira $M$, Sugimoto $M$, Nogaki $A$, Kuriyama $S$, Iwaizumi $M$, Yamade M, Terakawa I, Ohashi K, Ishizaki T, Hishida A. Pharmacogenomics-based tailored versus standard therapeutic regimen for eradication of $\mathrm{H}$. pylori. Clin Pharmacol Ther. 2007 Apr;81(4):521-8.

Gaedigk A, Simon SD, Pearce RE, Bradford LD, Kennedy MJ, Leeder JS. The CYP2D6 activity score: translating genotype information into a qualitative measure of phenotype. Clin Pharmacol Ther. 2008 Feb;83(2):234-42.

Goetz MP, Kamal A, Ames MM. Tamoxifen pharmacogenomics: the role of CYP2D6 as a predictor of drug response. Clin Pharmacol Ther. 2008 Jan; 83(1):160-6.

Hang HP, Dale MM, Ritter JM, Moore PK. Farmacologia. 5 ed. São Paulo: Elsevier; 2003.

Hersberger M, Marti-Jaun J, Rentsch K, Hänseler E. Rapid detection of the CYP2D6*3, CYP2D6*4, and CYP2D6*6 alleles by tetra-primer PCR and of the CYP2D6*5 allele by multiplex long PCR. Clin Chem. 2000 Aug;46(8 Pt 1):1072-7.

Hines RN, Koukouritaki SB, Poch MT, Stephens MC. Regulatory polymorphisms and their contribution to interindividual differences in the expression of enzymes influencing drug and toxicant disposition. Drug Metab Rev. 2008 Apr;40(2):263-301.

Hinrichs JW, Smallegoor WD, van Baalen-Benedek EH, Welker C, van der Weide J. Detection of CYP2D6 polymorphisms ${ }^{*}$, ${ }^{*} 10$, and ${ }^{*} 41$ using ARMS-PCR and their allelic frequencies in 400 psychiatric patients.Clin Chem Lab Med. 2007 Apr;45(4):555-7.

Hulot JS, Bura A, Villard E, Azizi M, Remones V, Goyenvalle C, Aiach M, Lechat P, Gaussem P. Cytochrome P450 2C19 loss-of-function polymorphism is a major determinant of clopidogrel responsiveness in healthy subjects. Blood. 2006 Oct $1 ; 108(7): 2244-7$. 
Ingelman-Sundberg M, Daly AK, Nebert DW. Home Page of the Human Cytochrome P450 (CYP) Allele Nomenclature Commitee. Avaliable from: http://www.cypalleles.ki.se/ [2009 Nov 09].

Ingelman-Sundberg M, Sim SC, Gomez A, Rodriguez-Antona C. Influence of cytochrome P450 polymorphisms on drug therapies: pharmacogenetic, pharmacoepigenetic and clinical aspects. Pharmacol Ther. 2007 Dec; 116(3):496526.

Ingelman-Sundberg M. Genetic polymorphisms of cytochrome P450 2D6 (CYP2D6): clinical consequences, evolutionary aspects and functional diversity. Pharmacogenomics J. 2005;5(1):6-13.

Ingelman-Sundberg M. Pharmacogenetics of cytochrome P450 and its applications in drug therapy: the past, present and future. Trends Pharmacol Sci. 2004 Apr;25(4):193-200.

Inomata S, Nagashima A, Itagaki F, Homma M, Nishimura M, Osaka Y, Okuyama K, Tanaka E, Nakamura T, Kohda Y, Naito S, Miyabe M, Toyooka H. CYP2C19 genotype affects diazepam pharmacokinetics and emergence from general anesthesia. Clin Pharmacol Ther. 2005 Dec;78(6):647-55.

Ito Y, Kondo H, Goldfarb PS, Lewis DF. Analysis of CYP2D6 substrate interactions by computational methods. J Mol Graph Model. 2008 Feb;26(6):947-56.

Jin, $Y$ et al. CYP2D6 genotype, antidepressant use, and tamoxifen metabolism during agjuvant breast cancer treatment. J Natl Cancer Inst. 2005 Jan;97; 30-39.

Johansson I, Lundqvist E, Bertilsson L, Dahl ML, Sjöqvist F, Ingelman-Sundberg M. Inherited amplification of an active gene in the cytochrome P450 CYP2D locus as a cause of ultrarapid metabolism of debrisoquine. Proc Natl Acad Sci U S A. 1993 Dec; 15;90(24):11825-9.

Johansson I, Lundqvist E, Dahl ML, Ingelman-Sundberg M. PCR-based genotyping for duplicated and deleted CYP2D6 genes. Pharmacogenetics. 1996 Aug;6(4):351-5.

Jorgensen A, Alfirevic A. Pharmacogenetics and pharmacogenomics: adverse drug reactions. Pharmacogenomics. 2008 Oct;9(10):1397-401.

Justenhoven C, Hamann U, Pierl CB, Baisch C, Harth V, Rabstein S, Spickenheuer A, Pesch B, Brüning T, Winter S, Ko YD, Brauch H. CYP2C19*17 is associated with decreased breast cancer risk. Breast Cancer Res Treat. 2009 May;115(2):391-6. Epub 2008 Jun 3. 
Kerb R. Implications of genetic polymorphisms in drug transporters for pharmacotherapy. Cancer Lett. 2006 Mar; 8; 234 (1):4-33.

Kim KA, Park PW, Hong SJ, Park JY. The effect of CYP2C19 polymorphism on the pharmacokinetics and pharmacodynamics of clopidogrel: a possible mechanism for clopidogrel resistance. Clin Pharmacol Ther. 2008 Aug;84(2):236-42.

Kim MJ, Huang SM, Meyer UA, Rahman A, Lesko LJ. A regulatory science perspective on warfarin therapy: a pharmacogenetic opportunity. J Clin Pharmacol. 2009 Feb;49(2):138-46.

Kimura S, Umeno M, Skoda RC, Meyer UA, Gonzalez FJ. The human debrisoquine 4-hydroxylase (CYP2D) locus: sequence and identification of the polymorphic CYP2D6 gene, a related gene, and a pseudogene. Am J Hum Genet 1989 Dec;45(6):889-904.

Kirchheiner J, Brockmöller J.Clinical consequences of cytochrome P450 2C9 polymorphisms. Clin Pharmacol Ther. 2005 Jan;77(1):1-16. Review.

Kirchheiner J, Nickchen K, Bauer M, Wong ML, Licinio J, Roots I, Brockmöller J. Pharmacogenetics of antidepressants and antipsychotics: the contribution of allelic variations to the phenotype of drug response. Mol Psychiatry. 2004 May;9(5):442-73.

Kirchheiner J, Seeringer A, Brockmöller J. State of the art of pharmacogenetic diagnostics in drug therapy. Bundesgesundheitsblatt Gesundheitsforschung Gesundheitsschutz. 2006 Oct;49(10):995-1003.

Kohlrausch FB, Gama CS, Lobato MI, Belmonte-de-Abreu P, Callegari-Jacques SM, Gesteira A, Barros F, Carracedo A, Hutz MH. Naturalistic pharmacogenetic study of treatment resistance to typical neuroleptics in European-Brazilian schizophrenics. Pharmacogenet Genomics. 2008 Jul;18(7):599-609.

Koo SH, Lee EJ. Pharmacogenetics approach to therapeutics. Clin Exp Pharmacol Physiol. 2006 May-Jun;33 (5-6): 525-32.

Korolkovas A, Burckhalter JH. Química Farmacêutica. Rio de Janeiro: Guanabara Koogan; 1988.

Krejsa C, Rogge M, Sadee W. Protein therapeutics: new applications for pharmacogenetics. Nat Rev Drug Discov. 2006 Jun;5(6):507-21.

Kubota T, Yamaura Y, Ohkawa N, Hara H, Chiba K. Frequencies of CYP2D6 mutant alleles in a normal Japanese population and metabolic activity of dextromethorphan 
O-demethylation in different CYP2D6 genotypes. $\mathrm{Br} \mathrm{J}$ Clin Pharmacol. 2000 Jul;50(1):31-4.

Kurzawski M, Gawrońska-Szklarz B, Wrześniewska J, Siuda A, Starzyńska T, Droździk M. Effect of CYP2C19*17 gene variant on Helicobacter pylori eradication in peptic ulcer patients. Eur J Clin Pharmacol. 2006 Oct;62(10):877-80.

Laika B, Leucht S, Heres S, Steimer W. Intermediate metabolizer: increased side effects in psychoactive drug therapy. The key to cost-effectiveness of pretreatment CYP2D6 screening? Pharmacogenomics J. 2009 May 19. [Epub ahead of print].

Lee $\mathrm{JH}$, Jeon JT. Methods to detect and analyze copy number variations at the genome-wide and locus-specific levels. Cytogenet Genome Res. 2008;123(1-4):33342. Epub 2009 Mar 11.

Lee SY, Ki CS, Hong KS, Kim JW.A case report of a poor metabolizer of CYP2D6 presented with unusual responses to nortriptyline medication. J Korean Med Sci. 2004 Oct;19(5):750-2.

Liao G., Zhang X., Clark J.D., Peltz G. A genomic "roadmap" to "better" drugs. Drug Metab Rev. 2008 Apr;40: 225-239.

Livak KJ, Schmittgen TD. Analysis of relative gene expression data using real-time quantitative PCR and the 2(-Delta Delta C(T)) Method. Methods. 2001 Dec;25(4):402-8.

Lopez M, Guerrero J, Jung-Cook H, Alonso ME. CYP2D6 genotype and phenotype determination in a Mexican Mestizo population. Eur J Clin Pharmacol. 2005 Nov; 61(10):749-54.

Løvlie R, Daly AK, Molven A, Idle JR, Steen VM. Ultrarapid metabolizers of debrisoquine: characterization and PCR-based detection of alleles with duplication of the CYP2D6 gene. FEBS Lett. 1996 Aug 19;392(1):30-4.

Lundqvist E, Johansson I, Ingelman-Sundberg M. Genetic mechanisms for duplication and multiduplication of the human CYP2D6 gene and methods for detection of duplicated CYP2D6 genes. Gene. 1999 Jan; 21;226(2):327-38.

Lynch T, Price A. The effect of cytochrome P450 metabolism on drug response, interactions, and adverse effects. Am Fam Physician. 2007 Aug; 1;76(3):391-6.

Madadi P, Ross CJ, Hayden MR, Carleton BC, Gaedigk A, Leeder JS, Koren G. Pharmacogenetics of neonatal opioid toxicity following maternal use of codeine 
during breastfeeding: a case-control study. Clin Pharmacol Ther. 2009 Jan;85(1):315. Epub 2008 Aug 20.

Maier W, Zobel A. Contribution of allelic variations to the phenotype of response to antidepressants and antipsychotics. Eur Arch Psychiatry Clin Neurosci. 2008 Mar;258 Suppl 1:12-20.

Martinus C. Feiters, Alan E. Rowan and Roeland J. M. Nolte. From simple to supramolecular cytochrome P450 mimics. Chem Soc Rev. 2000 29, 375-384

McMacarthy AD, Kennedy JL, Middleton LT. Pharmacogenetics in drug development. Philos Trans R Soc Lond B Biol Sci. 2005 Aug 29;360(1460):1579-88.

McMahon FJ, Buervenich S, Charney D, Lipsky R, Rush AJ, Wilson AF, Sorant AJ, Papanicolaou GJ, Laje G, Fava M, Trivedi MH, Wisniewski SR, Manji H. Variation in the gene encoding the serotonin $2 \mathrm{~A}$ receptor is associated with outcome of antidepressant treatment. Am J Hum Genet. 2006 May;78(5):804-14. Epub 2006 Mar 20.

Meijerman I, Sanderson LM, Smits PH, Beijnen JH, Schellens JH. Pharmacogenetic screening of the gene deletion and duplications of CYP2D6. Drug Metab Rev. 2007 Jan;39(1):45-60.

Meyer UA. Pharmacogenetics - five decades of therapeutic lessons from genetic diversity. Nat Rev Genet. 2004 Sep;5(9):669-76. Review.

Meyer UA. The molecular basis of genetic polymorphisms of drug metabolism. J Pharm Pharmacol. 1994 May;46 Suppl 1:409-15.

Motulsky AG, Qi M. Pharmacogenetics, pharmacogenomics and ecogenetics. J Zhejiang Univ Sci B. 2006 Feb;7(2):169-70.

Murray M. Role of CYP pharmacogenetics and drug-drug interactions in the efficacy and safety of atypical and other antipsychotic agents. J Pharm Pharmacol. 2006 Jul;58(7):871-85.

Naveen AT, Adithan C, Soya SS, Gerard N, Krishnamoorthy R. CYP2D6 genetic polymorphism in South Indian populations. Biol Pharm Bull. 2006 Aug;29(8):16558.(a).

Naveen AT, Prasanna T, Farzana BL, Rajan S, Adithan C. CYP2D6 genotype and phenotype relationship in South Indians. J Postgrad Med. 2006 Oct-Dec;52(4):253-6. 
Nebert DW, Zhang G, Vesell ES. From human genetics and genomics to pharmacogenetics and pharmacogenomics: past lessons, future directions. Drug Metab Rev. 2008 Apr;40(2):187-224. Review.

Neve EP, Ingelman-Sundberg $M$. Intracellular transport and localization of microsomal cytochrome P450. Anal Bioanal Chem. 2008 Nov;392(6):1075-84. Epub 2008 Jun 8.

Ohlsson Rosenborg S, Mwinyi J, Andersson M, Baldwin RM, Pedersen RS, Sim SC, Bertilsson L, Ingelman-Sundberg M, Eliasson E. Kinetics of omeprazole and escitalopram in relation to the CYP2C19*17 allele in healthy subjects. Eur $\mathrm{J}$ Clin Pharmacol. 2008 Dec;64(12):1175-9.

Paddock S, Laje G, Charney D, Rush AJ, Wilson AF, Sorant AJ, Lipsky R, Wisniewski SR, Manji H, McMahon FJ. Association of GRIK4 with outcome of antidepressant treatment in the STAR ${ }^{*}$ cohort. Am J Psychiatry. 2007 Aug;164(8):1181-8.

Perini JA, Struchiner CJ, Silva-Assunção E, Santana IS, Rangel F, Ojopi EB, DiasNeto E, Suarez-Kurtz G. Pharmacogenetics of warfarin: development of a dosing algorithm for brazilian patients. Clin Pharmacol Ther. 2008 Dec;84(6):722-8. Epub 2008 Aug 27.

Perlis RH, Moorjani P, Fagerness J, Purcell S, Trivedi MH, Fava M, Rush AJ, Smoller JW. Pharmacogenetic analysis of genes implicated in rodent models of antidepressant response: association of TREK1 and treatment resistance in the $\operatorname{STAR}\left({ }^{\star}\right) \mathrm{D}$ study. Neuropsychopharmacology. 2008 Nov;33(12):2810-9. Epub 2008 Feb 20.

Peters EJ, Slager SL, Kraft JB, Jenkins GD, Reinalda MS, McGrath PJ, Hamilton SP. Pharmacokinetic genes do not influence response or tolerance to citalopram in the STAR $^{\star}$ D sample. PLoS One. 2008 Apr 2;3(4):e1872.

Poolsup N, Li Wan Po A, Knight TL. Pharmacogenetics and psychopharmacotherapy. J Clin Pharm Ther. 2000 Jun;25(3):197-220.

Preskorn SH, Nichols Al, Paul J, Patroneva AL, Helzner EC, Guico-Pabia CJ. Effect of desvenlafaxine on the cytochrome P450 2D6 enzyme system. J Psychiatr Pract. 2008 Nov;14(6):368-78.

Ragia G, Arvanitidis KI, Tavridou A, Manolopoulos VG. Need for reassessment of reported CYP2C19 allele frequencies in various populations in view of CYP2C19*17 discovery: the case of Greece. Pharmacogenomics. 2009 Jan;10(1):43-9. 
Rau T, Wohlleben G, Wuttke H, Thuerauf N, Lunkenheimer J, Lanczik M, Eschenhagen T. CYP2D6 genotype: impact on adverse effects and nonresponse during treatment with antidepressants-a pilot study. Clin Pharmacol Ther. 2004 May;75(5):386-93.

Rogers JF, Nafziger AN, Bertino JS Jr. Pharmacogenetics affects dosing, efficacy, and toxicity of cytochrome P450-metabolized drugs. Am J Med. 2002 Dec; 15;113(9):746-50.

Rudberg I, Hendset M, Uthus LH, Molden E, Refsum H. Heterozygous mutation in CYP2C19 significantly increases the concentration/dose ratio of racemic citalopram and escitalopram (S-citalopram). Ther Drug Monit. 2006 Feb;28(1):102-5.

Rudberg I, Mohebi B, Hermann M, Refsum H, Molden E. Impact of the ultrarapid CYP2C19*17 allele on serum concentration of escitalopram in psychiatric patients. Clin Pharmacol Ther. 2008 Feb;83(2):322-7. Epub 2007 Jul 11.

Sabbagh A, Darlu P. Data-mining methods as useful tools for predicting individual drug response: application to CYP2D6 data. Hum Hered. 2006 Sep;62(3):119-34.

Schaeffeler E, Schwab M, Eichelbaum M, Zanger UM.CYP2D6 genotyping strategy based on gene copy number determination by TaqMan real-time PCR. Hum Mutat. 2003 Dec;22(6):476-85.

Schenk PW, van Fessem MA, Verploegh-Van Rij S, Mathot RA, van Gelder T, Vulto AG, van Vliet M, Lindemans J, Bruijn JA, van Schaik RH. Association of graded allele-specific changes in CYP2D6 function with imipramine dose requirement in a large group of depressed patients. Mol Psychiatry. 2008 Jun;13(6):597-605.

Schwab M, Schaeffeler E, Klotz U, Treiber G. CYP2C19 polymorphism is a major predictor of treatment failure in white patients by use of lansoprazole-based quadruple therapy for eradication of Helicobacter pylori. Clin Pharmacol Ther. 2004 Sep;76(3):201-9.

Scott SA, Edelmann L, Kornreich R, Erazo M, Desnick RJ. CYP2C9, CYP2C19 and CYP2D6 allele frequencies in the Ashkenazi Jewish population. Pharmacogenomics. $2007 \mathrm{Jul} ; 8(7): 721-30$.

Shah RR. Pharmacogenetics in drug regulation: promise, potential and pitfalls. Philos Trans R Soc Lond B Biol Sci .2005 Aug;29;360(1460):1617-38.

Shams ME, Arneth B, Hiemke C, Dragicevic A, Müller MJ, Kaiser R, Lackner K, Härtter S.CYP2D6 polymorphism and clinical effect of the antidepressant venlafaxine.J Clin Pharm Ther. 2006 Oct;31(5):493-502. 
Signature

Genetics.

Avaliable

from:

http://www.signaturegenetics.com/public/4/411.html\#21112 [2009 Apr 05].

Signature

Genetics.

Avaliable

from:

http://www.signaturegenetics.com/public/2/226.html [2009 Apr 05].

Sim SC, Risinger C, Dahl ML, Aklillu E, Christensen M, Bertilsson L, IngelmanSundberg M. A common novel CYP2C19 gene variant causes ultrarapid drug metabolism relevant for the drug response to proton pump inhibitors and antidepressants. Clin Pharmacol Ther. 2006 Jan;79(1):103-13.

Singh A. Pharmacogenomics--the potential of genetically guided prescribing. Aust Fam Physician. 2007 Oct;36(10):820-4

Sistonen J, Fuselli S, Palo JU, Chauhan N, Padh H, Sajantila A. Pharmacogenetic variation at CYP2C9, CYP2C19, and CYP2D6 at global and microgeographic scales. Pharmacogenet Genomics. 2009 Feb;19(2):170-9.

Sistonen J, Sajantila A, Lao O, Corander J, Barbujani G, Fuselli S. CYP2D6 worldwide genetic variation shows high frequency of altered activity variants and no continental structure. Pharmacogenet Genomics. 2007 Feb;17(2):93-101.

Smith RL. Human genetic variations in oxidative drug metabolism. Xenobiotica. 1986 May;16(5):359-509.

Stadoon S, Arranz J, Mancama D, Mata I, Kerwin RW. Clinical application of pharmacogenetics in psychiatry. Psychopharmacolog. 2002 Mar;162:18-23.

Steen VM, Andreassen OA, Daly AK, Tefre T, Børresen AL, Idle JR, Gulbrandsen AK. Detection of the poor metabolizer-associated CYP2D6(D) gene deletion allele by long-PCR technology. Pharmacogenetics. 1995 Aug;5(4):215-23.

Steimer W, Muller B, Leucht S, Kissiling W. Pharmacogenetics : a new diagnostic tool in the management of antidepressive drug therapy. Clin Chim Acta. 2001 Jun;308:33-41.

Steimer W, Zöpf K, von Amelunxen S, Pfeiffer H, Bachofer J, Popp J, Messner B, Kissling $\mathrm{W}$, Leucht $\mathrm{S}$. Amitriptyline or not, that is the question: pharmacogenetic testing of CYP2D6 and CYP2C19 identifies patients with low or high risk for side effects in amitriptyline therapy. Clin Chem. 2005 Feb;51(2):376-85.

Sugimoto $\mathrm{K}$, Uno T, Yamazaki H, Tateishi T. Limited frequency of the CYP2C19*17 allele and its minor role in a Japanese population. $\mathrm{Br} J$ Clin Pharmacol. 2008 Mar;65(3):437-9. 
Swen JJ, Wilting I, de Goede AL, Grandia L, Mulder H, Touw DJ, de Boer A, Conemans JM, Egberts TC, Klungel OH, Koopmans R, van der Weide J, Wilffert B, Guchelaar HJ, Deneer VH. Pharmacogenetics: from bench to byte.Clin Pharmacol Ther. 2008 May;83(5):781-7. Epub 2008 Feb 6. Erratum in: Clin Pharmacol Ther. 2008 Jul;84(1):175.

Testa B, Krämer SD. The biochemistry of drug metabolism--an introduction: part 1. Principles and overview. Chem Biodivers. 2006 Oct;3(10):1053-101.

The Uppsala Monitoring Centre. Avaliable from: http://www.whoumc.org/DynPage.aspx?id=22676 [2009 Jan 08].

Thuerauf N, Lunkenheimer J.The impact of the CYP2D6-polymorphism on dose recommendations for current antidepressants. Eur Arch Psychiatry Clin Neurosci. 2006 Aug;256(5):287-93.

Tomalik-Scharte D, Lazar A, Fuhr U, Kirchheiner J. The clinical role of genetic polymorphisms in drug-metabolizing enzymes. Pharmacogenomics J. 2008 Feb;8(1):4-15.

Ueda M, Hirokane G, Morita S, Okawa M, Watanabe T, Akiyama K, Shimoda K. The impact of CYP2D6 genotypes on the plasma concentration of paroxetine in Japanese psychiatric patients. Prog Neuropsychopharmacol Biol Psychiatry. 2006 May;30(3):486-91. Epub 2006 Jan 18.

Uhr M, Tontsch A, Namendorf C, Ripke S, Lucae S, Ising M, Dose T, Ebinger M, Rosenhagen M, Kohli M, Kloiber S, Salyakina D, Bettecken T, Specht M, Pütz B, Binder EB, Müller-Myhsok B, Holsboer F. Polymorphisms in the drug transporter gene $A B C B 1$ predict antidepressant treatment response in depression. Neuron. 2008 Jan 24;57(2):203-9.

van der Weide J, Hinrichs JW. The influence of cytochrome p450 pharmacogenetics on disposition of common antidepressant and antipsychotic medications. Clin Biochem Rev. 2006 Feb;27(1):17-25

Vianna-Jorge R, Perini JA, Rondinelli E, Suarez-Kurtz G. CYP2C9 genotypes and the pharmacokinetics of tenoxicam in Brazilians. Clin Pharmacol Ther. 2004 Jul;76(1):18-26.

Wolf CR, Smith G, Smith RL. Science, medicine, and the future: Pharmacogenetics. BMJ. 2000 Apr; 8;320(7240):987-90.

Zanger UM, Turpeinen M, Klein K, Schwab M. Functional pharmacogenetics/genomics of human cytochromes P450 involved in drug 
biotransformation. Anal Bioanal Chem. 2008 Nov;392(6):1093-108. Epub 2008 Aug 10.

Zhou SF, Di YM, Chan E, Du YM, Chow VD, Xue CC, Lai X, Wang JC, Li CG, Tian $M$, Duan W Clinical pharmacogenetics and potential application in personalized medicine. Curr Drug Metab. 2008 Oct; 9(8):738-84. 
ANEXO A - Haplótipos do gene CYP2D6 encontrados em nossa amostra.

\begin{tabular}{|c|c|c|c|c|c|c|c|c|c|c|c|c|c|c|c|c|c|}
\hline & alelo & -1584 & 31 & 100 & 137_138 & 1023 & 1661 & 1707 & 1846 & 1863_1864 & 2549 & 2613_2615 & 2850 & 2988 & 3183 & 4180 & CNV \\
\hline 130 & ${ }^{*} 1 * 2 \times N$ & CG & GG & $\mathrm{CC}$ & - & $\mathrm{CC}$ & $\mathrm{GC}$ & TT & GG & - & $\mathrm{AA}$ & AGA AGA & CT & GG & GG & CG & 3 \\
\hline 155 & $*_{1} * 17$ & CC & GG & $\mathrm{CC}$ & - & CT & GC & TT & GG & - & $\mathrm{AA}$ & AGA AGA & $\mathrm{CT}$ & GG & GG & CG & 2 \\
\hline 161 & $*_{1} 1 * 4$ & CC & GG & CT & - & $\mathrm{CC}$ & GC & TT & GA & - & $\mathrm{AA}$ & AGA AGA & $\mathrm{CC}$ & GG & GG & CG & 2 \\
\hline 165 & $* 1 * 35$ & CG & GA & $\mathrm{CC}$ & - & $\mathrm{CC}$ & GC & TT & GG & - & $\mathrm{AA}$ & AGA AGA & $\mathrm{CT}$ & GG & GG & CG & 2 \\
\hline 345 & ${ }^{*} 1 * 2 \mathrm{XN}$ & CG & GG & $\mathrm{CC}$ & - & $\mathrm{CC}$ & GC & TT & GG & - & $\mathrm{AA}$ & AGA AGA & CT & GG & GG & CG & 3 \\
\hline 407 & $* 35 * 41$ & CG & GA & $\mathrm{CC}$ & - & $\mathrm{CC}$ & CC & TT & GG & - & AA & AGA AGA & TT & GA & GG & $\mathrm{CC}$ & 2 \\
\hline 462 & $* 1 * 41$ & CC & GG & $\mathrm{CC}$ & - & CC & GC & TT & GG & - & AA & AGA AGA & CT & GA & GG & CG & 2 \\
\hline 503 & $*_{1} *_{1}$ & CC & GG & $\mathrm{CC}$ & - & CC & GC & TT & GG & - & AA & AGA AGA & CC & GG & GG & GG & 2 \\
\hline 569 & $* 2 * 2$ & GG & GG & $\mathrm{CC}$ & - & CC & CC & TT & GG & - & AA & AGA AGA & TT & GG & GG & CC & 2 \\
\hline 584 & $* 1 * 2$ & CG & GG & $\mathrm{CC}$ & - & CC & GC & TT & GG & - & AA & AGA AGA & CT & GG & GG & CG & 2 \\
\hline 594 & $* 1 * 5$ & C & $\mathrm{G}$ & $C$ & - & $\mathrm{C}$ & G & $T$ & G & - & $A$ & AGA & C & G & G & G & 1 \\
\hline 595 & $*_{1} * 1$ & $\mathrm{CC}$ & GG & $\mathrm{CC}$ & - & $\mathrm{CC}$ & GC & TT & GG & - & $\mathrm{AA}$ & AGA AGA & $\mathrm{CC}$ & GG & GG & GG & 2 \\
\hline 616 & $*_{1} *_{4}$ & CC & GG & $\mathrm{CT}$ & - & CC & $\mathrm{GC}$ & TT & GA & - & AA & AGA AGA & CC & GG & GG & CG & 2 \\
\hline 629 & $*_{1} * 41$ & CC & GG & $\mathrm{CC}$ & - & CC & GC & TT & GG & - & AA & AGA AGA & CT & GA & GG & CG & 2 \\
\hline 633 & $* 1 * 17$ & CC & GG & $\mathrm{CC}$ & - & CT & GC & TT & GG & - & AA & AGA AGA & CT & GG & GG & CG & 2 \\
\hline 634 & $* 2 * 41$ & $\mathrm{CC}$ & GG & $\mathrm{CC}$ & - & $\mathrm{CC}$ & CC & TT & GG & - & $\mathrm{AA}$ & AGA AGA & TT & GA & GG & CC & 2 \\
\hline 637 & $*_{1} * 2$ & CG & GG & $\mathrm{CC}$ & - & CC & GC & TT & GG & - & AA & AGA AGA & CT & GG & GG & CG & 2 \\
\hline 639 & $*_{1} * 1$ & CC & GG & $\mathrm{CC}$ & - & CC & GC & TT & GG & - & AA & AGA AGA & $\mathrm{CC}$ & GG & GG & GG & 2 \\
\hline 642 & $* 1 * 5$ & $\mathrm{C}$ & $G$ & $\mathrm{C}$ & - & $\mathrm{C}$ & $\mathrm{G}$ & $T$ & $\mathrm{G}$ & - & A & AGA & $\mathrm{C}$ & G & G & G & 1 \\
\hline 643 & $* 1 * 4$ & $\mathrm{CC}$ & GG & CT & - & $\mathrm{CC}$ & GC & TT & GA & - & $\mathrm{AA}$ & AGA AGA & $\mathrm{CC}$ & GG & GG & CG & 2 \\
\hline 646 & $* 4 * 41$ & CC & GG & CT & - & CC & CC & TT & GA & - & AA & AGA AGA & CT & GA & GG & CC & 2 \\
\hline 647 & $*_{1} *_{17}$ & CC & GG & $\mathrm{CC}$ & - & CT & GC & TT & GG & - & AA & AGA AGA & CT & GG & GG & CG & 2 \\
\hline 656 & $* 2 * 4$ & CG & GG & $\mathrm{CT}$ & - & CC & CC & TT & GA & - & AA & AGA AGA & CT & GG & GG & CC & 2 \\
\hline 662 & $* 4 * 4$ & $\mathrm{CC}$ & GG & $\mathrm{TT}$ & - & $\mathrm{CC}$ & CC & TT & AA & - & AA & AGA AGA & $\mathrm{CC}$ & GG & GG & CC & 2 \\
\hline 664 & $* 4 * 17$ & $\mathrm{CC}$ & GG & $\mathrm{CT}$ & - & CT & CC & TT & GA & - & $\mathrm{AA}$ & AGA AGA & CT & GG & GG & CC & 2 \\
\hline 666 & $*_{1} * 2$ & CG & GG & $\mathrm{CC}$ & - & CC & $\mathrm{GC}$ & TT & GG & - & AA & AGA AGA & CT & GG & GG & CG & 2 \\
\hline 667 & $*_{1} * 2$ & CG & GG & $\mathrm{CC}$ & - & CC & GC & TT & GG & - & AA & AGA AGA & CT & GG & GG & CG & 2 \\
\hline 668 & $* 1 * 1$ & $\mathrm{CC}$ & GG & $\mathrm{CC}$ & - & $\mathrm{CC}$ & GC & TT & GG & - & $\mathrm{AA}$ & AGA AGA & $\mathrm{CC}$ & GG & GG & GG & 2 \\
\hline 669 & $* 2 * 4$ & CG & GG & CT & - & CC & CC & TT & GA & - & $\mathrm{AA}$ & AGA AGA & CT & GG & GG & CC & 2 \\
\hline 670 & $*_{1} * 1$ & CC & GG & $\mathrm{CC}$ & - & CC & $\mathrm{GC}$ & TT & GG & - & AA & AGA AGA & CC & GG & GG & GG & 2 \\
\hline 671 & $*_{1} * 1$ & CC & GG & $\mathrm{CC}$ & - & CC & GC & TT & GG & - & $\mathrm{AA}$ & AGA AGA & CC & GG & GG & GG & 2 \\
\hline 674 & $*_{1} * 35$ & CG & GA & $\mathrm{CC}$ & - & $\mathrm{CC}$ & GC & TT & GG & - & AA & AGA AGA & CT & GG & GG & CG & 2 \\
\hline 677 & $* 29 * 41$ & CC & GG & $\mathrm{CC}$ & - & CC & CC & TT & GG & - & $A A$ & AGA AGA & TT & GA & GA & CC & 2 \\
\hline 680 & $* 1 * 1$ & $\mathrm{CC}$ & GG & $\mathrm{CC}$ & - & $\mathrm{CC}$ & GC & TT & GG & - & $\mathrm{AA}$ & AGA AGA & $\mathrm{CC}$ & GG & GG & GG & 2 \\
\hline 683 & $*_{1} * 10$ & $\mathrm{CC}$ & GG & $\mathrm{CT}$ & - & $\mathrm{CC}$ & $\mathrm{GC}$ & TT & GG & - & $\mathrm{AA}$ & AGA AGA & $\mathrm{CC}$ & GG & GG & CG & 2 \\
\hline 686 & $* 2 * 4$ & CG & GG & CT & - & CC & CC & TT & GA & - & AA & AGA AGA & CT & GG & GG & $\mathrm{CC}$ & 2 \\
\hline 688 & $* 2 * 4$ & $\mathrm{CC}$ & GG & CT & - & CC & $\mathrm{CC}$ & TT & GA & - & $\mathrm{AA}$ & AGA AGA & CT & GG & GG & CC & 2 \\
\hline
\end{tabular}


ANEXO A - Haplótipos do gene CYP2D6 encontrados em nossa amostra (continuação).

\begin{tabular}{|c|c|c|c|c|c|c|c|c|c|c|c|c|c|c|c|c|c|}
\hline & alelo & -1584 & 31 & 100 & 137_138 & 1023 & 1661 & 1707 & 1846 & 1863_1864 & 2549 & $2613 \_2615$ & 2850 & 2988 & 3183 & 4180 & CNV \\
\hline 693 & $* 4 * 4$ & $\mathrm{CC}$ & GG & $\mathrm{TT}$ & - & $\mathrm{CC}$ & CC & TT & AA & - & AA & AGA AGA & CC & GG & GG & $\mathrm{CC}$ & 2 \\
\hline 702 & $* 17 * 35$ & CG & GA & CC & - & CT & $\mathrm{CC}$ & TT & GG & - & AA & AGA AGA & $\mathrm{TT}$ & GG & GG & $\mathrm{CC}$ & 2 \\
\hline 704 & $* 4 * 4$ & CC & GG & TT & - & CC & CC & TT & AA & - & AA & AGA AGA & CC & GG & GG & $\mathrm{CC}$ & 2 \\
\hline 705 & $* 2 * 2$ & GG & GG & $\mathrm{CC}$ & - & CC & $\mathrm{CC}$ & TT & GG & - & AA & AGA AGA & TT & GG & GG & $\mathrm{CC}$ & 2 \\
\hline 709 & $* 1 * 2 \times N$ & CG & GG & $\mathrm{CC}$ & - & CC & $\mathrm{GC}$ & TT & GG & - & AA & AGA AGA & CT & GG & GG & CG & 3 \\
\hline 715 & $* 6 * 17$ & CC & GG & CC & - & CT & $\mathrm{GC}$ & $T-$ & GG & - & $A A$ & AGA AGA & CT & GG & GG & CC & 2 \\
\hline 719 & $* 2 * 4$ & CG & GG & CT & - & CC & CC & TT & GA & - & AA & AGA AGA & CT & GG & GG & $\mathrm{CC}$ & 2 \\
\hline 720 & $*_{1} * 2$ & CC & GG & $\mathrm{CC}$ & - & $\mathrm{CC}$ & $\mathrm{GC}$ & TT & GG & - & AA & AGA AGA & CT & GG & GG & CG & 2 \\
\hline 726 & $*_{1}^{*} * 1$ & CC & GG & $\mathrm{CC}$ & - & $\mathrm{CC}$ & $\mathrm{GC}$ & TT & GG & - & AA & AGA AGA & CC & GG & GG & GG & 2 \\
\hline 739 & $* 1 * 35$ & CG & GA & $\mathrm{CC}$ & - & $\mathrm{CC}$ & $\mathrm{GC}$ & TT & GG & - & $A A$ & AGA AGA & CT & GG & GG & CG & 2 \\
\hline 740 & $* 2 * 2$ & GG & GG & $\mathrm{CC}$ & - & $\mathrm{CC}$ & $\mathrm{CC}$ & $\mathrm{TT}$ & GG & - & $\mathrm{AA}$ & AGA AGA & $\mathrm{TT}$ & GG & GG & $\mathrm{CC}$ & 2 \\
\hline 743 & $* 1 * 2$ & CG & GG & $\mathrm{CC}$ & - & $\mathrm{CC}$ & $\mathrm{GC}$ & TT & GG & - & AA & AGA AGA & CT & GG & GG & CG & 2 \\
\hline 751 & $* 4 * 35$ & CG & GA & $\mathrm{CT}$ & - & CC & CC & TT & GA & - & AA & AGA AGA & CT & GG & GG & CC & 2 \\
\hline 769 & $* 1 * 35$ & CG & GA & $\mathrm{CC}$ & - & $\mathrm{CC}$ & $\mathrm{GC}$ & TT & GG & - & $A A$ & AGA AGA & CT & GG & GG & CG & 2 \\
\hline 771 & $*_{1} * 2 \times N$ & CG & GG & $\mathrm{CC}$ & - & $\mathrm{CC}$ & $\mathrm{GC}$ & TT & GG & - & AA & AGA AGA & CT & GG & GG & CG & 3 \\
\hline 792 & $* 1 * 2$ & CG & GG & $\mathrm{CC}$ & - & $\mathrm{CC}$ & $\mathrm{GC}$ & TT & GG & - & AA & AGA AGA & CT & GG & GG & CG & 2 \\
\hline 794 & $*_{1} *_{1}$ & CC & GG & CC & - & $\mathrm{CC}$ & $\mathrm{GC}$ & TT & GG & - & AA & AGA AGA & CC & GG & GG & GG & 2 \\
\hline 817 & $*_{1} * 2$ & CG & GG & $\mathrm{CC}$ & - & CC & $\mathrm{GC}$ & TT & GG & - & $A A$ & AGA AGA & CT & GG & GG & CG & 2 \\
\hline 821 & $* 4 * 41$ & CC & GG & $\mathrm{CT}$ & - & CC & CC & TT & GA & - & AA & AGA AGA & CT & GA & GG & $\mathrm{CC}$ & 2 \\
\hline 838 & $*_{1} * 41$ & $\mathrm{CC}$ & GG & $\mathrm{CC}$ & - & $\mathrm{CC}$ & $\mathrm{GC}$ & TT & GG & - & AA & AGA AGA & CT & GA & GG & CG & 2 \\
\hline 849 & $* 4 * 6$ & CC & GG & CT & - & $\mathrm{CC}$ & $\mathrm{CC}$ & $T-$ & GA & - & $A A$ & AGA AGA & CC & GG & GG & CC & 2 \\
\hline 854 & $* 2 * 4$ & CG & GG & CT & - & $\mathrm{CC}$ & CC & TT & GA & - & $A A$ & AGA AGA & CT & GG & GG & CC & 2 \\
\hline 948 & $* 1 * 35$ & CG & GA & CC & - & CC & $\mathrm{GC}$ & TT & GG & - & AA & AGA AGA & CT & GG & GG & CG & 2 \\
\hline 949 & $*_{2} * 41$ & CG & GG & $\mathrm{CC}$ & - & $\mathrm{CC}$ & $\mathrm{CC}$ & $\mathrm{TT}$ & GG & - & AA & AGA AGA & $\mathrm{TT}$ & GA & GG & $\mathrm{CC}$ & 2 \\
\hline 956 & $*_{1} *_{1}$ & CC & GG & $\mathrm{CC}$ & - & $\mathrm{CC}$ & $\mathrm{GC}$ & TT & GG & - & AA & AGA AGA & CC & GG & GG & GG & 2 \\
\hline 990 & $* 5 * 1$ & $\mathrm{C}$ & $\mathrm{G}$ & $\mathrm{C}$ & - & $\mathrm{C}$ & $\mathrm{G}$ & $\mathrm{T}$ & $\mathrm{G}$ & - & $\mathrm{A}$ & AGA & $\mathrm{C}$ & $\mathrm{G}$ & $\mathrm{G}$ & $\mathrm{G}$ & 1 \\
\hline 999 & $* 1 * 2 \times N$ & CG & GG & $\mathrm{CC}$ & - & $\mathrm{CC}$ & GC & TT & GG & - & AA & AGA AGA & CT & GG & GG & CG & 3 \\
\hline 1003 & $* 2 * 4$ & CG & GG & CT & - & CC & $\mathrm{CC}$ & TT & GA & - & AA & AGA AGA & CT & GG & GG & CC & 2 \\
\hline 1172 & $*_{1} *_{1}$ & $\mathrm{CC}$ & GG & $\mathrm{CC}$ & - & $\mathrm{CC}$ & GC & TT & GG & - & $A A$ & AGA AGA & CC & GG & GG & GG & 2 \\
\hline 1494 & $*_{1} * 1$ & CC & GG & CC & - & CC & $\mathrm{GC}$ & TT & GG & - & AA & AGA AGA & CC & GG & GG & GG & 2 \\
\hline 1495 & $*_{1}{ }^{*} 2 \times N$ & CG & GG & $\mathrm{CC}$ & - & $\mathrm{CC}$ & $\mathrm{GC}$ & TT & GG & - & AA & AGA AGA & CT & GG & GG & CG & 3 \\
\hline 1496 & $*_{4} * 10$ & CC & GG & $\mathrm{TT}$ & - & $\mathrm{CC}$ & $\mathrm{CC}$ & TT & GA & - & AA & AGA AGA & CT & GG & GG & CC & 2 \\
\hline 1497 & $*_{1} * 1$ & $\mathrm{CC}$ & GG & CC & - & $\mathrm{CC}$ & $\mathrm{GC}$ & TT & GG & - & AA & AGA AGA & CC & GG & GG & GG & 2 \\
\hline 1498 & $* 2 * 2 \times N$ & CG & GG & CC & - & CC & CC & TT & GG & - & AA & AGA AGA & TT & GG & GG & $\mathrm{CC}$ & 3 \\
\hline 1499 & $* 2 * 2$ & GG & GG & $\mathrm{CC}$ & - & $\mathrm{CC}$ & $\mathrm{CC}$ & TT & GG & - & AA & AGA AGA & TT & GG & GG & $\mathrm{CC}$ & 2 \\
\hline 1501 & $*_{1} *_{4}$ & $\mathrm{CC}$ & GG & CT & - & $\mathrm{CC}$ & $\mathrm{GC}$ & TT & GA & - & AA & AGA AGA & CC & GG & GG & CG & 2 \\
\hline 1502 & $*_{1}^{*} * 4$ & $\mathrm{CC}$ & GG & CT & - & CC & GC & TT & GA & - & $\mathrm{AA}$ & AGA AGA & CC & GG & GG & CG & 2 \\
\hline
\end{tabular}


ANEXO A - Haplótipos do gene CYP2D6 encontrados em nossa amostra (continuação).

\begin{tabular}{|c|c|c|c|c|c|c|c|c|c|c|c|c|c|c|c|c|c|}
\hline & alelo & -1584 & 31 & 100 & 137_138 & 1023 & 1661 & 1707 & 1846 & 1863_1864 & 2549 & $2613 \_2615$ & 2850 & 2988 & 3183 & 4180 & CNV \\
\hline 1503 & $*_{1}^{*} * 1$ & $\mathrm{CC}$ & GG & $\mathrm{CC}$ & - & $\mathrm{CC}$ & $\mathrm{GC}$ & TT & GG & - & AA & AGA AGA & CC & GG & GG & GG & 2 \\
\hline 1504 & $*_{1} * 5$ & C & G & C & - & C & G & $T$ & G & - & $A$ & AGA & C & G & G & G & 1 \\
\hline 1505 & $*_{1} * 2$ & CC & GG & $\mathrm{CC}$ & - & CC & $\mathrm{GC}$ & TT & GG & - & AA & AGA AGA & CT & GG & GG & CG & 2 \\
\hline 1507 & $* 2 * 10 \mathrm{XN}$ & CG & GG & $\mathrm{CT}$ & - & CC & $\mathrm{CC}$ & TT & GG & - & AA & AGA AGA & CT & GG & GG & CC & 3 \\
\hline 1508 & $* 4 * 5$ & $\mathrm{C}$ & $\mathrm{G}$ & $T$ & - & $\mathrm{C}$ & $\mathrm{C}$ & $T$ & A & - & $A$ & AGA & C & $G$ & G & $\mathrm{C}$ & 1 \\
\hline 1509 & $* 2 * 41 \times N$ & CG & GG & CC & - & CC & CC & TT & GG & - & $A A$ & AGA AGA & TT & GA & GG & CC & 3 \\
\hline 1510 & $* 2 * 2 \times N$ & GG & GG & CC & - & CC & CC & TT & GG & - & AA & AGA AGA & TT & GG & GG & CC & 3 \\
\hline 1511 & $* 1 * 35$ & CG & $\mathrm{GA}$ & $\mathrm{CC}$ & - & $\mathrm{CC}$ & $\mathrm{GC}$ & TT & GG & - & AA & AGA AGA & CT & GG & GG & CG & 2 \\
\hline 1512 & $*^{*} 1 * 10$ & CC & GG & CT & - & $\mathrm{CC}$ & $\mathrm{GC}$ & TT & GG & - & AA & AGA AGA & CC & GG & GG & CG & 2 \\
\hline 1513 & $* 1 * 5$ & C & G & C & - & C & G & $T$ & G & - & A & AGA & C & G & G & G & 1 \\
\hline 1514 & $* 1 * 2$ & CG & GG & CC & - & $\mathrm{CC}$ & $\mathrm{CC}$ & $\mathrm{TT}$ & GG & - & $\mathrm{AA}$ & AGA AGA & $\mathrm{CT}$ & GG & GG & CG & 2 \\
\hline 1515 & $* 2 * 10 \times N$ & CG & GG & $\mathrm{CT}$ & - & $\mathrm{CC}$ & $\mathrm{CC}$ & TT & GG & - & AA & AGA AGA & CT & GG & GG & CC & 3 \\
\hline 1516 & $*_{1} * 1$ & CC & GG & CC & - & CC & $\mathrm{GC}$ & TT & GG & - & AA & AGA AGA & CC & GG & GG & GG & 2 \\
\hline 1517 & $* 1 * 35$ & CG & GA & $\mathrm{CC}$ & - & $\mathrm{CC}$ & $\mathrm{GC}$ & TT & GG & - & $A A$ & AGA AGA & CT & GG & GG & CG & 2 \\
\hline 1518 & $* 1 * 10 \times N$ & CC & GG & CT & - & $\mathrm{CC}$ & $\mathrm{GC}$ & TT & GG & - & AA & AGA AGA & CC & GG & GG & CG & 3 \\
\hline 1519 & $* 2 * 2$ & GG & GG & $\mathrm{CC}$ & - & $\mathrm{CC}$ & $\mathrm{CC}$ & TT & GG & - & AA & AGA AGA & TT & GG & GG & $\mathrm{CC}$ & 2 \\
\hline 1520 & $*_{1} *_{1}$ & CC & GG & CC & - & $\mathrm{CC}$ & $\mathrm{GC}$ & TT & GG & - & AA & AGA AGA & CC & GG & GG & GG & 2 \\
\hline 1561 & *1*17 & CC & GG & $\mathrm{CC}$ & - & CT & $\mathrm{GC}$ & TT & GG & - & $A A$ & AGA AGA & CT & GG & GG & CG & 2 \\
\hline 1568 & $* 2 * 41$ & CG & GG & CC & - & CC & $\mathrm{CC}$ & TT & GG & - & AA & AGA AGA & TT & GA & GG & CC & 2 \\
\hline 1571 & $* 2 * 4$ & CG & GG & $\mathrm{CT}$ & - & $\mathrm{CC}$ & $\mathrm{CC}$ & TT & GA & - & AA & AGA AGA & CT & GG & GG & $\mathrm{CC}$ & 2 \\
\hline 1578 & $*_{1} * 4$ & CC & GG & CT & - & $\mathrm{CC}$ & $\mathrm{GC}$ & TT & GA & - & $A A$ & AGA AGA & CC & GG & GG & CG & 2 \\
\hline 1583 & $*_{1} * 1$ & CC & GG & $\mathrm{CC}$ & - & $\mathrm{CC}$ & $\mathrm{GC}$ & TT & GG & - & $A A$ & AGA AGA & CC & GG & GG & GG & 2 \\
\hline 1599 & $*_{1}^{*} * 4$ & CC & GG & $\mathrm{CT}$ & - & $\mathrm{CC}$ & GC & TT & GA & - & AA & AGA AGA & CC & GG & GG & CG & 2 \\
\hline 1606 & $*_{5}^{*}{ }_{1}$ & C & G & C & - & C & G & $T$ & G & - & A & AGA & C & G & G & G & 1 \\
\hline 1657 & $* 1 * 35$ & CG & GA & $\mathrm{CC}$ & - & $\mathrm{CC}$ & $\mathrm{CC}$ & TT & GG & - & $A A$ & AGA AGA & CT & GG & GG & CG & 2 \\
\hline 1658 & $* 1 * 17$ & $\mathrm{CC}$ & GG & $\mathrm{CC}$ & - & $\mathrm{CT}$ & $\mathrm{GC}$ & $\mathrm{TT}$ & GG & - & AA & AGA AGA & $\mathrm{CT}$ & GG & GG & CG & 2 \\
\hline 1659 & $*_{1}^{*} * 9$ & CC & GG & $\mathrm{CC}$ & - & $\mathrm{CC}$ & GC & TT & GG & - & AA & AGA/del & CC & GG & GG & GG & 2 \\
\hline 1661 & $*_{1}^{*} * 4$ & $\mathrm{CC}$ & GG & $\mathrm{CT}$ & - & $\mathrm{CC}$ & $\mathrm{GC}$ & $\mathrm{TT}$ & GA & - & AA & AGA AGA & $\mathrm{CC}$ & GG & GG & CG & 2 \\
\hline 1662 & $*_{1} * 5$ & $\mathrm{C}$ & $G$ & $C$ & - & $\mathrm{C}$ & $\mathrm{G}$ & $T$ & $\mathrm{G}$ & - & A & AGA & $\mathrm{C}$ & G & G & $\mathrm{G}$ & 1 \\
\hline 1663 & $* 2 * 2$ & GG & GG & $\mathrm{CC}$ & - & $\mathrm{CC}$ & $\mathrm{CC}$ & $\mathrm{TT}$ & GG & - & AA & AGA AGA & TT & GG & GG & CC & 2 \\
\hline 1664 & *1*1 & CC & GG & $\mathrm{CC}$ & - & $\mathrm{CC}$ & GC & TT & GG & - & AA & AGA AGA & CC & GG & GG & GG & 2 \\
\hline 1665 & $*_{1} * 41$ & CC & GG & CC & - & $\mathrm{CC}$ & GC & TT & GG & - & AA & AGA AGA & CT & GA & GG & CG & 2 \\
\hline 1697 & $*_{1} *_{1}$ & $\mathrm{CC}$ & GG & CC & - & $\mathrm{CC}$ & GC & TT & GG & - & AA & AGA AGA & CC & GG & GG & GG & 2 \\
\hline 1698 & $* 2 * 4$ & CG & GG & CT & - & CC & CC & TT & GA & - & AA & AGA AGA & CT & GG & GG & CC & 2 \\
\hline 1699 & $*_{1}^{*} * 1$ & $\mathrm{CC}$ & GG & $\mathrm{CC}$ & - & $\mathrm{CC}$ & GC & TT & GG & - & AA & AGA AGA & $\mathrm{CC}$ & GG & GG & GG & 2 \\
\hline 1700 & $*_{1} * 4$ & CC & GG & $\mathrm{CT}$ & - & $\mathrm{CC}$ & GC & TT & $\mathrm{GA}$ & - & AA & AGA AGA & CC & GG & GG & CG & 2 \\
\hline 1701 & ${ }^{*} 2 * 2 \times N$ & GG & GG & $\mathrm{CC}$ & - & CC & $\mathrm{CC}$ & TT & GG & - & $\mathrm{AA}$ & AGA AGA & TT & GG & GG & CC & 3 \\
\hline
\end{tabular}


ANEXO A - Haplótipos do gene CYP2D6 encontrados em nossa amostra (conclusão).

\begin{tabular}{|c|c|c|c|c|c|c|c|c|c|c|c|c|c|c|c|c|c|}
\hline & alelo & -1584 & 31 & 100 & 137_138 & 1023 & 1661 & 1707 & 1846 & 1863_1864 & 2549 & $2613 \_2615$ & 2850 & 2988 & 3183 & 4180 & CNV \\
\hline 1702 & $*^{*} *_{2}$ & CG & GG & $\mathrm{CC}$ & - & $\mathrm{CC}$ & $\mathrm{GC}$ & $\mathrm{TT}$ & GG & - & $\mathrm{AA}$ & AGA AGA & CT & GG & GG & CG & 2 \\
\hline 1716 & $*^{*} * 4$ & $\mathrm{CC}$ & GG & $\mathrm{CT}$ & - & $\mathrm{CC}$ & $\mathrm{GC}$ & TT & GA & - & $\mathrm{AA}$ & AGA AGA & CC & GG & GG & CG & 2 \\
\hline 1717 & *1*17 & $\mathrm{CC}$ & GG & $\mathrm{CC}$ & - & CT & $\mathrm{GC}$ & TT & GG & - & $\mathrm{AA}$ & AGA AGA & CT & GG & GG & CG & 2 \\
\hline 1718 & $* 4 * 4$ & CC & GG & TT & - & $\mathrm{CC}$ & $\mathrm{CC}$ & TT & AA & - & AA & AGA AGA & CC & GG & GG & $\mathrm{CC}$ & 2 \\
\hline 1719 & $* 2 * 10$ & CG & GG & $\mathrm{CT}$ & - & $\mathrm{CC}$ & $\mathrm{CC}$ & TT & GG & - & $\mathrm{AA}$ & AGA AGA & CT & GG & GG & $\mathrm{CC}$ & 2 \\
\hline 1720 & $*_{1} * 10$ & CC & GG & $\mathrm{CT}$ & - & $\mathrm{CC}$ & $\mathrm{GC}$ & TT & GG & - & $\mathrm{AA}$ & AGA AGA & CC & GG & GG & CG & 2 \\
\hline 1721 & *1*41 & $\mathrm{CC}$ & GG & CC & - & CC & $\mathrm{GC}$ & TT & GG & - & AA & AGA AGA & CT & GA & GG & CG & 2 \\
\hline 1722 & $*_{1} * 2$ & CG & GG & $\mathrm{CC}$ & - & $\mathrm{CC}$ & $\mathrm{GC}$ & TT & GG & - & AA & AGA AGA & CT & GG & GG & CG & 2 \\
\hline 1723 & $* 2 * 29$ & CG & GG & CC & - & CC & $\mathrm{CC}$ & TT & GG & - & AA & AGA AGA & TT & GG & GA & $\mathrm{CC}$ & 2 \\
\hline 1726 & $*_{1} * 17$ & $\mathrm{CC}$ & GG & $\mathrm{CC}$ & - & CT & GC & TT & GG & - & AA & AGA AGA & CT & GG & GG & CG & 2 \\
\hline 1728 & $* 2 * 41$ & CG & GG & CC & - & $\mathrm{CC}$ & CC & TT & GG & - & AA & AGA AGA & TT & GA & GG & CC & 2 \\
\hline 1729 & $* 1 * 2$ & CG & GG & $\mathrm{CC}$ & - & $\mathrm{CC}$ & $\mathrm{GC}$ & TT & GG & - & $\mathrm{AA}$ & AGA AGA & CT & GG & GG & CG & 2 \\
\hline 1739 & $*_{1} * 4$ & CC & GG & $\mathrm{CT}$ & - & CC & $\mathrm{GC}$ & TT & GA & - & $\mathrm{AA}$ & AGA AGA & CC & GG & GG & CG & 2 \\
\hline 1740 & $*_{1} * 2$ & CG & GG & $\mathrm{CC}$ & - & $\mathrm{CC}$ & $\mathrm{GC}$ & TT & GG & - & AA & AGA AGA & CT & GG & GG & CG & 2 \\
\hline 1741 & $*_{1} *_{1}$ & CC & GG & CC & - & $\mathrm{CC}$ & GC & TT & GG & - & AA & AGA AGA & CC & GG & GG & GG & 2 \\
\hline 1742 & $*_{1}^{*} * 4$ & $\mathrm{CC}$ & GG & $\mathrm{CT}$ & - & $\mathrm{CC}$ & GC & TT & GA & - & $\mathrm{AA}$ & AGA AGA & CC & GG & GG & CG & 2 \\
\hline 1743 & $* 2 * 4 \times N$ & CG & GG & $\mathrm{CT}$ & - & $\mathrm{CC}$ & $\mathrm{CC}$ & TT & GA & - & $\mathrm{AA}$ & AGA AGA & CT & GG & GG & $\mathrm{CC}$ & 3 \\
\hline 1761 & $* 2 * 4$ & CG & GG & CT & - & $\mathrm{CC}$ & CC & TT & GA & - & AA & AGA AGA & CT & GG & GG & CC & 2 \\
\hline 1762 & $* 4 * 41$ & CC & GG & $\mathrm{CT}$ & - & CC & CC & TT & GA & - & AA & AGA AGA & CT & GA & GG & $\mathrm{CC}$ & 2 \\
\hline 1859 & $* 1 * 2$ & CG & GG & $\mathrm{CC}$ & - & $\mathrm{CC}$ & $\mathrm{GC}$ & TT & GG & - & $\mathrm{AA}$ & AGA AGA & CT & GG & GG & CG & 2 \\
\hline 1860 & $* 2 * 2$ & GG & GG & $\mathrm{CC}$ & - & $\mathrm{CC}$ & CC & TT & GG & - & AA & AGA AGA & TT & GG & GG & CC & 2 \\
\hline 1861 & $* 1 * 41$ & CC & GG & $\mathrm{CC}$ & - & CC & $\mathrm{GC}$ & TT & GG & - & AA & AGA AGA & CT & GA & GG & CG & 2 \\
\hline 1862 & $* 4 * 4$ & CC & GG & TT & - & CC & $\mathrm{CC}$ & TT & $\mathrm{AA}$ & - & $\mathrm{AA}$ & AGA AGA & CC & GG & GG & CC & 2 \\
\hline 1864 & *1 *35 & CG & GA & $\mathrm{CC}$ & - & $\mathrm{CC}$ & $\mathrm{GC}$ & $\mathrm{TT}$ & GG & - & AA & AGA AGA & CT & GG & GG & CG & 2 \\
\hline 1865 & $* 1 * 4$ & $\mathrm{CC}$ & GG & CT & - & $\mathrm{CC}$ & GC & TT & GA & - & AA & AGA AGA & $\mathrm{CC}$ & GG & GG & CG & 2 \\
\hline 1871 & $* 4 * 10$ & CC & GG & $\mathrm{TT}$ & - & CC & $\mathrm{CC}$ & TT & GA & - & AA & AGA AGA & CC & GG & GG & $\mathrm{CC}$ & 2 \\
\hline 1872 & $*_{1} *_{1}$ & CC & GG & $\mathrm{CC}$ & - & $\mathrm{CC}$ & GC & TT & GG & - & AA & AGA AGA & CC & GG & GG & GG & 2 \\
\hline 1873 & $* 4 * 41$ & $\mathrm{CC}$ & GG & $\mathrm{ct}$ & - & $\mathrm{CC}$ & $\mathrm{CC}$ & TT & GA & - & AA & AGA AGA & CT & GA & GG & $\mathrm{CC}$ & 2 \\
\hline 1930 & $*_{1}^{*} * 1$ & $\mathrm{CC}$ & GG & $\mathrm{CC}$ & - & CC & GC & TT & GG & - & AA & AGA AGA & CC & GG & GG & GG & 2 \\
\hline 1933 & $* 1 * 2$ & CG & GG & $\mathrm{CC}$ & - & $\mathrm{CC}$ & GC & TT & GG & - & AA & AGA AGA & CT & GG & GG & CG & 2 \\
\hline 1932 & $*_{1}^{*} * 1$ & $\mathrm{CC}$ & GG & $\mathrm{CC}$ & - & CC & GC & TT & GG & - & $\mathrm{AA}$ & AGA AGA & CC & GG & GG & GG & 2 \\
\hline 1934 & $*_{1} * 10$ & CC & GG & CT & - & CC & CC & TT & GG & - & AA & AGA AGA & CT & GG & GG & CG & 2 \\
\hline 2079 & $*_{1} *_{1}$ & $\mathrm{CC}$ & GG & $\mathrm{CC}$ & - & $\mathrm{CC}$ & $\mathrm{GC}$ & TT & GG & - & AA & AGA AGA & CC & GG & GG & GG & 2 \\
\hline 2133 & $* 1 * 2$ & CG & GG & $\mathrm{CC}$ & - & $\mathrm{CC}$ & $\mathrm{GC}$ & $\mathrm{TT}$ & GG & - & $\mathrm{AA}$ & AGA AGA & $\mathrm{CT}$ & GG & GG & CG & 2 \\
\hline 2134 & $* 2 * 2$ & GG & GG & $\mathrm{CC}$ & - & $\mathrm{CC}$ & $\mathrm{CC}$ & $\mathrm{TT}$ & GG & - & $\mathrm{AA}$ & AGA AGA & TT & GG & GG & $\mathrm{CC}$ & 2 \\
\hline 2233 & $*_{1} * 2$ & CG & GG & CC & - & $\mathrm{CC}$ & GC & TT & GG & - & AA & AGA AGA & CT & GG & GG & CG & 2 \\
\hline 2342 & $* 1 * 2$ & CG & GG & $\mathrm{CC}$ & - & $\mathrm{CC}$ & $\mathrm{GC}$ & TT & GG & - & $\mathrm{AA}$ & AGA AGA & CT & GG & GG & CG & 2 \\
\hline
\end{tabular}


ANEXO B - Haplótipos do gene CYP2C19 encontrados em nossa amostra.

\begin{tabular}{|c|c|c|c|c|c|}
\hline DNA & genótipo & -3402 & -806 & 17948 & 19154 \\
\hline 130 & $*_{1} * 1$ & $\mathrm{CC}$ & $\mathrm{CC}$ & GG & GG \\
\hline 155 & $*_{1 * 1}$ & CC & CC & GG & GG \\
\hline 161 & $*_{1 * 1}$ & CC & CC & GG & GG \\
\hline 165 & *1*17 & CT & CT & GG & GG \\
\hline 345 & *17*17 & TT & TT & GG & GG \\
\hline 407 & $* 17 * 17$ & TT & TT & GG & GG \\
\hline 462 & $* 2 * 17$ & CT & CT & GG & GA \\
\hline 503 & $*_{1} * 2$ & CC & $\mathrm{CC}$ & GG & GA \\
\hline 567 & $* 1 * 17$ & CT & CT & GG & GG \\
\hline 569 & *1*17 & CT & CT & GG & GG \\
\hline 584 & $*^{*} 1 * 1$ & CC & CC & GG & GG \\
\hline 594 & $* 2 * 2$ & CC & $\mathrm{CC}$ & GG & AA \\
\hline 595 & $* 2 * 17$ & CT & CT & GG & GA \\
\hline 616 & $* 1 * 2$ & CC & CC & GG & GA \\
\hline 629 & ${ }^{*} 1 * 1$ & CC & CC & GG & GG \\
\hline 633 & ${ }^{*} 1 *_{1}$ & CC & CC & GG & GG \\
\hline 634 & ${ }^{*} 1 * 17$ & CT & CT & GG & GG \\
\hline 637 & *1*17 & CT & CT & GG & GG \\
\hline 639 & $*_{1 * 1}$ & CC & CC & GG & GG \\
\hline 642 & $*_{1}^{*}{ }_{1}$ & CC & CC & GG & GG \\
\hline 643 & $*_{1 * 1}$ & CC & CC & GG & GG \\
\hline 646 & *1*17 & CT & CT & GG & GG \\
\hline 647 & $*_{1 * 1}$ & CC & CC & GG & GG \\
\hline 656 & $* 17 * 17$ & TT & TT & GG & GG \\
\hline 662 & $* 1 * 2$ & CC & CC & GG & GA \\
\hline 664 & *1*17 & CT & CT & GG & GG \\
\hline 666 & $* 1 * 17$ & CT & CT & GG & GG \\
\hline 667 & $* 1 * 2$ & CC & CC & GG & GA \\
\hline 668 & *1*17 & CT & CT & GG & GG \\
\hline 669 & ${ }^{*} 1 * 1$ & CC & CC & GG & GG \\
\hline 670 & $*_{1} * 2$ & CC & CC & GG & GA \\
\hline 671 & *1*17 & CT & CT & GG & GG \\
\hline 674 & $* 2 * 17$ & CT & CT & GG & GA \\
\hline 677 & $*_{1 * 1}$ & CC & CC & GG & GG \\
\hline 680 & $*_{1} * 1$ & $\mathrm{CC}$ & CC & GG & GG \\
\hline 683 & ${ }^{*} 1 * 1$ & CC & CC & GG & GG \\
\hline 686 & ${ }^{*} 1 * 1$ & CC & CC & GG & GG \\
\hline 688 & $* 1 * 17$ & CT & CT & GG & GG \\
\hline
\end{tabular}


ANEXO B - Haplótipos do gene CYP2C19 encontrados em nossa amostra (continuação).

\begin{tabular}{|c|c|c|c|c|c|}
\hline DNA & genótipo & -3402 & -806 & 17948 & 19154 \\
\hline 693 & $*_{1} * 1$ & $\mathrm{CC}$ & $\mathrm{CC}$ & GG & GG \\
\hline 702 & *1*17 & CT & CT & GG & GG \\
\hline 704 & $* 2 * 17$ & CT & CT & GG & GA \\
\hline 705 & $*_{1 * 1}$ & CC & CC & GG & GG \\
\hline 709 & $* 1 * 17$ & CT & CT & GG & GG \\
\hline 715 & ${ }^{*} 1 * 1$ & CC & CC & GG & GG \\
\hline 719 & ${ }^{*} 1 * 2$ & CC & CC & GG & GA \\
\hline 720 & *1*17 & CT & CT & GG & GG \\
\hline 724 & $* 1 * 17$ & CT & CT & GG & GG \\
\hline 726 & *1*17 & CT & CT & GG & GG \\
\hline 739 & $*_{1 * 1}$ & CC & CC & GG & GG \\
\hline 740 & $* 2 * 17$ & CT & CT & GG & GA \\
\hline 743 & ${ }^{*} 1 * 2$ & CC & CC & GG & GA \\
\hline 751 & ${ }^{*} 1 * 1$ & CC & CC & GG & GG \\
\hline 769 & ${ }^{*} 1 * 1$ & CC & CC & GG & GG \\
\hline 771 & ${ }^{*} 1 * 2$ & CC & CC & GG & GA \\
\hline 791 & ${ }^{*} 1 * 17$ & CT & CT & GG & GG \\
\hline 792 & $* 17 * 17$ & TT & TT & GG & GG \\
\hline 794 & *1*17 & CT & CT & GG & GG \\
\hline 817 & $* 1 * 17$ & CT & CT & GG & GG \\
\hline 821 & $*_{1 * 2}$ & CC & CC & GG & GA \\
\hline 838 & ${ }^{*} 1 * 2$ & CC & CC & GG & GA \\
\hline 849 & $* 1 * 17$ & CT & CT & GG & GG \\
\hline 854 & $*_{1 * 1}$ & CC & CC & GG & GG \\
\hline 948 & *1*17 & CT & CT & GG & GG \\
\hline 949 & *1*17 & CT & CT & GG & GG \\
\hline 956 & $* 1 * 17$ & CT & CT & GG & GG \\
\hline 990 & $* 17 * 17$ & TT & TT & GG & GG \\
\hline 999 & ${ }^{*} 1 * 2$ & CC & CC & GG & GA \\
\hline 1003 & ${ }^{*} 1 * 1$ & CC & CC & GG & GG \\
\hline 1172 & $*_{1} * 1$ & CC & CC & GG & GG \\
\hline 1494 & *1*17 & CT & CT & GG & GG \\
\hline 1495 & $*^{*} *_{1}$ & CC & CC & GG & GG \\
\hline 1496 & $*_{1 * 1}$ & CC & CC & GG & GG \\
\hline 1497 & *1*17 & CT & CT & GG & GG \\
\hline 1498 & $*_{1 * 1}$ & CC & CC & GG & GG \\
\hline 1499 & *1*17 & CT & CT & GG & GG \\
\hline 1500 & ${ }^{*} 1 * 1$ & CC & $\mathrm{CC}$ & GG & GG \\
\hline
\end{tabular}


ANEXO B - Haplótipos do gene CYP2C19 encontrados em nossa amostra (continuação).

\begin{tabular}{|c|c|c|c|c|c|}
\hline DNA & genótipo & -3402 & -806 & 17948 & 19154 \\
\hline 1501 & $*_{1} * 1$ & $\mathrm{CC}$ & $\mathrm{CC}$ & GG & GG \\
\hline 1502 & $*^{*} *_{1}$ & CC & CC & GG & GG \\
\hline 1503 & $*_{1 * 1}$ & CC & CC & GG & GG \\
\hline 1504 & $* 2 * 17$ & CT & CT & GG & GA \\
\hline 1505 & $* 1 * 17$ & CT & CT & GG & GG \\
\hline 1506 & *1*17 & CT & CT & GG & GG \\
\hline 1507 & *1*17 & CT & CT & GG & GG \\
\hline 1508 & $*_{1} *_{1}$ & CC & $\mathrm{CC}$ & GG & GG \\
\hline 1509 & $* 1 * 17$ & CT & CT & GG & GG \\
\hline 1510 & *1*17 & CT & CT & GG & GG \\
\hline 1511 & $* 2 * 17$ & CT & CT & GG & GA \\
\hline 1512 & $*_{1} * 2$ & CC & $\mathrm{CC}$ & GG & GA \\
\hline 1513 & ${ }^{*} 1 *_{1}$ & CC & CC & GG & GG \\
\hline 1514 & ${ }^{*} 1 * 1$ & CC & CC & GG & GG \\
\hline 1515 & *1*17 & CT & CT & GG & GG \\
\hline 1516 & $*^{*} *_{1}$ & CC & CC & GG & GG \\
\hline 1517 & $*_{1}^{*} *_{1}$ & CC & $\mathrm{CC}$ & GG & GG \\
\hline 1518 & $* 2 * 2$ & CC & CC & GG & AA \\
\hline 1519 & ${ }^{*} 1 * 1$ & CC & CC & GG & GG \\
\hline 1520 & $*_{1}^{*}{ }_{1}$ & CC & CC & GG & GG \\
\hline 1550 & ${ }^{*} 1 * 2$ & CC & CC & GG & GA \\
\hline 1561 & ${ }^{*} 1 * 2$ & CC & CC & GG & GA \\
\hline 1568 & $* 1 * 17$ & CT & CT & GG & GG \\
\hline 1571 & $*_{1 * 1}$ & CC & CC & GG & GG \\
\hline 1578 & $* 1 * 2$ & CC & CC & GG & GA \\
\hline 1583 & $* 2 * 2$ & CC & CC & GG & AA \\
\hline 1599 & $* 2 * 17$ & CT & CT & GG & GA \\
\hline 1600 & $*_{1 * 1}$ & CC & CC & GG & GG \\
\hline 1606 & $* 2 * 17$ & CT & CT & GG & GA \\
\hline 1657 & *1*17 & CT & CT & GG & GG \\
\hline 1658 & ${ }^{*} 1 * 1$ & CC & CC & GG & GG \\
\hline 1659 & ${ }^{*} 1 * 2$ & CC & CC & GG & GA \\
\hline 1661 & ${ }^{*} 1 * 1$ & CC & CC & GG & GG \\
\hline 1662 & $* 1 * 17$ & CT & CT & GG & GG \\
\hline 1663 & $* 1 * 2$ & $\mathrm{CC}$ & CC & GG & GA \\
\hline 1664 & ${ }^{*} 1 * 1$ & CC & CC & GG & GG \\
\hline 1665 & ${ }^{*} 1 * 1$ & CC & CC & GG & GG \\
\hline 1697 & $* 2 * 17$ & CT & CT & GG & GA \\
\hline
\end{tabular}


ANEXO B - Haplótipos do gene CYP2C19 encontrados em nossa amostra (continuação).

\begin{tabular}{|c|c|c|c|c|c|}
\hline DNA & genótipo & -3402 & -806 & 17948 & 19154 \\
\hline 1698 & $* 1 * 17$ & CT & CT & GG & GG \\
\hline 1699 & $*^{*} *_{1}$ & CC & CC & GG & GG \\
\hline 1700 & $* 1 * 2$ & CC & CC & GG & GA \\
\hline 1701 & *1*17 & CT & CT & GG & GG \\
\hline 1702 & ${ }^{*} 1 * 2$ & CC & CC & GG & GA \\
\hline 1716 & ${ }^{*} 1 * 2$ & $\mathrm{CC}$ & CC & GG & GA \\
\hline 1717 & ${ }^{*} 1 * 2$ & CC & CC & GG & GA \\
\hline 1718 & *1*17 & CT & CT & GG & GG \\
\hline 1719 & $*_{1}^{*}{ }_{1}$ & CC & CC & GG & GG \\
\hline 1720 & $* 2 * 2$ & CC & CC & GG & AA \\
\hline 1721 & $*^{*} 1 * 1$ & CC & CC & GG & GG \\
\hline 1722 & ${ }^{*} 1 * 2$ & CC & $\mathrm{CC}$ & GG & GA \\
\hline 1723 & $* 2 * 17$ & CT & CT & GG & GA \\
\hline 1726 & *1*17 & CT & CT & GG & GG \\
\hline 1727 & *1*17 & CT & CT & GG & GG \\
\hline 1728 & $*^{*} 1 * 1$ & CC & CC & GG & GG \\
\hline 1729 & ${ }^{*} 1 * 1$ & CC & $\mathrm{CC}$ & GG & GG \\
\hline 1739 & *1*1 & CC & CC & GG & GG \\
\hline 1740 & ${ }^{*} 1 * 1$ & CC & CC & GG & GG \\
\hline 1741 & $* 2 * 2$ & CC & CC & GG & AA \\
\hline 1742 & *1*17 & CT & CT & GG & GG \\
\hline 1743 & $* 2 * 2$ & CC & CC & GG & AA \\
\hline 1761 & ${ }^{*} 1 * 1$ & CC & CC & GG & GG \\
\hline 1762 & $*_{1 * 1}$ & CC & CC & GG & GG \\
\hline 1859 & ${ }^{*} 1 * 1$ & CC & CC & GG & GG \\
\hline 1860 & ${ }^{*} 1 * 1$ & CC & CC & GG & GG \\
\hline 1861 & $*_{1}^{*}{ }^{2}$ & CC & CC & GG & GG \\
\hline 1862 & $*_{1 * 1}$ & CC & CC & GG & GG \\
\hline 1864 & *1*17 & CT & CT & GG & GG \\
\hline 1865 & ${ }^{*} 1 * 1$ & CC & CC & GG & GG \\
\hline 1871 & $*_{1} * 2$ & CC & CC & GG & GA \\
\hline 1872 & $*_{1 * 1}$ & CC & CC & GG & GG \\
\hline 1873 & *1*17 & CT & CT & GG & GG \\
\hline 1930 & $*_{1 * 1}$ & CC & CC & GG & GG \\
\hline 1932 & $* 1 * 2$ & CC & CC & GG & GA \\
\hline 1933 & $*^{*} 1 * 1$ & CC & CC & GG & GG \\
\hline 1934 & ${ }^{*} 1 * 1$ & CC & CC & GG & GG \\
\hline 2079 & ${ }^{*} 1 * 1$ & CC & CC & GG & GG \\
\hline
\end{tabular}


ANEXO B - Haplótipos do gene CYP2C19 encontrados em nossa amostra (continuação).

\begin{tabular}{|c|c|c|c|c|c|}
\hline DNA & genótipo & -3402 & -806 & 17948 & 19154 \\
\hline 2133 & $*_{1 * 1}$ & CC & CC & GG & GG \\
\hline 2134 & *1*17 & CT & CT & GG & GG \\
\hline 2139 & ${ }^{*} 1 * 1$ & CC & CC & GG & GG \\
\hline 2233 & ${ }^{*} 1 * 2$ & CC & CC & GG & GA \\
\hline 2342 & *1*3 & CC & CC & GA & GG \\
\hline 2381 & ${ }^{*} 1 * 1$ & CC & CC & GG & GG \\
\hline 2384 & *1*1 & CC & CC & GG & GG \\
\hline 2386 & ${ }^{*} 1 * 2$ & CC & $\mathrm{CC}$ & GG & GA \\
\hline 2390 & *2*17 & CT & CT & GG & GA \\
\hline 2392 & ${ }^{*} 1 * 1$ & CC & CC & GG & GG \\
\hline 2407 & $*_{1 * 1}$ & CC & CC & GG & GG \\
\hline 2412 & $*_{1} * 1$ & CC & $\mathrm{CC}$ & GG & GG \\
\hline 2419 & $* 17 * 17$ & TT & TT & GG & GG \\
\hline 2420 & $* 1 * 2$ & CC & CC & GG & GA \\
\hline 2422 & ${ }^{*} 1 * 1$ & CC & CC & GG & GG \\
\hline 2436 & $*^{*} *_{1}$ & CC & CC & GG & GG \\
\hline 2444 & $*_{1 * 1}$ & CC & $\mathrm{CC}$ & GG & GG \\
\hline 2448 & *1*1 & CC & CC & GG & GG \\
\hline 2449 & $*_{1 * 1}$ & CC & CC & GG & GG \\
\hline 2474 & $*_{1 * 1}$ & CC & CC & GG & GG \\
\hline 2475 & ${ }^{*} 1 * 2$ & CC & CC & GG & GA \\
\hline 2482 & $* 2 * 17$ & CT & CT & GG & GA \\
\hline 2488 & $* 1 * 17$ & CT & CT & GG & GG \\
\hline 2490 & $* 1 * 2$ & CC & CC & GG & GA \\
\hline 2492 & *1*17 & CT & CT & GG & GG \\
\hline 2494 & $*_{1 * 1}$ & CC & CC & GG & GG \\
\hline 2495 & $* 1 * 17$ & CT & CT & GG & GG \\
\hline 2497 & ${ }^{*} 1 * 2$ & CC & CC & GG & GA \\
\hline 2498 & *1*1 & CC & CC & GG & GG \\
\hline 2501 & ${ }^{*} 1 * 1$ & CC & CC & GG & GG \\
\hline 2500 & $*_{1 * 1}$ & CC & CC & GG & GG \\
\hline 2486 & *1*17 & CT & CT & GG & GG \\
\hline 2507 & $*^{*} *_{1}$ & CC & CC & GG & GG \\
\hline 2496 & $* 1 * 17$ & CT & CT & GG & GG \\
\hline 2489 & $*_{1 * 1}$ & CC & CC & GG & GG \\
\hline 2487 & $*^{*} 1 * 1$ & CC & CC & GG & GG \\
\hline 2512 & ${ }^{*} 1 * 1$ & CC & CC & GG & GG \\
\hline 2516 & ${ }^{*} 1 * 1$ & CC & CC & GG & GG \\
\hline
\end{tabular}


ANEXO B - Haplótipos do gene CYP2C19 encontrados em nossa amostra (conclusão).

\begin{tabular}{|c|c|c|c|c|c|}
\hline DNA & genótipo & -3402 & $\mathbf{- 8 0 6}$ & $\mathbf{1 7 9 4 8}$ & $\mathbf{1 9 1 5 4}$ \\
\hline $\mathbf{2 5 0 2}$ & ${ }^{*} 1{ }^{*} 1$ & CC & CC & GG & GG \\
\hline $\mathbf{2 5 0 5}$ & ${ }^{*} 1{ }^{*} 17$ & CT & CT & GG & GG \\
\hline $\mathbf{2 5 1 7}$ & ${ }^{*} 2 * 17$ & CT & CT & GG & GA \\
\hline $\mathbf{2 5 1 4}$ & ${ }^{*} 1 * 1$ & CC & CC & GG & GG \\
\hline $\mathbf{2 5 1 5}$ & ${ }^{*} 1 *^{*} 17$ & CT & CT & GG & GG \\
\hline $\mathbf{2 5 1 3}$ & ${ }^{*} 1 * 17$ & CT & CT & GG & GG \\
\hline $\mathbf{2 5 0 9}$ & ${ }^{*} 2 * 17$ & CT & CT & GG & GA \\
\hline $\mathbf{2 5 1 0}$ & ${ }^{*} 1 * 2$ & CC & CC & GG & GA \\
\hline
\end{tabular}

